UNIVERSIDADE de SÃo PaUlo

Faculdade de Filosofia, Letras e Ciências Humanas

Programa de Pós-Graduação em Geografia Humana

\title{
A cidade e o mapa: representações cartográficas da urbanidade de São Paulo
}

EDUARDO DUTENKEFER

Exemplar corrigido 



\section{A cidade e o mapa: representações cartográficas da urbanidade de São Paulo}

\section{EDUARDO DUTENKEFER}

Tese apresentada ao Programa de Pós-Graduação em Geografia Humana da Faculdade de Filosofia, Letras e Ciências Humanas da Universidade de São Paulo, para obtenção do título de Doutor em Geografia.

Orientadora: Profa. Dra. Fernanda Padovesi Fonseca

\section{Exemplar corrigido}

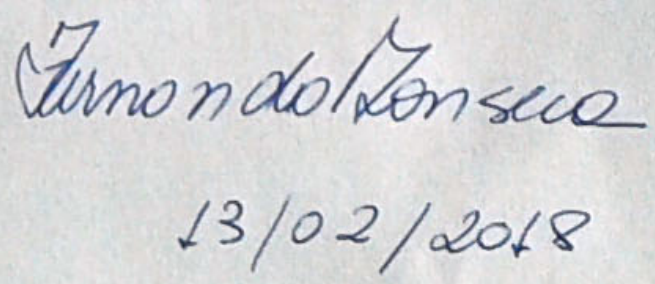


Autorizo a reprodução e divulgação total ou parcial deste trabalho, por qualquer meio convencional ou eletrônico, para fins de estudo e pesquisa, desde que citada a fonte.

Catalogação na Publicação

Serviço de Biblioteca e Documentação

Faculdade de Filosofia, Letras e Ciências Humanas da Universidade de São Paulo

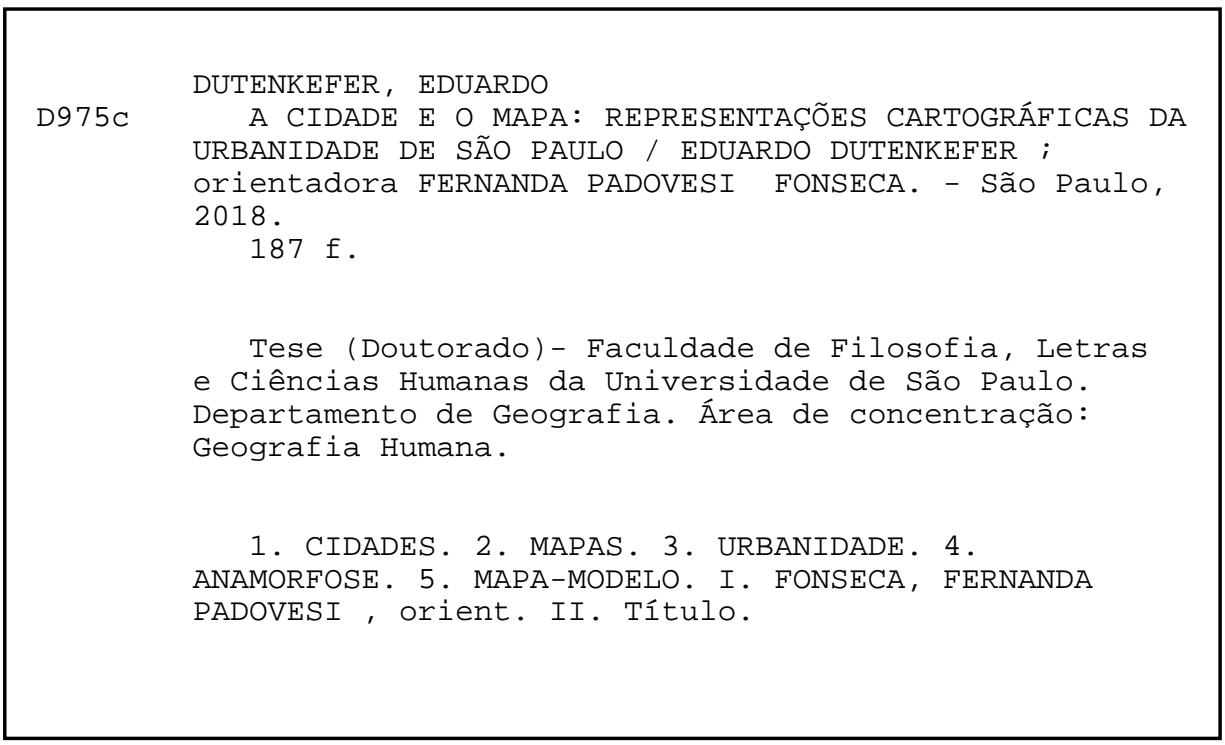





\section{Agradecimentos}

À minha orientadora professora Fernanda Padovesi Fonseca pelas orientações, discussões, ponderações, sabedoria e carinho ao longo de minha trajetória de reflexões iniciadas na graduação, mestrado e agora no doutorado.

Aos professores Gustavo Soares e Ricardo Mendes pelas sugestões, ponderações e discussões no exame de qualificação.

Também ao longo de minha graduação, mestrado e doutorado gratidão ao professor Jaime Oliva pelos incentivos, discussões e sua sapiência em temas epistemológicos em Geografia e sobre a alma de uma cidade que é a urbanidade.

Ao professor Hervé Théry que me acolheu no mestrado e influenciou profundamente o meu entusiasmo pelos mapas e modelos em minha jornada.

À professora Diana Sarita Hamburger que orientou com muito carinho e discussões uma Pós graduação Lato-sensu em temas de densidades e mobilidades urbanas que culminaram em pesquisas sobre os mapas dasimétricos no mestrado.

À Eliane Kuvasney mestre em minha graduação que me formou, acompanhou, influenciou e incentivou com sua sabedoria e carinho este percurso.

Aos mestres e amigos que de alguma forma impactaram, incentivaram e contribuíram para as minhas reflexões e formação como Geógrafo: Arlete Ohata, Benjamin Capellari, Diana Sarita Hamburger, Eliane Kuvasney, Fernanda Padovesi Fonseca, Hervé Théry, Jaime Tadeu Oliva, José Pereira de Queiroz Neto, Sandro Magro, Ricardo Mendes Antas Júnior e Valdeir Cavalcante.

Ao flerte em Cartografia Histórica com a professora Iris Kantor do departamento da História da USP. Com a professora Beatriz Piccolotto Siqueira Bueno da FAU/USP e a professora Enali de Biagi da Université Jean Moulin Lyon 3 - France.

Aos mestres (in-memoriam) Antônio Carlos Robert Moraes, Jorge Gustavo da Graça Raffo e Ailton Luchiari que tive o prazer de discutir e prosear nestes anos de mestrado e doutorado.

Agradecimentos ao programa USP-COFECUB onde tive a oportunidade de conviver com pesquisadores franceses em Lyon e Strasbourg. Particularmente em conhecer pessoalmente a professora Colette Cauvin e seu companheiro Henry Reymond, fortes influências em minha formação em cartografia analítica transformacional. Suas breves orientações sobre o capítulo de acessibilidade foram importantes nesta tese.

Outra referência fundamental em minhas reflexões em Cartografia Analítica foi o conviver em dois momentos com o professor Aziz Serradj, do Laboratoire Image et Ville (CNRS) Université Louis Pasteur Strasbourg. Um momento em São Paulo (2013), outro em Strasbourg e em sua cidade de residência, Nancy, em 2014 junto a sua carinhosa companheira Béatrice (in-memoriam).

Aos amigos de trabalho do Laboratório de Geoprocessamento (LabGeo) da Procuradoria do Patrimônio Imobiliário (PPI) - órgão da Procuradoria Geral do Estado de São Paulo (PGE): Ana Helena, Arlete, Carolina, Daniela, Fausto, João, Leandro, Maria, Mario, Pablo, Phillipp, Rafael, Rosangela, Rubens, Santiago, Valdeir, Vania e Vivi, pelo incentivo e apoio em todo o percurso. 
Ao meu amigo Joni, João E. A. Rodrigues, pelas tentativas, como professor, de incentivar um velhote aprender inglês e francês nesta fase de vida e de contagiar e expandir a sua tentativa ao restante dos amigos do LabGeo da PPI.

Aos procuradores da PPI/PGE: Adriana Ruiz Vicentin, Camila Kohl Pintarelli, Egídio Carlos da Silva, Marco Antônio Gomes, Melissa Di Lascio Sampaio e Plinio Back Silva pelo apoio e ao proporcionarem um ambiente estimulante de formação e pesquisa no LabGeo, fundamentais ao meu aprendizado e da equipe do LabGeo.

Não poderia esquecer de agradecer aos meus ex-alunos do Centro Universitário Fundação Instituto de Ensino para Osasco [UNIFIEO] onde tive a minha formação como aluno de graduação e depois como professor. Alunos que são sempre fundamentais em alimentar discussões, polémicas, dúvidas, questionamentos. Alunos que sempre alimentaram a alma de minhas pesquisas. Perdoem-me os alunos das turmas de 2009 a 2012 que não se encontram na pequena listagem abaixo. 0 relapso do seu ex-professor não conseguiu encontrar em seus alfarrábios eletrônicos os vossos nomes. Mas quem foi meu aluno e tiver acesso a esta pesquisa considere-se eternamente agradecido.

ANTONIO EVALDO DO NASCIMENTO COSTA
ADRIANO DOS SANTOS FAZAM
ALESSANDRO LEMOS DE CARVALHO
ANGELITA ALMEIDA JESUS
BRUNA VIEIRA DOS SANTOS
CARLA MARTIN MEIRA
CARLOS RODRIGUES DE ALMEIDA JUNIOR
CARMELIA MARIA DA SILVA
CAROLINA CALANCHA LIORBANO
CELIO ANDRADE VIEIRA SANTOS
CLEIDE ALVES LIMA
DANILO NALON FERREIRA
EDERALDO SILVA DO NASCIMENTO
ELLEN FRANCO SOUZA
FELIPE GROSSI PINTO
FRANCESCO ALLEGRINI JUNIOR
GIBSON DIEGO SAMPAIO DA COSTA
HEIDE REGINA GOIS
JOSE MOULAZM DA LUZ

JULIANA MARSAL DA ROCHA JUSSARA APARECIDA DOS SANTOS DE SOUZA KATRINE DA SILVA BARROS LILIAN RODRIGUES DIAS DO SANTOS LUANA MENDONÇA BARBOSA MARCELO BRUNO TREDEZINI MARCELO MACHADO ALBUQUERQUE MIGUEL RODRIGUES DEL BARCO NIVALDO MENDONCA DE FREITAS PAULA BARROS RIBEIRO PHILLIPP OLIVEIRA SANTOS POLYANA NASCIMENTO SANTOS RAFAEL RODRIGUES BATISTA RAFHAELA DA SILVA COELHO RODRIGO NOVAES ALVES MONTEIRO SERGIO VIEIRA DA SILVA JUNIOR SORAIA SANTOS DA SILVA VALDEIR SOARES CAVALCANTE GONCALVES

À minha companheira Marileide e ao meu filho Vinícius pelo incentivo e apoio incondicional durante toda esta jornada. 


\section{Sumário}

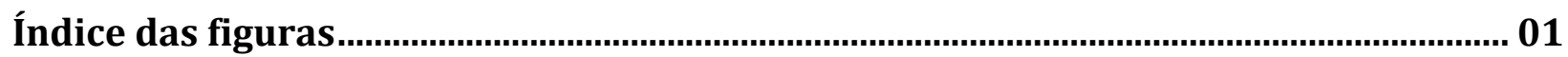

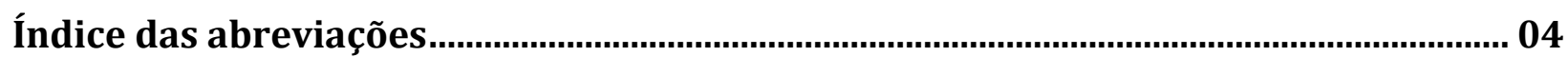

Resumo

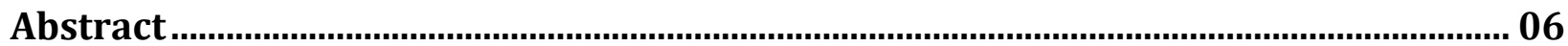

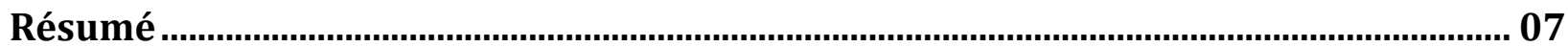

Apresentação

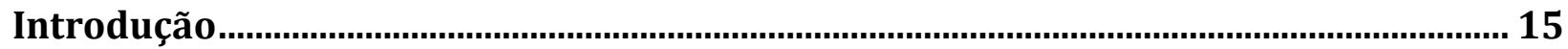

1.0 - Urbanidade - Fazer do urbano ser "urbano" ............................................................. 19

1.1 - Modelo de Urbanidade: princípios metodológicos .....................................................21

2.0 - Elaborar e construir um mapa: reflexões necessárias................................................ 24

2.1 - 0 mapa em cena: refletir a montante, construir ao centro, interpretar e comunicar a jusante ........................................................................................2

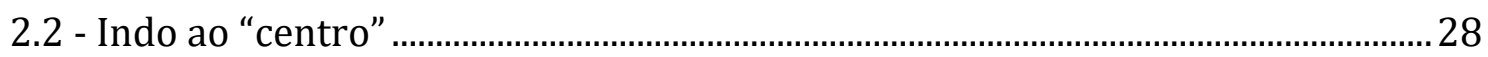

2.3 - Trabalhando com os temas ................................................................................................ 31

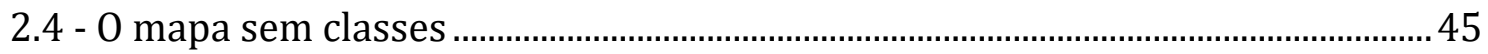

2.5 - Alterando a construção do mapa …………………………………………………4 46

3.0 - 0 mapa como imagem da urbanidade: possibilidades ……..................................... 51

3.1 - Densidade: urbanidade absoluta e relativa.................................................................51

3.2 - 0 território em cena ................................................................................................52

3.3 - 0 território retirado de cena: as "massas" urbanas

e a sua urbanidade absoluta ................................................................................................... 53

3.4 - Opção semiológica adotada: um breve parêntese........................................................ 54

3.5 - 0 território e as "massas" urbanas retiradas de cena;

o revelar da urbanidade relativa e seu anticartograma ....................................................5

3.6 - Diversidade e densidade ...................................................................................................6

3.7 - A busca de uma "constância" por meio de sua "inconstância" ............................... 67

4.0 - Densidades e diversidades em “quadrados" .............................................................. 72

4.1 - A grade estatística do IBGE.............................................................................................. 72

4.2 - 0 método "Carroyage" ............................................................................................ 74

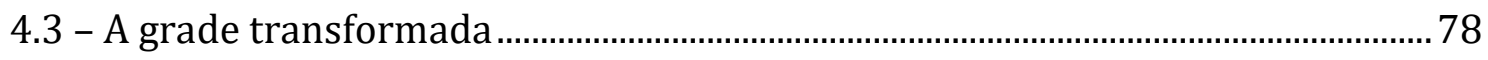

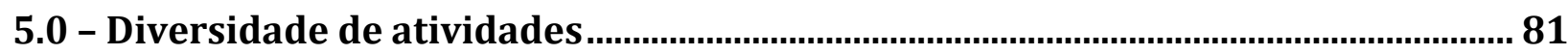

5.1 - Os dados do CNEFE............................................................................................... 82

5.2 - Os blocos ativos da urbanidade - método cartográfico de duas variáveis ...... 90

5.3 - 0 recorte intraurbano como exemplo de densidades e diversidades expressivas 
6.0- Acessibilidade no município de São Paulo …………............................................. 119

6.1 - Conceitos estruturadores: distância e métrica ..............................................................120

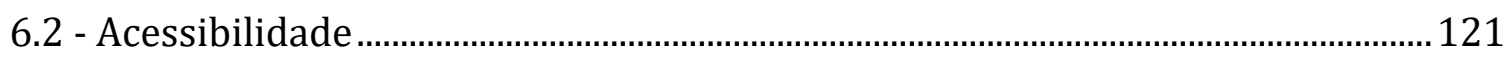

6.3 - A cartografia do revelar o invisível: a cartografia analítica e transformacional .............................................................................................122

6.4 - Cartografando a distância-tempo: os instrumentos computacionais ..................123

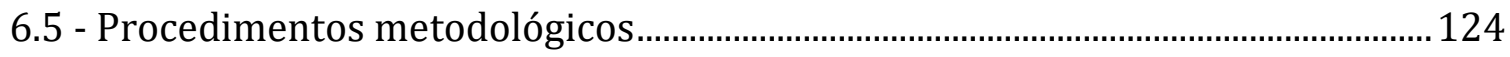

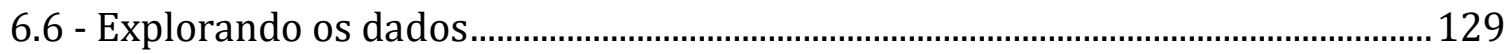

6.7 - Resultados .................................................................................................................

6.7.1- Etapa 1 - Aplicativo IsoDistAngle ..............................................................................133

6.7.2 - Etapa 2 - Aplicativo Darcy ……………………………………………………135

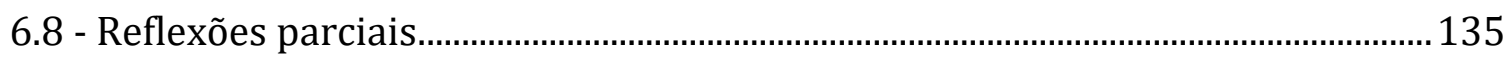

7.0 - Um mapa-modelo para representar a urbanidade de São Paulo ............................ 138

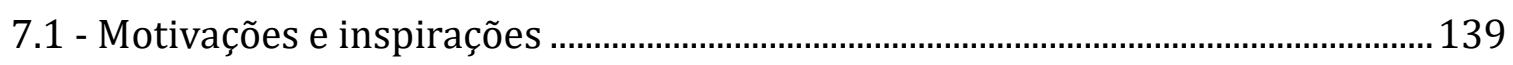

7.2 - 0 mapa-modelo de São Paulo ........................................................................................148

8.0 - 0 mapa-modelo da urbanidade em São Paulo ……............................................... 152

Conclusões |celebrando uma etapa| .......................................................................... 173

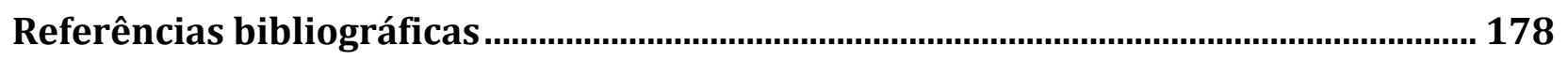




\section{Índice de figuras e tabelas}

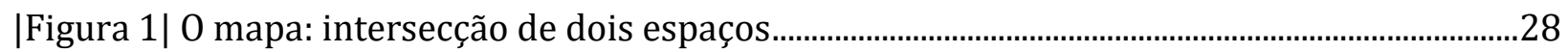

|Figura 2| Família de transformações .................................................................................................... 30

|Figura 3| População brasileira em 2010 ................................................................................................33

|Figura 4| Gráfico e histograma da densidade demográfica em 2010.................................................36

|Figura 5| Tipos de distribuição de Z em histogramas de frequência .................................................37

|Figura 6| Tela do ColorBrewer 2.0 .........................................................................................................39

|Figura 7| Mapas de densidade demográfica 2010 com vários métodos de discretização............40

|Figura 8| Mapa de densidade demográfica sem método de discretização ..........................................46

|Figura 9| Mapa em anamorfose [9.1] e Cartograma em anamorfose [9.2] ........................................47

|Figura 10| Os dois tipos de transformações cartográficas.....................................................................49

|Figura 11| Histograma de frequência - densidade demográfica França, 2012 .................................51

|Figura 12| Urbanidade Brasil 2010 ..........................................................................................................57

|Figura 13| Urbanidade França 2012 ……………...........................................................................58

|Figura 14| Urbanidade na escala regional...........................................................................................59

|Figura 15| Histograma de frequência da densidade demográfica

em 2010 para a metrópole de São Paulo ........................................................................................................60

|Figura 16| Urbanidade da cidade de São Paulo - 2010 .........................................................................61

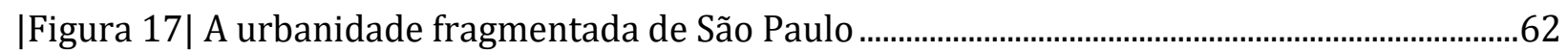

|Figura 18| A urbanidade das etnias em porcentagem da população total.........................................65

|Figura 19| A urbanidade das etnias em densidades ................................................................................66

|Figura 20| Mapas de diversidade .......................................................................................................69

|Figura 21| Articulação da grade estatística IBGE 2016 ........................................................................73

|Figura 22| Recorte da Grade estatística IBGE.......................................................................................74

|Figura 23| Densidades: São Paulo em "quadrados" ...................................................................................76

|Figura 24| Urbanidade em São Paulo em “quadrados" -2010 - ..........................................................77

|Figura 25| Urbanidade em São Paulo [Absoluta e Relativa]- 2010 - ..................................................80

|Figura 26| Exemplo de tela de planilha já transformada e editado os endereços para posterior uso em geocodificação.................................................................................82

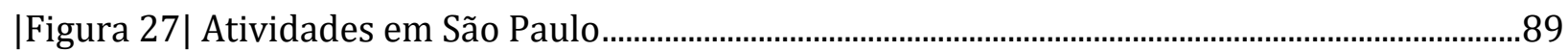

|Figura 28| Agregando dados de uma camada de pontos para uma camada de superfície (polígonos].

|Figura 29|Esquema sintético da elaboração

de um mapa coroplético com duas variáveis ["bivariado"] .......................................................................93

|Figura 30| Densidades de habitação, comércio, serviços e indústria - 2010 ....................................94

|Figura 31| Predomínio residencial e não residencial...............................................................................95

|Figura $31 \mathrm{~A}$ | Número de atividades não residenciais e número de domicílios por distrito .......97

Figura 32| Algumas características de áreas como exemplo de baixas, médias e altas densidades e diversidades $\mathrm{n} 1$ 
Figura 32A| Algumas características de áreas como exemplo de baixas, médias e altas densidades e diversidades $\mathrm{n} 2$. 100

|Figura 32B| Logradouros e atividades não residenciais. 101

Figura 33| Comparando baixas, médias e altas densidades $n^{\circ} 1$ 103

|Figura 33A| Gráficos dos mapas da figura 33 .104

|Figura 34| Comparando baixas, médias e altas densidades $n^{\circ} 2$... .105

|Figura 34A| Gráficos dos mapas da figura 34 .106

|Figura 34B| Exemplo de percurso a pé de uma residência até uma padaria no distrito do Morumbi em aplicativo Google Maps. 107

|Figura 35A| Gráficos dos mapas da figura 35 .108

|Figura 35| Comparando baixas, médias e altas densidades $n^{\circ} 3$ 109

|Figura 36| Comparando baixas, médias e altas densidades $n^{\circ} 4$ .110

|Figura 36A| Gráficos dos mapas da figura 36 .111

|Figura 37A| Gráficos dos mapas da figura 37 . .113

|Figura 37| Comparando baixas, médias e altas densidades $\mathrm{n}^{\circ} 5$ 114

|Figura 38| Comparando baixas, médias e altas densidades $n^{\circ} 6$ 115

|Figura 38A| Gráficos dos mapas da figura 38 [38.1 a 38.6] .116

|Figura 38B| Gráficos dos mapas da figura 38 [38.7 a 38.12]

|Figura 39| Fundo de mapa dos distritos do município de São Paulo com o local de origem e destino .126

|Figura 40| Trajeto Sé-Grajaú em modalidade ônibus. 127

|Figura 41| Planilha eletrônica dos dados coletados .128

|Figura 42| Coordenadas dos pontos e tempo de percurso em formato txt. 128

|Figura 43| Acessibilidade em função do tempo médio e velocidade média 130

|Figura 44| Método de quadrantes

|Figura 45| Deslocamento por meio de automóvel e ônibus e localizações em distância-tempo - Aplicativo IsoDistAngle .

|Figura 46| Mapas elaborados no aplicativo Darcy com indicações dos setores com maior acessibilidade média relativa da rede viária com a métrica tempo de percurso com automóvel e ônibus

|Figura 47| As variáveis visuais de Bertin: 2 DP = as duas dimensões do plano,

$\mathrm{T}=$ tamanho, $\mathrm{F}=$ forma, valor, $\mathrm{OR}=$ orientação, $\mathrm{C}=\mathrm{Cor}, \mathrm{G}=$ granulação

|Figura 48| Fundo de mapa territorial de Londres com as suas subdivisões administrativas e mais o rio Tamisa.

|Figura 49| A“London Squared".

|Figura 50| A forma hexagonal da França.

|Figura 51| A França octagonal de Elisée Reclus

|Figura 52| Capa da obra de Arnold Guyot de 1866 com o método construtivo

"map drawing"da América do Sul e Europa..

|Figura 53| Modelização gráfica do território paulista do prof. Hervé Théry.

|Figura 54| Mapa da região metropolitana de São Paulo usado pela EMPLASA na década de 70/80 para estudos industriais. 
|Figura 55| Mapa-modelo 1 - distritos de São Paulo em malha quadrada 149

|Figura 56| Mapa-modelo dos distritos de São Paulo em malha retangular 150

|Figura 57| Mapa-modelo dos distritos de São Paulo em malha hexagonal. 151

|Figura 58| Mapa-modelo em densidades. 152

|Figura 58A| Mapa Euclidiano das densidades. .153

|Figura 59| A urbanidade absoluta em mapas-modelos. .155

|Figura 60| A urbanidade relativa em mapas-modelos. .156

|Figura 61| A urbanidade absoluta e relativa em cartogramas de fundo de mapa euclidiano....157

|Figura 62| Gráfico da quantidade de atividades selecionadas nos 96 distritos de São Paulo.....160

|Figura 63| Tela do aplicativo Magrit para escolha do método de discretização. .161

|Figura 64| Mapa-modelo de densidades e atividades .162

|Figura 65| Índices de diversidade em mapa-modelo em malha quadrada .166

|Figura 66| Gráfico do método de quadrantes para as variáveis densidade e diversidade. .167

|Figura 67| Sequência da construção da legenda com o método de duas variáveis . .170

|Figura 68| Mapa-modelo síntese das densidades e diversidades de São Paulo. .172

|Tabela 1| Fonte: (LÉVY, 1999, p. 243 e 2013c, p.1056). 23

|Tabela 2| Divisão em classes de valores com diferentes softwares que utilizam o método de discretização de Jenks. 42

|Tabela 3| Número de atividades e atividades geocodificadas por distrito no município de São Paulo 83

|Tabela 4| Extrato de nosso "dicionário tradutor" para auxiliar na classificação de atividades 86

|Tabela 5| Principais sistematizações utilizadas na classificação das atividades no município de São Paulo. 87

|Tabela 6| Amostra das atividades selecionadas para os 96 distritos de São Paulo. .158

|Tabela 7| Relações do código da Prefeitura de São Paulo, IBGE, nome e sigla dos distritos de São Paulo .168 


\section{Lista de abreviações}

AED - Analise Exploratória de Dados

AEDE - Analise Exploratória de Dados Espaciais

CMYK - Cyan, Magenta, Yellow [Amarelo], black [ preto]

CNA - Classificação Nacional de Atividades Econômicas

CNRS - Centre National de la Recherche Scientifique

CNEFE - Cadastro Nacional de Endereços para Fins Estatísticos

EMPLASA - Empresa Paulista de Planejamento Metropolitano

EUA - Estados Unidos da América

ESRI - Environmental Systems Research Institute

GPS -Global Positioning System

ha - hectare

hab - habitantes

hab/ativ - habitantes por atividades

hab $/ \mathrm{km}^{2}$ - habitante por quilômetro quadrado

IBGE - Instituto Brasileiro de Geografia e Estatística

IPTU - Imposto Predial e Territorial Urbano

IGC - Instituto Geográfico e Cartográfico

$\mathrm{km}$ - quilômetro

$\mathrm{km}^{2}$ - quilômetro quadrado

$\mathrm{m}$ - metro

$\mathrm{m}^{2}-$ metro quadrado

ONU - Organização das Nações Unidas

RGB - Red, Green e Blue

RIATE - Rede Interdisciplinar para o Ordenamento e a Coesão dos Territórios da Europa e suas vizinhanças

RMSP - Região Metropolitana de São Paulo

SAD - South American Datum

SEADE - Sistema Estadual de Análise de Dados

SENAC - Serviço Nacional de Aprendizagem Comercial

SENAI - Serviço Nacional de Aprendizagem Industrial

SESI - Serviço Social da Indústria

SIG - Sistema de Informações Geográficas

TCP - Transformações Cartográficas de Posição

TPCL - cadastro Territorial e Predial, de Conservação e Limpeza

UTM - Universal Transversa de Mercator 


\section{Resumo}

Esta pesquisa tem como objeto de estudo a cidade. Ela será conduzida pelo conceito de urbanidade, que por sua vez será expresso graficamente cartograficamente. Teremos então uma relação, um diálogo entre a urbanidade de uma cidade e o mapa. Esse mapa será o destaque e o revelador maior do "medir" a urbanidade de uma cidade. A urbanidade, em uma primeira aproximação, é uma qualidade, um indicador fundamental do estado em que se encontra a organização de objetos da sociedade no interior da vida urbana. A tese que podemos apontar é que o mapa como linguagem tem o poder de aproximar e avaliar como se encontra a urbanidade de uma cidade - uma urbanidade revelada a priori. A priori no sentido de antecipar, antever determinadas características importantes da urbanidade de uma cidade em diferentes escalas. A urbanidade tem como origem a união, ou melhor, a ligação da densidade e da diversidade de objetos da sociedade no espaço. É esta liga, densidade-diversidade que iremos priorizar nesta tese, e a cidade de São Paulo será o exemplo desse espaço urbano privilegiado de nossas reflexões e experimentos. 0 objetivo principal desta pesquisa é explorar métodos e metodologias ligadas à construção de mapas e/ou a outros tipos de representações gráficas que sejam capazes de representar, aproximar e revelar a urbanidade de uma cidade. Outro elemento importante da urbanidade de uma cidade é a sua acessibilidade. Mostraremos também métodos e metodologias que propiciam um desvendar da acessibilidade no município de São Paulo. Iremos utilizar dados estatísticos disponíveis publicamente e que aproximem e indiquem densidades e diversidades. Utilizaremos, de forma inovadora, o Cadastro Nacional de Endereços para Fins Estatísticos do Instituto Brasileiro de Geografia e Estatística (IBGE), para evidenciar diversidades de atividades não residenciais. Serão elaboradas representações cartográficas como o cartograma em anamorfose, o anticartograma, a grade estatística do IBGE, mapas com o método "Carroyage" e uma síntese da dupla densidade-diversidade em um mapamodelo.

Palavras-chave: cidade, mapa, urbanidade, anamorfose, anticartograma, mapa-modelo, densidade-diversidade. 
This research has as its object of study the city. It will be driven by the concept of urbanity, which in turn will be expressed graphically cartographically. We will then have a relationship, a dialogue between the urbanity of a city and the map. This map will be the highlight and the biggest revealer of the "measuring" of a city's urbanity. Urbanity, in a first approximation, is a quality, a fundamental indicator of the state of organization of society's objects within urban life. The thesis that we can point out is that the map, as language, has the power to approach and assess how the urbanity of a city is found - a urbanity

revealed a priori. A priori in the sense of anticipating, foreseeing certain important characteristics of the urbanity of a city at different scales. Urbanity has its origin in the union, or rather, the connection of the density and diversity of society's objects in space. It is this league, density-diversity that we will prioritize in this thesis, and the city of São Paulo will be our example of this privileged urban space for our reflections and experiments. The main objective of this research is to explore methods and methodologies linked to the construction of maps and / or other types of graphic representations that are able to represent, approximate, and reveal the urbanity of a city. Another important element of the urbanity of a city is its accessibility. We will also show methods and methodologies that provide an unveiling of accessibility in the city of São Paulo. We will use publicly available statistical data that will approximate and

indicate densities and diversities. We will use, in an innovative way, the National Register of Addresses for Statistical Purposes of the Brazilian Institute of Geography and Statistics (IBGE) to evidence diversities of non-residential activities. Cartographic representations such as the cartography in cartograms, anticartograms, the IBGE statistical grid, maps with the "Carroyage" method and a synthesis of the dual density-diversity in a model map will be elaborated.

Key words: city, map, urbanity, cartogram, anticartogram, model-map, density-diversity. 


\section{Résumé}

Cette recherche a pour objet d'étudier la ville. Il sera conduit par le concept d'urbanité, qui à son tour sera exprimé graphiquement cartographiquement. Nous aurons alors une relation, un dialogue entre l'urbanité d'une ville et la carte. Cette carte sera le point culminant et le plus grand révélateur de la "mesure" de l'urbanité d'une ville. L'urbanité, en première approximation, est une qualité, un indicateur fondamental de l'état de l'organisation des objets de la société dans la vie urbaine. La thèse que nous pouvons souligner est celle de que la carte, comme un langage, a le pouvoir d'approcher et d'évaluer comment l'urbanité d'une ville est trouvée une urbanité révélée a priori. A priori dans le sens d'anticiper, prévoir certaines caractéristiques importantes de l'urbanité d'une ville à différentes échelles. L'urbanité a son origine dans l'union, ou plutôt dans la connexion de la densité et de la diversité des objets de la société dans l'espace. C'est cette ligue, densité-diversité que nous prioriserons dans cette thèse, et la ville de São Paulo sera notre exemple de cet espace urbain privilégié de nos réflexions et expérimentations. L'objectif principal de cette recherche est d'explorer les méthodes et les méthodologies liées à la construction de cartes et / ou d'autres types de représentations graphiques capables de représenter, d'approcher et de révéler l'urbanité d'une ville. Un autre élément important de l'urbanité d'une ville est son accessibilité. Nous montrerons également des méthodes et des méthodologies qui permettent de dévoiler l'accessibilité dans la ville de São Paulo. Nous utiliserons des données statistiques accessibles au public pour approximer et indiquer les densités et les diversités. Nous utiliserons de manière innovante le registre national des adresses à des fins statistiques de l'Institut Brésilien de Géographie et de Statistique (IBGE) pour mettre en évidence la diversité des activités non-résidentielles. Des représentations cartographiques telles que la cartographie en anamorphose, l'anticartogramme, la grille statistique de IBGE, des cartes avec la méthode Carroyage et une synthèse de la double densité-diversité dans une carte- modèle seront élaborées.

Mots clés: ville, carte, urbanité, anamorphose, anticartogramme, cartemodèle, densité-diversité 



\section{Apresentação}

As reflexões que iremos trilhar agora são fruto de pesquisas iniciadas pelos idos de 2006-2007 e que culminaram em uma dissertação de mestrado em 2010: "Representações do espaço geográfico: mapas dasimétricos, anamorfoses e modelização gráfica" (DUTENKEFER, 2010). Na época trabalhamos com dois instrumentos, os mapas e a modelização gráfica, que permitem perceber, conhecer, apreender, explorar e atuar sobre realidades espaciais. Nosso fio condutor foi a densidade populacional da metrópole de São Paulo. Concentrações humanas fundamentais para caracterizar e dar vida ao espaço de uma cidade. Mobilizamos, por exemplo, autores como Milton Santos (2002, 2002a, 2008) e Jacques Lévy (2003, 2003e, 2003f) para refletirmos sobre o conceito de espaço geográfico.

$\mathrm{Na}$ cartografia fomos influenciados por Jacques Bertin $(1988,1998)$, Brian J. Harley (1991, 2005), Fernanda P. Fonseca e Jaime Oliva (2001), Fernanda P. Fonseca (2004), Jacques Lévy (2003c), Gilles Palsky (1998, 2007, 2009) e Marcello Martinelli (1991). Ao utilizarmos a Cartografia Analítica Transformacional, em particular para as anamorfoses, somos devedores de Colette Cauvin (1995), Colette Cauvin, Francisco Escobar e Aziz Serradj (2007a, 2007b, 2008b) e Waldo Tobler (1961, 1984, 2004). Também Christian Grataloup (2003a, 2003b), Roger Brunet (1987, 2000, 2001, 2007) e Hervé Théry $(2004,2006)$, para pensar e mobilizar a modelização gráfica. Foram elaborações cartográficas que tentaram dialogar com estes autores. Autores expoentes de uma geografia e cartografia renovada, permitem e orientam práticas cartográficas inovadoras e preocupadas com este diálogo geográfico $<=>$ cartográfico. As reflexões que iniciamos agora nesta tese continuam a sondar as possibilidades que o mapa e um mapa-modelo, um "cartemodèle" - como expressaria Brunet (1987) - oferecem neste diálogo.

Quando Milton Santos formula a sua reflexão de que o espaço geográfico "é formado por um conjunto indissociável, solidário e também contraditório, de sistemas de objetos e sistemas de ações" (SANTOS, 2002a, p. 63) introduz um novo paradigma para a geografia. O espaço geográfico não será mais estático, absoluto, um palco externo às dinâmicas sociais. Não teremos objetos no espaço e sim "objetos geográficos em relação como constitutivos do espaço geográfico. 
Portanto, uma cidade não está no espaço, ela é espaço geográfico" (FONSECA, 2004, p. 36).

A formulação do professor Milton Santos introduz novas reflexões de que o espaço geográfico pode ser compreendido como uma dimensão da sociedade. Dimensão que, para o geógrafo Jacques Lévy (2003), é estabelecida pelo conjunto de relações sociais que ocorrem simultaneamente e mediadas pela(s) distância(s) que aproximam ou afastam realidade(s) diferentes ou "iguais". Neste olhar, o espaço é um objeto social definido por sua dimensão espacial e, segundo Lévy (2003), por três componentes fundamentais: "a escala, a métrica e a substância" (LÉVY, 2003, p. 332). A métrica - é o "modo de medir e de tratar a distância" (LÉVY, 2003e, p. 607, tradução nossa), a escala - que define o tamanho do espaço e a substância - "componente não espacial de uma configuração espacial" (LÉVY, 2003f, p.880, tradução nossa). Nesta abordagem a métrica é um modo social de medir as distâncias. Para a concepção do espaço geográfico concebido como absoluto é a métrica euclidiana em metros e quilômetros. Para a concepção de Milton Santos e Lévy como um espaço relativo-relacional ou como "elemento transversal das relações sociais, cria distâncias cujas métricas não correspondem às métricas euclidianas" (FONSECA, 2004, p.40). Estas novas reflexões começam a ter peso na Cartografia.

Lévy (2004, 2008 e 2008b) nos aponta que depois dos trabalhos inovadores sobre as linguagens gráficas - a semiologia gráfica estreitam-se atualmente as teorias sobre o espaço e o fazer cartográfico. Este fazer cartográfico será explorado nesta tese. Utilizaremos ferramentas matemáticas e estatísticas, mapas em anamorfoses, cartogramas e anticartogramas em anamorfose, recursos oferecidos pelo Sistema de Informação Geográfica (SIG) e a modelização gráfica. Serão esforços mobilizados para tentarmos sair do esquema tradicional e naturalizado do espaço euclidiano que a quase totalidade dos trabalhos e pesquisas em Geografia, que utilizam o mapa, estão mergulhados. É nessa renovação e estreitamento do espaço geográfico e cartográfico que construiremos uma Cartografia-Geográfica, como apontam Fonseca (2004) e Girardi $(2011,2014)$, isto é, em novas bases conceituais e com novas relações e funções que o mapa tem para a Geografia.

A cidade é o espaço ideal para este estreitamento do fazer cartográfico e das novas formulações da Geografia. Bertin já colocava que o 
mapeamento das "referências naturais... úteis aos homens acabam de ser terminados.... Não temos mais uma "Terra Incógnita”" (BERTIN, 1988, p. 45). Essa função inicial dos mapas está cumprida, ou seja, o mapear a superfície terrestre com objetivo de descobrir algo não revelado pelos sensores de satélites, fotos aéreas, drones, etc., é menos provável. 0 desafio atual é buscar representações cartográficas ou póscartográficas que sejam possíveis de apreender os espaços cada vez mais complexos, diversos e velozes da sociedade humana atual. Para este mapear, instrumentos analíticos novos têm que ser construídos para propiciar o desvendar e o apreender da essência destes espaços, em particular o núcleo central do urbano, a cidade e sua alma; a sua urbanidade.

Esta pesquisa tem seu objeto de estudo, a cidade, conduzido pelo conceito de urbanidade. Esta urbanidade será revelada e expressa graficamente e cartograficamente. O mapa será a "régua" que utilizaremos para "medir" a urbanidade de uma cidade.

O conceito de urbanidade que teremos como referencial de nossas reflexões e produções gráficas será como um indicador, um "farol" do estado em que se encontra a organização de objetos da sociedade no seio da vida urbana. A urbanidade é uma qualidade inerente ao espaço urbano (LUSSAULT, 2013). Este estado e organização serão retratados em imagens gráficas: os mapas. Estes retratos podem revelar o que uma cidade pode oferecer, incrementar, intensificar, em suas múltiplas possibilidades, o que o cidadão necessita, quer, almeja, deseja e de fato tem.

A tese que podemos apontar é que o mapa como linguagem tem o poder de aproximar e avaliar como se encontra a urbanidade de uma cidade. Uma urbanidade revelada a priori. A priori no sentido de antecipar, antever determinadas característica importantes da urbanidade de uma cidade em diferentes escalas.

Esta urbanidade, rapidamente apresentada aqui, tem como origem a união, ou melhor, a ligação da densidade e da diversidade de objetos da sociedade no espaço. É esta liga, densidade-diversidade que iremos privilegiar nesta tese.

As cidades sempre despertaram e ainda despertam discussões acaloradas sobre suas virtudes e mazelas, mas que, indiscutivelmente, propiciaram à espécie humana a possibilidade de que suas relações e trocas sociais diversas fossem intensas. Sem interações sociais não 
teríamos desenvolvido a escrita, a política, as ciências, a filosofia e as artes. A cidade aqui é pensada como o núcleo central do urbano, é um objeto espacial por excelência. 0 mapa por sua vez é fruto do que as cidades propiciaram à sociedade humana em seu modo de perceber e produzir imagens espaciais. 0 mapa é uma linguagem visual universal antiga e um "saber" das diferentes culturas humanas e não apenas um mero produto técnico.

Como iremos confluir cidade e mapa, continuamos no campo de uma Cartografia-Geográfica, isto é, com uma cartografia que busca um diálogo com as reflexões teóricas renovadoras que a Geografia contemporânea está produzindo sobre o espaço geográfico, a cidade e o urbano. Por outro lado, a cartografia pode oferecer alternativas, reflexões e propostas inovadoras do seu modo de elaborar, pensar, usar, explorar e analisar os mapas.

Continuamos aqui abordando a cidade de São Paulo como exemplo deste recorte espacial privilegiado de nossas reflexões e experimentos.

Exploraremos dados estatísticos disponíveis publicamente e que aproximam e expressam densidades e diversidades. Utilizaremos o Cadastro Nacional de Endereços para Fins Estatísticos ${ }^{1}$ para expressar diversidades de atividades. Representações cartográficas como o anticartograma, a "grade estatística do IBGE" (IBGE, 2016), mapas com o método "Carroyage ${ }^{2 "}$ e o mapa-modelo serão também apreciados.

Esta tese tem como objetivo principal explorar métodos e metodologias espaciais ligadas aos mapas e/ou a outros tipos de representações gráficas que sejam capazes de representar, aproximar, revelar a urbanidade de uma cidade.

Esta tese está estruturada em 8 capítulos.

0 primeiro explorará o conceito de urbanidade e princípios metodológicos que serão utilizados como guia em nossas representações gráficas.

O segundo capítulo será dedicado a reflexões do papel do mapa como construtor de imagens. Particularmente será centrado no como

\footnotetext{
${ }^{1}$ O Cadastro Nacional de Endereços para Fins Estatísticos - CNEFE apresenta uma lista com 78.056.411 endereços urbanos e rurais do território nacional, distribuídos pelos 316574 setores censitários, classificados por tipo: unidades residenciais, unidades de ensino, unidades de saúde e outros.

< http://www.ibge.gov.br/home/estatistica/populacao/censo2010/cnefe/default_cnefe.shtm> Acesso: $16 / 11 / 2016$

2 "associa e trata os dados com o objetivo de uma exploração estatística e cartográfica. Decompõe o território em unidades de extensões iguais, por exemplo, em quadrados". (BRUNET, Roger. FERRAS, Robert. THÉRY, Hervé. 1993, p. 88)
} 
elaborar, construir um mapa. E em procedimentos, como tratar dados estatísticos, tipos de discretizações para mapas coropléticos e outros.

No terceiro capítulo introduzimos o mapa como imagem da urbanidade. São possibilidades de diálogo do mapa com os conceitos utilizados nesta tese: densidade, urbanidade absoluta e relativa, território, opções semiológicas e diversidade.

O quarto capítulo será dedicado a explorar densidade e diversidade no método que o IBGE introduz no Brasil em 2016. Um método cartográfico que na literatura francesa é conhecida como "Carroyage".

A diversidade de atividades com dados do Cadastro Nacional de Endereços para Fins Estatísticos - CNEFE será explorada no quinto capítulo. Utilizaremos o método cartográfico para duas variáveis para obter imagens de densidades e diversidades expressivas.

O sexto capítulo, que parece destoar um pouco do foco de trabalhar a urbanidade, com a sua dupla densidade e diversidade, terá como eixo explorar o conceito de acessibilidade e suas possíveis representações cartográficas. Um importante elemento da urbanidade de uma cidade. 0 capítulo mostra metodologias que propiciam um desvendar da acessibilidade no município de São Paulo.

No sétimo capítulo apresentaremos uma proposta de um novo fundo de mapa para o município de São Paulo que denominamos de mapamodelo. Serão apresentadas as motivações e inspirações para esta construção e três propostas para este novo fundo de mapa serão evidenciados.

No capítulo 8 encerramos esta tese com um mapa-modelo síntese da urbanidade do município de São Paulo. 



\section{"Cidades significam falta de espaço físico entre pessoas e empresas. Elas representam proximidade, densidade, intimidade...[GLAESER, 2011, P. 6]. Introdução}

Uma grande parcela dos seres humanos viventes nesta grande morada que é a Terra movimenta seus corpos ao ritmo de passadas cotidianas sobre um chão "marcado" de variadas direções e sentidos. Aprumamos nossa existência em velocidades variadas para ir e voltar de lugares diversos. Mal damos conta em nosso cotidiano labutar que cada vez mais tendemos a nos concentrar em lugares específicos nomeados como cidades.

Com aproximadamente 7 bilhões de pessoas, $52,1 \%$ vivem em áreas urbanas ${ }^{3}$. 0 economista Edward L. Glaeser - um entusiasta das cidades e do urbano - em sua obra "Os centros Urbanos - a maior invenção da humanidade" faz alguns cálculos e mostra que toda a população atual da terra caberia no estado do Texas, nos Estados Unidos da América [EUA], e cada um teria uma área para construir sua morada de aproximadamente $98 \mathrm{~m}^{2}$ (GLAESER, 2011). Fazendo uma analogia ao Brasil, que tal morarmos na Bahia com mais 6.999.999.999 de pessoas? 0 estado da Bahia tem uma área de 564 bilhões de metros quadrados ${ }^{4}$, teríamos disponíveis, portanto, uma área de $80,5 \mathrm{~m}^{2}$ para cada um de nós. Queremos ruas, comércio, uma infraestrutura típica urbana? Oferecendo a metade desta área à infraestrutura, poderíamos compartilhar com mais uma pessoa estes $80,5 \mathrm{~m}^{2}$. Dois seres humanos nesta modesta área residencial, nos parece razoável. Que tal Mato Grosso, com área de 903 bilhões de metros quadrados, que ofereceria $129 \mathrm{~m}^{2}$ para cada ser humano? E o restante do planeta? Ficaria para a agropecuária, turismo e para as outras diversidades naturais!? Prazerosa visão utópica que uma vida urbana possibilitaria. Viver em grandes aglomerações, densas, pontilhadas de diversidades culturais, que propiciam o aumento de nossas relações sociais.

Em seu livro "A cidade no Brasil” o antropólogo, poeta e ensaísta Antônio Risério nos brinda com um texto delicioso sobre o que é a cidade...

...um espaço onde a imprevisibilidade e o acaso assumem proporções inéditas. Onde a variedade e a intensidade dos processos produzem uma dimensão do viver. Substituindo a rosa, na frase de Gertrude Stein 5 , uma cidade é uma cidade é uma cidade. É uma entidade psicofísica única. Nada tem de linear ou

3 Segundo a ONU, em 2011 temos 6.974 milhões de habitantes [United Nations, Department of Economic and Social Affairs, Population Division (2012). Disponível em:< http://www.un.org/esa/population/unpop.htm> Acesso: 12/02/2013.

4 Segundo o IBGE o estado da Bahia possui $564.733,177 \mathrm{~km}^{2}$, arredondamos para 564 bilhões de metros quadrados para facilitar o cálculo. Mato Grosso com 903.366,192 $\mathrm{km}^{2}$. Disponível em:

<http://www.ibge.gov.br/home/geociencias/areaterritorial/principal.shtm>. Acesso: 12/02/2013.

5 Risério se refere ao fragmento do poema "Sacred Emily" [http://www.lettersofnote.com/p/sacred-emily-bygertrude-stein.html] da poeta estadunidense: "A rose is rose is a rose". Disponível em:

[http://falacultura.com/gertrude-stein/]. Acesso: 4/6/2015. 
homogênea. É um mosaico em movimento, ainda mais quando se oferece em variedade étnica. No campo, pode haver isolamento. Na cidade não. 0 máximo que pode ocorrer, no sentido da reclusão ou do autocentramento individual ou grupal, é uma espécie qualquer de dialética entre solidão e mobilidade, ou entre segregação e contágio, porque a visão é contínua e o bombardeio simbólico não cessa. Mesmo que um grupo étnico se concentre em determinado segmento da superfície urbana, com práticas tradicionais e casamentos endógenos, ele não consegue bloquear o circuito das informações, estancar as trocas simbólicas, neutralizar estímulos externos. Em vez do aprisionamento na teia primária do parentesco ou da vida comunitária, vigoram a instabilidade, a abertura, o espaço público, o encontro casual, o risco e o fascínio das aventuras pessoais. (RISÉRIO, 2012, p. 255)

Além dessa "dimensão do viver" de Risério, a cidade pode ser caracterizada fundamentalmente pela sua dimensão espacial particular, onde as distâncias materiais e imateriais tendem a ser "zero", onde a concentração de uma sociedade é máxima. O local que tem a possibilidade de maximizar a densidade e a diversidade das interações sociais (LÉVY, 1999). O lugar no qual a distância não é mais pertinente e que é identificado como o espaço que privilegia o contato das interações de seus habitantes (LÉVY, 2003g).

Os atos de relacionar-se e coexistir são as condições universais e fundamento do ser social. Intensificar essas relações com um grau elevado de diversidade é algo que a ocorrência das cidades favoreceu e tornou exponencial.... A coexistência permite a cidade ser o lugar do encontro da diferença, o que abre as chances para que se supere, ao menos em parte, as segregações sociais e econômicas, culturais e étnicas. (OLIVA, 2003, p. 74)

A cidade pensada em um espaço onde a distância tende a "zero" traduz uma dimensão espacial que significa uma "falta" de espaço, significando, portanto, a possibilidade de um maior contato físico entre os seus habitantes. Ela é o melhor representante de nossa necessidade, como seres sociais, de proximidade, de ser íntimo e denso em nosso existir e ao mesmo tempo propicia um passar e um viver incólume, despercebido em nosso cotidiano frente a esta frenética "máquina relacional". "Máquina” que propicia a nossa experiência de viver e de sentir as múltiplas dimensões do espaço-temporal na escala societal. A Cidade é "gente" e não "concreto".

...devemos nos libertar de nossa tendência de ver as cidades como sendo suas edificações e lembrar que a cidade é constituída de gente e não de concreto. (GLAESER, 2011, p. 16)

Reforcemos mais uma vez: nosso olhar não deve ser guiado apenas ao esplendor da arquitetura das edificações de uma cidade. Os seres viventes constituem, constroem este espaço societal, relacional, que dá "vida" à cidade.

A cidade, propiciando está proximidade, possibilita conexões de culturas e reduz o complexo processo de comunicação entre elas. Glaeser (2011) salienta que as múltiplas interações pessoais que a cidade arquiteta e concretiza oferecem uma melhor compreensão, 
entendimento quando estamos face a face com o nosso interlocutor. "Involuntariamente, é fácil ofender alguém de uma cultura diferente, mas um caloroso sorriso pode atenuar os conflitos que, de outra forma, se transformariam em e-mails inflamados" (GLAESER, 2011, p. 24). Como apontado por Risério e Oliva, em parágrafos anteriores, grupos étnicos isolados em uma cidade não tem como bloquear totalmente as trocas alucinantes que a cidade produz e oferece e deve facilitar a superação de segregações econômicas, sociais e culturais que espacialmente estão instaladas nas cidades.

Interações pessoais facilitam a troca de ideias. "As ideias se movem de pessoa para pessoa, dentro dos densos espaços urbanos, e essa troca eventualmente gera milagres da criatividade humana" (GLAESER, 2011, p. 19).

A cidade de Mileto, lá pelo século VI a.C., era um lugar central de produtores de lã com seu importante porto, encravada a oeste do que conhecemos hoje como Turquia. Esta cidade, ligação com civilizações do oriente próximo, engendrou o filósofo Tales e o "pai do planejamento urbano europeu, Hipódamo, cujas plantas em forma de grade forneceram um modelo para os romanos e para inúmeras cidades desde então" (GLAESER, 2011, p. 19).

Atenas no século V a.C. foi um polo aglutinador da criatividade humana. Atraiu Hipódamo de Mileto, e as "melhores mentes da Ásia menor" (GLAESER, 2011, p. 19). Esta Atenas de Péricles e Sócrates gerou e ensinou Platão, que por sua vez gerou Aristóteles, que por sua vez gerou....!?

Da polis ateniense à Civita Romana, das cidades medievais às ruas dos centros renascentistas, das cidades industriais às metrópoles, megacidades, megalópoles e gigalópoles, as cidades propiciaram novas reflexões, pensamentos, impulsionaram e revolucionaram culturas, artes, técnicas, ciências e filosofias. São gestoras das inovações que garantem a espécie humana viver em sociedade. Ela é uma "multiplicadora de relações, aceleradora de trocas, ...acompanha a gênese de valores qualificados como urbanos" (MONGIN, 2009, p.29). Em sua evolução e transformações, no decorrer dos tempos, ela tornou possível o urbano. Somos hoje da "espécies urbanus".

Em pesquisa anterior (DUTENKEFER, 2010) iniciamos reflexões e exercitamos um fazer cartográfico do urbano, em particular da metrópole de São Paulo, evidenciando uma característica fundamental de seu caráter, a sua densidade populacional. Trabalhamos com um olhar geográfico orientado por reflexões de que o espaço geográfico é uma dimensão da sociedade. Dimensão que decompõe a realidade em várias partes "privilegiando o cruzamento de pontos de vista parciais sobre um vasto conjunto de fenômenos" (LÉVY, 2013a, p. 281, tradução nossa). Dimensão no sentido de fazer um recorte da realidade complexa da 
sociedade e apreendê-la optando pelo conjunto de relações sociais que se dão simultaneamente e são mediadas pela(s) distância(s) que aproximam ou afastam realidade(s) diferentes ou "iguais". A cidade é este recorte privilegiado, esta dimensão mediada por vários tipos de distâncias que aproximam ou afastam possibilidades de interações sociais. Sendo uma dimensão, é possível medi-la? 0 mapa seria este instrumento? Que tipo de mapa? Ou seria a modelização gráfica? Poderíamos ir um pouco além e assumir como Brunet (1987), e adotar uma "expressão cartográfica nova" com o seu "mapa-modelo" [carte-modèle], não como um simples esquema, um vago resumo: não visando a uma "simplificação" da carta tradicional [diríamos euclidiana] por uma generalização extrema, mas para "exprimir a estrutura e a dinâmica" (BRUNET, 1987 p. 189, tradução nossa) do espaço geográfico. Utilizando os recursos tecnológicos do computador e de seus aplicativos associados e específicos para elaborar mapas que a Cartografia contemporânea utiliza hoje, é possível superar as visões naturalizadas do mapa como expressão de um olhar matemático originário da época de Euclides de Alexandria, por volta de 300 ac? E mais, ela serve à Geografia, em particular ao estudo do urbano? Produzimos em 2010 representações do espaço geográfico por meio de mapas dasimétricos, transformações cartográficas de posição, conhecidas como anamorfoses, e uma produção pós-cartográfica, a modelização gráfica. Foi um início de representações cartográficas do urbano e que esperamos agora dar continuidade revelando o que deveria ser a essência de uma cidade, de "qualificarmos e detalharmos a sua substância" (OLIVA, 2004, p. 106), a sua urbanidade. 


\section{1 - Urbanidade - Fazer do urbano ser urbano}

"Flanando" o livro de Jacques Le Goff (1998), "Por amor às cidades", deparamo-nos com o termo cidade e fomos conduzidos ao século XI e XII, onde o conhecimento da escrita era quase que exclusivo dos "doutos" que em latim registravam em seus "papiros" o termo "civitas" [do latim civitas - singular e civitates - plural] para designar uma cidade. Indo ainda mais longe neste tempo-espaço, à época do império romano, o termo era "urbs" [cidade; urbes, cidades - plural]. "Civitas" designava "um distrito administrativo, depois a capital deste distrito e mais tarde substituiu urbs no uso geral” (NASCENTES, 1955, p. 117). Louiset (2011) assinala que "civitas" exprimia uma dupla identidade da cidade na época dos romanos; "uma comunidade cívica e ao mesmo tempo um lugar físico, a urbs" (LOUISET, 2011, p. 44, tradução nossa). "Urbs" era o aspecto físico, material da cidade, com seus muros e pedras, contrastando do seu aspecto imaterial, a "civitas" - que expressava a comunidade humana que vivia neste lugar, com suas dimensões política, artística, filosófica....

Jean-Marc Besse (2005) também salienta a distinção entre "civitas" e "urbs" ao discutir e refletir sobre a iconografia do urbano no renascimento. São dois termos que expressam dois conceitos diferentes e, ao mesmo tempo, se articulam um ao outro. "Como civitas, a cidade é considerada como uma entidade política que é definida pelo tipo de organização que foi alcançado entre seus habitantes" (BESSE, 2005, tradução nossa). Por outro lado, considerar a cidade como urbs é ressaltar os seus edifícios e muralhas, o seu espaço delimitado, organizado e construído. A cidade é vista como "um espaço construído, uma organização política e um espaço organizado, uma ideia e uma realidade espacial” (BESSE, 2005, tradução nossa).

0 vocábulo urbanidade é derivada do latim "urbanitas" - "qualidade de quem é urbano, civilizado" (AULETE, 2015) ou ainda a "qualidade ou caráter do urbano" e, no seu sentido mais figurativo, como sendo: "civilidade, cortesia, delicadeza, polidez" (LAROUSSE, 1998, p. 5842). Portanto, à época do império romano, o termo urbanidade designava a "polidez", a "civilidade", o "civilizado" que se contrapunha aos "bárbaros" que fustigavam o seu império. A urbanidade de Roma e de seu cidadão romano representava um ícone de um poder quase sem limites...

O sítio do Centre National de Ressources Textuelles et Lexicales ${ }^{6}$ além de remeter o termo urbanidade ao "caráter do que faz uma cidade" encaminha também ao que Nicolas Oresme, em 1370, traduziu da obra de Aristóteles [Ética] como sendo as "relações sociais

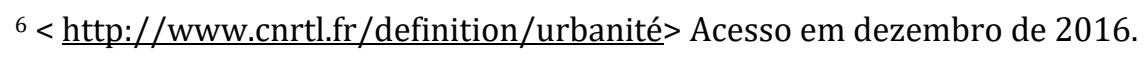


entre habitantes de uma cidade" (ORESME, 1488, p.437)7. Estas relações sociais estabeleceram, permitiram produzir uma personalidade, qualidade, entranha, marca, originalidade, sabor, traço, peculiaridade, temperamento, caráter própria para uma cidade?

De Nicolas Oresme, de 1370, vamos agora dar um "pequeno" salto temporal e aportarmos em 2013. Não encontramos Aristóteles e sim o geógrafo Jacques Lévy que, não mais em registros em "papiros", mas em "registros" em papel, contribuirá com novas elaborações e reflexões sobre a cidade, o urbano e a urbanidade. Michel Lussault, parceiro de Lévy no Dicitionnaire de la Géographie et de l'espace des sociétés aponta que a urbanidade é o “caráter propriamente de um espaço urbano" (LUSSAULT, 2013a, p. 1053, tradução nossa). Lembram da "qualidade ou caráter do urbano", apontado em parágrafos anteriores?

Em entrevista concedida à revista [em linha] "Urbanités"8, a propósito de seu filme “Urbanité9, Lévy registra que "a palavra urbanidade está se tornando um termo sintético para descrever o que torna o urbano, urbano" (LÉVY, 2014). Salienta ainda que o termo tem se tornado um conceito integrador e não mais associado a uma configuração espacial particular e cada vez mais usado na língua alemã [urbanität] e inglesa [urbanity].

Na literatura de língua inglesa, Krafti e Horton (2009) apresentam o termo urbanidade [urbanity] ao se referir a "política dos lugares urbanos, culturas e estilos de vida" e que propicia uma "interpretação mais subjetiva das condições que tornam um lugar urbano" (KRAFTI e HORTON, 2009, p. 94, tradução nossa). Urbanidade seria um conceito subjetivo?

Temos também o termo urbanismo (urbanism) associado a Louis Wirth que, em 1938, em seu famoso artigo "Urbanism as a Way of Life" apresenta a cidade "como um núcleo relativamente grande, denso e permanente, de indivíduos socialmente heterogêneos" (WIRTH, 1967, p. 94) e o urbanismo "como modo de vida urbano" e não mais apreendido como "a entidade física da cidade" (WIRTH, 1967, p. 92).

Para Lussault (2013a) a urbanidade é uma qualidade inerente ao espaço urbano. É um indicador do estado em que se encontra a organização de objetos da sociedade no seio do urbano. É, ao mesmo tempo, o resultado e um operador da organização e do funcionamento

\footnotetext{
${ }^{7}$ Existe uma edição da obra em linha de 1488 em http://gallica.bnf.fr/ark:/12148/bpt6k109464g/f1.image Titre: Les Ethiques en françois, traduites par Nicolas Oresme. Auteur: Aristote (0384-0322 av. J.-C.); Éditeur: [Antoine Caillaut et Guy Marchant pour] Antoine Vérard (Paris). Date d'édition: 1488; Contributeur Oresme, Nicole (1322?-1382). Traducteur.

8 <http://www.revue-urbanites.fr/entretien-jacques-levy-a-propos-du-film-urbanites-urbanityies/>. Acesso:18/5/2015. 9 Disponível em: <https://vimeo.com/84457863>. Acesso:18/5/2015. Production: Chôros. Image: Thomas Bataille (animées), Jacques Lévy (fixes). Textes extraits de Italo Calvino, Le città invisibili, 1972. Avec Luca Ortelli, Elsa Chavinier et Verity Elston. Cartes: Laboratoire Chôros/ÉPFL. Musique: Alban Berg, Györgi Ligeti, Wolfang Rihm, Anton Webern. Montage: Olivier Zuchuat. Film : 78min. Versions française et anglaise. (CChôros, 2013.Conception et réalisation: Jacques Lévy.
} 
da vida urbana. Ela tem como origem a união ou ligação da densidade e da diversidade de objetos da sociedade no espaço. Lussault (2007) reforça, que dependendo do arranjo espacial da densidade e da diversidade, a urbanidade permite caracterizar o estado que se encontra a organização das realidades da sociedade.

A densidade "é um indicador que mostra a importância que a copresença tem em revelar o contato topográfico de realidades sociais (materiais e imateriais) distintas (não necessariamente diferentes)" (LUSSAULT, 2007, p. 323, tradução nossa). A copresença é "caracterizada por reunir e agregar em um mesmo lugar realidades sociais distintas" (LUSSAULT, 2013, p. 234, tradução nossa). Junto com a mobilidade e as telecomunicações, é uma das modalidades que os atores sociais elaboraram para diminuir as distâncias de realidades sociais, propiciando um aumento das interações sociais que a sociedade humana necessita para a sua existência. A cidade é uma escolha que a sociedade encontrou para maximizar a copresença, estabelecendo assim agregados sociais densos que potencializam, facilitam as interações sociais. Não esquecemos Claval em 1982:

...porque é que os comércios, as administrações, os bancos, os escritórios das grandes empresas, os teatros, os cinemas e os museus se apertam em áreas tão restritas até aí criar uma acumulação vertiginosa? Que têm eles de comum senão a necessidade de estabelecer relações com uma população numerosa, com uma clientela apressada? Não é função de todas as cidades facilitar ao máximo todas as formas de interação social? Não são os bairros centrais, à escala de uma aglomeração, comutadores cujo papel é análogo ao duma central numa rede telefónica - permitir a fácil e rápida passagem de um interlocutor, a outro? (CLAVAL, 1982, p.138, grifos nossos)

\section{1 - Modelo de Urbanidade: princípios metodológicos}

Pretendemos medir a cidade pelo olhar da urbanidade. A cidade sendo um objeto por excelência da sociedade e, portanto, sendo a urbanidade um indicador, é passível de ser qualificada e quantificada?

Baseado nas reflexões de Lévy (1999, 2003g, 2008a, 2013c), Lussault (2007, 2013a), Oliva $(2003,2004)$ e Poncet (2011) podemos estruturar alguns princípios metodológicos norteadores para apreender a essência de uma cidade ou nas palavras de Lévy: "em princípios de construção de um instrumento de medida" (LÉVY, 1999, p. 208, tradução nossa):

1 - Densidade e Diversidade: Buscar elementos de máxima densidade e diversidade de substancias societais em espaços onde as distâncias materiais e imateriais tendem a zero;

2 - Urbanidade absoluta e relativa: Diferenciar a totalidade de sua substância - a sua "massa" - o tamanho dos objetos urbanos considerados, a sua urbanidade absoluta, de sua 
urbanidade relativa, isto é, de sua urbanidade específica à escala própria de cada objeto urbano considerado, revelando-nos a intensidade de suas ligações urbanas;

3 - Urbanidade em todos os lugares: Medir a urbanidade em todos os lugares da cidade, sem prejulgar estes espaços antecipadamente. Considerar as estruturas espaciais que Lévy chama de "“forma urbana” com seus aspectos imateriais e materiais - físicos, com suas descontinuidades e seus gradientes" (LÉVY, 1999, p.209, tradução nossa) considerando as zonas de baixa densidade como configurações urbanas específicas e não como oposição à cidade ou, ainda, considerá-las negativamente como rurais.

4 - Urbanidade a priori e a posteriori: Diferenciar as potencialidades oferecidas pela configuração espacial de uma cidade que sintetizariam um nível ideal de desempenho funcional deste espaço (urbanidade a priori), de suas características positivas e negativas particulares realizadas em um dado tempo histórico (urbanidade a posteriori);

5 - Múltiplas métricas: Diferenciar a forma como medimos e tratamos as distâncias na cidade - as suas múltiplas métricas. Por exemplo "distinguindo as métricas pedestres das métricas dos automóveis" (LÉVY, 1999, p.209, tradução nossa), podemos flanar a pé pelos percursos diversos que uma cidade oferece ou percorrê-la dirigindo um automóvel. São ações diferentes e fortes estruturadoras do espaço urbano.

6 - Território e rede geográfica: Analisar simultaneamente os territórios e as redes é estabelecer indicadores com métricas topográficas - o território -, as estruturas e as formas que nos oferecem uma contiguidade do ambiente urbano constituído e, por outro lado, as métricas topológicas das redes, que podem revelar a descontinuidade e os limites da cidade. Podem revelar proximidades espaciais visíveis e invisíveis das estruturas das cidades. Lévy (2003g) caracteriza a cidade por esta relação específica de território e rede. A cidade que tem uma interacessibilidade entre os lugares necessita de redes rápidas que criam a territorialização destes espaços tornando-os contínuos e contíguos. Com uma urbanidade alta a imagem que vemos da cidade é seu peso territorial, ao contrário, com baixa urbanidade o peso de suas redes é o que sobressai.

Lévy (1999, p.242-243) nos oferece um desdobramento mais refinado, que orientará as nossas pesquisas metodológicas, de quais indicadores de urbanidade poderemos utilizar. Ele elabora dois grandes modelos de urbanidade e os denomina modelo “Amsterdã' e modelo "Joanesburgo". Modelos que mostram, em oposição, urbanidade elevada, "Amsterdã" e urbanidade baixa, "Johanesburgo".- (tabela 1). Decorrente dos 6 princípios anteriormente apresentados, ele abre o nosso leque em 13 propostas que poderão compor uma base de indicadores. Lévy (2013c) acrescenta mais um indicador; "Respeito ao ambiente natural". 
Nesta tese iremos trabalhar particularmente com a dupla densidade e diversidades. Densidade de habitantes, domicílio, densidade e diversidades de atividades não residenciais, diversidades de renda, idade, cor/raça. Teremos ainda um capítulo em que trataremos especificamente da acessibilidade.

Tabela 1 - Fonte: (LÉVY, 1999, p. 243 e 2013c, p.1056).

\begin{tabular}{|c|c|c|}
\hline Indicadores de urbanidade & Modelo "Amsterdã" & Modelo "Joanesburgo" \\
\hline 1. Densidade & + & - \\
\hline 2. Compacidade & + & - \\
\hline 3. Interacessibildade entre os lugares & + & - \\
\hline 4. Presença de espaços públicos & + & - \\
\hline 5. Métricas pedestres & + & - \\
\hline 6. Copresença habitação/emprego & + & - \\
\hline 7. Diversidade de atividades & + & - \\
\hline 8. Heterogeneidade sociológica & + & - \\
\hline 9. Fortes polaridade intraurbanas & + & - \\
\hline $\begin{array}{l}\text { 10. Produtividade: mercadoria/habitante } \\
\text { PIB/hab? [uma "Proxy"?] }\end{array}$ & + & - \\
\hline 11. Respeito ao ambiente natural & + & - \\
\hline 12. Auto-avaliação positiva do conjunto dos lugares urbanos & + & - \\
\hline 13. Autovisibilidade/auto-identificação da sociedade urbana & + & - \\
\hline 14. Sociedade política de escala urbana & + & - \\
\hline
\end{tabular}




\section{2 - Elaborar e construir um mapa: reflexões necessárias}

Antes de prosseguirmos nas primeiras elaborações cartográficas da urbanidade, este pequeno capítulo se faz necessário em nossas pesquisas porque temos que pensar a cartografia com o olhar dos esforços empregados na renovação que ocorre no pensamento geográfico contemporâneo. Esforços estes que colocam o mapa alinhado também às reflexões teóricas e práticas, necessárias, de seu papel como construtor de imagens, que podem reforçar ou não seu poder como instrumento gráfico fundamental de comunicação visual que desempenha para análises do espaço geográfico e em particular aqui, para o conceito de urbanidade.

O mapa pode desempenhar um papel de construtor de imagens "verdadeiras" ou "falsas". Mark Monmonier em 1991 já alertava em sua obra "How to Lie with Maps" o poder que os mapas têm de transmitir visualmente equívocos, mentiras, ou apenas pequenas omissões. Podem se transformar em imagens como "verdades absolutas", "naturalizadas". 0 mapa desempenha, se faz num instrumento que pode revelar estruturas espaciais propicias para os nossos estudos ou, pelo contrário, pode fornecer imagens, no mínimo, equivocadas. Estamos empenhados em utilizar as representações cartográficas como instrumentos fundamentais do revelar a essência da cidade, a sua urbanidade e, portanto, temos que refletir também os seus aspectos metodológicos que deveriam ser básicos em sua construção.

A proliferação vertiginosa de instrumentos técnicos contemporâneos que buscam, como resultado final, representações e modelos em forma de imagens para a compreensão de nossa vida social é uma evidência que observamos em nossos afazeres cotidianos, como cientistas sociais e como cidadãos.

Fazer uso do mapa de forma produtiva e não reducionista da complexidade do espaço geográfico esbarra na superficialidade em que é apresentado, bem como na sua elaboração e finalização. Não é de hoje o alerta que vários autores na Geografia que pensam o mapa oferecem provas do uso irrefletido em seu processo de construção. A sofisticação e o alto poder de processar um volume crescente de dados que os computadores possibilitam, não são correspondidos nos resultados apresentados pelos mapas em seu formato final de visualização. "Fazedores de mapas" adotam práticas que podemos nomear como "inocentes" ou "ingênuas" em questões que deveriam ser básicas na sua elaboração.

Este capítulo também é uma contribuição à todos àqueles que pretendem usar o mapa como instrumento fundamental de suas reflexões de estudos e pesquisas e não meramente como coadjuvante, figurativo. Particularmente, expõe metodologias necessárias para pensar o 
seu elaborar, seus componentes, formas que podem ser mobilizadas em sua representação e métodos de sua construção.

\section{1 - O mapa em cena: refletir a montante, construir ao centro, interpretar e comunicar a jusante}

O subtítulo acima foi inspirado em Bord (2013) que, por sua vez, nos remete à sua obra de 2012; " $L$ ' Univers des Cartes". Particularmente em seu capitulo 2, "Une approche personnalisée de la carte" (BORD, 2012, p. 25-65), onde apresenta fundamentais reflexões de três momentos importantes que participam na elaboração e realização de um mapa. Em um primeiro momento - "a montante" - deve ou deveria ser um aspecto mais reflexivo, que compreende os motivos e questionamentos do[s] autor[es] em por que elaborar um mapa (Bord, 2012). É importante para sua pesquisa/estudo? Por quê? Quais conceitos e questões o mapa poderia representar e dialogar com as preocupações teóricas e práticas de sua pesquisa? Não sendo pesquisa e/ou estudo - a princípio, então, fora do mundo acadêmico que reflexões deveria fazer para elaborar um mapa? Qual a necessidade do mapa? Qual seu público alvo [no linguajar publicitário]? Questões que nos levam a outras indagações:

Qual o título? Qual fundo de mapa: em função da projeção, da escala, do formato, dos limites do espaço estudado, da seleção dos indicadores que irão constituir a legenda? Quais dados devemos levar em conta: qualitativos ou quantitativos? A partir de qual suporte: mapas topográficos, temáticos, fotografias aéreas, imagens de satélites, estatísticos, enquetes de pesquisas, etc.? (BORD, 2012, p. 26, tradução nossa)

O segundo momento é a construção do mapa em si. Esta fase deveria ser exclusiva e/ou reservada ao profissional cartógrafo e/ou geógrafo-cartógrafo. Mas como assinala Bord (2012), esta fase hoje em dia pode ser realizada por "qualquer pessoa" (BORD, 2012, p. 26) que tenha domínio de softwares de desenho, de cartografia e/ou de Sistema de Informações Geográficas em computadores pessoais e/ou disponíveis na Web. É a etapa mais prática e técnica do desenho de um mapa. Mesmo sendo uma parte mais prática o "desenhista do mapa" deve ou deveria refletir ao manipular numerosos elementos que compõem o mapa. Em primeiro lugar deveria analisar os dados que escolhe em uma primeira etapa; onde encontrálos, quais fontes são confiáveis, quais tratamentos geométricos e/ou matemáticos serão necessários, que signos serão utilizados, qual semiologia gráfica será empregada, enfim, qual a melhor maneira de realizar um mapa tendo como objetivo final a sua melhor visualização, e questionar ao final: foi feito um bom mapa? Como questionaria Bertin (1988): é um mapa para "ler" ou "ver"? 
O terceiro momento é refletir em sua interpretação e comunicação. A partir de Joly, 200210, Bord (2012) exprime que podemos interpretar "intrinsecamente", ou seja, apenas com os elementos presentes no mapa - o que revela? E "extrinsecamente", o que o mapa produz de significados não presentes diretamente sobre o mapa. Como o mapa é um instrumento de comunicação, o que ele comunica? Fornece uma imagem global do fenômeno que pretendíamos representar por meio de mapas?

Focaremos aqui algumas reflexões e questionamentos necessários ao que Bord elenca como "centro"- a construção do mapa. Antes disso, voltemos um pouco quando ele escreve que "qualquer pessoa" pode desenhar um mapa. Em seu artigo "Cartes e Géomatique", Bord (2013) coloca um paradoxo contemporâneo onde um dos produtos finais de toda uma série de análises, coleta de dados, interpretações, técnicas matemáticas e estatísticas, pode ser um mapa, mas...o que revela este mapa nas maiorias das vezes? Consegue-se interpretá-lo? Seriam, como apontou Muller em seu artigo de 1983 - "Ignorância gráfica ou cartografia da ignorância"?

As manifestações de ignorância gráfica na produção de mapas podem observar-se em diversos níveis, desde a insuficiência das escalas estatísticas e gráficas, a incoerência simbólica .... Conduz-se assim a uma cartografia da ignorância, ou o mapa é parcial ou totalmente desprovido de significado. Os exemplos são expressivos tanto na cartografia conhecida como "tradicional" e nos mapas produzidos por computador. Neste último caso, constata-se uma contradição crescente entre a sofisticação dos instrumentos de trabalho e os programas e a negligência dos princípios mais elementares da expressão gráfica (MULLER, 1983, p.17, tradução nossa).

Estamos apenas ignorando ou somos realmente praticantes de uma cartografia que evita reflexões fundamentais em seus afazeres?

Voltando ainda em Bord (2013) a Geomática [Géomatique] é o tratamento de dados geográficos por meio de instrumentos da informática. Na língua inglesa a geomática "geomatics" - segundo o "Oxford dictionaries online" é "o ramo da ciência que lida com a coleta, análise e interpretação de dados relativos à superfície da Terra”. Para Duckham et al [2009] o estudo da geomática tem suas raízes nas disciplinas que estudam a Terra, examinando-a e mapeando-a. Ainda segundo Duckham o termo emergiu no início dos anos 1970, derivado do termo francês "géomatique". Na literatura francesa encontramos, segundo Guermond (2003), Geomática [Géomatique] é um termo que designa a análise de dados espaciais no qual o computador desempenha um papel determinante nos procedimentos das pesquisas. De um modo geral a geomática é um conjunto de técnicas de informática utilizadas

10 JOLY, Martinel. L'image et son interpétation. Paris: Nathan, Coll. "Nathan Cinéma”, 2002.

${ }^{11}$ In:< http://www.oxforddictionaries.com/us/definition/english/geomatics>. Acesso: 8/8/2014 
em geografia. Este campo de aplicação já ultrapassa atualmente o campo da geografia e expande-se para outras áreas como urbanismo, arquitetura, em estudos de logística, exploração de recursos minerais, da gestão da água, etc. Estaria a Geomática "democratizando" e levando a "qualquer pessoa" a possibilidade de fazer um mapa? Guermond também inclui neste termo o Sistema de Informações Geográficas [SIG] ${ }^{12}$, a utilização do GPS [Global Positioning System] e softwares diversos que utilizam de cálculos estatísticos aplicados à análise espacial.

Para Goodchild (2009) a elaboração de mapas é um campo antigo que retoma aos primeiros seres humanos criando representações pictóricas do mundo ao seu redor. Ainda segundo Goodchild a cartografia moderna é uma disciplina onde o desenho do mapa, a sua compilação e publicação estão associadas com o mapa em papel. Com o advento da tecnologia digital, na década de 1960, a cartografia começou uma transição do meio analógico para o digital. 0 desenvolvimento dos primeiros SIGs ocorreu entre 1950 e 1960, com computadores tornando-se capazes de processar grandes volumes de dados e, como consequência, grandes volumes de informações geográficas. Nas décadas de 1960 e 1970 conseguíamos ainda distinguir quem elaborava mapas de modo analógico e digital. Contemporaneamente, esta distinção praticamente não mais existe. A grande maioria dos geógrafos, cartógrafos e demais pesquisadores/profissionais empregam em seus estudos e análises o computador em seus afazeres cartográficos. Somos hoje "artesãos cartógrafos digitais".

${ }^{12}$ A grafia adotada nesta pesquisa para a sigla SIG é: Sistema de Informações Geográficas e não Sistemas [para tal preciosismo, ver: FITZ, 2008, p. 22]. Resumidamente, trata-se de um sistema computacional; logo, tem a possibilidade de trabalhar com um número "infinito" de informações de caráter geográfico. 


\section{2 - Indo ao "centro"}

Voltemos ao nosso "centro" - a construção do mapa. Entremos agora em algumas reflexões e passos importantes na elaboração de um mapa. Quando estamos interessados em estudar e/ou analisar uma distribuição espacial de um fenômeno, a sua natureza e elaborar esta análise de uma forma visual, particularmente como uma representação cartográfica, temos que refletir, pelo menos, sobre 3 fatores importantes que irão impactar visualmente o resultado final desta representação; a correspondência entre a variável temática escolhida para a elaboração do mapa [ $1^{\circ}$ fator], as possíveis variações de seus atributos [2ำ fator] identificaremos aqui com a letra "Z" e o fundo de mapa [3을 fator], ou localizantes espaciais ${ }^{13}$, identificadas aqui com as letras "X" e "Y" (Cauvin, Reymond e Serradj, 1987).

|Figura 1| O mapa: intersecção de dois espaços (DUTENKEFER, 2010, p. 18)

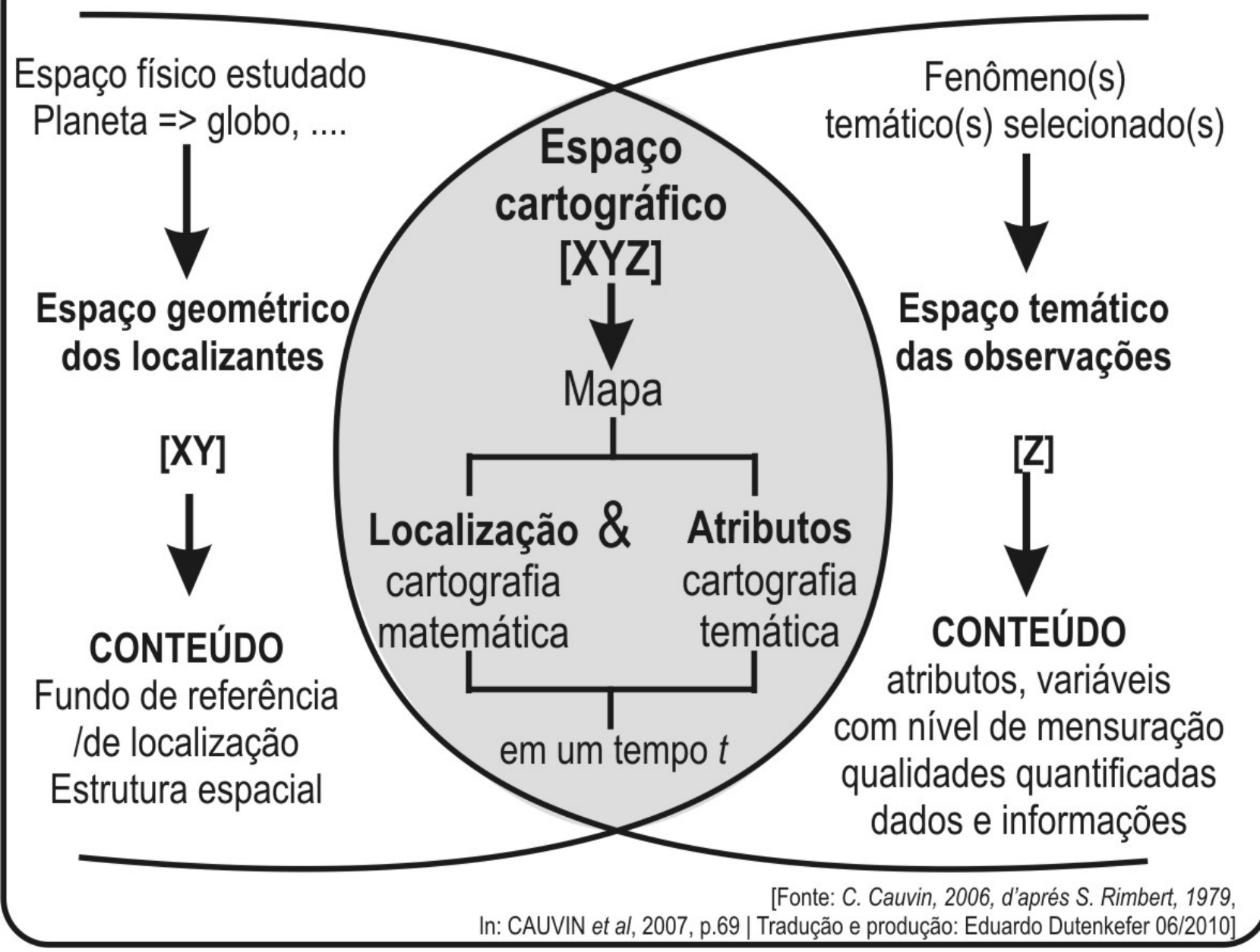

Qual o tratamento matemático e ou gráfico que daremos aos localizantes espaciais [3ํㅜㄴ fator] e ao seu conteúdo temático [variável + atributo - $1^{\circ}$ e $2^{\circ}$ fator]? 0 mapa pode ser uma

${ }^{13}$ Localizantes espaciais: Terminologia sugerida por S. Rimbert - suporte, fundo de referência, fundo de mapa, descritos pelas letras X e Y. (CAUVIN, 1995, p.306). 
imagem como sugere Cauvin et al, (2007a, p. 69), a partir de Sylvie Rimbert ${ }^{14}$,- figura 1. É o espaço cartográfico, fruto da intersecção do espaço geométrico dos localizantes espaciais [XY] e do seu conteúdo temático e/ou espaço temático [Z] [espaço de uma ou mais variáveis temáticas, qualitativas ou quantitativas, sujeitas a variações de seus atributos e candidatas a representar o fenômeno em estudo/analise]. Para Lévy (2003b e 2008) está intersecção possui dupla espacialidade - a da referência e a da linguagem. No esquema de Sylvie Rimbert e Colette Cauvin o espaço de referência seria o espaço dos localizantes espaciais e o espaço da linguagem seria o espaço "temático".

Tradicionalmente, o mapa é classificado, separado em dois mundos. 0 mundo da cartografia sistemática - a cartografia matemática - e o mundo da cartografia temática. Estes "dois mundos" podem ser sintetizados em apenas uma única expressão: todo mapa é temático. Uma carta típica, representante da cartografia sistemática, a carta topográfica - o que ela coloca em evidência? Ela revela fundamentalmente dois temas: os seus elementos planimétricos e altimétricos.

O mapa passa por uma sequência, por uma sucessão de transformações espaciais. Pensar o mapa como uma sequência de transformações vem do que Cauvin, Escobar e Serradj (2007a) chamam de "Cartografia Analítica Transformacional". Iniciada por Waldo Tobler nas décadas de 1960 e 1970 e desenvolvida por Clarke em 1990, nos EUA e na França, por Sylvie Rimbert e Colette Cauvin (Dutenkefer, 2010). Esta linha de pesquisa teve como origem a necessidade de transportar os métodos gráficos utilizados pela cartografia analógica em reformulações matemáticas para uso em computadores (Tobler, 2000).

Tobler assinalava, em 1979, que a ideia de transformações em cartografia não é nova. Em artigo de 1958, Perkal ${ }^{15}$ exprimia que as "transformações cartográficas, empregadas para representar a superfície da terra em mapas, são de dois tipos simples: projeções de mapas e generalizações" (TOBLER apud PERKAL, 1979, p.101, tradução nossa).

Em sua obra coletiva Cauvin, Escobar e Serradj (2007a) sintetizam as reflexões de Perkal, Tobler, Clarke e Rimbert - figura 2.

\footnotetext{
${ }^{14}$ RIMBERT, S. et al., Cartographie informatisée et géographie humaine. ATP 3457 CNRS-LCT, tome 2, fascicule A: Expérimentations em cartographie transformationnelle, 76 . + annexes, 1979.

15Perkal, J., "An Attempt at Objective Generalization," translated from "Proba Obiektywnej Generalizacji”

Geodezja I Kartografia, VII, 2 (1958), 130-142; Michigan Inter university Community of Mathematical

Geographers. Discussion Paper No. 10, (1966), Univ. Microfilms No. OP33067. Ann Arbor.
} 


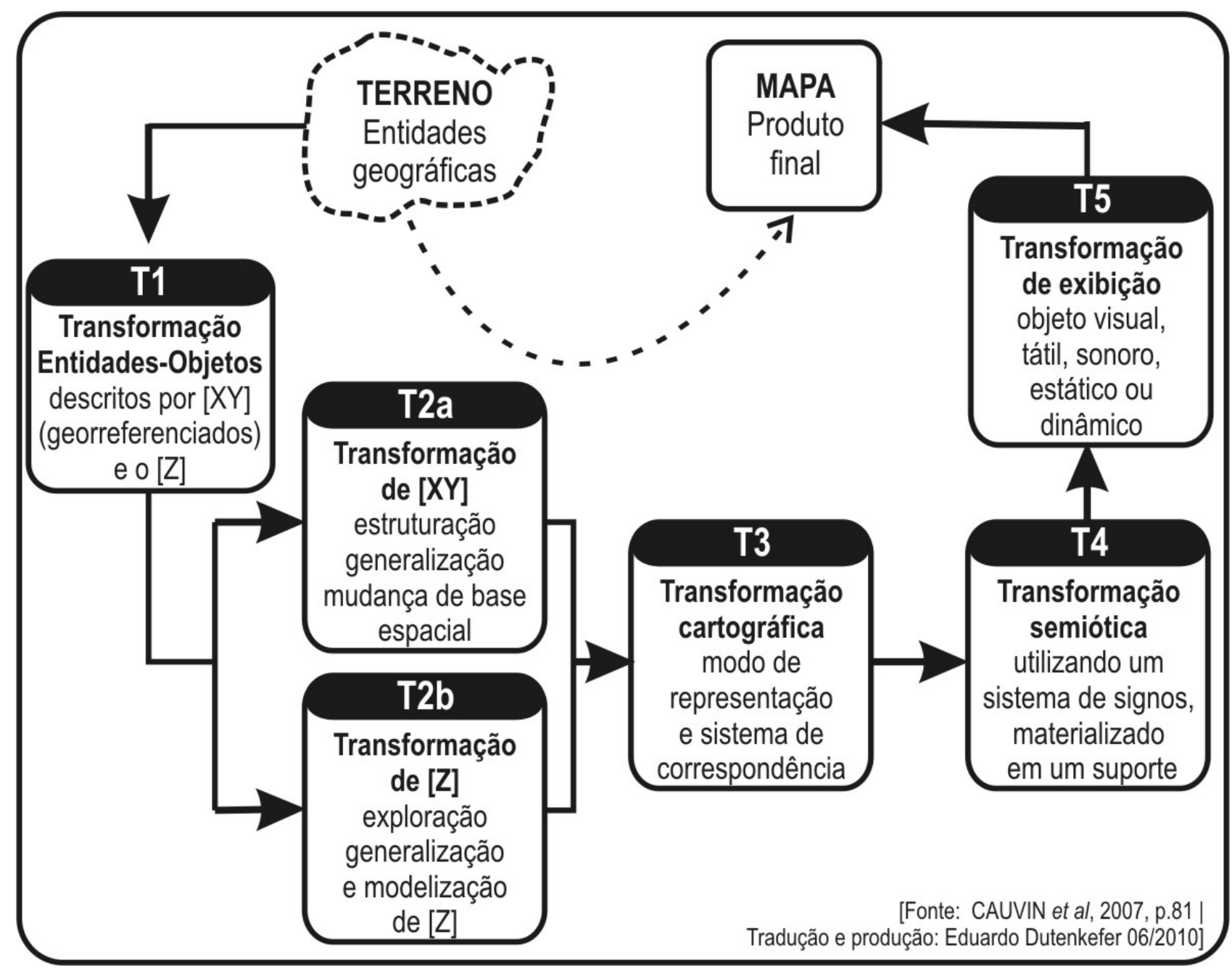

A primeira transformação (T1) é a correspondência homóloga entre entidades/objetos geográficos da superfície terrestre e objetos cartográficos em determinado tempo $\boldsymbol{t}$. A segunda (T2) subdivide-se em uma transformação dos localizantes X e Y [T2a], por exemplo, a generalização e eventualmente uma mudança de projeção cartográfica e a transformação de Z (generalização, estruturação e modelização) [T2b]. 0 terceiro tipo [T3] é quando aplicamos o espaço de Z no espaço dos localizantes espaciais "X" e "Y". Cauvin et al, (2007a) a denomina de transformação de estado quando aplicamos [Z] no localizantes [X,Y]; típico de mapas coropléticos. Quando os localizantes forem função do atributo $[\mathrm{x}=\mathrm{f}[\mathrm{Z}]$ e $\mathrm{y}=\mathrm{g}[\mathrm{Z}]$ estabelece uma transformação cartográfica de posição, conhecida também como anamorfose. A etapa T4 é a transformação semiótica onde podemos utilizar os ensinamentos da Semiologia Gráfica de Bertin para estabelecer os melhores sistemas de signos que irão compor o mapa e oferecer uma expressão visual para a sua leitura e interpretação.

Para realizar a etapa T4 temos que refletir, ou melhor, já termos refletido e talvez respondidas a algumas questões. Comecemos: "ONDE FICA?" Este “onde fica" é da responsabilidade das transformações que os localizantes espaciais sofreram; transformações 
T1 e T2a. Mas existe a transformação T3, onde os localizantes espaciais são alterados e estão ligados ao conteúdo temático e a pergunta "onde fica" perde o sentido. Outra pergunta deve entrar em cena; "o que?", "O QUE É ISTO?" Ou do tipo “onde fica isto, o que é" ? Seria um questionamento da qualidade do fenômeno a representar. Se esta "qualidade" pode ser mensurada, indagamos; “QUANTO?” Mesmo depois de respondida, podemos ainda inquirir: "É DE ORDEM?", “expressa Ordem?” Dependendo destas respostas o fenômeno pode ser visualizado pelas representações qualitativas, ordenadas, quantitativas ou dinâmicas ${ }^{16}$.

Por fim, na transformação T5 o mapa é materializado para exibição, visualização, reprodução e difusão em diferentes meios.

\section{3 - Trabalhando com os temas}

Um dos temas que trabalhamos nesta pesquisa é a população total dos municípios do Brasil e a das comunas da França. Temos dois tipos de variáveis que podemos usar para expressar esta temática: o total da população, dado original do IBGE, e a densidade demográfica. Qual a melhor forma de representá-los cartograficamente?

Temos que estabelecer qual a natureza de Z, se é do tipo de variável continua ou não? Quando temos, por exemplo, valores do tipo medida - 1,45 m, ou 4500,98 $\mathrm{km}^{2}$ - a variável é do tipo continua. Por outro lado, quando temos valores inteiros como, por exemplo, o número de habitantes, números de carros, são valores matematicamente expressos como inteiros, ou seja, são variáveis discretas, não temos 2,5 habitantes ou 1,5 carros ou é 2 ou 3 habitantes, ou 1 ou 2 carros!

Reflitamos então; devemos estabelecer um símbolo gráfico diferente para cada valor da variável ou devemos reagrupá-los em classes de valores que são do tipo continuo e transformá-los em valores discretos ou, ainda, "sub-discretizar" o que já é discreto? (Cauvin, Reymond e Serradj, 1987).

Seguindo as orientações da Semiologia Gráfica, elaborada por Bertin, variáveis estatísticas de caráter quantitativo absoluto [variável discreta] são expressas graficamente

\footnotetext{
${ }^{16}$ Para melhores referências ver por exemplo: BERTIN, J. Sémiologie graphique: Les diagrammes, lês réseaux, les cartes. Paris: La Haye, Mouton, Gauthier-Villars, 1967. Edição mais recente: Editions de l'Ecole dês Hautes Etudes em Sciences Sociales, 2013; BERTIN, Jacques. Ver ou ler. Seleção de Textos (AGB), São Paulo, n.18, p. 45-62, maio 1988; MARTINELLI, M. Curso de Cartografia Temática. São Paulo: Contexto, 1991;

CAUVIN, Colette. ESCOBAR, F.,SERRADJ, A. Cartographie Thématique 2. Paris: Lavoisier, 2007.

Outras referências de seu estudo na internet:

<http://datavis.ca/milestones/index.php?group=1950\%2B\&mid=ms222>; O link acima faz parte de um ótimo site de história da cartografia temática em inglês: Friendly, M. \& Denis, D. J. (2001). Milestones in the history of thematic cartography, statistical graphics, and data visualization. Web document:

$<$ http://www.datavis.ca/milestones/>. Accessed: March 1, 2015. Trabalhos exemplares de cartografia no referencial da Semiologia Gráfica de Bertin

$<$ http://cartographie.sciences-po.fr/>.
} 
com a variável visual tamanho e, variáveis quantitativas relacionais [variáveis continuas], com a variável visual valor. A população total é do tipo quantitativo absoluto e, portanto, deve ser expressa com a variável visual tamanho. Mas questionaríamos: não posso transformar a variável discreta em uma nova discretização ${ }^{17}$ ? Do ponto de vista estritamente estatístico poderíamos representar estes valores discretizados (figura 3, mapa 3.1, superior). Mas, neste caso o diâmetro dos círculos não é mais proporcional ao total da série de valores e sim a uma classe em particular. A relação visual da proporcionalidade entre o valor numérico de referência e o tamanho do círculo se perde. 0 correto é estabelecer uma relação de proporcionalidade entre o valor da variável e o tamanho do símbolo utilizado - figura 3, mapa 3.2 - inferior.

A variável estatística quantitativa relacional do tipo densidade demográfica expressa uma relação entre um atributo quantitativo absoluto, o número total de habitantes, e a área de cada unidade territorial municipal, em $\mathrm{km}^{2}$. 0 primeiro passo na construção do mapa é fazer uma análise prévia dos dados da variável escolhida. A sua representação cartográfica é estabelecida pela variável visual valor. Ela cria uma imagem de ordenamento visual. Estabelece uma relação de hierarquia entre o atributo da variável e a área territorial do município.

Temos que escolher o melhor método de discretização para atingirmos uma representação visual do mapa adequada.

A transformação do atributo $\mathrm{Z}$, etapa $\mathrm{T} 2 \mathrm{~b}$, "muitas vezes é negligenciada e não completamente explorada, mas é essencial quando o objetivo de um mapa é ser legível e útil” (CAUVIN, ESCOBAR E SERRADJ, 2008b, p.14). Nesta etapa é necessário explorar os dados que iremos compor em um fundo de mapa. Ele se inscreve no âmbito da matemática, iniciada por John Wilder Tukey ${ }^{18}$, conhecida como “Analise Exploratória de Dados" [AED], e transformada por Luc Anselin ${ }^{19}$ em "Analise Exploratória de Dados Espaciais" [AEDE]. Para esta analise

\footnotetext{
${ }^{17}$ A operação de dividir em classes de valores as variáveis temáticas é chamada de discretização.

18 Ver por exemplo: TUKEY, John Wilder, Exploratory Data Analysis. New York: Addison-Wesley, 1977.

19 Ver: ANSELIN, Luc. Spatial econometrics: methods and models, Kluwer Academic Publishers, Studies, dans Operational Regional Science, Dordrecht, Londres, Boston.1988.

Ver também na página <http://www.csiss.org/clearinghouse/GeoDa/> e <https://geodacenter.asu.edu/> referências as pesquisas em Análise de Dados Espaciais, ver por exemplo o software desenvolvido por este centro de pesquisa: "GeoDa" que reúne ferramentas matemáticas e mapas para análise de dados espaciais. Ver também artigo de Anselin e outros: Luc Anselin, Ibnu Syabr,Youngihn Kho.GeoDa: Introduction to Spatial Data Analysis. Geographical Analysis. Volume 38, Issue 1, pages 5-22, January 2006. Disponível em:

<http://onlinelibrary.wiley.com/doi/10.1111/j.0016-7363.2005.00671.x/epdf>
} 
exploratória de dados podemos utilizar, por exemplo, softwares conhecidos como "editor de planilhas eletrônicas": Microsoft Office Excel ${ }^{20}$ ou LibreOffice 21.

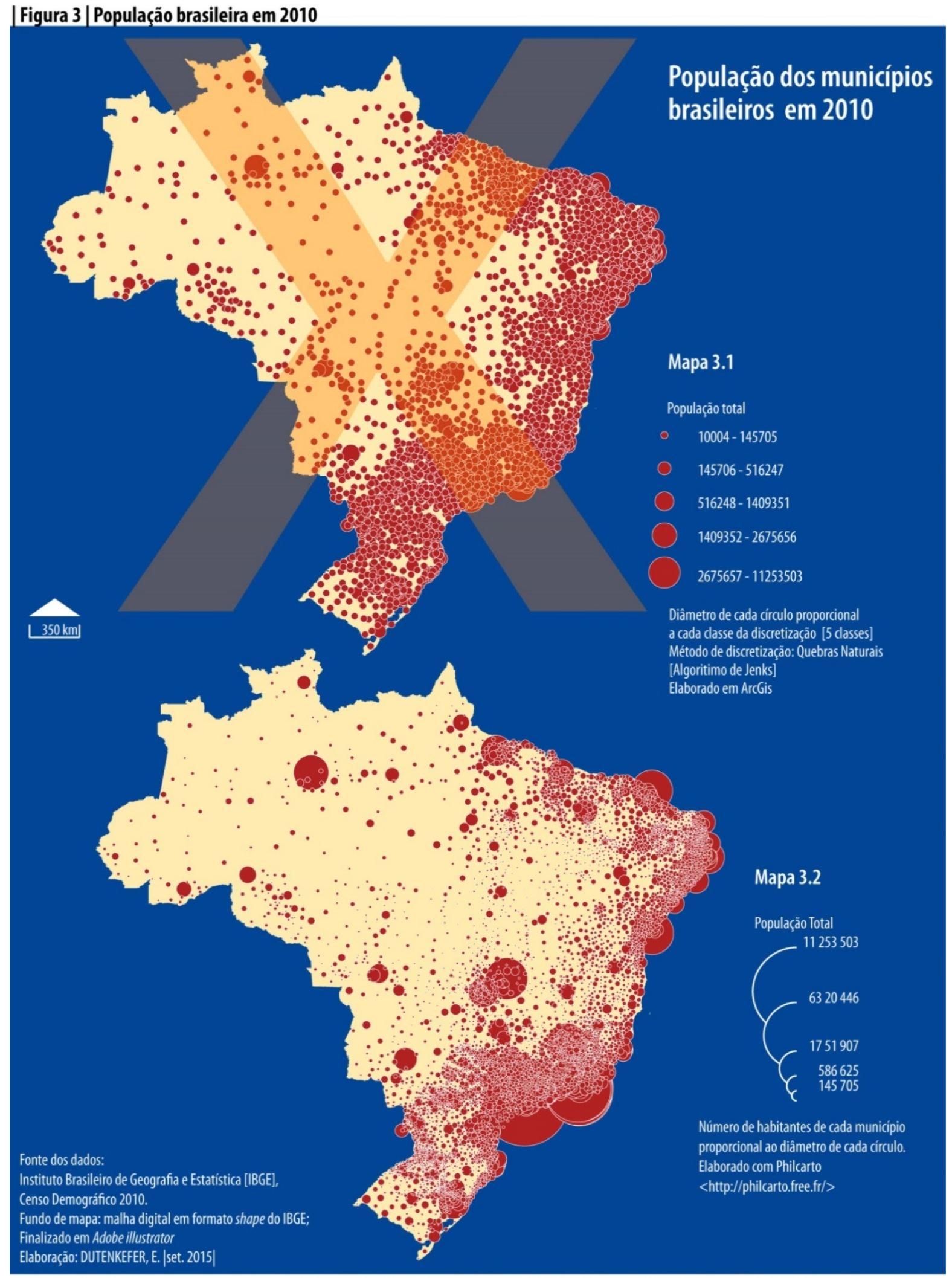

${ }^{20}$ Da empresa Microsoft Corporation. Disponível para compra em: <https://products.office.com/ptBR/excel?omkt=pt-BR>

${ }^{21}$ Softwares de código livre que reúne planilha eletrônica, editor de texto e editor de apresentação. Disponível em: <https://pt-br.libreoffice.org/> 
O primeiro passo é termos uma ideia de como se comporta a distribuição da variável, em nosso caso, a densidade demográfica [habitantes $/ \mathrm{km}^{2}$ ]. Com o auxílio de um dos softwares indicado anteriormente, podemos construir um gráfico de histograma de frequência, para orientarmos na escolha do melhor método de discretização.

Um pequeno parêntese: temos vários métodos de discretização e, na bibliografia em língua portuguesa, em particular a usada no Brasil, de autores geógrafos, temos poucas orientações de como entender, executar e refletir os vários métodos da operação de dividir em classes de valores as variáveis temáticas |discretização|. Temos algumas orientações como, por exemplo, do professor André Libault (1975) [particularmente às páginas 252 a 284 e de valores absolutos às páginas 287 a 295], do professor Marcello Martinelli (1991, 2003, 2014) e da professora Ruth E. Nogueira Loch (2006). Em linha, temos o artigo da professora Rosely Sampaio Archela e do professor Hervé Théry²2 - Archela e Théry (2008). De Portugal temos uma obra importante da Ana Alexandrino Silva (2006) ${ }^{23}$. Grande parte das orientações que utilizamos aqui foram de Cauvin et al (1987 e 2008a), Béguin e Pumain (2007), Silva (2006) e Waniez (2008). Para orientações de métodos estatísticos usados em geografia usamos Rogerson (2012), do Groupe Chadule (1994) e de Costa Neto (1977), não geógrafo. Os softwares de SIG praticamente não detalham e/ou explicam em uma linguagem mais acessível os seus métodos para um público cada vez mais amplo de "fazedores" de mapas, mas que não são "iniciados" nas noções básicas de estatística ${ }^{24}$. Por outro lado, softwares de cartografia digital como, por exemplo, "Philcarto", onde o professor Philippe Waniez disponibiliza em seu site $^{25}$, o livro "Cartographie Thématique et Analyse des Données" - Waniez (2008). Outro

\footnotetext{
22 Orientação metodológica para construção e leitura de mapas temáticos. Disponível em: <http://confins.revues.org/3483>

${ }^{23}$ Esta obra orienta em questionamentos do tipo: Qual a imagem indicada para os seus dados? Que cuidados ter na construção de uma imagem gráfica? Como tornar mais legíveis os seus gráficos e mapas? Como analisar graficamente os dados? Como classificar os dados para construir mapas por classes? Quais os gráficos mais comuns na análise exploratória de dados [AED]? Ver também o blog de Ana Alexandrino Silva:

$<$ https://graficosemapas.wordpress.com/>

${ }^{24}$ Para aprofundar no campo da estatística e da analise exploratória de dados recomendamos, na língua inglesa o livro "Geospatial Analysis A Comprehensive Guide to Principles, Techniques and Software Tools - Fifth Edition Michael J de Smith, Michael F Goodchild, Paul A Longley. Disponível em

$<$ http://www.spatialanalysisonline.com/HTML/index.html>

E de estatística: Engineering Statistics Handbook. Disponível em:

<http://www.itl.nist.gov/div898/handbook/index.htm>

Softwares livres, além do já citado anteriormente, GeoDA, temos o PySAL: Open Source Python Library for Spatial Analytical Functions. Disponível em: <https://geodacenter.asu.edu/pysal>

SAM (Spatial Analysis in Macroecology) da Universidade Federal de Goiás. Disponível em:

$<$ http://www.ecoevol.ufg.br/sam/>

${ }^{25}$ Disponível gratuitamente em:<http://philcarto.free.fr/>
} 
software importante é o "Cartes \& Données"26 que também disponibiliza textos explicativos ${ }^{27}$ de seus métodos.

Para uma primeira exploração dos dados temos que realizar resumidamente as seguintes operações:

i - ordenar os atributos em ordem crescente;

ii - calcular os índices clássicos de estatística;

iii - elaborar um gráfico simples contrapondo, no eixo $\boldsymbol{Y}$, a densidade em ordem crescente de valores e, no eixo $\boldsymbol{X}$, as unidades territoriais, no nosso caso os 5.565 municípios, para uma primeira aproximação visual do comportamento da distribuição dos atributos;

iv - e, por fim, elaborar um gráfico de histograma de frequência com o maior número de classes de Z para uma boa visualização da distribuição.

Na figura 4, gráfico 4.1, [Gráfico da densidade de população dos municípios brasileiros] temos a visualização do comportamento da nossa distribuição dos atributos Z [densidade de população] nas unidades espaciais [municípios]. Visualmente, é perceptível uma curva de um pico alto de densidade decrescendo exponencialmente ao longo do eixo "X" do gráfico [Municípios].

Ainda na figura 4, temos o histograma dos dados da densidade demográfica dos municípios brasileiros em 2010 e os valores dos índices estatísticos clássicos, elaborados em Excel - gráfico 4.2. Com os valores ordenados crescentemente, no eixo "X”, visualizamos uma a grande quantidade de valores de pequenas densidades.

0 que o gráfico 4.2 [Distribuição do atributo $\mathrm{Z}$ em histograma de frequência da densidade demográfica dos municípios brasileiros] nos revela? Se voltarmos em nossas aulas de estatística, percebemos visualmente que os valores de $\mathrm{Z}$ estão concentrados à esquerda do gráfico e valores de maior atributo à direita. E, talvez, ainda classificá-la como uma distribuição assimétrica. Assimetria significa que uma distribuição de atributos não é simétrica, isto é, o valor médio de sua distribuição não é centrado em torno da média aritmética de seus valores. Na figura 5 temos alguns tipos de histogramas de frequência e suas simetrias. São 5 tipos clássicos que nos orientam na tomada de decisão de qual método de discretização utilizaremos.

\footnotetext{
${ }^{26}$ Disponível em <http://www.articque.com>. No link: <http://www.articque.com/geocampus> estudantes podem obter uma licença grátis por um ano deste software.

27 Ver: <http://support.articque.com/cd/doc/stats.htm>
} 
Os cálculos dos índices estatísticos também podem ser reveladores. Com os valores máximo e mínimo temos uma medida de dispersão como a amplitude ou intervalo, isto é, a diferença entre o maior e o menor valor da variável [Amplitude $=Z_{M a x}-Z_{\min }$ ] |eq. 1|. Em nosso caso temos um intervalo de 12913,78.

Outro indicador de dispersão é a variância que, segundo COSTA NETO (1977, p. 26), “é,

\section{| Figura 4 | Gráfico e histograma da densidade demográfica em 2010}

Densidade 2010

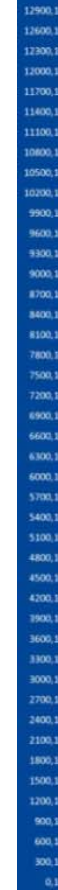

$\operatorname{lin}_{1000}$

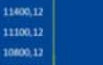

4.1 - Gráfico da densidade de população dos municípios brasileiros

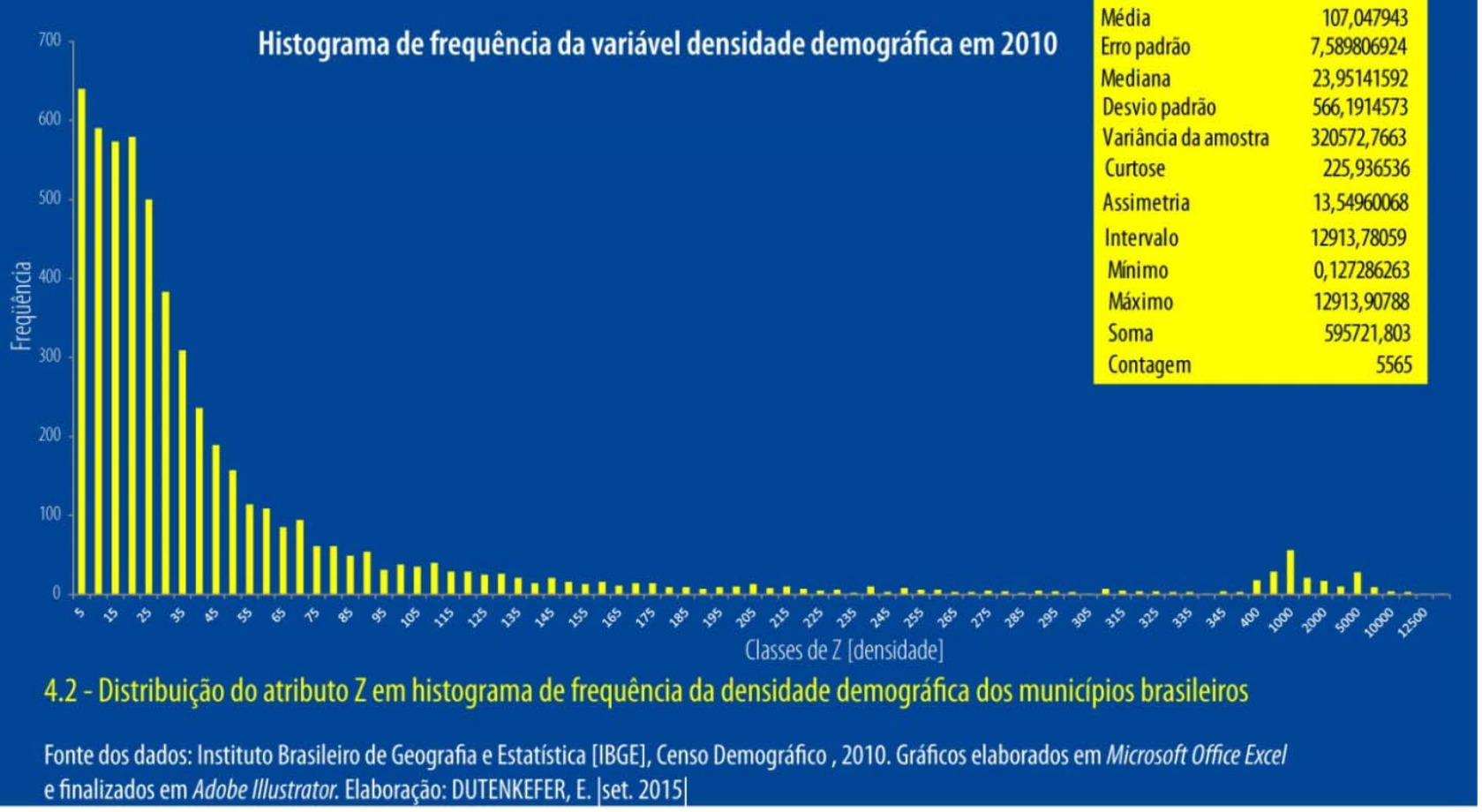


por definição, a média dos quadrados das diferenças dos valores em relação à sua média", isto é:

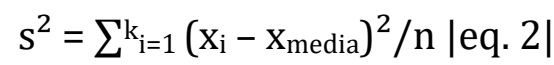

$\mathrm{s}^{2}$ |variância| e n |número total de dados de nossa variável|

Ela mostra o quão distante os valores de Z estão em relação ao seu valor central, ou seja, a sua média. Em nosso exemplo temos uma média de 107,048 e uma variância de 320.572 !

Outro indicador de dispersão muito utilizado é o desvio-padrão. Derivado da variância, ele é a raiz quadrada da variância: $\sigma=\sqrt{ }$ var |eq. $3 \mid$ ou, em outra notação matemática $\sigma=$ (var) ${ }^{1 / 2}$ |eq. 4|. Se pretendêssemos usar o valor médio como um valor "confiável" de nossos dados deveríamos indicá-lo com um valor de sua variação ou "erro". Ele caracteriza a variação ou dispersão que existe em relação à média de Z. Um valor baixo significa que os valores de Z estão próximos da média, se alto, estão espalhados por uma graduação de valores de Z. Em nosso caso temos um valor de $\sigma=566$. Um valor também alto em relação à média de 107 $\mathrm{hab} / \mathrm{km}^{2}$.

Estes dois índices, variância e desvio-padrão, indicam em nosso exemplo, que temos que ser cautelosos ao usar métodos de discretização que utilizem a média em sua formulação, quando temos indicadores de dispersão altos.

Já o índice de assimetria com um valor positivo [13,55] indica uma distribuição alongada à direita, conhecidas como positivamente assimétricas. Os valores de $\mathrm{Z}$ se concentram à esquerda em nosso gráfico do histograma [figura 4, gráfico 4.2] e, com menores valores de frequência à direita, se assemelha como em nosso terceiro gráfico da figura 5 , item $5 \mathrm{C}$.

|Figura 5 | Tipos de distribuição de Z em histogramas de frequência

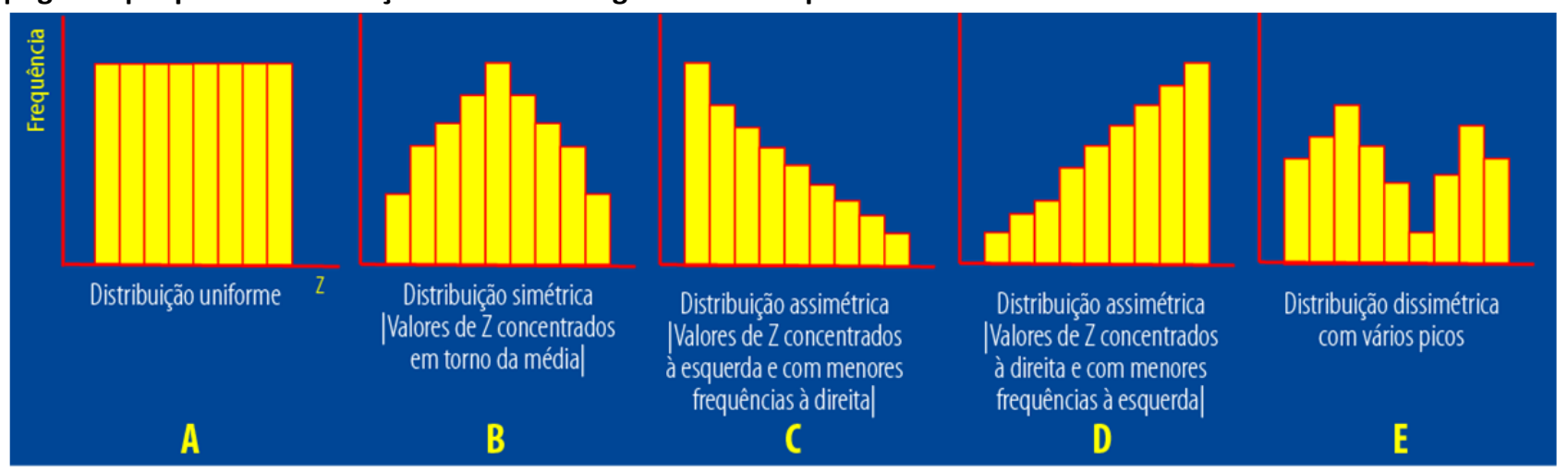

Cada método tem as suas vantagens e desvantagens. É necessário uma reflexão e questionamento dos vários métodos utilizados para a construção do mapa. Queremos um método que melhor represente a distribuição de nosso tema de estudo e análise. 
Antes de prosseguirmos, temos que avaliar qual o número de classes que iremos adotar para a nossa representação. 0 número de classes irá influir na quantidade de detalhes expressos e no grau de generalização efetuada na elaboração de um mapa. Teremos que ter um compromisso entre a matemática e a cartografia, ou seja, entre os métodos gráficos, e/ou matemático/estatísticos e a nossa capacidade de percepção visual gráfica final - Cauvin et al (1987 e 2008a) e Béguin e Pumain (2007).

De Cauvin et al (1987 e 2008a) temos, por exemplo, a proposta de Brooks e Carruthers ${ }^{28}$ :

$$
\mathrm{K} \leq 5^{*} \log _{10} \mathrm{~N} \quad \text { |eq. } 5 \text { | }
$$

ou de Hunstberge 29

$$
K=(3,3 * \log 10 N)+1 \quad \mid \text { eq. } 6 \mid
$$

Onde $\boldsymbol{K}=$ número de classes e $\boldsymbol{N}=$ número total dos atributos

Aplicando à nossa variável temos $\mathbf{N}=5565$ [5565 municípios]

Da equação 5 temos:

$\mathrm{K} \leq 5^{*} \log _{10} 167=>\mathrm{K} \leq 11,11 \quad$ significa $\leq 19$ classes;

e da eq. 6 :

$K=(3,3 * \log 10167)+1=>K=13,3 \quad$ significa $=13$ classes.

Estas duas equações acima fornecem uma primeira opção da quantidade de classes a adotar. Outra importante decisão é se este número adotado é adequado à "percepção do olhar humano", isto é, se nosso cérebro é capaz de distinguir as variações, as gradações de valores de uma única cor. Cauvin et al (1987 e 2008a) indica de 6 a 7 classes, para um público em geral e até 10 se o mapa for utilizado particularmente pelos pesquisadores; ainda indica que na clássica obra de Robinson ${ }^{30}$ é enfatizado que podemos distinguir até 5 variações de tonalidades. 
|Figura 6| Tela do ColorBrewer 2.0

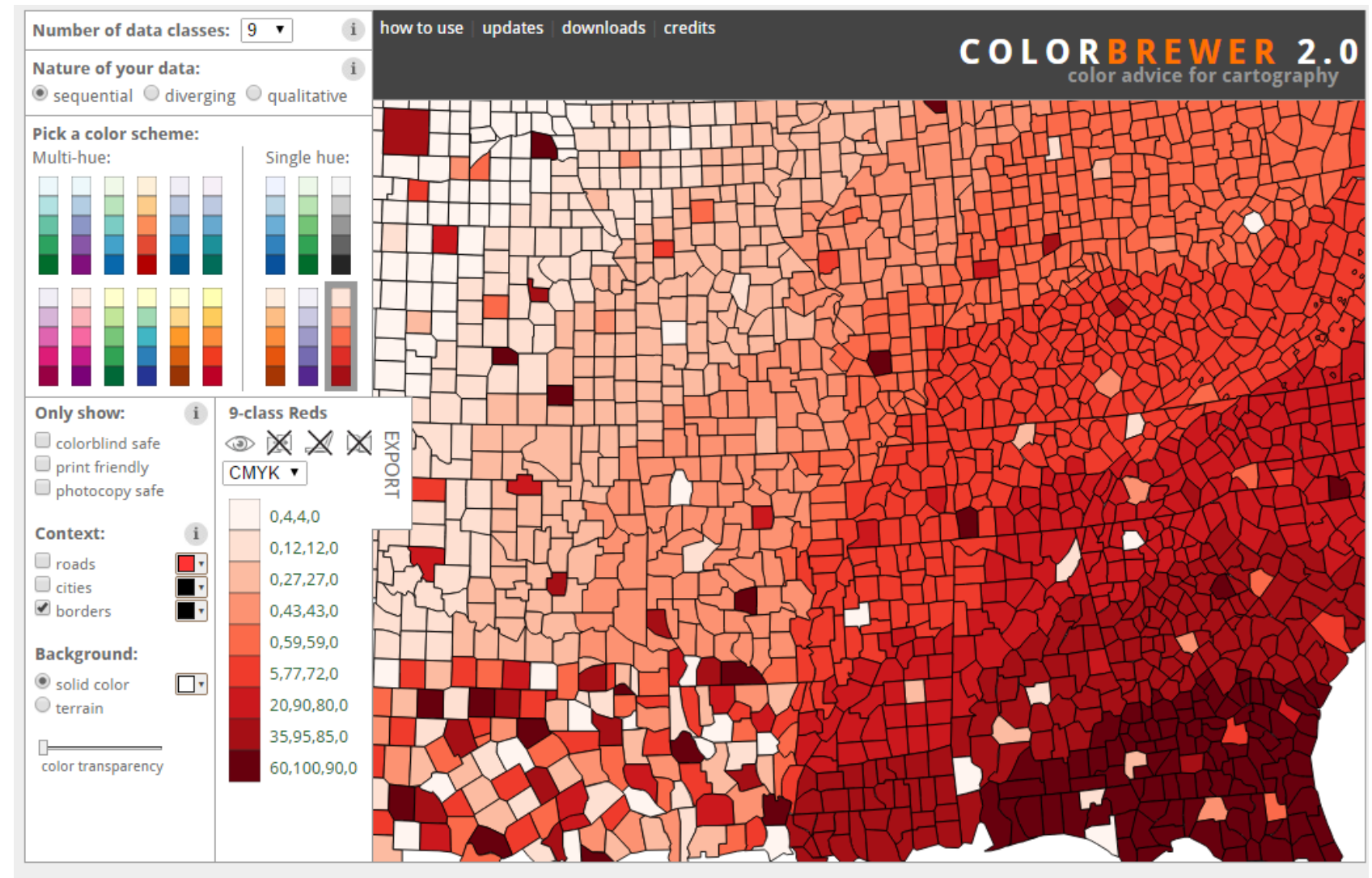

๑c Cynthia Brewer, Mark Harrower and The Pennsylvania State University Support
Back to Flash version

Coxismaps

0 aplicativo em linha ColorBrewer"31, (figura 6) fruto das pesquisas realizadas por Cynthia A. Brewer e Mark Harrowen (Brewer e Harrowen, 2003) da Universidade da Pennsylvania em 2003, é um importante instrumento para esta decisão. Ele fornece sugestões de Cores de até 9 classes para mapas que expressem ordem, sequência; seis opções de cores com uma única matiz e 12 opções de cores com matizes maiores que um. É importante salientar que este aplicativo ainda oferece um "alerta" se a quantidade de classes escolhida é capaz de oferecer uma boa visualização em diferentes mídias para daltônicos [é uma boa reflexão de qual público queremos atingir com nossa comunicação cartográfica].

Na figura 7 temos alguns métodos de discretização com os dados de densidade demográfica de 2010. Adotamos aqui, de um modo geral, 7 classes para a representação da variável densidade demográfica de 2010. Foi utilizado o software Philcarto que oferece 5 métodos diferentes de discretização e estão representados nos mapas 7.1, 7.2, 7.3, 7.4 e 7.5. Na versão utilizada, 5.75, as paletas de Cores sugeridas pelo aplicativo já utilizam algumas opções do ColorBrewer. 
|Figura 7| Mapas de densidade demográfica 2010 com vários métodos de discretização

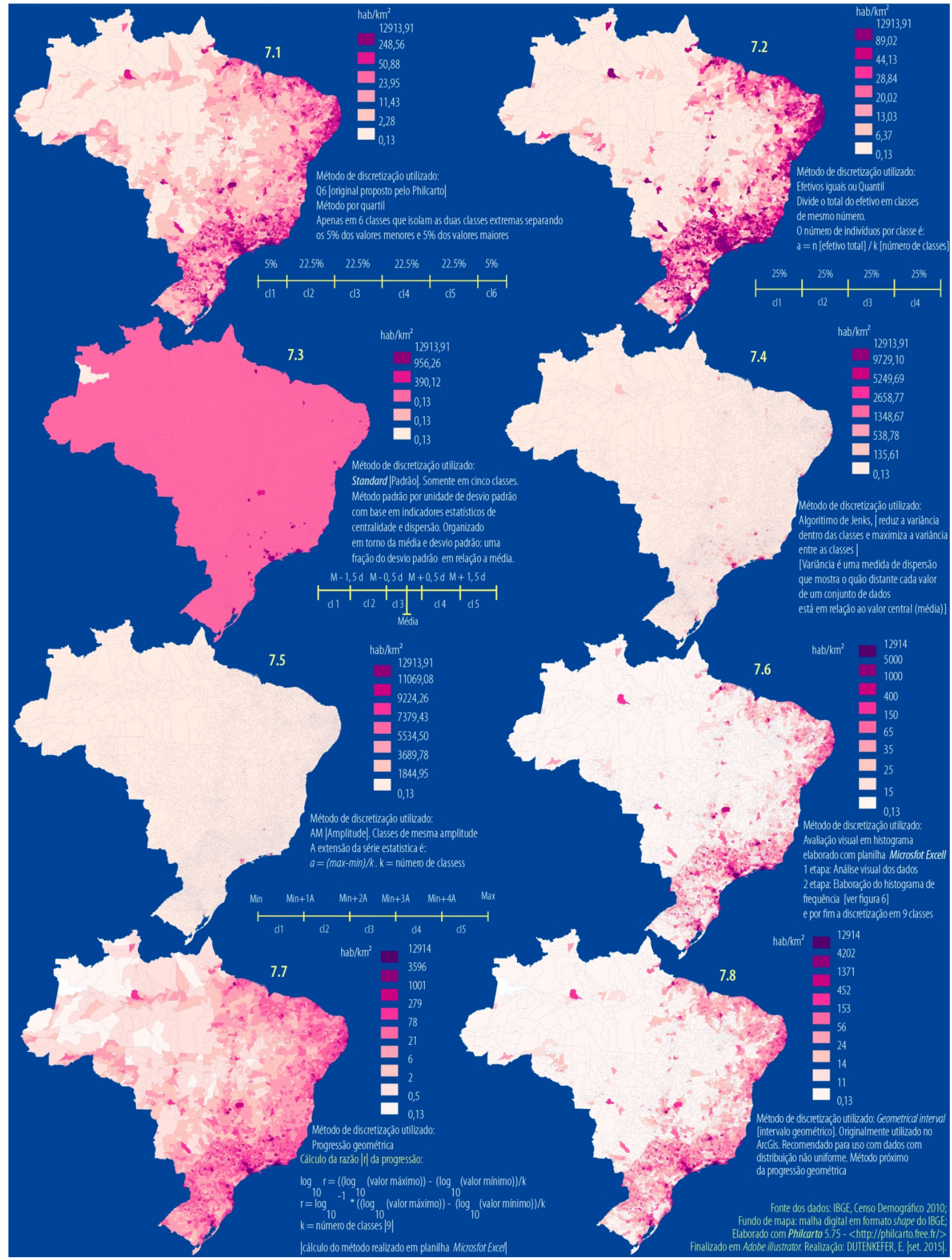


O mapa 7.1 usa um método original proposto pelo software Philcarto denominado método de quartil. É proposto para apenas 6 classes que isolam as duas classes extremas separando $5 \%$ dos valores menores [classe 1] e 5\% dos valores maiores [classe 6] dos atributos. Os restantes das classes [classes 2, 3, 4 e 5] contém um número igual de atributos distribuídos na proporção de 22,5\% cada.

0 mapa 7.2 utiliza o método de efetivos iguais ou quantil ${ }^{32}$. Divide o total do efetivo em classes de mesmo número. 0 número de indivíduos por classe é:

$\mathrm{a}=\mathrm{n}$ [efetivo total] / $\mathrm{k}$ [número de classes] |eq. 7|

Os dois métodos acima normalmente são aplicados a todos tipos de distribuições estatísticas, garantem uma razoável comparação entre diferentes séries de dados, mas podem eliminar amplitudes muito desiguais, perdendo informações importantes da série como um todo. Em nosso caso, os dois métodos conseguiram equilibrar as classes de pequena densidade até valores de $50 \mathrm{hab} / \mathrm{km}^{2}, 4$ classes para o mapa 7.1 e 5 para o 7.2. Os valores mais altos são mais homogeneizados em apenas duas classes. Uma classe de 50 até 250 no mapa 8.1 e outra para maiores que 250 até o máximo. No mapa 7.2 uma de 44 até 90 e outra acima de 90 até o máximo, na ordem de 13000 habitantes por quilômetro quadrado.

0 método do mapa 7.3 é conhecido como Standard|Padrão|. Somente em cinco classes. Utiliza método padrão por unidade de desvio padrão com base em indicadores estatísticos de centralidade e dispersão. É organizado em torno da média e desvio padrão: uma fração do desvio padrão em relação à média. Como apontamos anteriormente, usar indicadores de dispersão para uma série como a nossa, com variância e desvio padrão alta e com uma assimetria acentuada, este método não é recomendável. Homogeneizou todos os valores até $390 \mathrm{hab} / \mathrm{km}^{2}$ e isolou os maiores deste, em apenas uma classe.

No mapa 7.4 utilizamos o método ${ }^{33}$ apresentado pelo geógrafo George Frederick Jenks |1916-1996| de 197734, utilizando algoritmo de Fisher de $1958^{35}$ (Cauvin, Reymond e Serradj,1987). Conhecido como método de Jenks ou de "quebras naturais"36, é um método "iterativo que procura minimizar a variância intraclasses - maximizando assim a

\footnotetext{
${ }^{32}$ Designação genérica dos valores (centil, decil e quartil) que correspondem à divisão em porções de um conjunto de dados ordenados. Do latim quantum, [quantidade] "quantum" + il". in Dicionário da Língua Portuguesa com Acordo Ortográfico [em linha]. Porto: Porto Editora, 2003-2015. [acesso: março 2015]. Disponível em:<http://www.infopedia.pt/dicionarios/lingua-portuguesa/quantil>.

${ }^{33}$ Utilizamos aqui o software Philcarto e segundo Waniez (2008, p. 15) o programa fonte deste método foi fornecido por Colette Cauvin.

${ }^{34}$ JENKS, G.F. Optimal data classification for choropleth maps. Occasional Paper, $\mathrm{n}^{\circ} 2$. Kansas: University of Kansas, Department of Geography, 24 p.1977.

35 FISHER W.D. On grouping for maximum homogeneity. Journal of American Statistical Association, Vol. 53, p. 789-798., 1958. < https://csiss.ncgia.ucsb.edu/SPACE/workshops/2004/SAC/files/fisher.pdf>. Acesso: $20 / 3 / 2015$

${ }^{36}$ Em alguns softwares como ArcGis e Qgis, por exemplo, usam o termo de "quebras naturais" (Jenks)
} 
homogeneidade das classes - e, por outro lado, maximizando a variância interclasses" (CAUVIN, REYMOND e SERRADJ, 1987, p. 42, tradução nossa). Reduz a dispersão dos dados em cada classe e aumenta a variância entre as classes. É bem próximo ao que seria realçado visualmente ou "naturalmente" as rupturas, descontinuidades de uma sequência de atributos observados como, por exemplo, em histogramas de frequência. Como o método é algorítmico, isto é, matematicamente é um conjunto de regras e operações próprias do seu fazer, não entraremos aqui em seus detalhes ${ }^{37}$.

Observamos que o método aplicado ao mapa 7.4 não foi capaz de contemplar mais classes com valores menores e médios de densidade, uma classe para densidades menores que $135 \mathrm{hab} / \mathrm{km}^{2}$ e outra para densidades até 540. Por sua vez, criou 4 classes para as demais densidades. 0 algoritmo de certa forma homogeneíza em uma mesma classe os valores mais próximos possíveis [uma baixa variação intraclasse] e isola em 4 grupos os valores com uma mais forte variância interclasses.

Tem a vantagem de propor um corte onde os indivíduos das mesmas classes são o mais próximo possível (baixa variação intraclasses) e isolar os diferentes grupos (forte variância interclasses).

É importante assinalar que softwares como Philcarto, ArcGis ${ }^{38}$, Qgis $^{39}$ e Carte \& Données [utilizados aqui para referência de possíveis instrumentos computacionais] utilizam algoritmos diferentes em sua implementação, pois as classes geradas por estes softwares com nossos dados de densidade demográfica de 2010, por exemplo, oferecem resultados ligeiramente diferentes, mas que, de um modo geral, contemplam a observações mencionadas acima - tabela 2.

Tabela 2 - Divisão em classes de valores com diferentes softwares que utilizam o método de discretização de Jenks.

\begin{tabular}{|c|c|c|c|c|}
\hline C & Philcarto & ArcGis & QGis & Carte \& Données \\
\hline 1 & [0,1-136[ & {$[0,1-130[$} & {$[0,1-77[$} & {$[0,1-32$} \\
\hline 2 & [136-539] & [130-492[ & [77-250[ & [32-95[ \\
\hline 3 & [539-1349[ & [492-1264] & [250-580] & [95-330[ \\
\hline 4 & [1349-2659[ & [1264-2549[ & [580-1526[ & [330-1107[ \\
\hline 5 & [2659-5250[ & [2549-4627[ & {$[1526-3644[$} & [1107-2338[ \\
\hline 6 & {$[5250-9729[$} & [4627-8368[ & [3644-9729[ & [2338-4938[ \\
\hline 7 & [9729-12914] & [8368-12914] & [9729-12914] & [4938-12914] \\
\hline
\end{tabular}

Elaboração: DUTENKEFER, Eduardo |set. 2015|

\footnotetext{
37 Uma seqüência ou "démarche" simplificada pode ser obtida em (CAUVIN, 1987, p. 42).

${ }^{38}$ Software de SIG da ESRI [Environmental Systems Research Institute].

${ }^{39}$ Disponível em < http://www.qgis.org/es/site/>
} 
A discretização em classes de igual extensão ou amplitude ou ainda de intervalos constantes foi aplicado ao mapa 7.5. 0 cálculo da amplitude é dado por:

$\mathrm{a}=$ (Valor máximo - Valor mínimo) / k [número de classes] |eq. 8|

Em nosso caso teremos:

$\mathrm{a}=(12913,91-0,13) / 7=>\mathrm{a}=1844,82$

Percebemos que só a primeira classe $\mathrm{Cl} 1=[0,13-1844,95]$ já englobaria a maioria de nossos valores de densidade!

Este método não é adequado, portanto, para séries estatísticas assimétricas como é o nosso caso. Para séries uniformes, como no primeiro gráfico da Imagem 7, seria a mais indicada, mas é difícil de encontrarmos séries com esta distribuição.

A discretização do mapa 7.6 foi realizado pela observação visual do histograma de frequência da figura 4, gráfico 4.2 e dividida em 9 classes. Esta divisão foi orientada pelo máximo número de classes que o aplicativo ColorBrewer oferece para a variável visual valor. 0 aplicativo é o resultado mais atual em estudos de percepção de valor para uso em cartografia.

Tanto Cauvin et al (1987 e 2008a) quanto Béguin e Pumain (2007) e Silva (2006) indicam que o método de discretização utilizando a progressão geométrica é o mais adequado para séries assimétricas, como em nosso exemplo. Este foi aplicado ao mapa 7.7. o Philcarto não realiza automaticamente este procedimento. 0 seu cálculo foi realizado em Excel e posteriormente os valores foram aplicados no Philcarto.

Como este método não é facilmente encontrado em softwares, vamos detalhar um pouco o método para facilitar aos interessados em utilizar esta discretização.

Primeiro temos que calcular a razão geométrica que é dada por:

$\log [10] \mathrm{r}=(\log [10] \max -\log [10] \mathrm{min}) / \mathrm{k}$

$\mathrm{r}=\log [10]^{-1}(\log [10] \mathrm{r}) \quad$ |eq. 9|

$\max =$ valor máximo da série e min = valor mínimo da série

$\mathrm{r}=$ razão geométrica

$\mathrm{k}=$ número de classes escolhida

Em notação do Excel teríamos:

$r=10^{\wedge}(((\log 10($ maximo $))-(\log 10($ minimo $))) / K) \mid$ eq. $10 \mid$

Com nossos dados temos $r=3,591161$

As quebras de classes seriam:

valor mínimo* ${ }^{1}$

em notação do Excel: valor mínimo*POTENCIA(valor da razão;1)

valor mínimo*r² notação do Excel: valor mínimo*POTENCIA(r;2) 
Valor mínimo*r³ $\quad$ notação do Excel: valor mínimo*POTENCIA(r;3)

valor mínimo*r9 $\quad$ notação do Excel: valor mínimo*POTENCIA(r;9)

Com nossos dados temos como limites:

$0,5,2,6,22,78,279,1001,3596,12914$

Portanto, com as seguintes classes com os valores já arredondados como número inteiro [excetuando a classe 1 e 2]:

$\mathrm{Cl} 1=<0,5[, \mathrm{Cl} 2=[0,5-2[, \mathrm{Cl} 3=[2-6[, \mathrm{Cl} 4=[6-22[, \mathrm{Cl} 5=[22-78[$

$\mathrm{Cl} 6=[78-279[, \mathrm{Cl} 7=[279-1001[, \mathrm{Cl} 8=[1001-3596[, \mathrm{Cl} 9=[3596-12914]$

No mapa 7.8 utilizamos um método originário do software ArcGis, geometrical interval, intervalo geométrico. No blog da ESRI, Charlei Frye ${ }^{40}$ explica que o método foi desenvolvido para aplicações onde os dados estão mais "distorcidos". Seria indicado, então, para distribuições assimétricas e dissimétricas mostradas anteriormente na figura 5 - distribuições do tipo C, D e E. É um algoritmo mais próximo de uma discretização utilizando o método da progressão geométrica, mas que varia o coeficiente da razão geométrica, isto é, a razão não é a mesma utilizada para cada classe.

Existem outros métodos de discretização, mas paramos por ora com estes mais comuns e significativos. Não temos um método único, perfeito, que dê conta dos vários tipos de distribuições estatísticas que os atributos podem assumir. 0 fundamental é termos um visual prévio do tipo da distribuição, utilizando, por exemplo, os histogramas de frequência para uma primeira aproximação, e depois realizar alguns testes com os aplicativos cartográficos automatizados que tenham os métodos de discretização mais recomendados para o tipo de distribuição de nossos dados. Não podemos deixar que o software realize automaticamente a discretização sem uma prévia reflexão dos pesquisadores e dos "fazedores de mapas". Para maiores detalhes de outros métodos ver a obra de Cauvin et al (1987 e 2008a) e Béguin e Pumain (2007).

Cada método tem sua vantagem e desvantagem e, observando os vários mapas da figura 7, verificaremos que os métodos de discretização baseados em uma prévia exploração de seu histograma de frequência [mapa 7.6], o de progressão geométrica [mapa 7.7] e por fim o de intervalo geométrico [mapa 7.8] permitem representar mais significativamente o conjunto dos dados da densidade demográfica dos municípios do Brasil em 2010. Mesmo com a vantagem de duas classes a mais que os demais métodos representados aqui, estes

40 <http://blogs.esri.com/esri/arcgis/2007/10/18/about-the-geometrical-interval-classification-method/>. Acesso: 7/7/2015 
propiciaram uma melhor visualização da distribuição das densidades, sejam as baixas, que são a maioria dos municípios brasileiros, as médias e os poucos municípios com densidades mais elevadas.

\section{4 - O mapa sem classes}

Podemos também tentar ultrapassar as limitações que todos os métodos anteriores apresentam e propor como Tobler (1973) sugeriu em seu artigo "Choropleth maps without class intervals?": abolir a discretização e representar cada valor da densidade por uma variação de cinza, se utilizarmos uma variação de 0 até $100 \%$ de preto ou de uma cor de um mesmo matiz. Se escolhermos uma variação de cor é recomendável evitar Cores "com um espectro estreito, como o amarelo, ou Cores frias" (SILVA, 2006, p. 217), pois temos que distinguir minimamente as variações do "valor" do atributo. Na figura 8 temos o mapa da densidade demográfica com esta proposta.

O mapa sem classes permite, por um lado, não termos que ficar limitados ao número de classes adotado mas, por outro, ficaremos reféns da capacidade de nosso olhar para percebermos as variações. De certa forma quem vai classificar visualmente a imagem será o "leitor visualizador" final. Como o mapa coroplético não tem como objetivo principal individualizar o valor de cada atributo, esta solução permite obter uma imagem visual geral da distribuição dos dados. Isto faz com que esta opção sirva também como um método prévio de visualização dos dados em um fundo de mapa para depois optarmos por um método de discretização e, por fim, comparar visualmente o método de discretização por nós escolhido com o mapa sem classes. Fazendo esta comparação visual com os métodos apresentados na figura 7 podemos apontar o método de progressão geométrica como o mais indicado para os nossos dados? 
|Figura 8| Mapa de densidade demográfica sem método de discretização

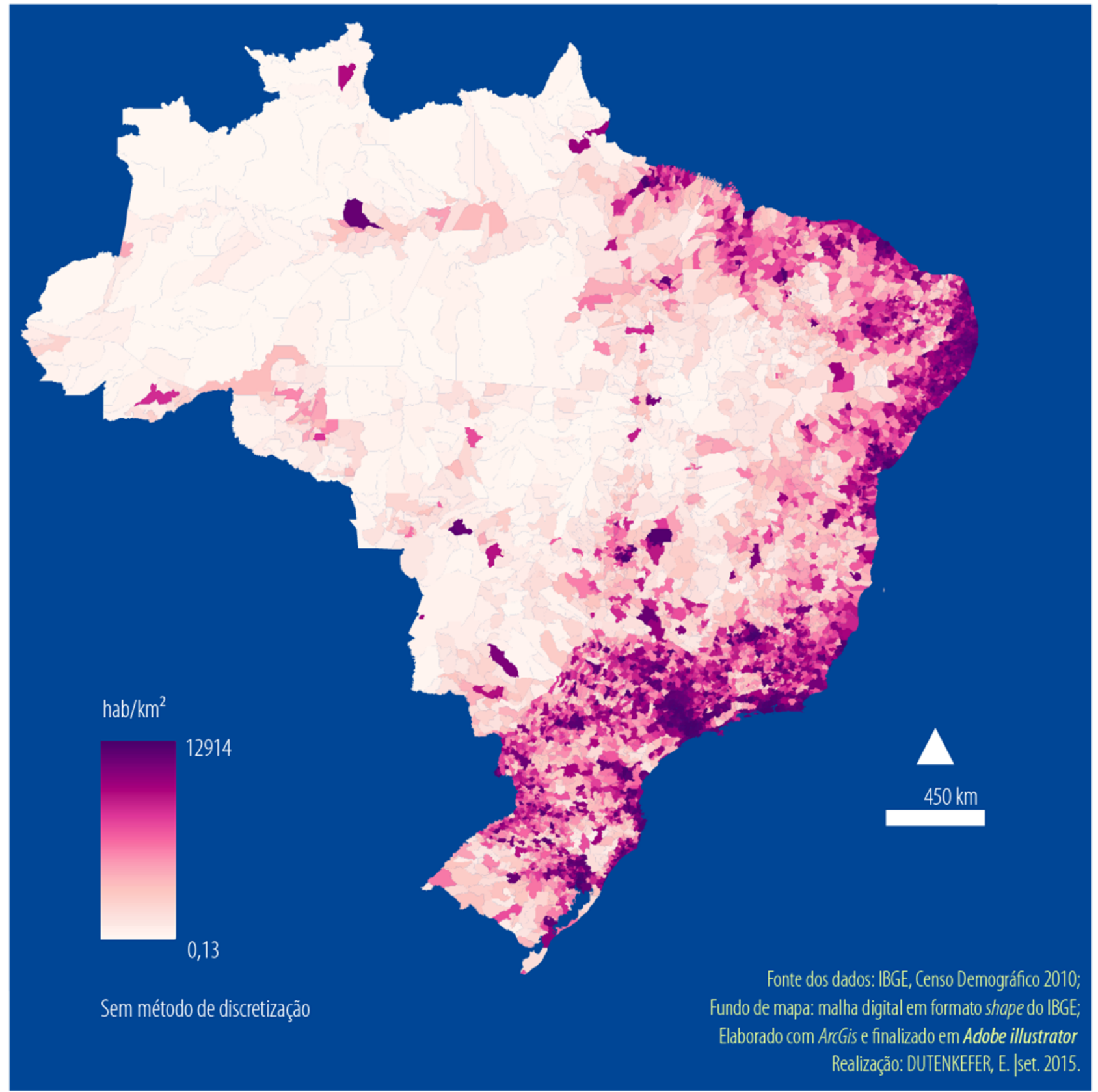

\section{5 - Alterando a construção do mapa}

Até agora trabalhamos com um tipo de transformação cartográfica de estado, isto é, aplicamos os atributos nos espaços dos localizantes espaciais. Na figura 9 introduzimos mais dois tipos de representação cartográfica, a anamorfose [9.1] e o cartograma em anamorfose [9.2]. Falamos em anamorfose quando o mapa passa por uma transformação cartográfica onde seus localizantes espaciais são alterados. 
|Figura 9| Mapa em anamorfose [9.1] e Cartograma em anamorfose [9.2]

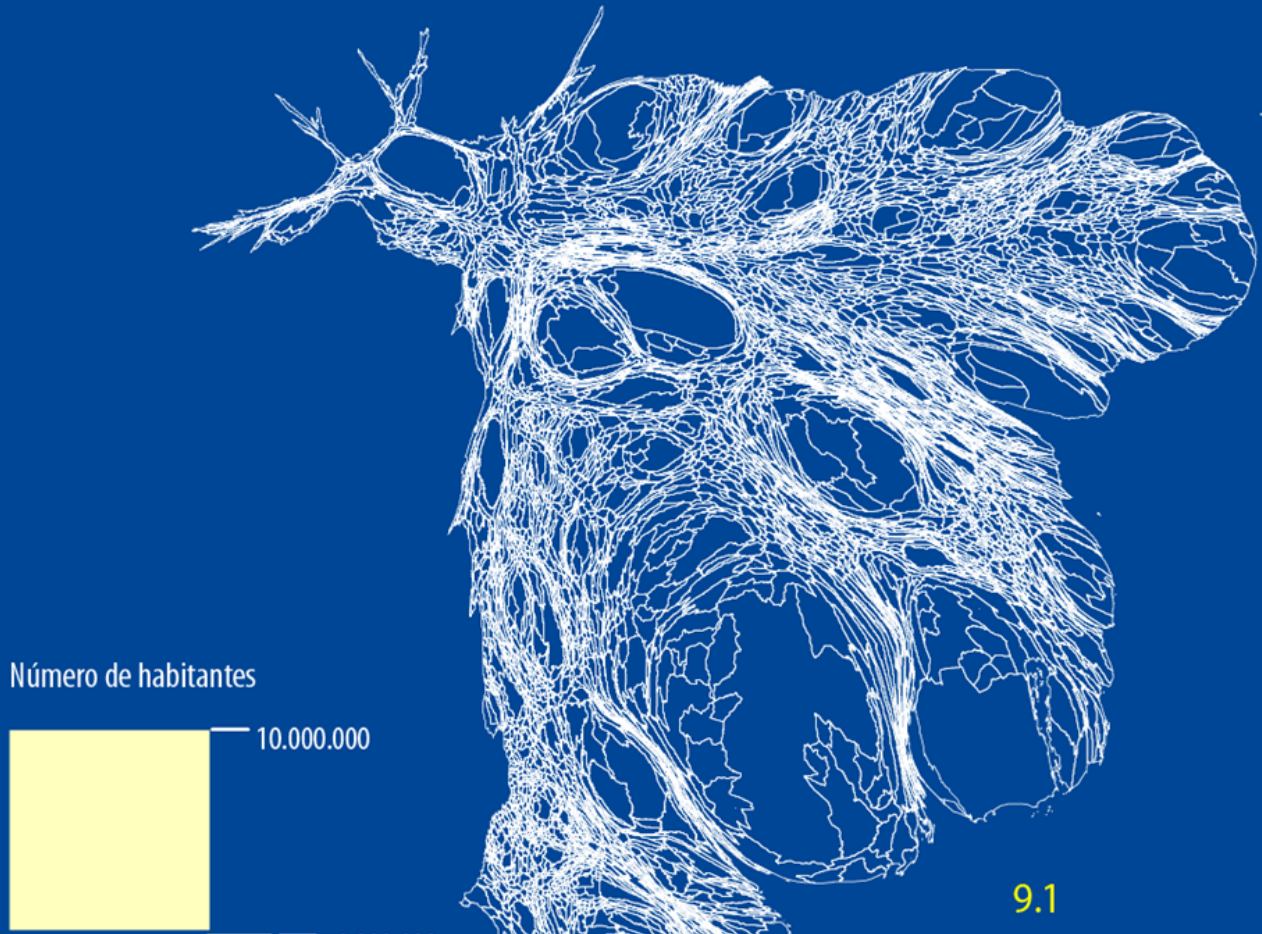

Mapa em anamorfose

Superfície do município proporcional ao número da populaçäo

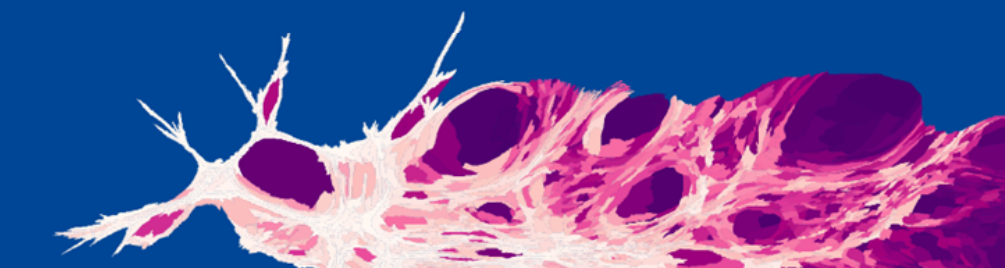

$\mathrm{hab} / \mathrm{km}^{2}$

12914
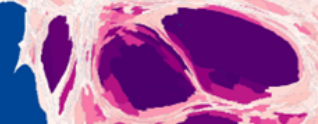

$\rightarrow+\infty$
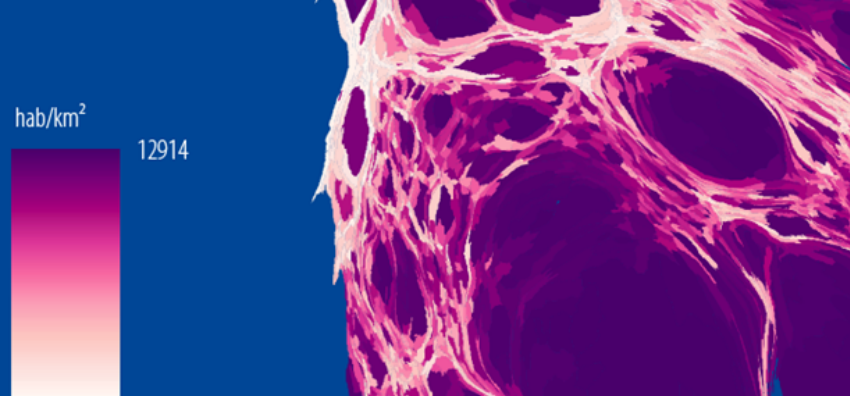

0,13

Sem método de discretização

FONTES

Fundo de mapa:

IBGE |Instituto Brasileiro de Geografia e Estatística|

Malha digital, Censo 2010. Disponivel em:

<http://www.bge.gov.br/home/geociencias/default_prod.shtm>

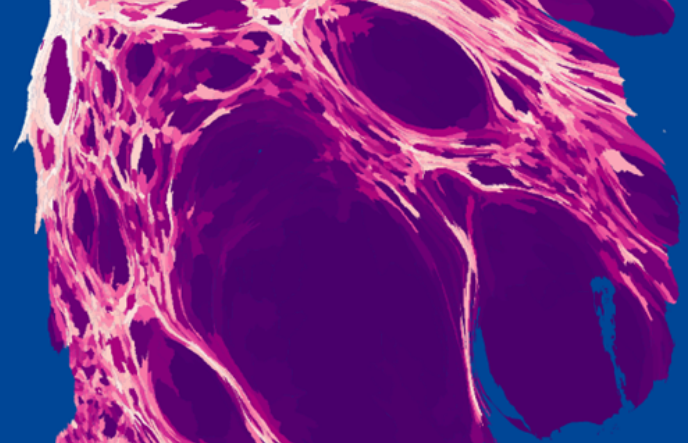

Dados estatísticos: IBGE - Censo Demográfico 2010.

Transformação cartográfica de posição [Anamorfose]

realizado com Scape Toad. <www.scapetoad.choros.ch>

Elaborado em ArcGis e finalizado em Adobe Illustrator

Realização: DUTENKEFER, E. set. 2015. 
É uma transformação cartográfica de posição segundo a terminologia usada por Cauvin, Escobar e Serradj (2008b) e conhecida como "anamorfose". Os localizantes espaciais são funções do atributo: $[\mathrm{X}=\mathrm{f}[\mathrm{Z}]$ e $\mathrm{y}=\mathrm{g}[\mathrm{Z}]$. Os atributos $[\mathrm{Z}]$ induzem as modificações de $[\mathrm{X}, \mathrm{Y}]$. Na figura 10 temos uma síntese dos dois tipos de transformações.

Das reflexões de Lévy (2003b e 2004) e do uso polissêmico do termo "cartograma" observado por Dutenkefer (2010a), adotamos aqui também o termo mapa em anamorfose quando o tema explorado e o fundo de mapa se confundem, isto é, o mapa é uma imagem que coloca em primeiro plano os atributos da variável que alteram e transformam o fundo de mapa. Não mais a imagem do fundo de mapa tradicional, "naturalizado" que prevalece e sim o tema que estamos a estudar [Fundo = Tema]!

Outra possibilidade é assumir este mapa em anamorfose como nosso fundo de mapa e transformar o seu estado, isto é, aplicar novos atributos em seus novos localizantes espaciais originários de outra temática.

Foi o que fizemos na figura 9, mapa 9.1, transformamos um mapa de fundo euclidiano, pois obedece a leis da geometria a época de Euclides no plano [X e Y], em imagens que correspondem a uma metáfora, no sentido grego 41 do termo: foi um "transportar" o "peso", a "força", de seus habitantes, aos territórios de sua morada societal. Este "transportar" transformou, alterou profundamente as feições, o contorno de um território que até então era imutável, não sensível a outras "forças". Mas quais "forças" estão a invadir o território de nossos espaços contíguos, sem lacunas, sem "buracos", com limites esquadrinhados minuciosamente por sábios cartógrafos até há pouco tempo atrás? São "forças" que, segundo Beaude (2008), podem ser as mulheres, crianças, homens, urbanos, rurais, camponeses, latifundiários, agricultores, vacas, televisão, soja, cana, pobreza, miséria, que dão "peso", "força" as nossas configurações espaciais. São substâncias que expressam um "componente não espacial de uma configuração espacial” (LÉVY, 2003f, p.880). Elas “decidem” e alteram profundamente as "distâncias" geográficas dos fenômenos em estudo.

\footnotetext{
${ }^{41}$ Do grego metaphorá, «transporte», pelo latim metaphŏra.in Dicionário da Língua Portuguesa sem Acordo Ortográfico [em linha]. Porto: Porto Editora, 2003-2015. [consult. 2015-03-21 21:35:16]. Disponível na Internet: http://www.infopedia.pt/dicionarios/lingua-portuguesa-aao/metáfora
} 
|Figura 10| Os dois tipos de transformações cartográficas (DUTENKEFER, 2010a, p.38)

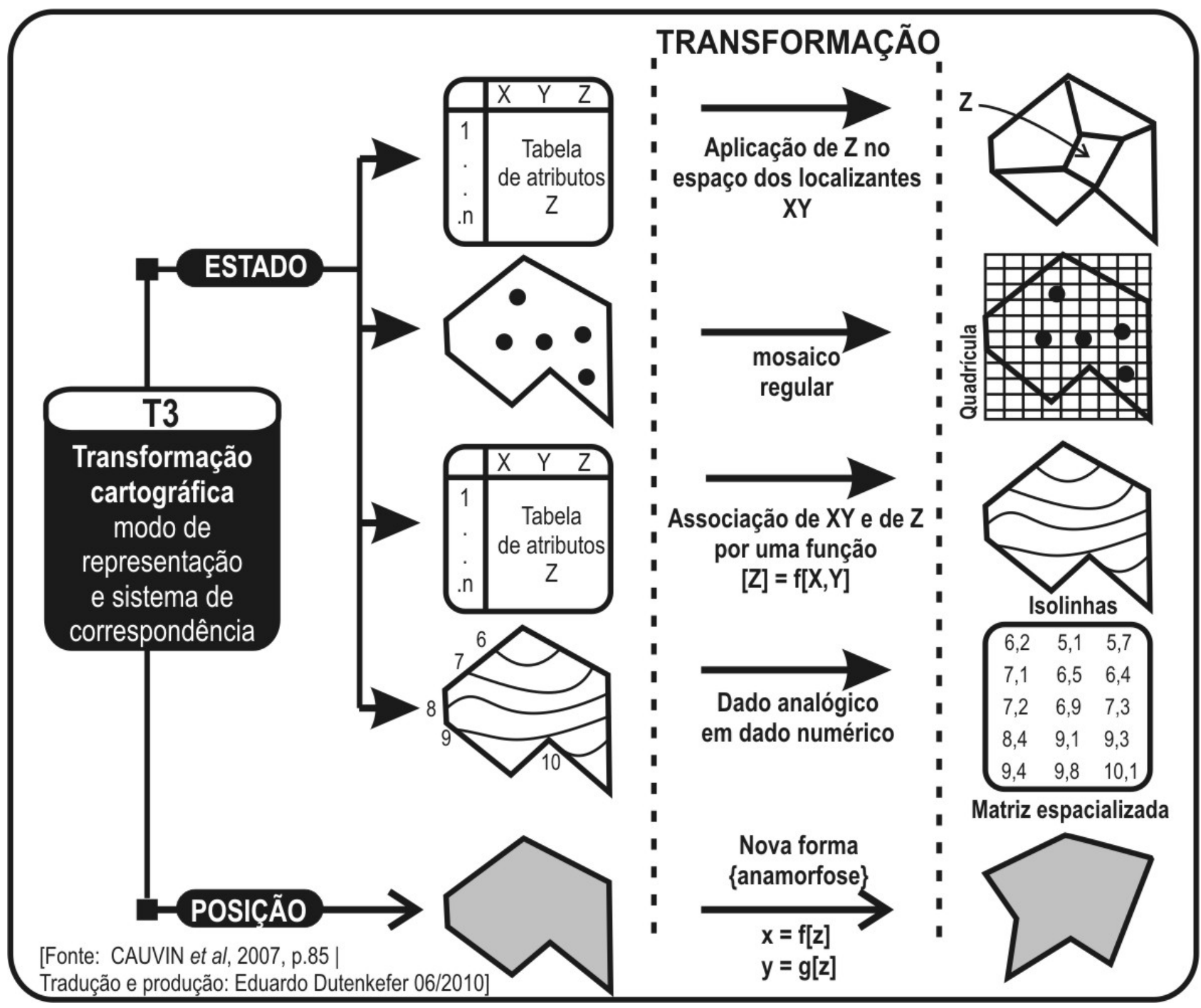

O fundo de mapa sendo uma anamorfose foi aplicado um novo tema [fundo + tema] figura 9, mapa 9.2, ou seja, transformamos em um cartograma em anamorfose ou simplesmente cartograma [cartogramme] adotado por Lévy em sua nova edição do "Dictionnaire de La Géographie"; "é um componente da linguagem cartográfica já mais aceita, exceto pelas correntes mais conservadoras da cartografia" (LÉVY, 2013, p. 157, tradução nossa). 0 fundo é a população total de cada município e o tema é a densidade demográfica.

A transformação cartográfica de posição possibilita uma comunicação visual ligada a uma variação de superfície, ou seja, privilegia o que na Semiologia gráfica de Bertin é identificada como a variável visual tamanho. É importante assinalar que o tamanho das unidades de superfície dos territórios representados em mapas mundi também tem um "peso" visual importante, principalmente quando escolhemos o tipo de projeção que adotamos em nossa representação cartográfica. Portanto as projeções cartográficas também alteram os tamanhos das superfícies representadas nos mapas de escalas geográficas regionais, continentais e, como é mais comum perceber, em mapas a escala global. É clássica a 
imagem de comparação do tamanho da Groenlândia e do continente Africano em projeção de Mercator. O que influi aqui nesta representação, nesta transformação de posição dos localizantes espaciais não é o tema escolhido e sim a forma como transformamos matematicamente uma "esfera", um elipsoide, usando cálculos de uma matemática não euclidiana [três dimensões] para uma matemática euclidiana [duas dimensões]. Este comentário é importante pois, na elaboração de mapas cronológicos, temos que refletir qual a melhor forma técnica ou artística que utilizaremos para transmitir visualmente uma uniformidade das formas de nossas representações. Formas em que o fundo de mapa "grita" ao nosso olhar, dependendo da projeção e datum adotado. Um "gritar" que é mais sensível quando aplicados em algum meio que os transforme em "animação", ou seja, em uma sequência de quadros elaborados um por um. 0 cuidado dessas construções tem que fazer parte do repertório do "artesão geocartógrafo".

Cauvin, Escobar e Serradj (2008b) classificam em transformação cartográfica de posição temática de peso quando os atributos são aplicados aos lugares e, no caso, as superfícies são alteradas como se uma "força" ou "peso" fosse aplicado a ela. Ela distingue estas transformações de peso em cartogramas de superfície não contiguas e contiguas, elaboradas com vários procedimentos matemáticos. Para detalhes e exemplos de alguns destes procedimentos ver Dutenkefer (2010a e 2010b).

No próximo capítulo apresentaremos algumas elaborações cartográficas onde os mapas foram pensados e elaborados com as reflexões e metodologias aqui apresentados associando o conceito de urbanidade. 


\section{3 - O mapa como imagem da urbanidade: possibilidades}

\section{1 - Densidade: urbanidade absoluta e relativa}

Pensar a urbanidade como uma composição, uma combinação de densidade [de homens e de coisas] e diversidade sociológica ou funcional (LÉVY, 2013b) é um bom começo para elaborarmos uma representação cartográfica da urbanidade. Além desta proposição metodológica inicial que apresentamos anteriormente - número 1 - iremos também testar a possibilidade de representar a urbanidade absoluta e relativa [proposição metodológica número 2].

Baseado em artigo de Patrick Poncet (2011) realizamos uma primeira experiência cartográfica para representar a urbanidade absoluta e relativa do urbano na escala nacional do Brasil, regional no estado de São Paulo e local na cidade de São Paulo. Neste artigo Poncet:

...propõe uma reflexão multidimensional sobre o conceito de urbanidade relativa. Baseia-se na apresentação e análise detalhada de uma inovação cartográfica, o anticartograma, ou seja, um cartograma cuja anamorfose é calculada sobre o inverso matemático de sua população. A tese central do artigo é que o anticartograma está para uma representação da urbanidade relativa, assim como o cartograma "clássico" [em função da população] está para uma imagem da urbanidade absoluta. (PONCET, 2011, tradução nossa).

|Figura 11| Histograma de frequência - densidade demográfica França, 2012

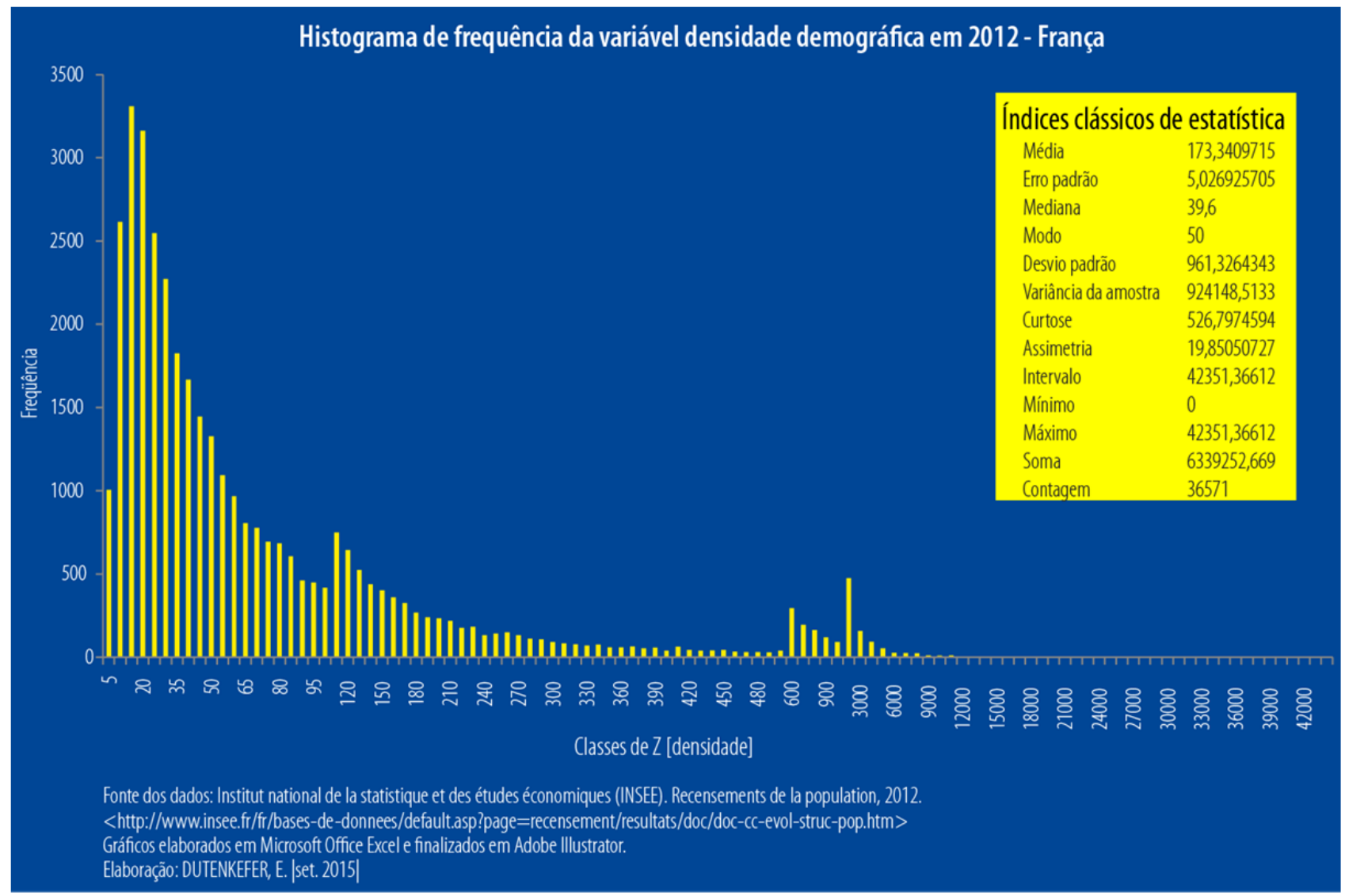


Em seu artigo original Poncet produz o anticartograma da França na escala de comunas e três mapas dos Estados Unidos na escala de condado; um em fundo euclidiano, um segundo como cartograma em anamorfose e o terceiro como anticartograma. Esta comparação serviu para verificar o comportamento do anticartograma em unidades espaciais bem diferentes. As comunas da França são bem menores que os condados estadunidenses. Temos uma escala regional no caso francês e uma escala "continental" no caso dos EUA. Testaremos também aqui o comportamento do anticartograma em unidades espaciais bem maiores que as comunas, os municípios brasileiros. É o Brasil também representando uma escala continental em relação ao território francês. Refizemos a trajetória do mapa da França em três etapas; a densidade de população em fundo euclidiano, o cartograma em anamorfose e o anticartograma. Poncet não indica qual o método de discretização que utilizou. Como vimos no capítulo anterior, é importante sabermos o método de construção de uma representação cartográfica para avaliarmos se o método é o mais adequado aos dados utilizados.

$\mathrm{Na}$ figura 11 temos a distribuição do atributo $\mathrm{Z}$ em histograma de frequência da densidade demográfica das Comunas no caso francês e os índices clássicos de estatística. A distribuição também é assimétrica como em nossos dados de densidade demográfica dos municípios brasileiros [ver figura 4, gráfico 4.2].

A imagem final que a representação cartográfica produz é fundamental para analisarmos o fenômeno em estudo. Adotamos um mesmo método de discretização, intervalo geométrico indicado para distribuições assimétricas, para os mapas da França e do Brasil, para avaliar o resultado visual, principalmente ao que Poncet chama de "inovação cartográfica", o "anticartograma".

Em uma primeira abordagem elaboramos seis mapas - figuras 12 e 13. A substância utilizada foi a população e o dado utilizado foi o número de habitantes residentes nos 5.565 municípios brasileiros, segundo o Censo Demográfico realizado pelo IBGE em 2010. 0 indicador de urbanidade utilizado foi a concentração populacional, expressa pela densidade populacional destes municípios. No caso francês também utilizamos o número de habitantes residentes nas 36.571 comunas existentes no território francês em 2012. É uma tentativa de aproximação da representação cartográfica da urbanidade em escala nacional.

\section{2 - 0 território em cena}

O primeiro mapa - coroplético - um clássico de fundo euclidiano que vimos no capítulo anterior, figura 12, mapa 12.1. Ele representa a extensão territorial dos municípios marcados pelas altas, médias e baixas densidades populacionais. Revela as altas densidades na costa atlântica, sudeste e parte da região sul do território brasileiro. A extensão do "vazio 
populacional" no restante do território também é evidente visualmente, graças às grandes extensões das áreas administrativas municipais. Também o mapa "marca" as "ilhas densas" que são as capitais urbanas das unidades da federação. No mapa da França, - figura 13, mapa 13.1- Paris sobressai visualmente, pela sua densidade, enquanto o restante do território é pontilhado de áreas densas com menor intensidade no eixo que vai do sul ao centro em direção ao nordeste da França - entre Paris e região da Alsacea e também a sudeste.

\section{3 - O território retirado de cena: as "massas" urbanas e a sua urbanidade absoluta}

No segundo mapa utilizamos um cartograma em anamorfose - figura 12, mapa $12.2 \mathrm{e}$ figura 13, mapa 13.2. 0 fundo do mapa foi transformado pelo "peso", por uma "massa", a sua substância - o número de habitantes, ou seja, o total da população que reside nas unidades administrativas municipais, no caso brasileiro, e nas comunais, no caso francês. Com este "novo" fundo de mapa transformamos seu estado, isto é, aplicamos um novo tema, em particular o total da população residente por unidade de área, a densidade demográfica, habitantes por quilometro quadrado $\left[\mathrm{hab} / \mathrm{km}^{2}\right]$.

Visualmente, o que temos é uma tentativa de expressar cartograficamente o tamanho do objeto urbano escolhido, o número de habitantes, a sua "massa", a totalidade de sua substância alterando o tamanho das unidades administrativas municipais no caso brasileiro e as comunais no caso francês [nossa proposição metodológica 3 - apresentada anteriormente]. Privilegia a variável visual tamanho, se relacionarmos com a semiologia gráfica de Bertin. "Engrossam-se assim os territórios povoados, e "esmagam-se" os territórios pouco povoados" (PONCET, 2011). A proposta é expressar cartograficamente o conceito da urbanidade absoluta. Nesta representação o território é retirado de cena. Mostra o "peso" de sua população [o fundo de mapa em anamorfose] e, ao mesmo tempo, evidencia uma hierarquia relacionada com os valores de sua densidade, da concentração populacional [o cartograma]. Privilegia a variável visual valor; variável que ordena, que transmite visualmente uma hierarquia de valores. Uma imagem que pretende transmitir ao nosso "olhar", àqueles visualizadores de mapas que em um "relance" visual totalizante percebem, são sensibilizados ao que a imagem do mapa coloca em evidencia; polos potencialmente mais fortes e menos fortes de urbanidade. 


\section{4 - Opção semiológica adotada: um breve parêntese...}

Faremos aqui uma breve pausa desta sequência de reflexões e voltaremos para alguns aspectos semiológicos. A opção visual por nós adotada nos mapas elaborados até aqui contraria um pouco a maneira que tradicionalmente mapas de atributos relativos, em nosso caso a densidade demográfica, deveriam ser representados. Costumeiramente os valores deveriam ser ordenados a partir de um matiz de cor escolhido; preto, vermelho, azul. etc., e variarmos a sua saturação e/ou a sua luminosidade. Valores quantitativos menores associados com uma menor saturação e/ou luminosidade e valores quantitativos maiores com uma saturação e/ou luminosidade maior. Nestas elaborações procuramos valorizar e colocar em cena também a base, o fundo de "página" que os nossos mapas foram concebidos. É uma tentativa de reter o nosso "leitor-visualizador" nos aspectos mais centrais de nosso fenômeno espacializado nas formas de representações cartográficas e gráficas. Visualmente, procuramos "impactar" o nosso olhar. Densidades menos expressivas quase se confundem com o fundo visual adotado em nosso "design de página" para os nossos mapas.

Optamos também em trabalhar todas as imagens produzidas nesta pesquisa no universo de Cores RGB, isto é, no efeito que os comprimentos de ondas vermelho [Red], verde [Green] e azul [Blue] produzem em nosso "olhar geográfico". Fundos de "página" escuros e de cor preta, como nas imagens da urbanidade da cidade de São Paulo, ver figuras 16 e 17, propiciam um "brincar" com os contrastes fortes entre as cores mais claras e mais escuras, com intensidades de luzes que chegam diretas às nossas retinas por meio de aparelhos que tem uma tela como emissor final de alguma mensagem visual; o monitor de vídeo de nossos computadores, telas de notebooks, tablets, smartphones... Estas tecnologias propiciam uma síntese de cores que chamamos de aditivas, em oposição às cores subtrativas, usadas nas tecnologias de impressão gráfica em mídias como papel jornal, papeis de alta qualidade, como o couché, lonas ou plásticos em banner, etc. Na tela de um computador, a cor branca é adição máxima de luminosidade das cores vermelha, verde e azul $[R+G+B]$. Na ausência delas teremos como resultado a cor preta. Nas tecnologias de impressão usamos três cores básicas Cyan, Magenta e Amarelo [yellow] [CMY] que, teoricamente, com estas três combinações teríamos o preto. Na prática, temos que adicionar uma tinta exclusiva da cor preta para reforçar principalmente as letras de um texto em uma obra impressa. Temos assim o clássico sistema CMYK [Cyan, Magenta, Yellow, e blacK] que as artes gráficas utilizam para sensibilizar indiretamente as nossas retinas. 0 que vemos de cor em uma obra impressa é apenas o refletir das luzes das tintas utilizadas que interagiram com a base material que foi impressa. Quantas vezes não ficamos irritados com as cores que escolhemos cuidadosamente em nossas 
telas de computadores e, quando impressas em papel, temos a triste surpresa que não era bem isso que gostaríamos de representar...!? Esta pesquisa, portanto, deveria ter um aviso em sua "embalagem final" de alerta ao seu leitor: ATENÇÃo! Obra melhor visualizada em equipamentos que emitem luzes RGB!

O espaço de cores RGB é muito superior ao espaço de cores CMYK. A opção de utilizarmos principalmente em nossos anticartogramas os altos contrastes que a luz permite ao nosso olhar não é gratuito ou mero esmero de design gráfico final. Deve fazer parte das reflexões e dos afazeres dos "artesãos cartógrafos digitais". Nossos mapas deveriam enviar luzes diretas e não indiretas ao nosso cérebro!

...o fundo preto apresenta algumas vantagens, entre as quais a de permitir indicar os "feixes" urbanos à maneira de uma radiografia, como redes de luzes, em cores claras ou pelo menos em tons luminosos que permitem a síntese aditiva. Os espaços vazios, por outro lado são "figurados" em tons mais "sombrios", próximos do preto... ou de matizes de azuis... (PONCET, 2011, tradução nossa).

Outra pequena observação nesse parêntese: no mapa de urbanidade de São Paulo, que veremos mais adiante, o método de discretização utilizado foi o algoritmo de Jenks, mas, na prática, é um mapa sem classes; uma sequência de 256 níveis de tons de cinza, isto é, de luz branca e ausência de luz branca em que as telas de nossos aparelhos tecnológicos atuais emitem. Na prática nossa percepção visual não atinge individualmente toda a variação deste gradiente, mas apenas uma percepção mais geral das nuances de luzes... que é a proposta original de Tobler nos mapas coropléticos sem métodos de discretização.

\section{5 - O território e as "massas" urbanas retiradas de cena: o revelar da urbanidade relativa e seu anticartograma}

Vamos agora esboçar o "oposto", o "contrário", o "anti" do cartograma em anamorfose; o anticartograma.

Indaguemos: como podemos representar cartograficamente a intensidade das relações sociais? Uma possível resposta seria diminuir as distâncias que afastam as potencialidades de intensificarmos as nossas relações sociais. Na sequência uma nova indagação surge: como transmitir graficamente uma distância societal que tende a "zero" em um mapa?

Em uma primeira aproximação a resposta seria obter um número, uma função matemática que representasse esta distância pequena, quase tendendo a zero em nossas representações cartográficas.

Em tese um maior número de pessoas concentradas espacialmente pode propiciar a possibilidade de realizarem inúmeras relações sociais. Pensar matematicamente em uma grandeza quantitativa maior que outra, ou seja, um número maior que outro, na dimensão dos 
números reais [R], o número 1 é maior que 0,5; 2 é maior que 1 e assim sucessivamente... Este valor, este número qualquer que transforme uma função diretamente proporcional ao quanto maior a grandeza em um resultado menor, uma função candidata seria a função inversa: 1/P! Isto é, o inverso do número de habitantes! Quanto maior a quantidade de pessoas em um espaço considerado, menor é a distância societal e, portanto, uma maior probabilidade de interação social. A redução da distância para propiciar um aumento de relações sociais! Esta função inversa aplicada às unidades municipais e comunais nos mapas expressaria imagens de urbanidade relativa?

Com estas reflexões exercitamos uma representação cartográfica alinhada à proposição metodológica 3: demonstrar a intensidade das possíveis ligações urbanas existentes, ou seja, a sua urbanidade relativa. A opção semiológica adotada na elaboração do mapa é uma tentativa de visualizar a existência ou não destas ligações. A função inversa [1/P] minimiza a "massa" populacional transformando as áreas mais densas em pontos geométricos que auxiliem em nossa análise. Nesta minimização, as distâncias espaciais dos objetos geográficos mais densos ficam mais próximas. Áreas, superfícies territoriais transformadas, reduzidas a quase pontos visuais, também deveriam revelar visualmente "filamentos", captar as ligações mais intensas entre os objetos. No anticartograma do mapa da França - figura 13, mapa 13.3 - estas ligações são bem evidentes. É como se uma rede "neural" se revelasse aos olhos do observador da imagem cartográfica. Em oposição às “massas" menos densas, menos urbanas, são opacas e se confundem com o fundo visual adotado. Na escala do Brasil, uma escala continental, com um recorte espacial de seus 5.565 municípios, o anticartograma - figura 12, mapa 12.3 - tenta "captar" as ligações das capitais estaduais do sudeste, sul e nordeste do Brasil com seu entorno. Temos fortes ligações no estado de São Paulo [na figura 14 observamos melhor visualmente estes eixos] que vai de Limeira, na região de Piracicaba, passa pela metrópole de Campinas, São Paulo e Baixada Santista e um eixo que avança até São José dos Campos. As ligações de Rio de Janeiro, Belo Horizonte e Porto Alegre também são expressivas. 0 restante, Curitiba, Florianópolis e Vitória, parece-nos isoladas em si mesmas. No Nordeste temos um leque que vai da região do leste Potiguar, passando em direção a João Pessoa, metrópole de Recife, Maceió, Aracajú e Salvador.

O anticartograma revelaria também outras análises ligadas a outros conceitos importantes para a caracterização do urbano? Por exemplo, explicitar outras escalas do urbano: a metrópole, megalópole e gigalópole? Na figura 14 mostramos esta possibilidade. 
|Figura 12| Urbanidade Brasil 2010

\section{Urbanidade Brasil 2010}

Mapa 12.1

URBANIDADE ABSOLUTA

Cartograma em anamorfose

Superfície do município proporcional ao número da população
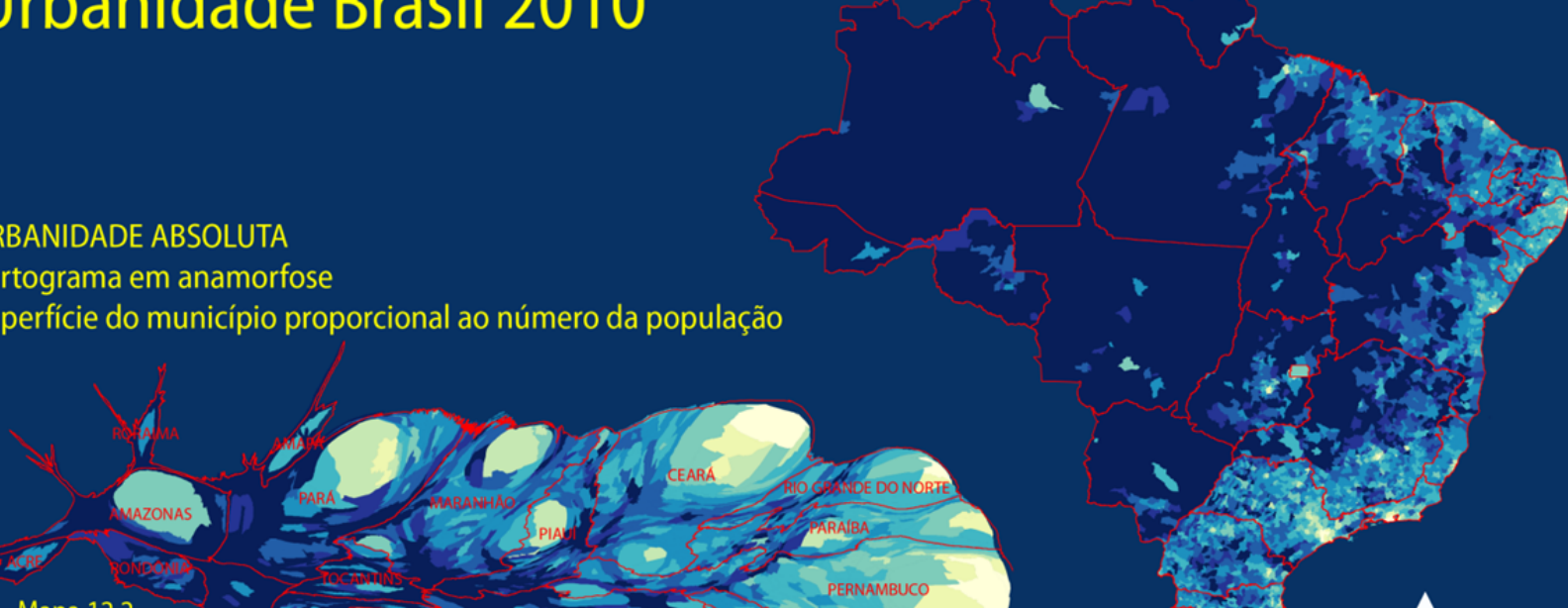

Mapa 12.2
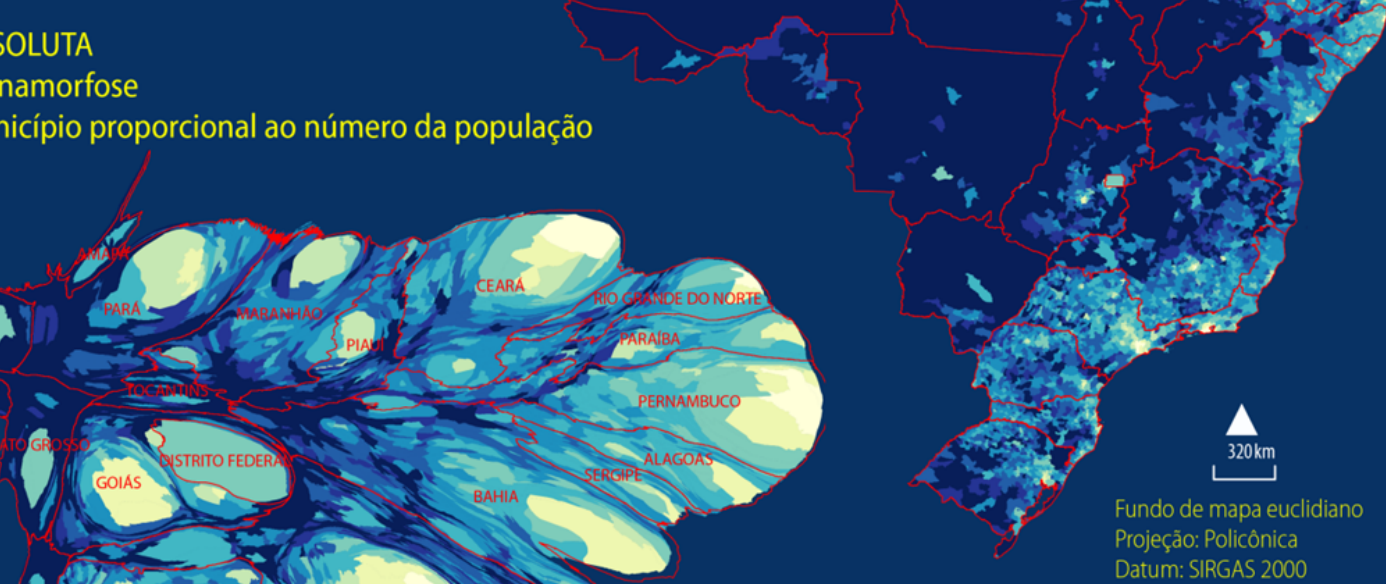

Unidade da Federaçâo

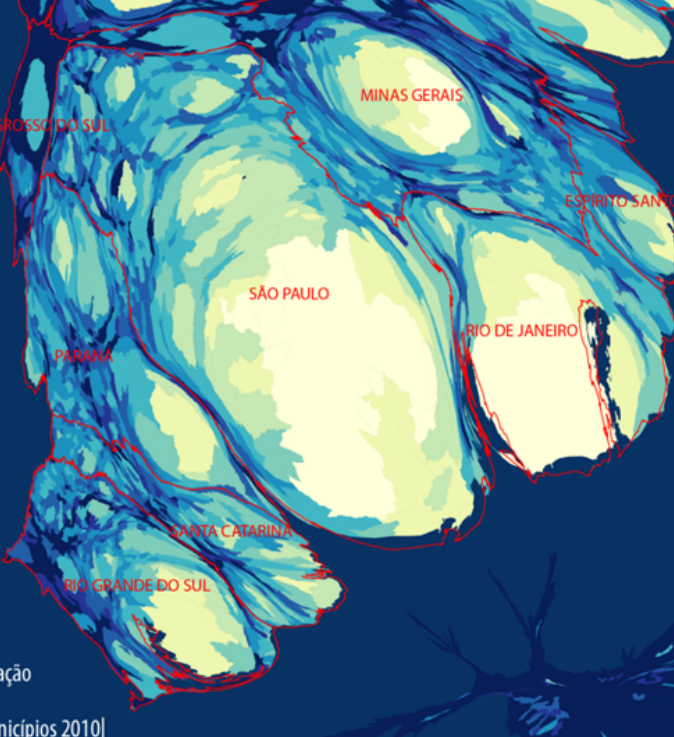

Número de habitantes

Densidade Populacional |Municípios 2010

habitantes $/ \mathrm{km}^{2}$

\begin{tabular}{l}
\hline$[4202-12914[$ \\
{$[1371-4202[$} \\
{$[452-1371]$} \\
{$[153-452[$} \\
{$[56-153]$} \\
{$[24-56[$} \\
{$[14-24[$} \\
{$[11-14[$} \\
$<11[$
\end{tabular}

Mapa 12.3

URBANIDADE RELATIVA

Anticartograma em anamorfose

Superfície do município proporcional

ao inverso do número da população [1/P]

Geometrical intenval Intervalo geométrico

FONTES

Fundo de mapa:

Instituto Brasileiro de Geografia e Estatistica ||BGE|

Malha digital, Censo 2010. <http://www.ibge.gov.br/home/geociencias/default_prod.shtm>

Dados estatísticos: IBGE - Censo Demográfico 2010.

Transformaçāo cartográfica de posiçāo [Anamorfose] realizado com Scape Toad.

$<$ wwwscapetoad.choros.ch>

Método de discretizaçāo do cartograma e anticartograma em anamorfose: ArcGis

Cores da discretizaçāo: Modo RGB , ColorBrewer <http://colorbrewer2.org/>

Finalizado em Adobe lllustrator

Concepção e elaboraçāo: DUTENKEFER, Eduardo |dez. 2012, revisado em jul. 2015

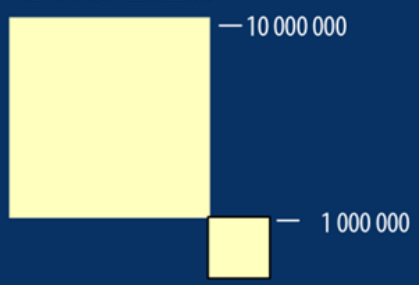

leste de Potiguar,

Joăo Pessoa, metrópole

de Recefi. Maceio, Aracajú Salvador
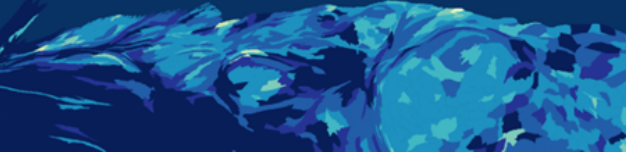
|Figura 13| Urbanidade França 2012

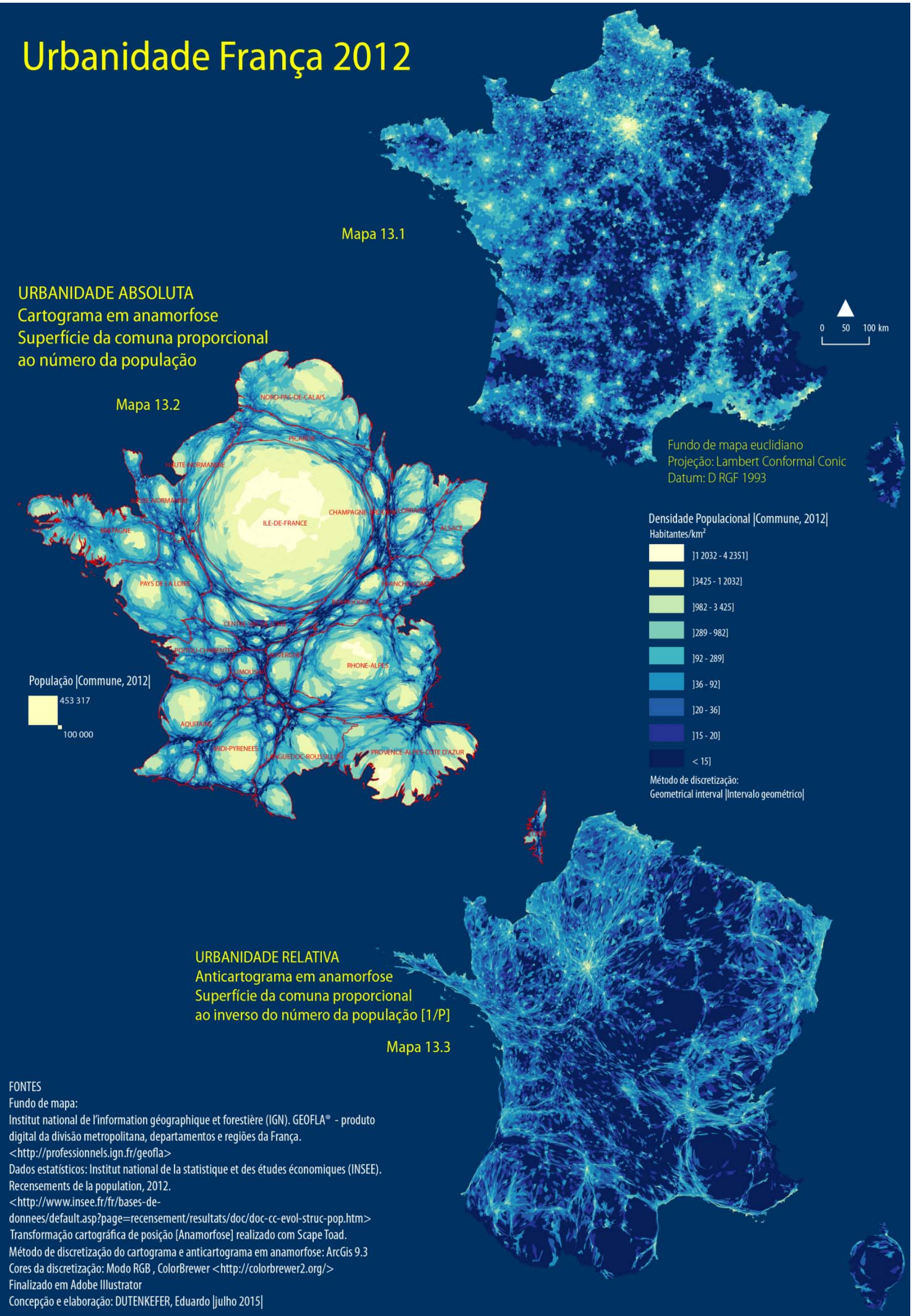




\section{|Figura 14| Urbanidade na escala regional}

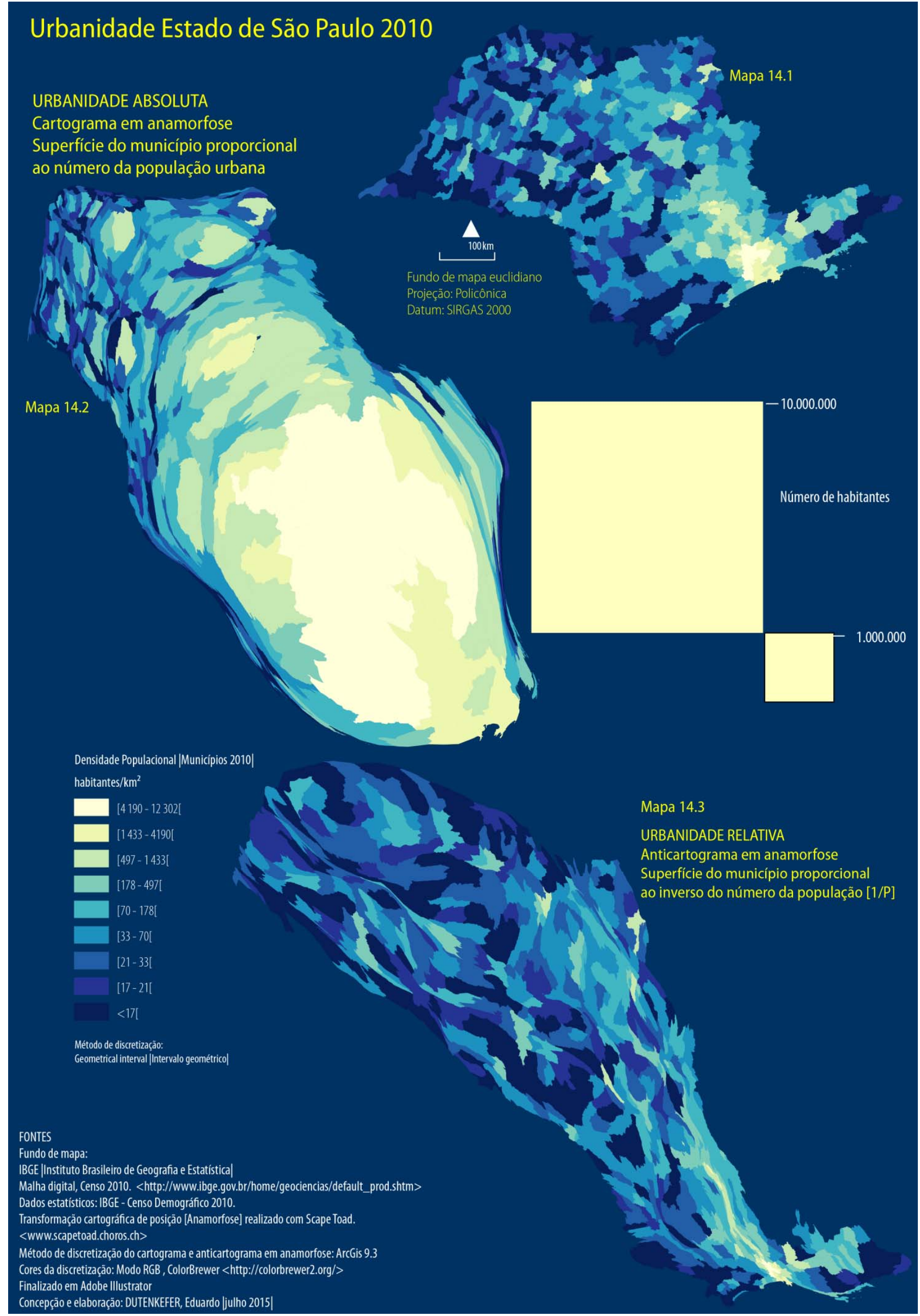


Prosseguindo, na figura 16 temos o cartograma e o anticartograma na escala da cidade de São Paulo. Optamos aqui por utilizar os dados populacionais das unidades censitárias utilizadas pelo IBGE, que são as menores unidades espaciais que temos disponíveis com dados do levantamento do Censo Demográfico de 2010.

Na figura 15 temos o histograma de frequência dos dados de densidade demográfica. Observamos que a sua distribuição não é equivalente ao que até então temos observado nos dados de densidade dos municípios, no caso brasileiro e comunal, no caso francês, uma distribuição claramente assimétrica. Não é o caso aqui. Temos uma assimetria baixa, índice 5, com uma média mais centrada no histograma. Não utilizamos, portanto, o mesmo método de discretização. Resolvemos aqui utilizar o método do algoritmo de Jenks, mas para 256 classes, ou seja, visualmente é como se não tivéssemos uma discretização e sim 256 níveis de cinza, um mapa sem classes.

|Figura 15| Histograma de frequência da densidade demográfica em 2010 para a metrópole de São Paulo

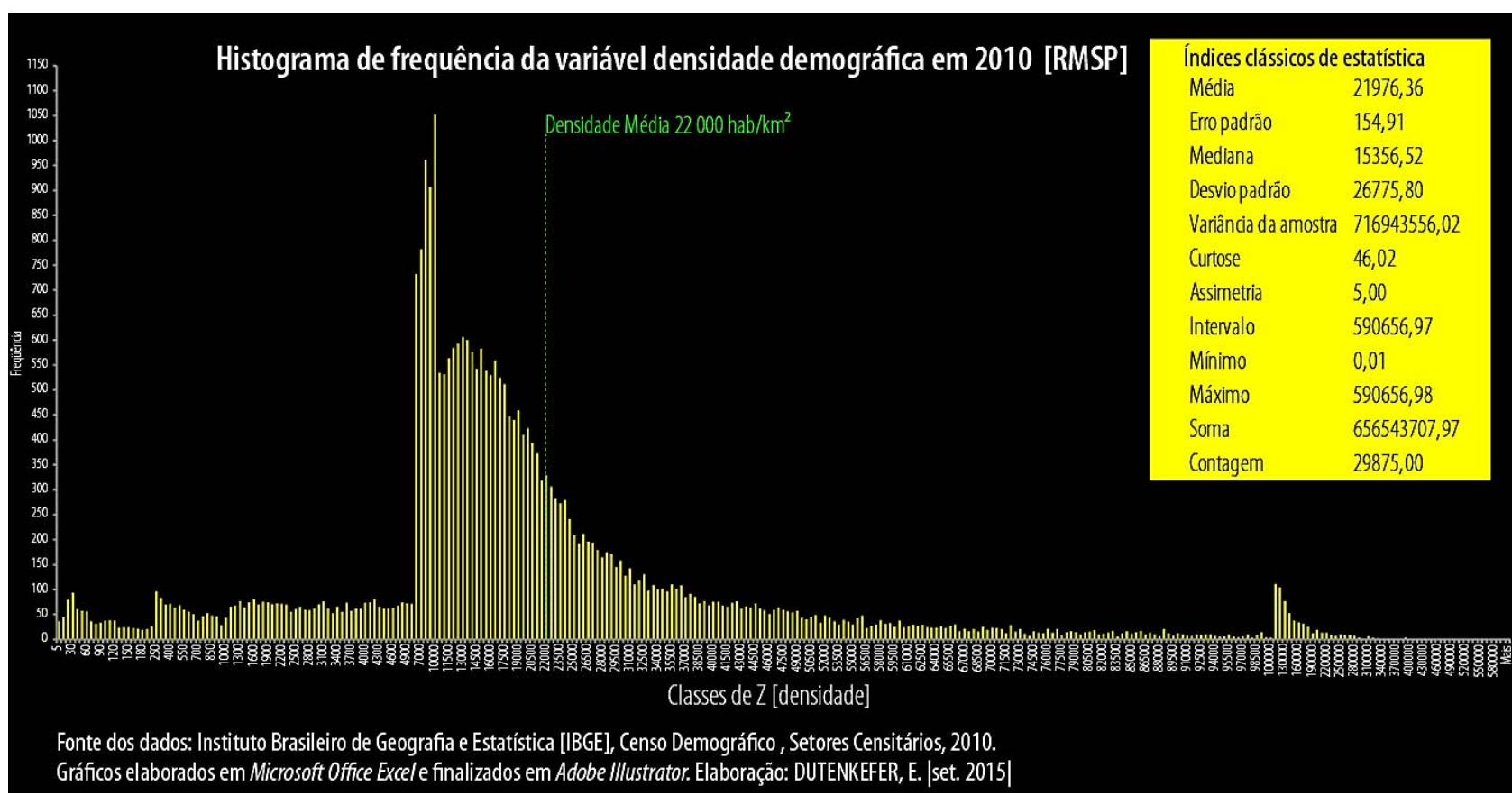


|Figura 16| Urbanidade da cidade de São Paulo - 2010

\section{Urbanidade de São Paulo - 2010}

Fundo euclidiano

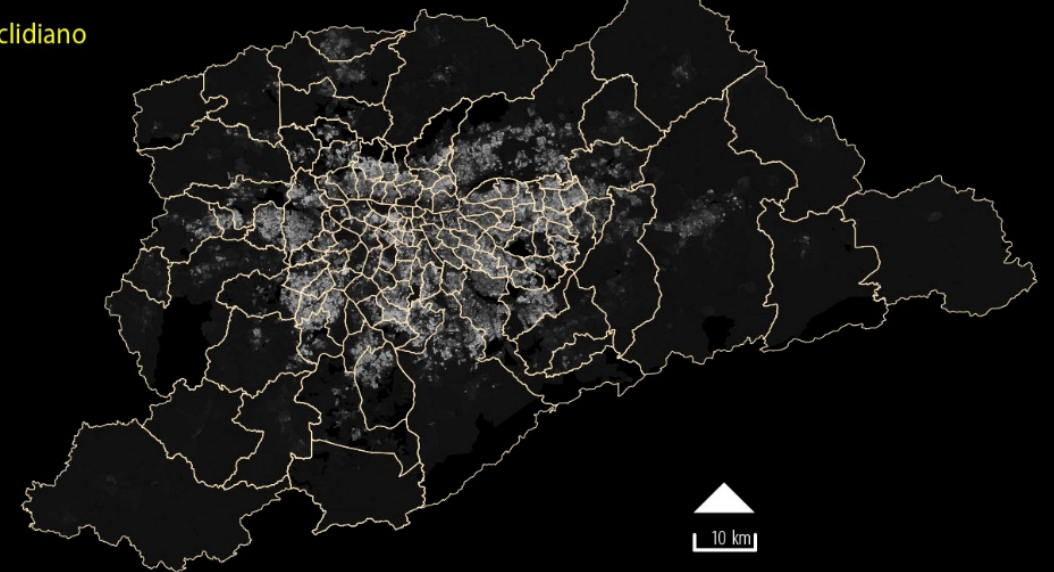

Urbanidade absoluta - Cartograma em anamorfose

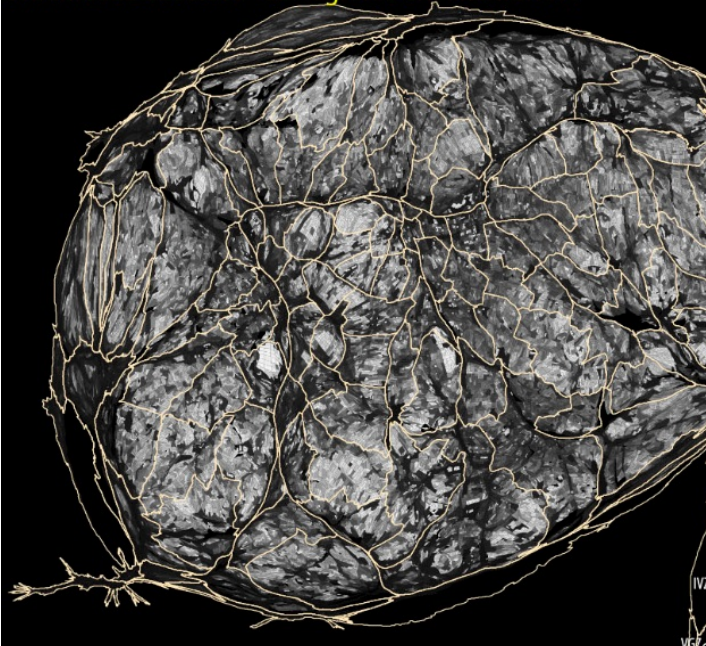

Urbanidade relativa - Anticartograma em anamorfose Fundo inverso matemático da população total $|1 / p|$

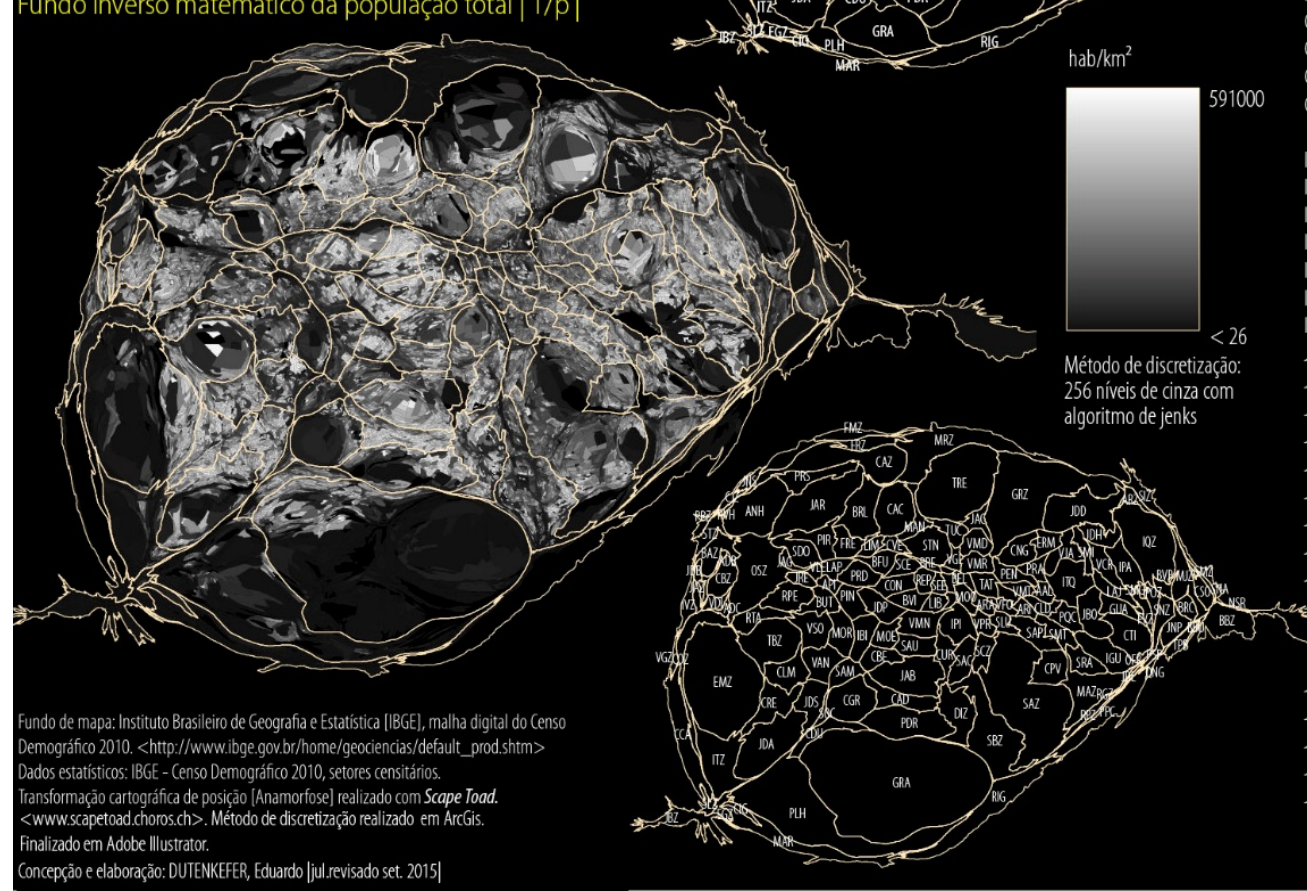

SIGLA NOME

AAL Artur Av

ADB Aldeia

JN Jundapeba

ADC Aldeia de Carpiculiba JRE Jaguaré

ANH Anhanguera LAI Lajeado

API Alto de Pinheiros LAP Lapa

ARA Agua Rasa $\quad$ LBB Liberdade

ARI Aricanduva LIM Limão

ARZ Arujá MAN Mandaqui

BAz Barteri

BBU Biritiba-Ussu MAZ Mauá

BBZ Bintiba-Mirim MIZ Moï das Cruzs

BEL Belém - MOE Moema

BFU Barra Funda MOO Mooce

BRC Brás Cubas - MOR Mormbto

BRE Bom Retirio - MR7 Majipora

BRL Brasilândia NSR Nossa Sra. do Reméd

BRS Brás OFF Ouro Fino Paulist

BUT Butantä $\quad$ OSZ Osassco

BVI Bela Vista PBZ Pirapora do Bom Jesus

BVP BoaVista Paulista PDR Pedrein

CAC Cachoeirinha PEN Penha

CAD Cidade Ademar PIN Pinheiros

CAR Carräo PR Pirtituba

CAZ Caleiras $\quad$ PLH Pareheiros

CBE Campo Belo POZ POS

CBZ Carapicuiba PPC Paranapiacaba

CCA Caucaia do Alto POC Parque do Carmo

CDU Cidade Dutra PRA Ponte Rass

PRD Perdins

IGG Cipó-Guaçu PRI Part

UIZ Cajamar PRS Perus

CKE Cidade Kemel PSP Palmeiras de Săo Paulo

CLD cidade Líder PVH Polvitho

CMM Campo Limpo $\quad$ NNG Ouating

CMB Cambuci REP Repíblict

CNG Cangabara RGZ Rio Grandeda Serra

CON Consolaçẵo RIG Riacho Grande

COZ Cotia

CPV Capuava

CRE Capão Redondo

CSO Cezar de Souza

तl cidade Tiradentes

CUR Cusino

CVE Gasalerde

DIZ Diadema

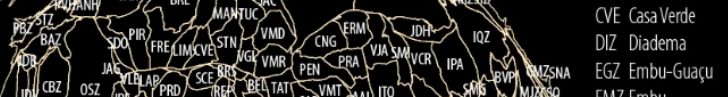

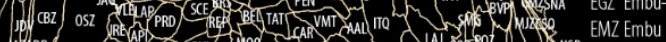

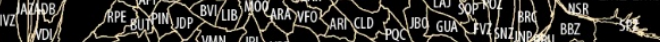
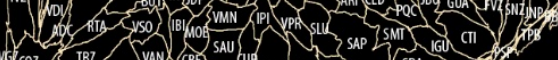

ERM Emelino Matarazto

FMZ Francisco Morato

FRE Freguesia do E

FRZ Franco da Rocha

FVZ Ferrazde Vasconcels

GMZGuararema

GRA Grajaú

GRZ Guarulhos

GUA Guaianases

BI Itaim Bit

IGU Iguatemi

IPA Itaim Paulista

IPI Ipiranga

QQZ Itaquaquecetuba

ITO Itaquera

ITZ Itapecerica da Serra

IVZ Itapevi

JAB Jabaquara

Jickna

JAG Jaguara

JAR Jaraquá

JAZ Jandira

JBO José Bonifácio

B. Juquitiba

JDA Jardim Ângela

JDB Jardim Beval

JDH Jardim Helena

JDL Jardim Santa Luzia

JDP Jardim Paulista

JDS Jardim São Luis

JDV Jardim Silveira
RPZ Ribeiräo Pires

RTA Raposotovare

SAc Sacoma

SAP Sapopemba

SAU Saúde

SAZ Santo And

SBZ Säo Bernardo do Campo

SCE Santa Cecilia

SCZ Säo Caetano do Su

SDO Săo Domingos

SIZ Santa lsabel

SLIZ Säo Lourenco da Serra

SIII Săo Migue

Sro Mateus

SNA Sabaún

SNZ Suzano

SOP Santo Antônio Paulist

SPZ Salesópolis

SRA Säokatát

STN Santana

TAT Tatuape

TBZ Taboãoda Serr

TPB Taiaçupebs

TRE Tremembe

TUC Tucunvivi

VAN Vila Andrade

VFO Vila Formosa

VGL Vila Guilherme

VIA Vila lacuí

VLE Vila Leopoldina

VMD Vila Medeiros

VMN Vila Mariana

VPR Vil Made

VSO Vila Sônia
STZ Santana de Parnalba 


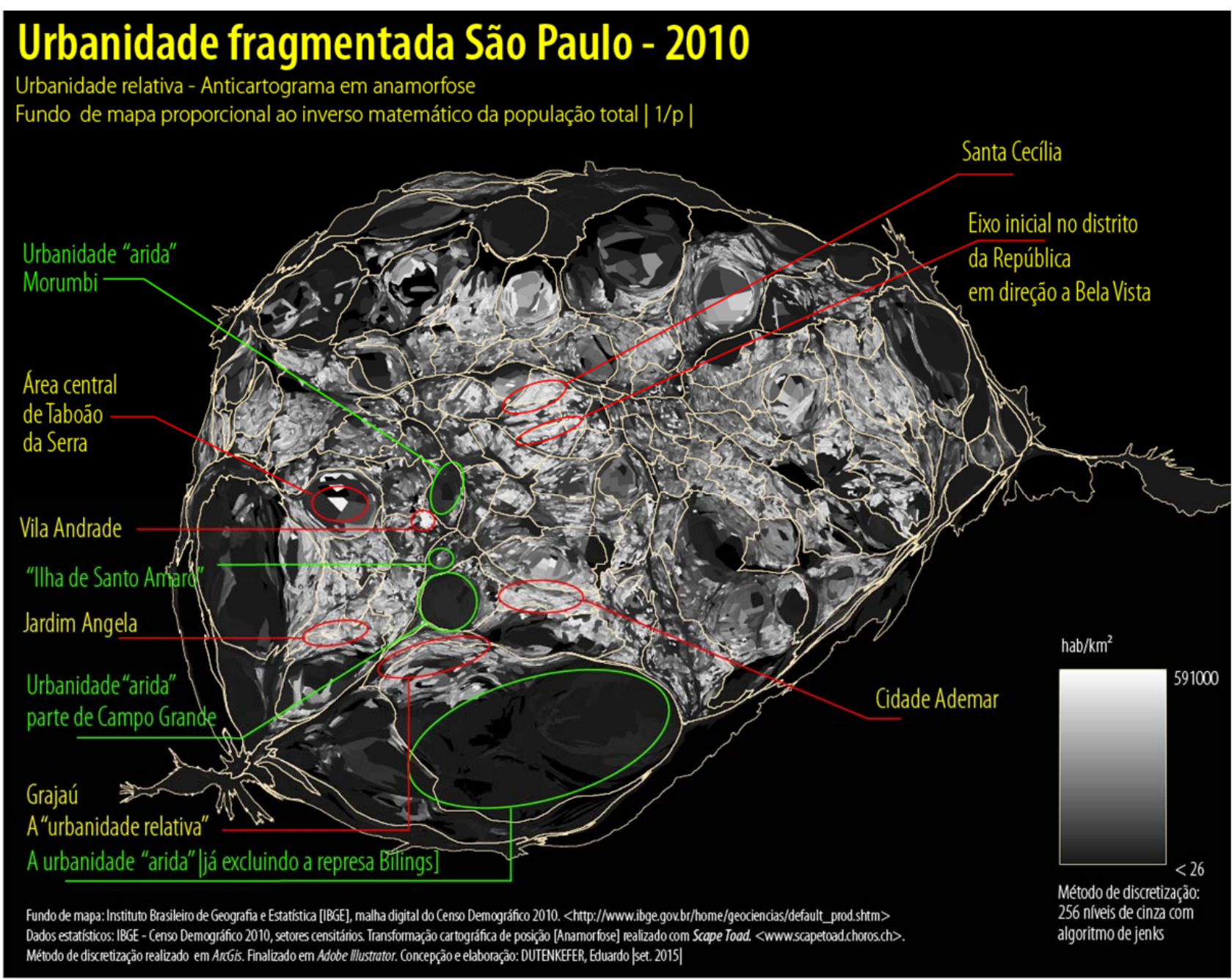

Os mapas na figura 16 são de difícil interpretação. Uma das dificuldades da anamorfose é quando a imagem final que ela apresenta não tem uma "referência" mais conhecida em mapas de fundo euclidiano. No caso dos setores censitários é, então, mais difícil. Podemos aproximar, se necessitarmos ter uma pequena ideia das localizações que os mapas revelam, de recorrer aos distritos da cidade. Colocamos esta referência com as siglas dos distritos no cartograma e anticartograma e uma tabela de equivalência para auxiliar.

No cartograma em anamorfose temos uma imagem que associa o "peso" das massas populacionais, visualmente perceptíveis nos limites dos distritos que transformam os seus tamanhos e, ao mesmo tempo, as densidades destes "pesos" expressos pelas áreas proporcionais de cada setor censitário. É visualizar o "interior" de cada distrito, como se encontra a distribuição espacial das densidades das populações residentes. É uma aproximação indicando a urbanidade absoluta da cidade utilizando o indicador densidade como tema. A ideia é que o cartograma elaborado evidencie polos potencialmente mais fortes e menos fortes de urbanidade. 
Já no anticartograma a proposta seria de revelar as "intensidades das ligações destas "massas"”, transmitir graficamente as distribuições espaciais de distâncias societais que tendem a "zero".

Na figura 17 focamos apenas no anticartograma. Chamamos de uma imagem de urbanidade relativa "fragmentada". Não temos "filamentos" mais expressivos como no anticartograma das comunas francesas. Mas encontramos algumas áreas, "fragmentos" assinalados no mapa em círculo vermelho de eixos significativos de uma possível urbanidade relativa mais intensa. Não foi uma proposta exaustiva apontar todas neste mapa, apenas algumas, para referência. Um eixo expressivo que vai do sul do distrito da República para o "miolo"' do distrito de Bela Vista. Outro eixo é no Distrito de Santa Cecilia. Exemplos de áreas centrais da cidade que ainda parece-nos oferecer a possibilidade de realizarmos interações sociais mais intensas. Fugindo da área central, mais ao sul, encontramos no distrito de Cidade Ademar outro eixo sugestivo.

A imagem do distrito do Grajau é um caso expressivo. 0 anticartograma ampliou o espaço "vazio" do território, mesmo depois de excluídas as áreas da represa Billings. Era essa a proposta de usar uma função inversa. Parece-nos que o resultado é significativo. Mesmo que visíveis no mapa de fundo euclidiano, o anticartograma ampliou ainda mais os "espaços" menos densos e chamamos aqui de áreas de urbanidade "árida" [nos círculos de cor verde], e concentrou as áreas mais densas e, portanto, mais indicativas de uma urbanidade relativa maior. Parte do distrito do Morumbi também é interessante pela sua expressão gráfica de "aridez" de urbanidade, assim como o centro de Santo Amaro e Taboão da Serra expressarem uma "ilha" de urbanidade, isoladas e não conectadas com as suas vizinhanças mais próximas.

\section{6 - Diversidade e densidade}

0 conceito de diversidade faz par com a densidade formando uma dupla fundamental para medir a cidade e seu grau de urbanidade, como já apontamos anteriormente. Falemos agora sobre a diversidade. De um modo mais amplo podemos definir a diversidade como uma "relação entre o nível de heterogeneidade de realidades copresentes em um espaço dado" (LÉVY, 2013b, p. 295, tradução nossa). Estas realidades podem ser do tipo econômico, sociológica, política, das composições dos grupos sociais, das atividades produtivas, uma heterogeneidade de objetos geográficos presentes em uma cidade, sejam eles materiais e/ou imateriais.

Procuramos em uma primeira aproximação quais dados desfrutamos no censo demográfico do IBGE que podem auxiliar em nossas representações de diversidade. Continuando ainda na escala local, para os setores censitários encontramos: 
1 - Quanto a uma heterogeneidade de gênero, encontramos só duas distinções; número de habitantes do sexo masculino e feminino;

2 - quantidade de população por faixa de idade;

3 - uma aproximação de diversidade de etnia nos dados de cor/raça;

4- outra aproximação de "classe social" pela massa salarial em termos de número de salários mínimos que seus habitantes têm como renda.

Nos mapas das figuras 18 e 19 mostramos algumas possibilidades de representação cartográfica usando o anticartograma para a diversidade “étnica”. Uma urbanidade "retratada" pela população autodeclarada branca, preta, parda, amarela e como indígena. Na figura 18, pela porcentagem em relação ao total da população de cada setor censitário e, na figura 19, pela densidade de população total autodeclarada. Optamos por uma semiologia gráfica para reforçar na discretização utilizada a classe com maior concentração para cada "etnia". Com "fundos de página" diferentes para exercitar, experimentar, criticar o nosso olhar visual gráfico e geográfico. 
|Figura 18| A urbanidade das etnias em porcentagem da população total

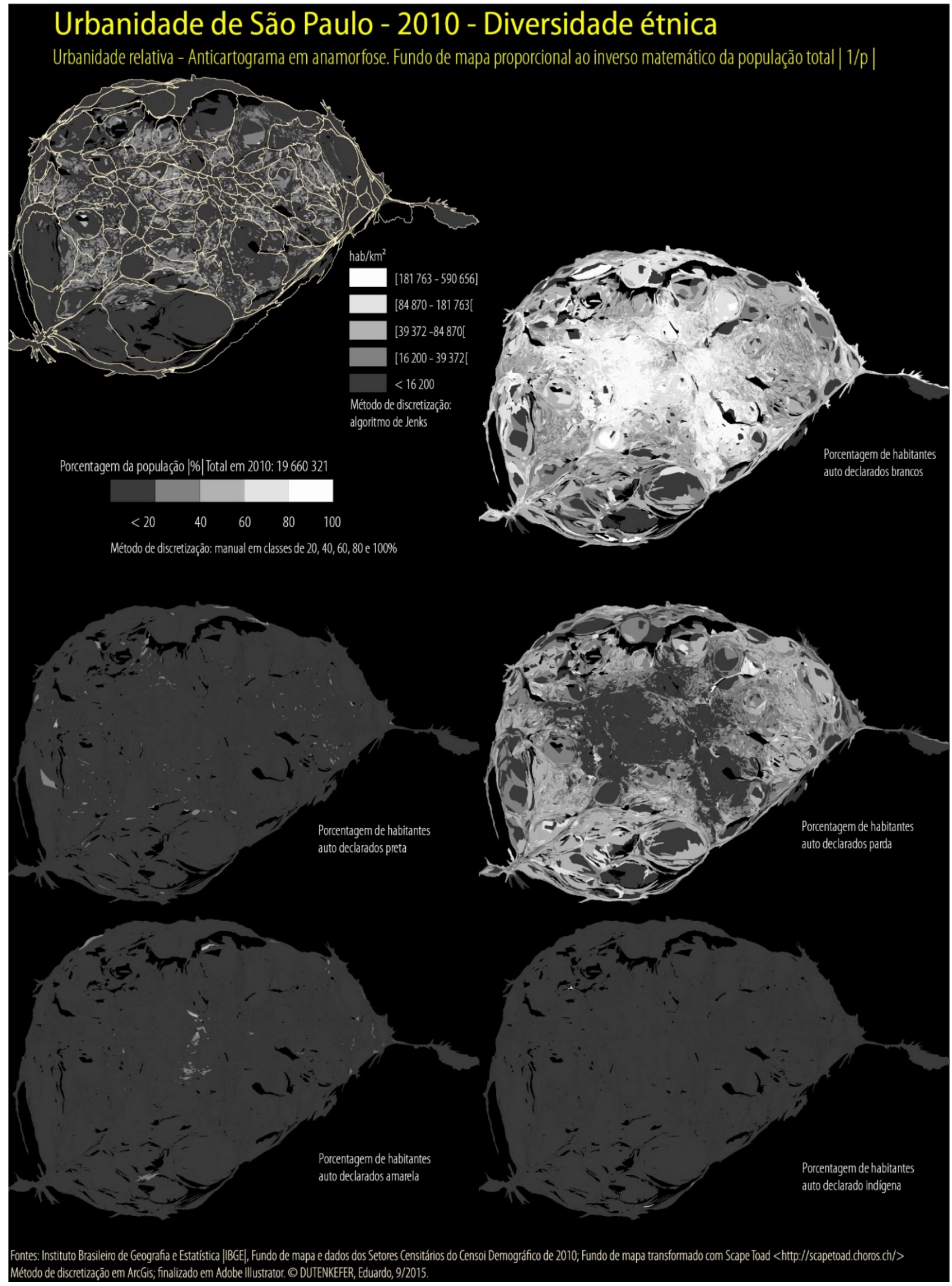


|Figura 19| A urbanidade das etnias em densidades

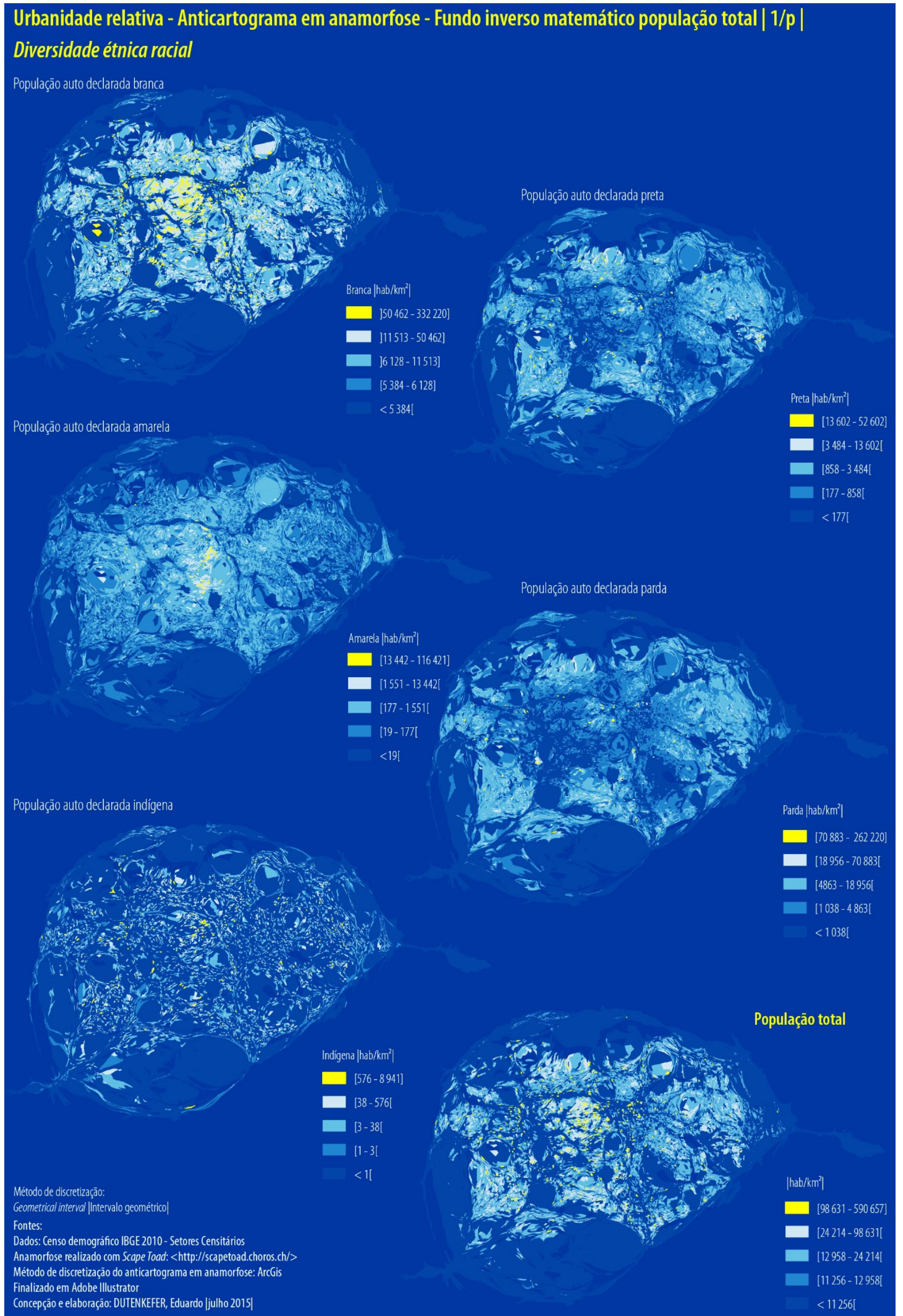


As altas porcentagens autodeclaradas brancas no mapa da figura 18 dominam a maior parte da extensão da cidade de São Paulo, com índices altos de um eixo norte ao sul no município de São Paulo e outro eixo rumo ao sudeste - municípios do ABC. Mas só parte dessas concentrações coincide com algumas faixas com altas densidades como podem ser observadas na imagem 19. A imagem dos autodeclarados pardos é o oposto aos dos brancos, isto é, as maiores porcentagens se espraiam em direção às franjas da cidade, mas com poucas concentrações com densidade elevadas visualizadas na figura 18. As imagens dos autodeclarados pretos, amarelos e indígenas apenas pontuam os mapas das figuras 18 e 19. São fragmentadas e bem localizadas as suas maiores expressões. No caso dos "amarelos" é evidente o predomínio no distrito da Liberdade. No cenário geral o "sombrio" predomina para as "pretas", "amarelas" e "indígenas".

Será que poderíamos encontrar expressões visuais que poderiam indicar um mínimo de sobreposição entre as "etnias" autodeclaradas, ou seja, teríamos um mínimo de diversidade "étnica”, uma heterogeneidade "étnica” copresente nos espaços da cidade de São Paulo?

\section{7 - A busca de uma "constância" por meio de sua "inconstância"}

Os vocábulos expressam sinônimos ou analogias que auxiliam em nossas reflexões e a língua portuguesa é riquíssima neste aspecto. Um instrumento interessante, já usado por nós é o Dicionário AULETE. Outro auxílio é o dicionário PORTO [online]. Do AULETE, usaremos agora a sua forma analógica do vocábulo diversidade 42 e para o PORTO o vocábulo variabilidade 43 . Encontraremos referência que "soam" como metáforas em nossas reflexões; o "buscar o heterogêneo, o oscilar, o variável, o escabroso" em uma cidade. É a busca de formas de representações cartográficas que retratem, por meio de um mosaico de objetos geográficos, imagens quase instáveis, que evidenciem uma ausência de constância, de uma negação do homogêneo, da "mesmice". Ou ao contrário, teremos imagens de uma cidade "nebulosa", "sombria" ausente de diversidade ou com uma urbanidade menos intensa ou ainda com graus do "escabroso", imagem em gradientes da urbanidade de uma cidade.

Elencamos algumas variáveis estatísticas deste ideal de inconstância que entendemos que a cidade deveria proporcionar aos seus habitantes. Mas, para utilizarmos estas variáveis em dados passíveis de serem cartografados, teremos que transformá-las em uma quase "constância", em uma relação matemática quase "constante" que traduziria em uma faixa do número zero [0] até um [1] a probabilidade de encontrarmos, pelo menos dois [2] elementos

42 <http://www.aulete.com.br/analogico/variabilidade/1/Diversidade> Acesso: 2/4/2015.

43 variabilidade in Dicionário da Língua Portuguesa com Acordo Ortográfico [em linha]. Porto: Porto Editora, 2003-2015. [consult. 2015-10-01 23:02:13]. Disponível em: http://www.infopedia.pt/dicionarios/linguaportuguesa/variabilidade 
do atributo em estudo diferentes, diversos. Usaremos um indicador, um índice de diversidade para as nossas variáveis estatísticas encontradas e selecionadas no censo demográfico 2010 e presentes como dados nos setores censitários da cidade de São Paulo.

Jack P. Gibbs, da Universidade do Texas, e Martin T. William, da Universidade de Oregon [EUA] em 1962 escrevem o "paper" "Urbanization, technology, and the division labor: international patterns" onde relatam os testes que realizaram para diversas proposições relacionadas ao "grau de urbanização, a divisão do trabalho, a dispersão de bens de consumo de uma população em áreas urbanas e seu nível de desenvolvimento tecnológico" (GIBBS, MARTIN, 1962, p. 667, tradução nossa) alcançado. Ao medirem a diversidade industrial de uma sociedade elaboram um índice para medir esta diversidade.

A fórmula original de dispersão de Gibbs e Martin é:

$=1-\left[\left[\sum \mathrm{X}^{2} /\left(\sum \mathrm{X}\right)^{2}\right]\right.$ eq. 11 (GIBBS, MARTIN, 1962, p.670).

Onde "X" é o número de pessoas empregadas em cada uma das diferentes categorias de indústrias analisadas por Gibbs e Martin.

Se o resultado tende mais para o valor zero (0) significa pouca diversidade industrial, uma maior especialização e, se tende para um (1), significa uma maior diversidade. Portanto o Índice de Gibbs e Martin [ $\left.\mathrm{I}_{\mathrm{GM}}\right]$ varia de zero (0) a um (1).

Calculamos também o índice de diversidade de Simpson, testado por Borruso (2009), que o utiliza em análises da distribuição espacial de imigrantes na Itália contemporaneamente e os resultados foram idênticos ao de Gibbs e Martin.

Utilizamos a equação 11 em nossos dados para cada variável dos temas disponíveis no Censo demográfico 2010, para os setores censitários. Calculamos estes índices no aplicativo Microsoft Excel e elaboramos os mapas da figura 20. 
|Figura 20| Mapas de diversidade

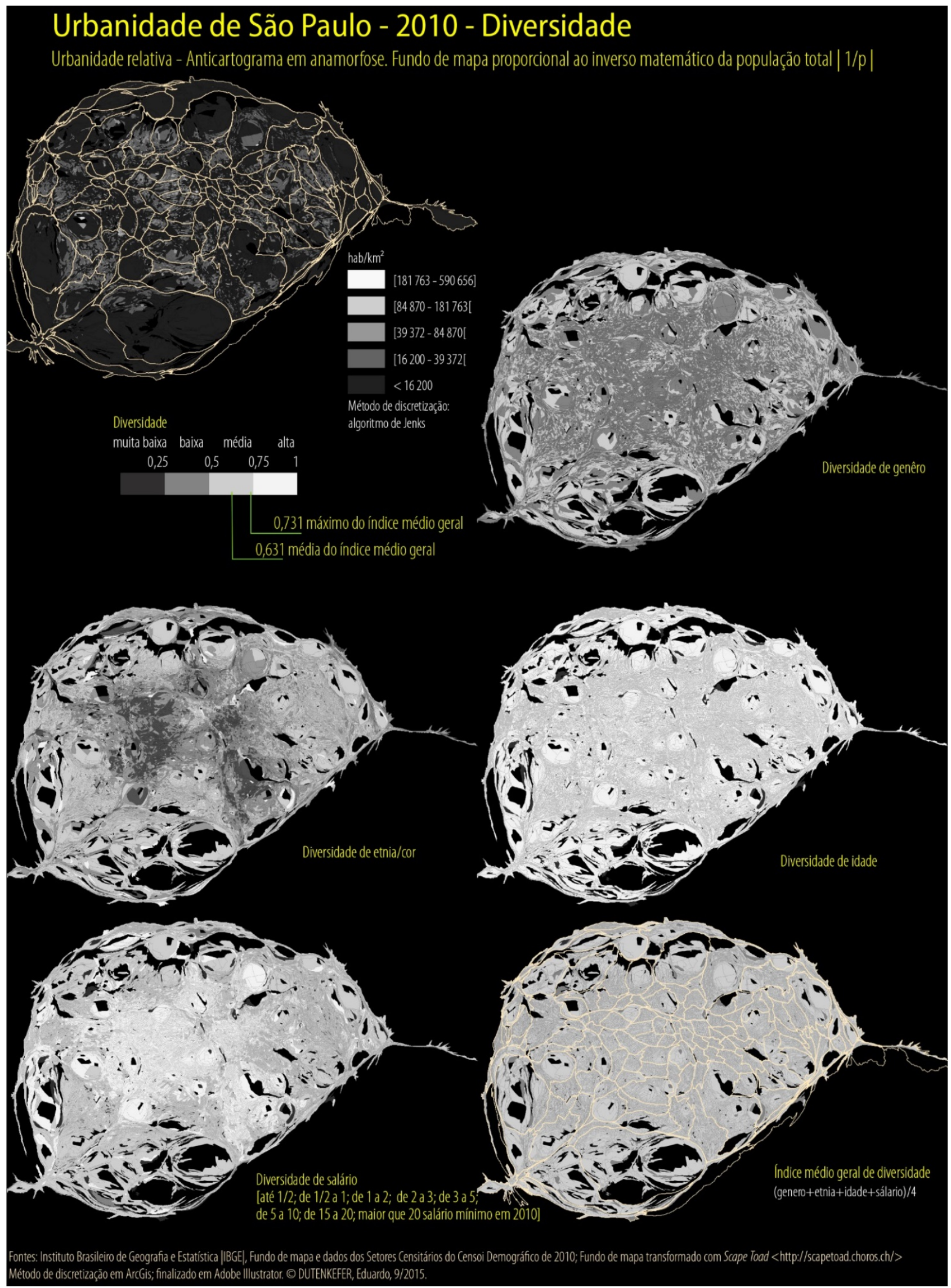

O método de discretização utilizado foi o que Cauvin et al (1987 e 2008a) denominam de exógeno, isto é, não foi utilizado nenhum método gráfico e/ou estatístico. Decidimos uma 
classificação próxima ao que o Índice de Desenvolvimento Humano utiliza para expressar índices altos, médios e baixos. Outra justificativa para esta decisão é que podemos estabelecer, futuramente, uma relação com a densidade com o método de quadrantes ${ }^{44}$. Optamos em 4 classes de mesma amplitude para expressar faixas indicativas de diversidade:

1 - $[0$ a 0,25$]=>$ muito baixa diversidade;

2 - ]0,25 a 0,5] => baixa diversidade;

3 - ]0,5 a 0,75$]=>$ média diversidade

4 - ]0,75 a 1] => alta diversidade

A diversidade de Gênero, infelizmente apenas com duas variáveis, dá apenas a diversidade em ser masculino ou feminino. Na média o índice gira em torno de 0,498 , isto significa um equilíbrio entre homens e mulheres ou em termos de porcentagem, temos 50\% de chance de encontrar entre dois "elementos" dos dados serem um do sexo masculino e o outro do sexo feminino e o mapa expressa uma distribuição equilibrada entre os dois sexos.

A média geral do índice de diversidade de etnia/cor é de 0,47 . Isto significa que temos uma probabilidade de $47 \%$ de encontrar dois habitantes diferentes em termos de etnia/cor. No mapa é visível áreas com menor diversidade, que coincidem em geral com as áreas da maior porcentagem de brancos do mapa da figura 18. Uma diversidade pouco mais elevada no restante da cidade.

Na diversidade de idade temos como média geral do índice o valor de 0,84. Uma média que se enquadra dentro de uma diversidade alta. No mapa a sua distribuição espacial é, em geral, homogênea para o conjunto da cidade.

Quanto à diversidade de renda temos o índice médio de 0,73 que representa a diversidade de rendimentos das faixas de salário mínimo. Um índice médio, segundo a nossa classificação, é mais acentuado na área central do anticartograma e com baixa diversidade no restante da cidade.

Se tomarmos apenas estes indicadores utilizados, a imagem do mapa síntese do índice médio geral de diversidade nos revela uma cidade com uma média diversidade em geral. A média do índice é de 0,631 e o máximo que encontramos é de 0,731. Nenhum setor censitário "conseguiu" atingir a faixa de uma diversidade alta.

Relacionar os mapas da figura 20 a dupla densidade/diversidade não é tão óbvia. A visualização que os mapas oferecem na proposta do anticartograma é um dos possíveis caminhos.

\footnotetext{
${ }^{44}$ Detalhes desta metodologia veremos no capítulo 6.0 que foca na acessibilidade.
} 
Veremos, no próximo capítulo, outros caminhos possíveis e futuramente mostraremos outras propostas onde tentaremos visualizar esta relação agregando os dados em distritos, na escala do município de São Paulo, em uma expressão gráfica que chamaremos de "mapa modelo". 


\section{4 - Densidades em "quadrados"}

Explorando novas oportunidades que o mapa oferece para a urbanidade de uma cidade, mudaremos mais uma vez o nosso recorte espacial, a sua escala e sua forma de visualização.

A nossa intenção é oferecer alternativas de visualizações cartográficas na escala do intraurbano, que podem representar as quadras, as localizações de atividades outras que não sejam apenas a de moradias, residências. Este recorte agora será o núcleo da cidade de São Paulo, do município de São Paulo, ou em outras palavras, o núcleo da metrópole paulistana. Veremos, mais adiante, que uma das razões para tal escolha é oferecer um exercício com os dados do Cadastro Nacional de Endereços para Fins Estatísticos [CNEFE] do Censo Demográfico de 2010 realizado pelo IBGE. Este Cadastro nos oferece a possibilidade de espacializar as diversas atividades não exclusivamente residenciais, aquelas ligadas à dimensão econômica, sejam elas como funções comerciais, industriais e de serviços.

Apresentaremos neste capítulo uma visualização cartográfica de densidades em "quadrados", ou seja, em elementos geométricos regulares na forma de uma grelha quadricular.

\section{1 - A grade estatística do IBGE}

Uma das alternativas de visualização cartográfica por nós explorada tem origem no trabalho de doutorado de Maria do Carmo Bueno, realizada na UNICAMP em 2014: “Grade estatística: uma abordagem para aumentar o potencial analítico de dados censitários" onde, em seus escritos, destacamos:

propõe a utilização de células regulares dispostas em um sistema de grade para a agregação e disseminação de dados censitários, denominada "grade estatística". As células desta grade têm pequenas dimensões, podendo ser consideradas como "tijolos" que se juntam para formar qualquer recorte espacial desejado e não se alteram ao longo do tempo. (BUENO, 2014, p. VII)

Em 2016 o IBGE lança a sua grade estatística, trabalho coordenado por Maria do Carmo Bueno, onde afirma:

A proposta de criação de um sistema de grades regulares para disseminação de dados estatísticos surge a partir da necessidade de integração de dados de origens diversas e agregados em unidades geográficas incompatíveis, além da necessidade de se ter dados agregados em unidades pequenas e sem variação ao longo do tempo. (IBGE, 2016, p.6)

Não temos mais fronteiras bem estabelecidas em uma cidade. Já não contamos com muros, muralhas e fosso bem delimitados que permitam o estabelecimento de limites, um perímetro, uma fronteira clara da extensão de uma cidade. Temos limites administrativos de municípios e suas sedes que, em princípio, correspondem a uma ideia de cidade em áreas urbanas. Estes limites administrativos mudam ao longo do tempo, aos sabores dos atores 
sociais e políticos. Estabelecer unidades geométricas simples como o quadrado, por exemplo, e que correspondam ou lembrem células territoriais invariáveis no tempo é tentador. A proposta de grade estatística de Bueno, e agora do IBGE, explicitam esta tentação. Esta proposta elimina, em parte, a necessidade de utilizarmos o fundo de mapa como os setores censitários, distritos, bairros, municípios, estados que compõem níveis de mensuração, de agregação de dados estatísticos oriundos dos censos realizados pelo IBGE.

O Japão, em 1969, utilizou este sistema para "medir" Tóquio. Na década de 1970, a Finlândia e Inglaterra igualmente trilharam o mesmo caminho (IBGE, 2016). No Brasil, na realização do censo de 2010, foi utilizada tecnologia que capturou as coordenadas geográficas do domicílio onde o recenseador fez sua pesquisa. Podemos também utilizar os endereços destes domicílios e transformá-los em pares de coordenadas como fizeram Finlândia e Suécia (IBGE, 2016). A grade estatística do IBGE contou também com o auxílio de técnicas de desagregação de dados, que "transferem os dados existentes em um suporte espacial para outro suporte espacial, através da criação de um denominador espacial comum entre as unidades de origem e de destino" (IBGE, 2016, p. 11). Estas técnicas são do tipo de "ponderação zonal simples, que utiliza densidade da variável na unidade de origem para a realocação na unidade destino" (IBGE, 2016, p. 11). Outro método utilizado pelo IBGE foi o dasimétrico, já utilizado, por exemplo, em nossas pesquisas de mestrado, em 2010 (DUTENKEFER, 2010).

O IBGE adotou células de $1 \mathrm{~km} \mathrm{X} 1 \mathrm{~km}$ em áreas rurais e 200m X $200 \mathrm{~m}$ nas áreas urbanas.

| Figura 21| Articulação da grade estatística IBGE 2016

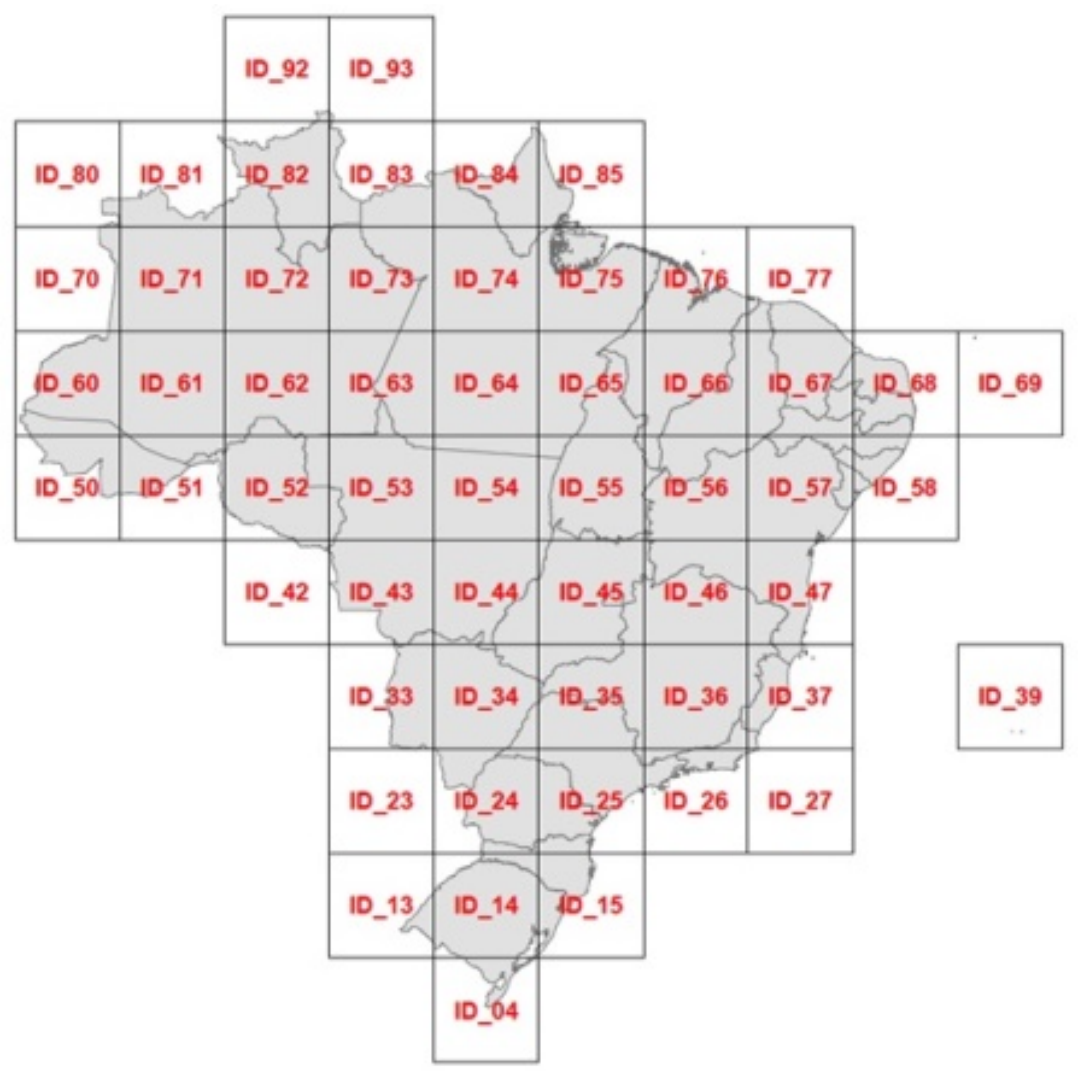




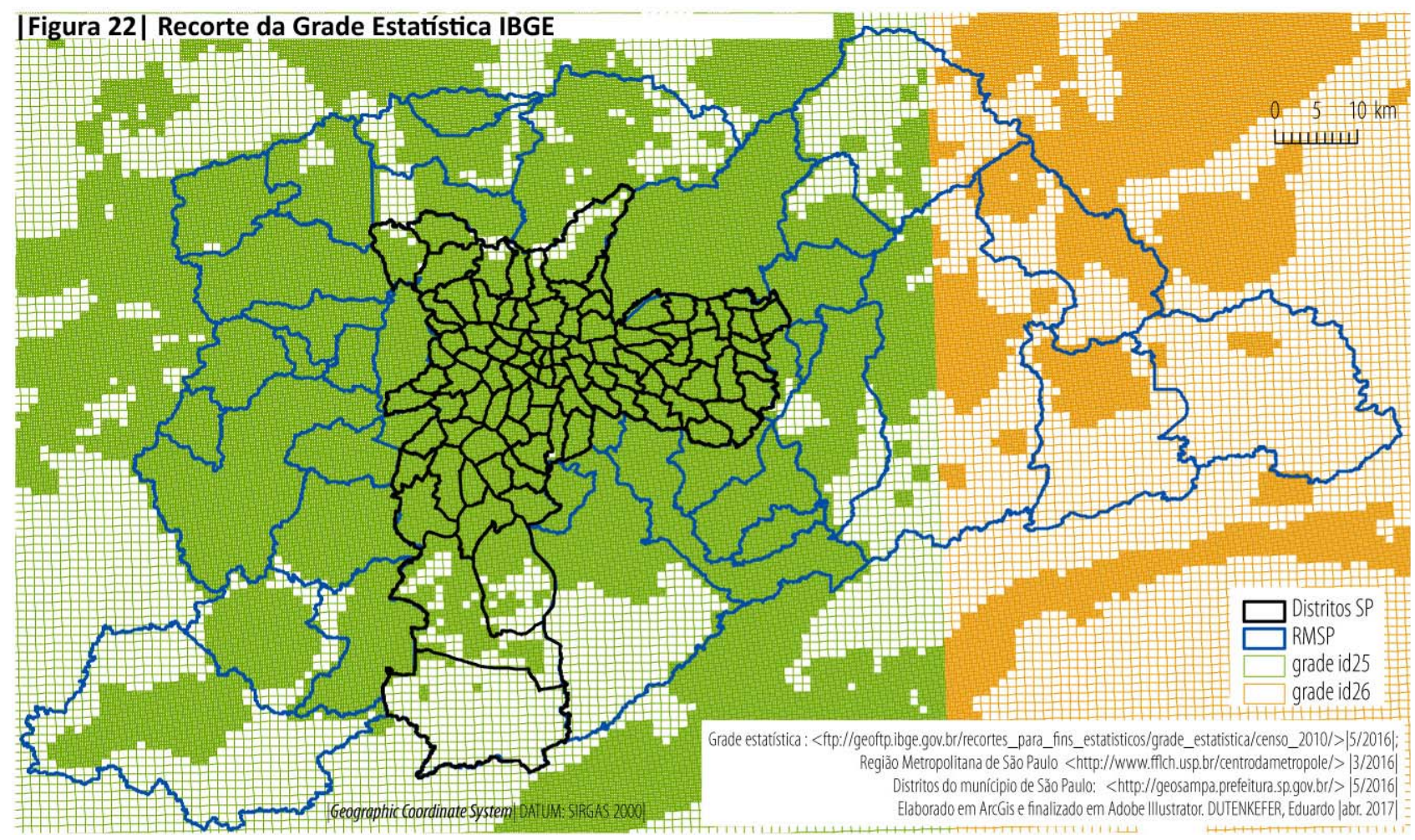

Na figura 21 temos a articulação das áreas do território nacional mapeadas em grade estatística ${ }^{45}$.

$\mathrm{Na}$ figura 22 temos o recorte que utilizamos para as nossas pesquisas. No caso utilizamos o recorte do munícipio de São Paulo.

\section{2 - O método "carroyage"}

Esta grade estatística do IBGE nos remete, na bibliografia em língua francesa, ao método de carroyage, onde em

uma grade regular sobre a imagem de um território, "contamos" os objetos em cada quadrado da grade. Em geral está grelha, grade é feita de quadrados, mas pode ser de retângulos ou hexágonos" (BRUNET, 1987, p. 93)

Segundo Cauvin (2007), o interesse por este método cresceu depois dos anos 1970 com os trabalhos de Tobler, principalmente com suas abordagens matriciais em cartografia e com recenseamentos baseados neste método no Canadá, Inglaterra e Suécia.

Os mapas em carroyage têm a vantagem de eliminar o "peso" que o fundo territorial tamanho variável das unidades, limites irregulares - exercem na visualização de mapas coropléticos, por exemplo. As divisões administrativas de uma cidade podem ser eliminadas para focarmos nas principais tendências da distribuição espacial de dados que estamos a

45 Imagem disponível em:

<ftp://geoftp.ibge.gov.br/recortes_para_fins_estatisticos/grade_estatistica/censo_2010/articulacao.jpg> Acesso: 01/05/2016 
analisar. 0 método "associa e trata os dados com o objetivo de uma exploração estatística e cartográfica". (BRUNET at al, 1993, p. 88)

Na figura 23 comparamos a grade estatística do IBGE com o mapa em Carroyage. Recortamos a malha do IBGE em aplicativo de Sistema de Informações Geográficas [ArcGis] correspondente 46 a área do município de São Paulo com os seus 92 distritos. Para o mapa em Carroyage utilizamos o software Cartes\&Données, utilizando os dados de densidade presentes nos setores censitários do município de São Paulo. Utilizamos o mesmo método de discretização para os dois mapas. O resultado visual de comparação é muito próximo. Excetuando densidades menores que 6.051 habitantes por quilômetro quadrado, os mapas são bem parecidos. O IBGE disponibiliza para download apenas o número de habitantes e o número de domicílios ocupados em seu arquivo vetorial [formato shapefile]. Esta comparação permite-nos exercitar outras possibilidades. São outras variáveis presentes nos dados dos setores censitários que podemos utilizar em uma representação cartográfica no método Carroyage. 0 mapa resultante deste método pode revelar as principais tendências da distribuição espacial do fenômeno. 


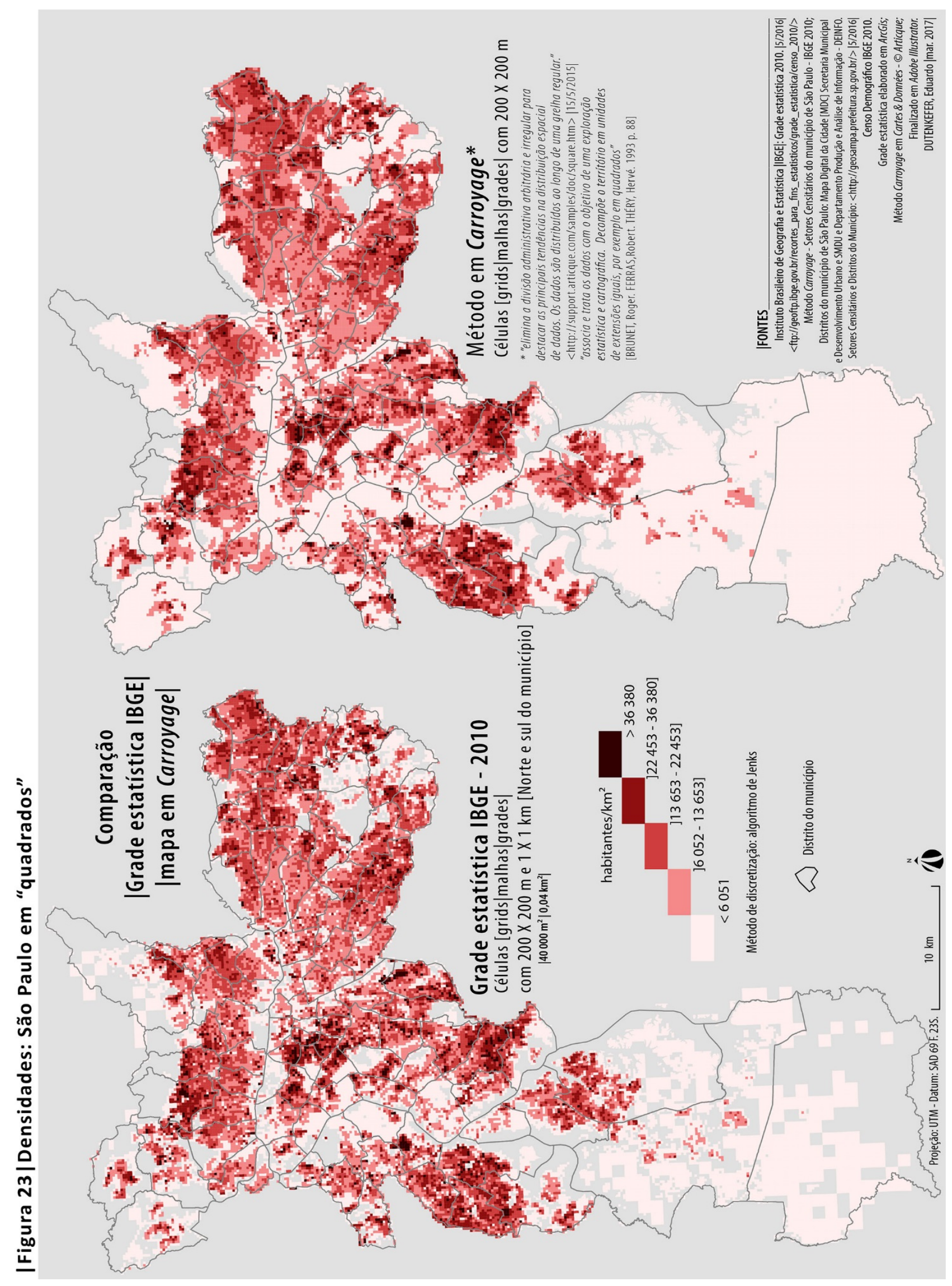




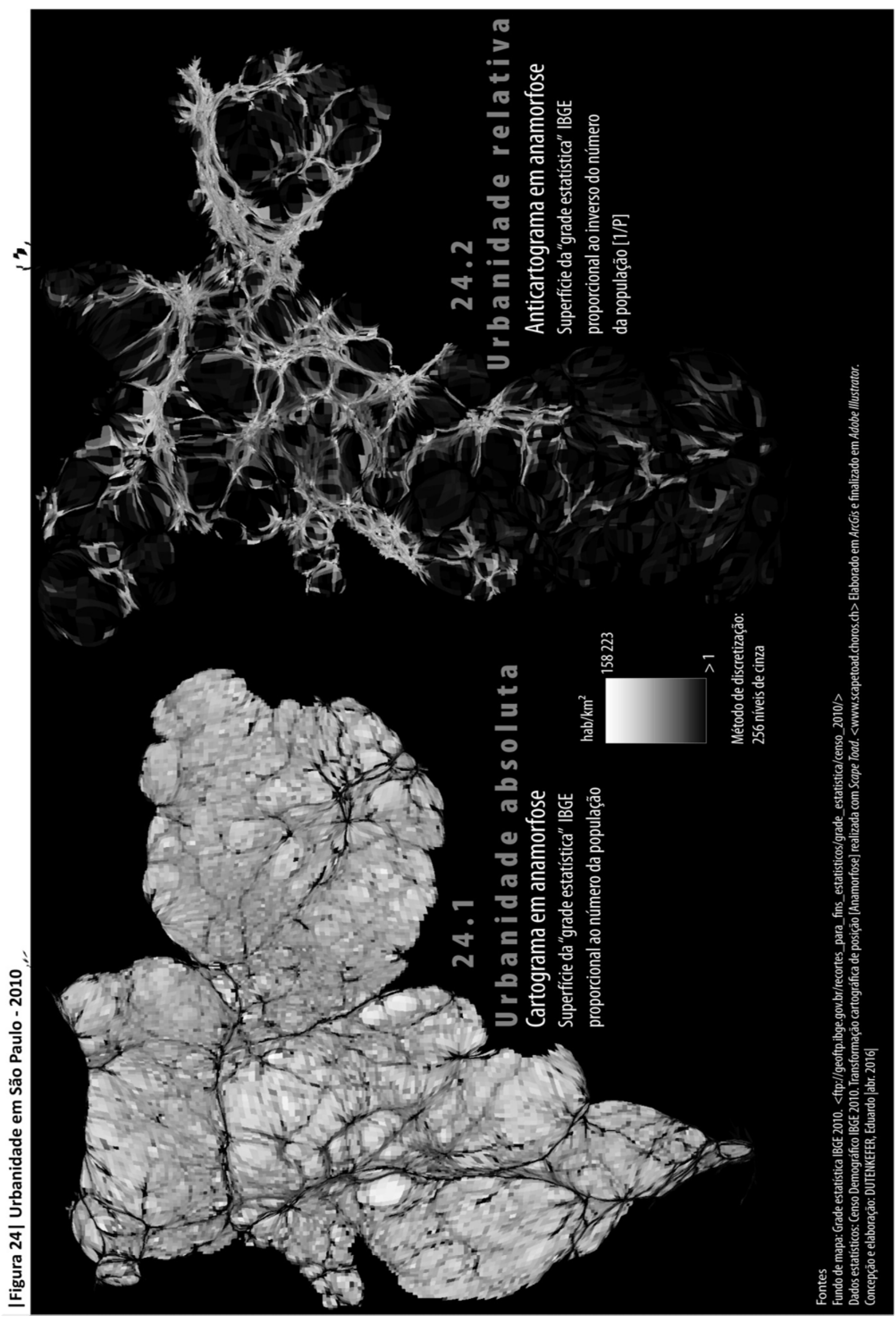




\section{3-A grade transformada}

Na figura 24 exploramos o potencial da grade estatística do IBGE nas representações da urbanidade absoluta e urbanidade relativa que anteriormente apresentamos ${ }^{47}$. Neste recorte atual, o município de São Paulo na imagem do anticartograma é impactante. A urbanidade relativa é revelada pelos "filamentos", pelas nuances geometricamente diminutas presentes no mapa em 24.2. Ela mostra uma rede com suas possíveis conexões e interconexões. São possibilidades que o peso das compactações humanas propicia, aqui representadas pelo seu inverso matemático [1/p]. Tão pouco as células quadradas de 200 X $200 \mathrm{~m}$, visíveis no cartograma em anamorfose em 24.1, deixa de ser revelador. Elas dão pistas, tentam antecipar o mapa em anticartograma, que deixará explicitas as principais tendências de uma distância societal que tende a "zero". A malha estatística do IBGE, da figura 23, antes de ser transformada, já antecipava visualmente onde ocorrem as principais tendências das concentrações humanas.

Vamos explorar um pouco estas concentrações comparando as representações cartográficas da urbanidade absoluta e relativa em setores censitários e na grade estatística do IBGE.

Focando o nosso olhar nas transformações cartográficas da figura 25 e, em uma primeira aproximação visual, nos mapas em 25.1.1 e 25.2.1 - não notaremos grandes mudanças nos contornos de áreas dos distritos já transformadas pelas massas dos objetos urbanos representados. Elas representam aproximações cartográficas do conceito de urbanidade absoluta deste recorte espacial. É a "massa" - o tamanho dos objetos urbanos considerados. Em nosso caso é a substância destes espaços - o número de habitantes. Esta substância altera a forma e o tamanho dos setores censitários que, por sua vez, alteram o tamanho e formas dos distritos administrativos. Este "peso" populacional é evidenciado pela sua concentração populacional nos cartogramas 25.1 - em setores censitários - e 25.2 - em grade estatística. São expressões de suas densidades populacionais. O cartograma em anamorfose da grade estatística do IBGE [22.2] tem um conjunto de 30.695 células de $200 \mathrm{X}$ 200 m e apenas 379 células com $1 \mathrm{~km} \mathrm{X} 1 \mathrm{~km}$ [em sua maioria com baixas densidades]. Este tamanho "padrão", de 200 m X 200 m, contribuiu profundamente para revelar as áreas mais densamente povoadas do município. Em 25.2 destacamos 4 áreas, que também estão presentes no cartograma em anamorfose dos setores censitários, mas nesta transformação da grade estatística ficou mais "refinado" e evidente o potencial da urbanidade absoluta.

\footnotetext{
47 Com o recorte espacial dos setores censitários da Região Metropolitana de São Paulo. Ver por exemplo a figura
} 17 - A urbanidade fragmentada de São Paulo. 
Mais ao centro do município temos "células" de densidades que se destacam no distrito de Santa Cecília, República, Consolação e indo em direção a Liberdade e Vila Mariana. Mais a leste temos Sapopemba parte de São Lucas, Vila Formosa e Carrão. O sudoeste tem Vila Andrade em grande destaque e, em seguida, Campo Limpo, parte de Capão Redondo, São Luís e norte do distrito de Jardim Ângela. O sudeste tem como destaque Cidade Ademar, parte sul de Jabaquara e norte de Pedreira.

O tamanho das áreas dos setores censitários é variável, na grade estatística não. A nossa tese é que está "homogeneidade" de tamanhos da grade no município fez o método utilizado pelo aplicativo que elaboramos a anamorfose obter o seu melhor desempenho.

Observemos um detalhe deste aplicativo, o Scape Toad, que utiliza o método de Gastner e Newman ${ }^{48}$ :

...criar um cartograma dando uma densidade demográfica particular é permitir que a população, de alguma maneira, flua das áreas de alta densidade para as de baixa densidade, pois a densidade é igual em toda parte desta área. (GASTNER e NEWMAN, 2004, p.7500, tradução e adaptação nossa).

Como a área é igual em boa parte de nosso recorte de estudo é presumível admitir que o algoritmo, ao processar o número de elementos matemáticos - em nosso caso o número de habitantes na área de cada célula de 200 X 200 m - permitiu uma equalização mais equilibrada da densidade de elementos nestas superfícies. Ela não é tão evidente no anticartograma em setores censitários, como observamos em 25.3. Em compensação, esta "equalização mais equilibrada" é nitidamente percebida no anticartograma de anamorfose da grade estatística em 25.4. As áreas dos distritos que destacamos acima se contraíram de tal forma que praticamente se "fundiram" revelando a suas conexões como em uma rede de "neurônios". O "vazio" também ficou expressivo em ambos anticartogramas - 25.3 e 25.4.

\footnotetext{
48 Já apontado também em DUTENKEFER, 2010, p 91.
} 


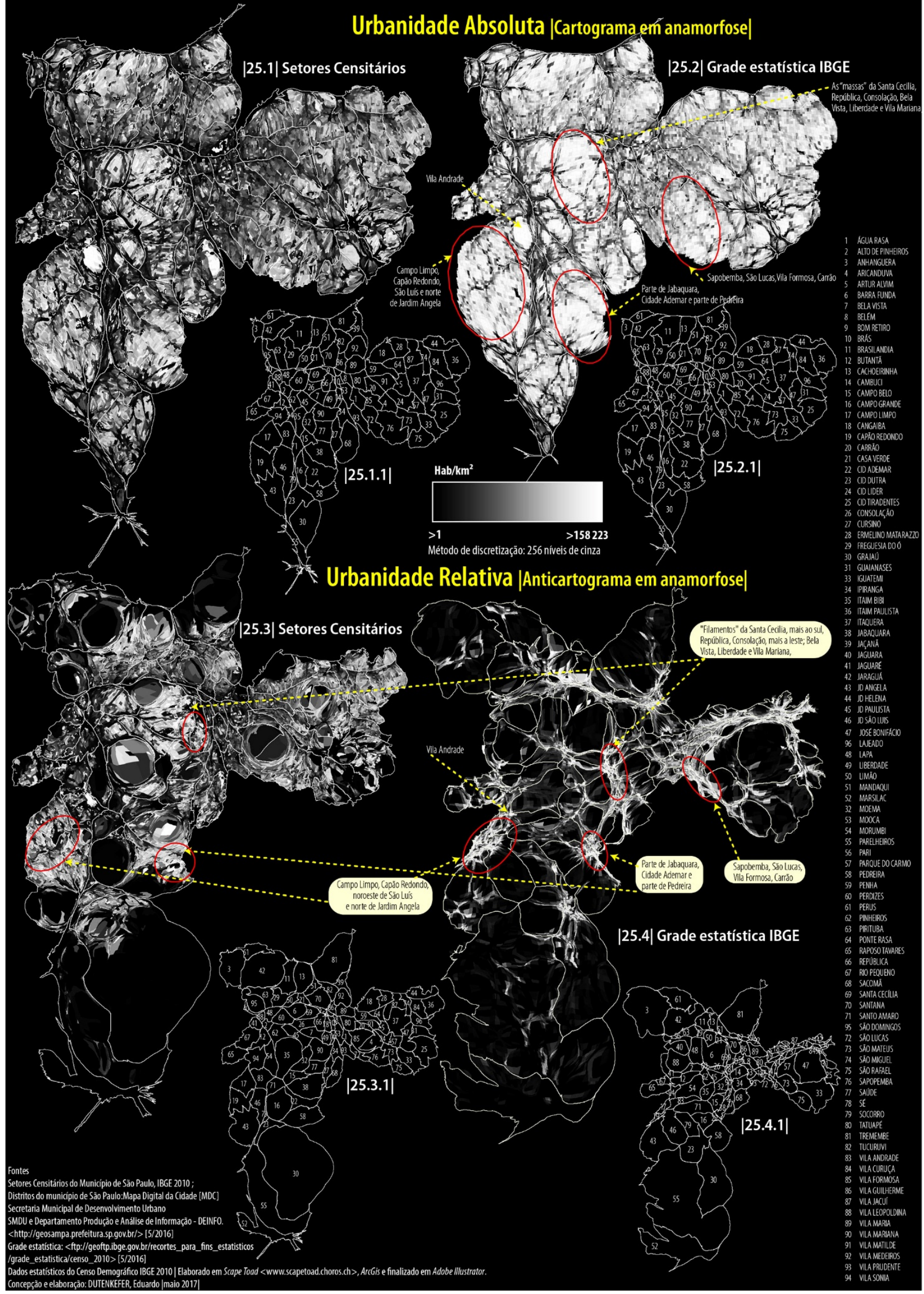




\section{5 - Diversidades de atividades}

No item 3.6 utilizamos alguns dados sociais para expressar a diversidade na metrópole paulistana. Diversidade como quantidade de elementos heterogêneos copresentes no espaço da metrópole.

Neste capítulo utilizaremos diversidades materiais presentes no espaço urbano do município de São Paulo. Continuando com o nosso objetivo de manter a utilização de dados públicos acessíveis, empregamos os dados do Cadastro Nacional de Endereços para Fins Estatísticos do IBGE $^{49}$ (CNEF) do censo de 2010 para o município de São Paulo. Utilizamos o uso não residencial, ou seja, atividades ligadas aos setores comerciais, industriais e de serviços que o recenseador obteve ao pesquisar cada unidade do imóvel em tela.

Mais do que dimensões econômicas, estas atividades não residenciais são locais potenciais de interações sociais. Além de suas funções clássicas de produção, comercialização e prestação de serviços materiais e imateriais, compõem e dão ritmo ao "sistema de ações" reportando-nos ao professor Milton Santos - que contribuem, são matérias primas da construção do espaço geográfico. São as "substâncias do espaço geográfico" de Jacques Lévy. Espaço da copresença de densidades [atividades não residenciais] e diversidades [com funções não habitacionais] que nos remetem à indicadores da urbanidade de uma cidade. São espaços bem precisos em métricas euclidianas com suas coordenadas que os endereços de logradouros permitem. Mas também espaços onde atores sociais estabelecem marcas no sentido de marcos físico bem materiais, e de marcas imateriais, imagéticas como, por exemplo, o "M" da franquia Mcdonalds... São objetos geográficos por excelência, que podem estabelecer ritmos de interesse de acesso diferenciados aos habitantes de uma cidade. Acessos em métricas euclidianas e/ou em métricas sociais (distância-tempo, distância-custo, distância-salário, distância-cognitiva, afetiva, cultural...).

490 Cadastro Nacional de Endereços para Fins Estatísticos - CNEFE apresenta uma lista com 78.056.411 endereços urbanos e rurais do território nacional, distribuídos pelos 316574 setores censitários, classificados por tipo: unidades residenciais, unidades de ensino, unidades de saúde e outros. A listagem contém, apenas, os endereços com identificação do nome do logradouro, número, complemento e coordenadas nos setores rurais, sem mencionar informação econômica ou social correspondente àquele endereço. < http://www.ibge.gov.br/home/estatistica/populacao/censo2010/cnefe/default_cnefe.shtm> Acesso: $16 / 11 / 2016$ 


\section{1 - Os dados do CNEFE: aspectos metodológicos}

Foram geocodificados 50466.635 endereços de atividades ligadas aos setores comerciais, industriais e de serviços. São 96 arquivos em formato txt equivalente aos 96 distritos do município de São Paulo. Transformamos em planilha eletrônica no software Microsoft Excel - figura 26. Excluímos os endereços residenciais e formatamos as colunas do endereço para uso no aplicativo TerraView sobre base de logradouros em formato shapfile ${ }^{51 .}$ Por meio dos endereços cadastrados o software geocodifica, isto é, localiza o endereço e o representa por meio de um ponto. Uma das razões de alterarmos a nossa escala do urbano, da metrópole para o município é o volume de dados e o tempo que levaria ao processar os dados do CNEF para todos os municípios da metrópole. Na tabela 3 sintetizamos o número total, o número de atividades que foram geocodificadas e a porcentagem do acerto que o processamento obteve para cada distrito. De um total de 466.635 conseguimos uma geocodificação de 447.791 endereços. Isto significa que 95,6 \% dos endereços foram

\begin{tabular}{|c|c|c|c|c|c|c|c|c|c|}
\hline 1 SEQ & TIPO & TIPOLOG & TITULO & NOMETIT & NOME & NUM & BAIRRO & COD & ATIVIDADE \\
\hline 21 & RUA & R & & & ABELARDO PINTO & 34 & CENTRO & 6 & HOTEL \\
\hline 32 & RUA & $\mathrm{R}$ & & & ABELARDO PINTO & 73 & CENTRO & 6 & PROTESE DENTARIA \\
\hline 411 & RUA & $\mathrm{R}$ & & & ABOLICAO & 94 & BELA VISTA & 6 & FECHADO \\
\hline 51001 & RUA & $\mathrm{R}$ & & & DA CONSOLACAO & 371 & CONSOLACAO & 6 & PREDIO COMERCIAL \\
\hline 61002 & RUA & $\mathrm{R}$ & & & DA CONSOLACAO & 374 & REPUBLICA & 6 & EDFICIO FREDERICO COMERCIAL \\
\hline 71003 & RUA & $\mathrm{R}$ & & & DA CONSOLACAO & 382 & REPUBLICA & 6 & EDFICIO TRANSCONTINENTAL COMERCIAL \\
\hline 81004 & RUA & $\mathrm{R}$ & & & DA CONSOLACAO & 385 & CONSOLACAO & 6 & FARMACIA \\
\hline 91005 & RUA & $\mathrm{R}$ & & & DA CONSOLACAO & 391 & CONSOLACAO & 6 & COPIADORA \\
\hline 101006 & RUA & R & & & DA CONSOLACAO & 393 & CONSOLACAO & 6 & ESCRITORIO CML \\
\hline 111007 & RUA & $\mathrm{R}$ & & & DA CONSOLACAO & 393 & CONSOLACAO & 6 & ESCRITORIOS \\
\hline 121008 & RUA & $\mathrm{R}$ & & & DA CONSOLACAO & 394 & REPUBLICA & 6 & BAR \\
\hline 131009 & RUA & $\mathrm{R}$ & & & DA CONSOLACAO & 397 & CONSOLACAO & 6 & BAR \\
\hline 141010 & RUA & $\mathbf{R}$ & & & DA CONSOLACAO & 398 & REPUBLICA & 6 & LOTERICA \\
\hline 151011 & RUA & $\mathrm{R}$ & & & DA CONSOLACAO & 419 & CONSOLACAO & 6 & LOCALIZA ALUGUEL DE CARROS \\
\hline 161012 & RUA & $\mathrm{R}$ & & & DA CONSOLACAO & 424 & REPUBLICA & 6 & POSTO DE GASOLINA SHELL. \\
\hline $17^{\prime} 1013$ & RUA & $\mathrm{R}$ & & & DA CONSOLACAO & 431 & CONSOLACAO & 6 & LOCADORA HERTZ RENT A CAR \\
\hline 181014 & RUA & $\mathrm{R}$ & & & DA CONSOLACAO & 437 & CONSOLACAO & 2 & PENSIONATO SANTA CECILIA \\
\hline 191015 & RUA & R & & & DA CONSOLACAO & 439 & CONSOLACAO & 6 & EDIFICIO JOSEPHA MIGUEL \\
\hline 201016 & RUA & $\mathrm{R}$ & & & DA CONSOLACAO & 480 & REPUBLICA & 6 & BANCO ITAU \\
\hline 211017 & RUA & $\mathrm{R}$ & & & DA CONSOLACAO & 574 & REPUBLICA & 6 & EDIFICIO GERMANO LEARDI \\
\hline 221018 & RUA & $\mathbf{R}$ & & & DA CONSOLACAO & 584 & REPUBLICA & 6 & EDIFICIO COMERCIAL \\
\hline 231019 & RUA & $\mathrm{R}$ & & & DA CONSOLACAO & 585 & CONSOLACAO & 6 & ALCOOLICOS ANONIMOS \\
\hline 241020 & RUA & $\mathrm{R}$ & & & DA CONSOLACAO & 585 & CONSOLACAO & 6 & IGREJA DA CONSOLACAO \\
\hline 251021 & RUA & $\mathrm{R}$ & & & DA CONSOLACAO & 605 & CONSOLACAO & 6 & BATALHAO DA POLICIA MILITAR TERCEIRA COM \\
\hline 261022 & RUA & $\mathrm{R}$ & & & DA CONSOLACAO & 605 & CONSOLACAO & 6 & GUARDA CIVIL METROPOLITANA \\
\hline $27^{\prime} 1025$ & PRACA & PRACA & & & DA REPUBLICA & 1 & CENTRO & 6 & BANCO REAL \\
\hline 281026 & PRACA & PRACA & & & DA REPUBLICA & 1 & REPUBLICA & 6 & LOJA DE ROUPAS \\
\hline $29^{\prime} 1030$ & PRACA & PRACA & & & DA REPUBLICA & 53 & CENTRO & 4 & SECRETARIA DA EDUCACAO \\
\hline 301032 & PRACA & PRACA & & & DA REPUBLICA & 71 & REPUBLICA & 6 & ENTREGAS EXPRESSAS \\
\hline 31105 & RUA & $\mathrm{R}$ & & & ALVARO DE CARVALHO & 22 & CENTRO & 6 & CONSTRUTORA \\
\hline 32106 & RUA & $\mathrm{R}$ & & & ALVARO DE CARVALHO & 22 & CENTRO & 6 & COPIADORA \\
\hline $33^{1} 107$ & RUA & $\mathrm{R}$ & & & ALVARO DE CARVALHO & 22 & CENTRO & 6 & ESC DE ADVOCACIA \\
\hline 341070 & PRACA & PRACA & & & DA REPUBLICA & 85 & REPUBLICA & 6 & ARTIGOS ESPORTIVOS \\
\hline 35108 & RUA & $\mathrm{R}$ & & & ALVARO DE CARVALHO & 22 & CENTRO & 6 & ESC DE ADVOCACIA \\
\hline 361071 & PRACA & PRACA & & & DA REPUBLICA & 95 & REPUBLICA & 6 & AGENCIA DE VIAGENS \\
\hline $37^{\prime} 1072$ & PRACA & PRACA & & & DA REPUBLICA & 105 & REPUBLICA & 6 & IMOBILIARIA \\
\hline 381073 & PRACA & PRACA & & & DA REPUBLICA & 115 & REPUBLICA & 6 & SALAO SE BELEZA \\
\hline $399^{\prime \prime} 1074$ & PRACA & PRACA & & & DA REPUBLICA & 119 & REPUBLICA & 6 & COMERCIO DE ROUPAS \\
\hline 40109 & RUA & $\mathrm{R}$ & & & ALVARO DE CARVALHO & 22 & CENTRO & 6 & ESC DE ADVOCACIA \\
\hline 411084 & PRACA & PRACA & & & DA REPUBLICA & 171 & REPUBLICA & 6 & LANCHONETE \\
\hline
\end{tabular}

localizados na base de logradouros utilizados.

Figura 26 - Exemplo de tela de planilha já transformada e editado os endereços para posterior uso em geocodificação

50 Utilizamos os dados disponíveis em:<ftp://ftp.ibge.gov.br/Censos/Censo_Demografico_2010/Cadastro_Nacional_de_Enderecos_Fins_Estatisticos /SP/> Acesso 16/11/2016

51 Software e logradouro disponível no Centro de Estudos da Metrópole [CEM]:

<http://www._ch.usp.br/centrodametropole/>. Acesso: 10/12/2016| 
Mesmo escolhendo apenas o município de São Paulo tivemos que classificar e organizar as atividades. Isto demandou um extenso trabalho. As descrições anotadas no campo de atividades variam de recenseador. Não existe uma padronização nas descrições, ou seja, uma "ausência de critérios únicos de definição de uma atividade econômica" (PORTO-SALES et al, 2014, p. 88). Temos ocorrência genérica de difícil definição; se é comércio ou produção industrial ou simplesmente de serviços. Exemplos: "alimentício", "alimentos", "edifício", "empresa", "prédio", "firma”. Mesmo classificado, como por exemplo: "edifício comercial" é óbvio que nem todo o edifício contém atividades de predomínio comercial. Neste caso, classificamos como de predomínio de serviços e/ou comércio. Temos ocorrências do uso do nome fantasia para identificar a atividade. Expressões genéricas do tipo "Fechado", "Não existe mais", "não informado", "Não tem gente", "igual ao anterior" "Sala vaga" e todas as sequências de "vaga”, loja, fabrica, galpão, etc. "Terreno vazio, vago”, "Apenas garagem”, "deposito fechado", "para alugar", "portão", “quintal do...” foram excluídas do arquivo final das possíveis identificações e classificações de atividades.

$\mid$ Tabela $3^{52} \mid$ - Número de atividades e atividades geocodificadas por distrito no município de São Paulo

\begin{tabular}{|c|c|c|c|c|c|c|}
\hline $\begin{array}{l}\text { CÓDIGO } \\
\text { DISTRITO }\end{array}$ & CÓDIGO BGE & NOME DISTRO & $\begin{array}{l}\text { SIGLA } \\
\text { DISTRITO }\end{array}$ & $\begin{array}{l}\text { ATIVIDAD } \\
\text { E }\end{array}$ & $\begin{array}{l}\text { ATIVIDADE } \\
\text { GEOCODIFICADA }\end{array}$ & PORCENTAGEM \\
\hline 1 & 35503080100 & AGUA RASA & ARA & 5205 & 5103 & 98,04 \\
\hline 2 & 35503080200 & ALTO DE PINHEIROS & API & 1359 & 1282 & 94,33 \\
\hline 3 & 35503080300 & ANHANGUERA & ANH & 1882 & 1617 & 85,92 \\
\hline 4 & 35503080400 & ARICANDUVA & ARI & 4126 & 4030 & 97,67 \\
\hline 5 & 35503080500 & ARTUR ALVIM & $A A L$ & 3683 & 3558 & 96,61 \\
\hline 6 & 35503080600 & BARRA FUNDA & BFU & 1815 & 1667 & 91,85 \\
\hline 7 & 35503080700 & BELA VISTA & BVI & 3443 & 3415 & 99,19 \\
\hline 8 & 35503080800 & BELEM & BEL & 5296 & 5231 & 98,77 \\
\hline 9 & 35503080900 & BOM RETIRO & BRE & 6210 & 6137 & 98,82 \\
\hline 10 & 35503081000 & BRAS & BRS & 7849 & 7802 & 99,40 \\
\hline 11 & 35503081100 & BRASILANDIA & BRL & 6488 & 6205 & 95,64 \\
\hline 12 & 35503081200 & BUTANTA & BUT & 3045 & 2910 & 95,57 \\
\hline 13 & 35503081300 & CACHOEIRINHA & CAC & 4029 & 3787 & 93,99 \\
\hline 14 & 35503081400 & CAMBUCI & $\mathrm{CMB}$ & 3229 & 3184 & 98,61 \\
\hline 15 & 35503081500 & CAMPO BELO & CBE & 4945 & 4764 & 96,34 \\
\hline 16 & 35503081600 & CAMPO GRANDE & CGR & 3848 & 3790 & 98,49 \\
\hline 17 & 35503081700 & CAMPO LIMPO & CLM & 6016 & 5572 & 92,62 \\
\hline 18 & 35503081800 & CANGAIBA & CNG & 4135 & 3983 & 96,32 \\
\hline 19 & 35503081900 & CAPAO REDONDO & CRE & 4954 & 4922 & 99,35 \\
\hline 20 & 35503082000 & CARRAO & CAR & 5043 & 5027 & 99,68 \\
\hline 21 & 35503082100 & CASA VERDE & CVE & 4953 & 4923 & 99,39 \\
\hline 22 & 35503082200 & CID ADEMAR & CAD & 8244 & 7978 & 96,77 \\
\hline
\end{tabular}

52 Um alerta necessário: As tabelas desta tese são elaboradas em aplicativo de planilha eletrônica Microsoft Excel e algumas de origem de aplicativos de SIG que não necessariamente são exemplos às normas da língua portuguesa. Optamos em não colocar nenhum símbolo além da grafia da letra. 


\begin{tabular}{|c|c|c|c|c|c|c|}
\hline 23 & 35503082300 & CID DUTRA & CDU & 6745 & 6565 & 97,33 \\
\hline 24 & 35503082400 & CID LIDER & CLD & 4179 & 4102 & 98,16 \\
\hline 25 & 35503082500 & CID TIRADENTES & CTI & 4604 & 4384 & 95,22 \\
\hline 26 & 35503082600 & CONSOLACAO & CON & 2729 & 2712 & 99,38 \\
\hline 27 & 35503082700 & CURSINO & CUR & 4383 & 3616 & 82,50 \\
\hline 28 & 35503082800 & $\begin{array}{l}\text { ERMELINO } \\
\text { MATARAZZO }\end{array}$ & ERM & 4104 & 3925 & 95,64 \\
\hline 29 & 35503082900 & FREGUESIA DO O & FRE & 5812 & 5490 & 94,46 \\
\hline 30 & 35503083000 & GRAJAU & GRA & 11543 & 11016 & 95,43 \\
\hline 31 & 35503083100 & GUAIANASES & GUA & 2992 & 2924 & 97,73 \\
\hline 32 & 35503083200 & MOEMA & MOE & 5406 & 5318 & 98,37 \\
\hline 33 & 35503083300 & IGUATEMI & IGU & 3770 & 3552 & 94,22 \\
\hline 34 & 35503083400 & IPIRANGA & IPI & 8090 & 7846 & 96,98 \\
\hline 35 & 35503083500 & ITAIM BIBI & $|\mathrm{B}|$ & 7842 & 6942 & 88,52 \\
\hline 36 & 35503083600 & ITAIM PAULISTA & IPA & 6561 & 6348 & 96,75 \\
\hline 37 & 35503083700 & ITAQUERA & ITQ & 6666 & 6100 & 91,51 \\
\hline 38 & 35503083800 & JABAQUARA & $J A B$ & 8220 & 7925 & 96,41 \\
\hline 39 & 35503083900 & JACANA & JAC & 2790 & 2695 & 96,59 \\
\hline 40 & 35503084000 & JAGUARA & JAG & 1437 & 1407 & 97,91 \\
\hline 41 & 35503084100 & JAGUARE & JRE & 1843 & 1796 & 97,45 \\
\hline 42 & 35503084200 & JARAGUA & JAR & 4272 & 3973 & 93,00 \\
\hline 43 & 35503084300 & JD ANGELA & JDA & 8207 & 7627 & 92,93 \\
\hline 44 & 35503084400 & JD HELENA & $\mathrm{JDH}$ & 4103 & 4009 & 97,71 \\
\hline 45 & 35503084500 & JD PAULISTA & JDP & 5716 & 5600 & 97,97 \\
\hline 46 & 35503084600 & JD SAO LUIS & JDS & 8015 & 7710 & 96,19 \\
\hline 47 & 35503084700 & JOSE BONIFACIO & $\mathrm{JBO}$ & 2655 & 2468 & 92,96 \\
\hline 48 & 35503084800 & LAPA & LAP & 7502 & 7397 & 98,60 \\
\hline 49 & 35503084900 & LIBERDADE & LIB & 3922 & 3850 & 98,16 \\
\hline 50 & 35503085000 & LIMAO & LIM & 3410 & 3340 & 97,95 \\
\hline 51 & 35503085100 & MANDAQUI & MAN & 3088 & 2984 & 96,63 \\
\hline 52 & 35503085200 & MARSILAC & MAR & 290 & 218 & 75,17 \\
\hline 53 & 35503085300 & MOOCA & MOO & 6078 & 5906 & 97,17 \\
\hline 54 & 35503085400 & MORUMBI & MOR & 1603 & 1443 & 90,02 \\
\hline 55 & 35503085500 & PARELHEIROS & PLH & 3747 & 3432 & 91,59 \\
\hline 56 & 35503085600 & PARI & PRI & 3499 & 3448 & 98,54 \\
\hline 57 & 35503085700 & PARQUE DO CARMO & $\mathrm{PQC}$ & 2274 & 2188 & 96,22 \\
\hline 58 & 35503085800 & PEDREIRA & PDR & 3809 & 3558 & 93,41 \\
\hline 59 & 35503085900 & PENHA & PEN & 6773 & 6644 & 98,10 \\
\hline 60 & 35503086000 & PERDIZES & PRD & 5089 & 4947 & 97,21 \\
\hline 61 & 35503086100 & PERUS & PRS & 2198 & 2080 & 94,63 \\
\hline 62 & 35503086200 & PINHEIROS & PIN & 7217 & 6985 & 96,79 \\
\hline 63 & 35503086300 & PIRITUBA & PIR & 5069 & 4947 & 97,59 \\
\hline 64 & 35503086400 & PONTE RASA & PRA & 5088 & 3369 & 66,21 \\
\hline 65 & 35503086500 & RAPOSO TAVARES & RTA & 2784 & 2683 & 96,37 \\
\hline 66 & 35503086600 & REPUBLICA & REP & 6411 & 6136 & 95,71 \\
\hline 67 & 35503086700 & RIO PEQUENO & RPE & 3788 & 3674 & 96,99 \\
\hline 68 & 35503086800 & SACOMA & SAC & 7698 & 7120 & 92,49 \\
\hline 69 & 35503086900 & SANTA CECILIA & SCE & 5273 & 5199 & 98,60 \\
\hline 70 & 35503087000 & SANTANA & STN & 6964 & 6861 & 98,52 \\
\hline 71 & 35503087100 & SANTO AMARO & SAM & 7696 & 7576 & 98,44 \\
\hline 72 & 35503087200 & SAO LUCAS & SLU & 5596 & 5493 & 98,16 \\
\hline
\end{tabular}




\begin{tabular}{lllllll}
\hline $\mathbf{7 3}$ & 35503087300 & SAO MATEUS & SMT & 6057 & 5918 & 97,71 \\
$\mathbf{7 4}$ & 35503087400 & SAO MIGUEL & SMI & 4436 & 4316 & 97,29 \\
$\mathbf{7 5}$ & 35503087500 & SAO RAFAEL & SRA & 3657 & 3408 & 93,19 \\
$\mathbf{7 6}$ & 35503087600 & SAPOPEMBA & SAP & 8208 & 7731 & 94,19 \\
$\mathbf{7 7}$ & 35503087700 & SAUDE & SAU & 6580 & 6454 & 98,09 \\
$\mathbf{7 8}$ & 35503087800 & SE & SEE & 4355 & 4319 & 99,17 \\
$\mathbf{7 9}$ & 35503087900 & SOCORRO & SOC & 2995 & 2951 & 98,53 \\
$\mathbf{8 0}$ & 35503088000 & TATUAPE & TAT & 8065 & 7927 & 98,29 \\
$\mathbf{8 1}$ & 35503088100 & TREMEMBE & TRE & 4672 & 4467 & 95,61 \\
$\mathbf{8 2}$ & 35503088200 & TUCURUVI & TUC & 4163 & 4069 & 97,74 \\
$\mathbf{8 3}$ & 35503088300 & VILA ANDRADE & VAN & 3073 & 2852 & 92,81 \\
$\mathbf{8 4}$ & 35503088400 & VILA CURUCA & VCR & 4389 & 4164 & 94,87 \\
$\mathbf{8 5}$ & 35503088500 & VILA FORMOSA & VFO & 4847 & 4695 & 96,86 \\
$\mathbf{8 6}$ & 35503088600 & VILA GUILHERME & VGL & 3233 & 3187 & 98,58 \\
$\mathbf{8 7}$ & 35503088700 & VILA JACUI & VJA & 4481 & 4151 & 92,64 \\
$\mathbf{8 8}$ & 35503088800 & VILA LEOPOLDINA & VLE & 2280 & 2245 & 98,46 \\
$\mathbf{8 9}$ & 35503088900 & VILA MARIA & VMR & 7618 & 7422 & 97,43 \\
\hline $\mathbf{9 0}$ & 35503089000 & VILA MARIANA & VMN & 7880 & 7737 & 98,19 \\
\hline $\mathbf{9 1}$ & 35503089100 & VILA MATILDE & VMT & 4636 & 4484 & 96,72 \\
\hline $\mathbf{9 2}$ & 35503089200 & VILA MEDEIROS & VMD & 5348 & 5254 & 98,24 \\
\hline $\mathbf{9 3}$ & 35503089300 & VILA PRUDENTE & VPR & 5230 & 5051 & 96,58 \\
\hline $\mathbf{9 4}$ & 35503089400 & VILA SONIA & VSO & 3670 & 3494 & 95,20 \\
\hline $\mathbf{9 5}$ & 35503089500 & SAO DOMINGOS & SDO & 3386 & 3303 & 97,55 \\
\hline $\mathbf{9 6}$ & 35503089600 & LAJEADO & LAJ & 4029 & 3897 & 96,72 \\
\hline & & & TOTAL & 466635 & 447911 & 95,99 \\
\hline
\end{tabular}

Contabilizamos em torno de 20.317 endereços com estes tipos de descrições que eliminamos. Além desses detectamos 4.927 endereços que foram geocodificados muito fora do distrito em que o endereço estava inserido. Foram, portanto, também não contabilizados. Ficamos assim com uma amostra de 422.667 endereços de atividades não residenciais, que utilizamos.

Muitos equívocos de digitação nas planilhas dificultaram o nosso trabalho em uma tentativa de hierarquizar as atividades em ordem crescente de palavras contidas no campo da descrição ou de uma forma mais automática encontrando, por exemplo, uma palavra chave que pudéssemos classificar a atividade em planilha do Excel. Exemplos de digitação presentes nas planilhas: "ASVOCACIA, DVOCAIA, ACOGEUE, ACOGUE, ACOGUI, ACOLGUE, ACOQUE, ACOUGE, CABEEIREIRA, CABEKEIREIRO, CABELEEEIRO, CABELEIRA, CABELEIRO, COM, COM, COME, COMECIAL, COMER, COMERC, COML, EBGENHARIA, BUTECO”, etc.

Na tabela 4 temos um extrato da planilha que elaboramos para auxiliar na classificação de atividades. Uma espécie de "dicionário tradutor". Na primeira coluna [NOME 1] a descrição de como estava digitado originalmente nas planilhas e na segunda coluna [ATIVIDADE] o tipo de atividade que classificamos. Utilizamos como referência em nossas classificações as 
orientações da Classificação Nacional de Atividades Econômicas [CNAE] ${ }^{53}$. Na tabela 5 sistematizamos as principais classificações utilizadas para esta pesquisa. Na figura 27 temos o mapa expressando o resultado de nossas geocodificações.

|Tabela 4| - Extrato de nosso “dicionário tradutor" para auxiliar na classificação de atividades

\section{NOME 1}

ABRIGO

ACABAMENTO GRAFICA

ACABAMENTOS GRAFICOS

ACADEMIA

ACESSORIA

ACOUGUE

ADEGA

ADMINISTRACAO

ADMINISTRACAO DIVERSOS

ADMINISTRACAO DO CONDOMINIO

ADVOCACIA

ADVOGADOS

AGENCIA

AGUA

ALUGUEL EM GERAL

AR CONDICIONADO,REFRIGERACAO

ARMARINHOS

ARMAZEM/DEPOSITO/BARRACAO/GALPAO/ALMOXARIFADO

ASSESSORIA DE IMPRENSA/RADIO E TV/JORNAL/

ASSISTENCIA TECNICA/MANUTENCAO/OFICINA DE CONCERTO

ASSOCIACAO

ASSOCIACAO/COOPERATIVAS/SINDICATOS

ATELIE

AUTO PECAS/ACESSORIOS P CARROS

BANCO

BAR

BAR E LANCHONETE

BAR E MERCADO

BAR E RESTAURANTE

BARZINHO

BASAR/BAZAR

BATERIAS

BICICLETRIA

BIJUTERIAS

BOATE/CASA DE DANCA/CASA NOTURNA/LOTERIA/CASA

JOGOS

\section{ATIVIDADE}

SERVICOS/SOCIAIS

SERVICOS/GRAFICOS

SERVICOS/GRAFICOS

SERVICOS/PESSOAIS

SERVICOS

COMERCIO/ALIMENTOS

COMERCIO/BEBIDAS

SERVICOS/ADMINISTRACAO/NAO ESPECIFICADO

SERVICOS/ADMINISTRACAO/DIVERSOS

SERVICOS/ADMINISTRACAO/IMOVEIS

SERVICOS/JURIDICOS

SERVICOS/JURIDICOS

SERVICOS

COMERCIO/AGUA

SERVICOS/ALUGUEL/OBJETOS DIVERSOS

COMERCIO/SERVICOS/REFRIGERACAO

COMERCIO/ARMARINHOS

SERVICOS/ARMAZEM/DEPOSITO/BARRACAO/GALPAO/ALMOXARI FADO

SERVICOS/COMUNICACAO/IMPRENSA

SERVICOS/ASSISTENCIA TECNICA

SERVICOS/SOCIAIS

SERVICOS/ATIVIDADES/ASSOCIATIVAS

SERVICOS/COMERCIO/DIVERSOS

COMERCIO/AUTOMOTIVOS/ACESSORIOS/PECAS

SERVICOS/FINANCEIROS

SERVICOS/ALIMENTOS/BEBIDAS

SERVICOS/ALIMENTOS/BEBIDAS

SERVICOS/BEBIDAS/COMERCIO

SERVICOS/ALIMENTOS/BEBIDAS

SERVICOS/ALIMENTOS/BEBIDAS

COMERCIO/VARIADOS

COMERCIO/AUTOMOTIVOS

SERVICOS/COMERCIO/BICICLETAS

COMERCIO/BIJUTERIA

SERVICOS/OUTROS

${ }^{53}$ Disponível em <http://concla.ibge.gov.br/busca-online-cnae.html> 
|Tabela 5 | - Principais sistematizações utilizadas na classificação das atividades no município de São Paulo

CLASSIFICAÇÃO
COMERCIO
COMERCIO V SERVICOS
COMERCIO/SERVICOS
COMERCIO/AGUA
COMERCIO/ALIMENTOS
COMERCIO/ALIMENTOS/ACOUGUE
COMERCIO/ALIMENTOS/PADARIA
COMERCIO/AUTOMOTIVOS
COMERCIO/AUTOMOTIVOS/ACESSORIOS/PECAS
COMERCIO/BEBIDAS
COMERCIO/MALAS/BOLSAS/ACESSORIOS
COMERCIO/CALCADOS
COMERCIO/COMBUSTIVEL
COMERCIO/COSMETICOS/PERFUMARIA
COMERCIO/ELETRONICO/INFORMATICA
COMERCIO/ELETRICO/FERRAGENS/HIDRAULICA/ILUMINACAO
COMERCIO/FARMACEUTICO
COMERCIO/FLORICULTURA
COMERCIO/INSTRUMENTOS MUSICAIS
COMERCIO/LIMPEZA
COMERCIO/LIVRARIA
COATERIAL PARA CONSTRUCAO

COMERCIO/MERCADO/PRODUTOS VARIADOS

COMERCIO/MOVEIS

COMERCIO/OTICA

COMERCIO/PAPELARIA

COMERCIO/ROUPAS

TIPO DE ATIVIDADE/DESCRIÇÃO GERAL

COMÉRCIO GENÉRICO: LOJA EM GERAL, LOJA+NOME FANTASIA.

ATIVIDADE NÃO CLARA NA DESCRIÇÃO DO CAMPO DE ATIVIDADE. SE SÓ COMÉRCIO E/OU SÓ DE SERVIÇOS.

ATIVIDADE QUE PODE SER COMERCIAL E/OU DE SERVICOS.

COMÉRCIO EXCLUSIVO dE ÁGUA.

BOMBONIERI, DOCERIA, COMÉRCIO DE ALIMENTOS.

AÇOUgUe, CASA DE CARNES.

PADARIA.

COMÉRCIO de AUtOMOtIVOS EM GERAL: AGÊNCIA DE CARRO,

CONCESSIONÁRIA, VENDA DE AUTOMÓVEIS, MOTOS ETC.

COMÉRCIO DE ACESSÓRIOS E PEÇAS AUTOMOTIVAS EM GERAL.

Comércio de bebidAs: Adega, CASA do Vinho, Depósito de BEBIDAS.

COMÉRCIO DE MALAS, BOLSAS E ACESSÓRIOS.

COMÉRCIO dE CALÇADOS.

ComérCio de Combustível em Geral. Postos de GASOLINA, DE GÁs.

COMÉRCIO DE COSMÉtICOS E PERFUMARIA EM GERAL.

COMÉRCIO DE APARELHOS, ACESSÓRIOS E MATERIAL ELETRÔNICO E DE INFORMÁTICA EM GERAL.

COMÉRCIO DE MATERIAL ELÉTRICO, FERRAGENS, FERRAMENTAS, HIDRÁULICO, ILUMINAÇÃO EM GERAL.

DROGARIA, FARMÁCIA.

COMÉRCIO DE FLORES, FLORICULTURA.

COMÉRCIO ESPECIALIZADO EM INSTRUMENTOS MUSICAIS.

COMÉRCIO ESPECIALIZADO EM PRODUTOS DE LIMPEZA.

COMÉRCIO ESPECIALIZADO EM LIVROS, LIVRARIA, SEBOS.

LOJAS ESPECIALIZADAS EM MATERIAS PARA CONSTRUÇÃO, DEPÓSITO.

EMPÓRIOS, MERCADOS, SUPERMERCADOS, MERCADINHOS, MERCEARIAS.

LOJA ESPECIALIZADA EM MÓVEIS.

ÓtICA.

Papelaria.

COMERCIO/SERVICOS/ANIMAL

COMERCIO/SERVICOS/GALERIA COMERCIAL

COMERCIO/SERVICOS/INFORMATICA

COMÉRCIO ESPECIALIZADO EM ROUPAS, VESTUÁRIO EM GERAL, BRECHOS.

Comércio e/ou serviços para animais: Peth Shop,

VETERINÁRIO.

COMÉRCIO EM GERAL EM GALERIAS COMERCIAIS.

COMÉRCIO E/OU SERVIÇOS DE INFORMÁTICA. QUANDO NÃO CLARO

SE É COMERCIO OU SERVIÇO EXCLUSIVAMENTE OU AMBOS LIGADOS AO RAMO DE INFORMÁTICA.

COMERCIO/SERVICOS/VARIADOS

COMERCIO/SERVICOS/VEICULOS

INDUSTRIA

SHOPING, SHOPING CENTER, MINI SHOPING.

COMERCIALIZA E PRESTA SERVIÇOS AUTOMOTIVOS.

ATIVIDADE DESCRITA COMO INDUSTRIAL EM GERAL. QUANDO

DETALHADA É CLASSIFICADA COMO, POR EXEMPLO: INDUSTRIA/METALURGICA; INDUSTRIA/TECELAGEM

SERVICOS

SERVIÇO GENÉricos. Não detalHAdo OU NÃo CLARO. EXEMPLO:

OFICINA, SERVIÇO, STUDIO.

SERVICOS/ADMINISTRACAO/DIVERSOS

SERVICOS/ADMINISTRACAO/IMOVEIS

SERVICOS/ALIMENTOS/BEBIDAS

ATIVIDADE DE ADMINISTRAÇÃo EM GERAL. NÃO DETALHADO.

ATIVIDADE DE ADMINISTRAÇÃO DE IMÓVEIS EM GERAL.

Bar, LANCHONETE, BoteCo, RestauRANTE, BAR E CAFÉ, BAR E

Restaurante, Lanchonete E Restaurante, Casa do Queijo,

Cafeteria, Casa do Suco, Churrascaria.

SERVICOS/ALIMENTOS/PIZZARIA

SERVICOS/ADMINISTRACAO/ORGAO PUBLICO

PIZZARIA.

SERVIÇOS Públicos [eXCETO CULTURAIS, RECREATIVOS, DESPORTIVOS, EDUCAÇÃO, SAÚDE E SEGURANÇA] EXEMPLO: CORPO De Bombeiro, Secretarias do Estado/Prefeitura, Órgão PÚBLICO.

SERVICOS/ARMAZEM/DEPOSITO/BARRACAO/GALPAO/ALMOXARIFADO

Descritas genericamente como: ARmazém, depósito, BARRACÃO, GALPÃO, ALMOXARIFADO, ESTOQUE/GUARDA DE MERCADORIAS/PRODUTOS. 


\section{SERVICOS/ATIVIDADE/POLITICA/PARTIDARIA}

SERVICOS/ATIVIDADES/ASSOCIATIVAS

SERVICOS/ATIVIDADES/CULTURAIS

SERVICOS/ATIVIDADES/DESPORTIVAS/RECREATIVAS

SERVICOS/AUTOMOTIVOS

\section{SERVICOS/AUTOMOTIVOS/ESTACIONAMENTO} SERVICOS/COMUNICACAO

\begin{tabular}{l} 
SERVICOS/CONSTRUCAO \\
SERVICOS/CONTABEIS \\
\hline SERVICOS/COPIADORA \\
SERVICOS/CORREIO \\
SERVICOS/DESPACHANTE \\
SERVICOS/EDUCACAO
\end{tabular}

SERVICOS/ESTUDIO
SERVICOS/EXPORTACAO/IMPORTACAO
SERVICOS/FESTAS/EVENTOS
SERVICOS/FINANCEIROS
SERVICOS/GRAFICOS
SERVICOS/HOSPEDAGEM
SERVICOS/JURIDICOS
SERVICOS/LAN HOUSE
SERVICOS/LIMPEZA
SERVICOS/LOTERICA
SERVICOS/MOTO BOY
SERVICOS/OUTROS
SERVICOS/PESSOAIS

SERVICOS/PESSOAIS/MARCENARIA SERVICOS/PUBLICIDADE/PROPAGANDAS SERVICOS/PUBLICOS

\section{SERVICOS/PUBLICO/SEGURANCA SERVICOS/RELIGIOSOS}

SERVICOS/RELIGIOSOS/IGREJA SERVICOS/SAUDE

\section{SERVICOS/SOCIAIS \\ SERVICOS/TECNICOS/TECNOLOGICOS \\ SERVICOS/TELEMARKETING SERVICOS/TRANSPORTES/LOGISTICA}

SERVICOS/TURISMO SERVICOS/VESTUARIO
GERAL, DE MAQUINÁRIOS/ELETRO-ELETRÔNICOS, ETC.

DiRETÓRIO de PARTIDOS POLÍtICOS, COMITES ELEITORAIS, ESCRITÓRIO POLÍTICO.

ASSOCIAÇÕES/COOPERATIVAS PROFISSIONAIS, DE AMIGOS DO BAIRRO, MORADORES, BENEFICIENTE, SINDICATOS/FEDERAÇÕES DE TRABALHADORES E PATRONAIS.

Bibliotecas, Cinema, Teatro, Show, Espaços Culturais [Centros, Galerias de arte], Museus.

CLUBES RECREATIVOS, ESPORTIVOS, QUADRA DE ESPORTES EM GERAL.

SERVIÇOS AUTOMOtIVOS EM GeRAL: AUTO-ELÉTRICO, FUNILARIA, OFICINA MECÂNICA, BORRACHARIA, LAVA RÁPIDA.

ESTACIONAMENTO PARA AUTOMÓVEIS/MOTOS.

ÓRGÃo dE COMUNICAÇÃo JORNALISTICA, RÁDIO, TELEVISÃO, ASSESSSORIAS DE IMPRENSA.

CONSTRUTURAS, EMPREITEIRAS, ATIVIDADES LIGADA AO SETOR DE CONSTRUÇÃO EM GERAL.

SERVIÇOS DE CONTABILIDADE EM GERAL.

SERVIÇOS DE CÓPIA DE DOCUMENTOS EM GERAL.

CORREIO

\section{DESPACHANTE}

ESCOLAS DO ENSINO BÁSICO, CRECHES, ENSINO FUNDAMENTAL, MÉDIO - PÚBLICAS E PRIVADAS; FACULDADES, UNIVERSIDADES, CENTRO de Estudos, CuRsinHos, Escolas de IDIOMAS EM Geral. ESTUDIOS DE ARTE, DANÇAS, DESIGNER, GRAVAÇÃO, MUSICA, PINTURA, FOTOGRÁFICO.

SERVIÇOS DE EXPORTAÇÃO E IMPORTAÇÃO EM GERAL.

BUFFET, BUFFET INFANTIL, CASA DE EVENTOS, SALÃO DE FESTAS E EVENTOS.

BANCOS, INSTITUIÇÕES DO MERCADO FINANCEIRO EM GERAL.

GRÁFICA, COMPUTAÇÃO GRÁFICA.

Hotel, Pensão, República estudantil.

ADVOGADOS, ESCRITÓRIOS DE ADVOCACIA.

LAN HOUSE

RAMO QUE PRESTA SERVIÇO DE LIMPEZA EM GERAL.

LOTERICA

SERVIÇOS DE ENTREGA POR MEIO DE MOTOS.

Boate, Casa de Shown, Cabaré, Casa noturna,

Academia, Lavanderia, Barbearia, Cabeleireiro, Chaveiro,

Clinica de Estética , Salão de Beleza, Depilação, Massagem.

SERVIÇOS DE MARCENARIA, MARCENEIRO, CARPINTARIA.

AgênCIa de Publicidade, Propaganda, Marketing.

TODO SERVIÇO PÚBLICO/ÓRGÃO PÚBLICO EXCETO OS CLASSIFICADOS COMO SERVIÇOS CULTURAIS, DESPORTIVO, CORREIO, EDUCAÇÃO, SAÚDE E SEGURANÇA NAS ESFERAS FEDERAL, ESTADUAL E MUNICIPAL.

Delegacia Policial, Batalhão, Quartel da Polícia Militar. Centro Espirita, Comunidade Judaica, Centros Pastorais CATÓLICOS, TEMPLOS BUDISTAS, UMBANDA, CANDOMBLÉ. DESCRITA COMO IGREJA EM GERAL. Serviços ligados a saúde. Hospitais, Clínica MÉdica, ODONTOLÓGICAS, CONSULTÓRIO MÉDICO, ODONTOLÓGICO, CLÍNICAS DE EXAME LABORATORIAL, PSICOLOGOS, PSQUIATRAS, UNIDADES BásICAS de SAÚdE.

ORGANIZAÇÕES LIGADAS A SERVIÇOS SOCIAIS, ASSISTENCIAIS, ONGs.

SERVIÇOS LIGADAS A ENGENHARIA, ARQUITETURA, TECNOLOGIA DA INFORMAÇÃO, CONSULTORIA EM INFORMÁTICA

SERVIÇOS DE TELEMARKETING

SERVIÇOS LIGADAS AO RAMOS DE TRANSPORTES EM GERAL E LOGISTICA.

AGÊNCIA DE TURISMO, VIAGEM.

SERVIÇOS LIGADOS AO RAMOS DE VESTUÁRIO EM GERAL:

Costureira, Alfaitaria, oficina de costura, atelie de COSTURA. 


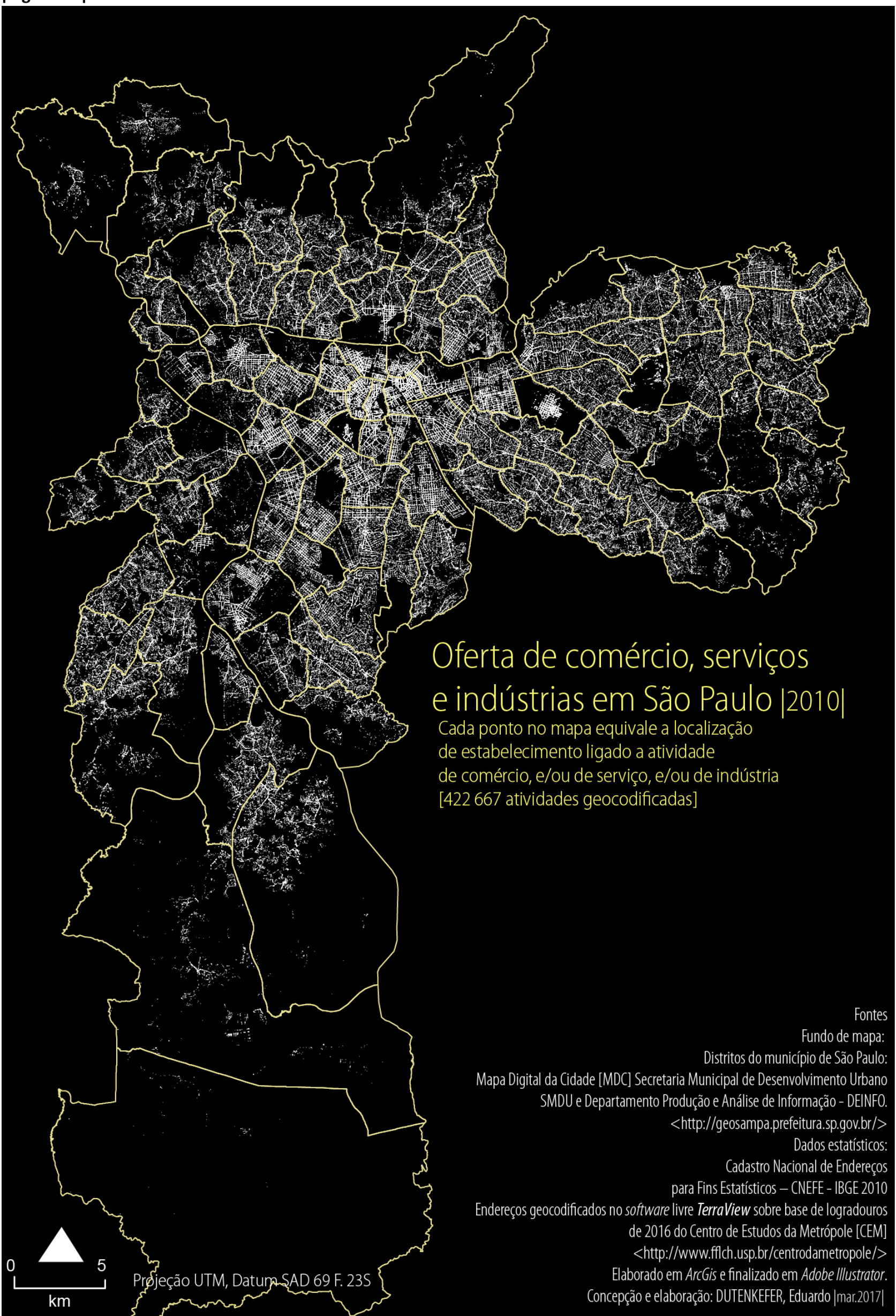




\section{2 - Os blocos ativos da urbanidade - método cartográfico de duas variáveis}

Com esta amostra de 422.667 endereços geocodificados podemos estabelecer as principais funções não residenciais no município de São Paulo. Mas o que queremos aqui é cruzar densidades e diversidades. Iremos agora apresentar uma representação cartográfica que permite apreender o cruzamento de duas variáveis.

Continuamos na opção de um fundo de mapa em "quadrados". Utilizamos a grade estatística do IBGE e nestas grelhas contamos o número de estabelecimentos não residenciais em cada célula proposta pelo IBGE, no recorte do município de São Paulo.

A proposta é elaborar uma representação cartográfica que permita revelar, evidenciar visualmente as concentrações de duas densidades; o número de domicílios presentes nas células da grade estatística do IBGE e a quantidade de atividades também presentes em cada célula da grade. Em tese, uma grande quantidade de estabelecimentos em cada célula também pode representar uma grande quantidade de funções econômicas diversas. Teremos assim um cruzamento de densidades residenciais com diversidades de funções não residenciais.

Na figura 27 é representado o que denominamos de "oferta de comércio, serviços e indústrias". Estas "ofertas" só fazem sentido quando confrontadas com as populações que delas se beneficiam. Urbanidade é também o confronto de oferta e demanda. É cotejar demandas e ofertas que o ser social necessita para sua vida em cidades. Níveis de concentrações que dão vida, uma particularidade essencial para uma cidade - os humanos e seus lares - com aglomerações e diversidades de substâncias que contribuem na construção deste espaço - o espaço urbano de uma cidade.

Para termos o número de atividades não residenciais expressos em cada célula optamos por utilizar uma função presente em aplicativos de SIG: "join data from another layer based on spatial location 54", ou seja, agregar, juntar dados de outra camada baseado em sua localização espacial. Quando o aplicativo executa essa função ele conta os elementos presentes na intersecção da camada fonte com a camada destino. Em nosso caso temos um "layer" em formato shapefile da grade estatística do IBGE em formato de superfície; polígonos quadrados de 200 X 200 m e 1 X 1 km e outra camada, em formato de ponto, dos endereços das atividades não residenciais. Quando executamos essa função teremos como resultado o número de pontos totais presentes em cada célula de nossa grade estatística. Eles são agregados à tabela de nosso shapefile da grade. Executamos a função primordial do método

\footnotetext{
${ }^{54}$ Opção presente no software ArcGis da ESRI utilizado.
} 
carroyage, como já salientado por Brunet (1987) anteriormente e contamos o número de objetos geográficos presentes em cada célula de nossa grade estatística - figura 28.

|Figura 28| Agregando dados de uma camada de pontos para uma camada de superfície [polígonos]
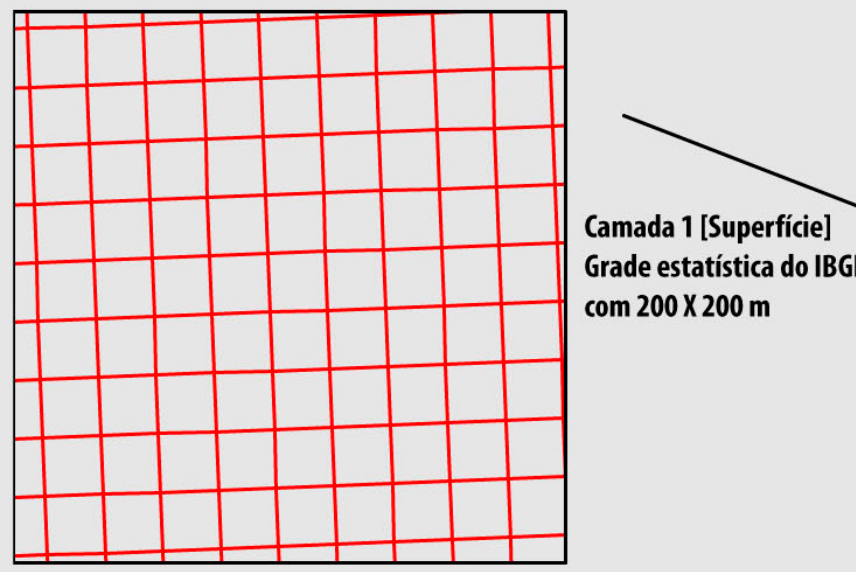
Grade estatística do IBGE com $200 \times 200 \mathrm{~m}$

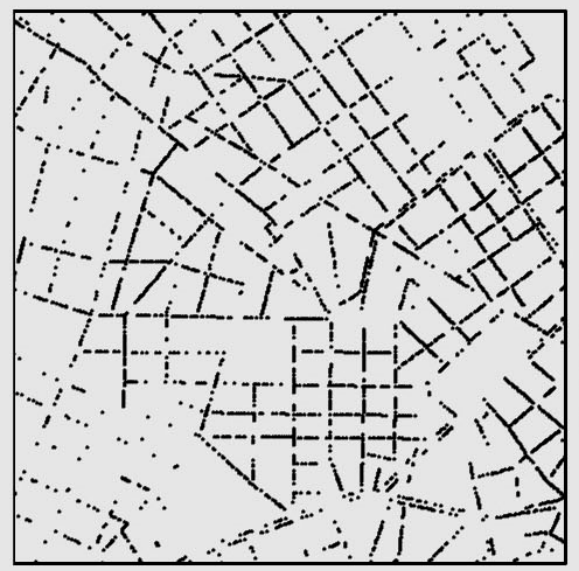

\section{Camada 2 [Pontos]}

Localização das atividades não residenciais

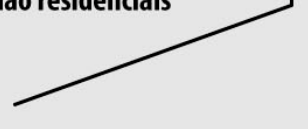

Os pontos são contados e transformados em número inteiro e incorporados na tabela dos atributos da camada 1 [superfície]. Representação em células de $200 \times 200 \mathrm{~m}$ com $50 \%$ de transparência sobreposta a camada 2.

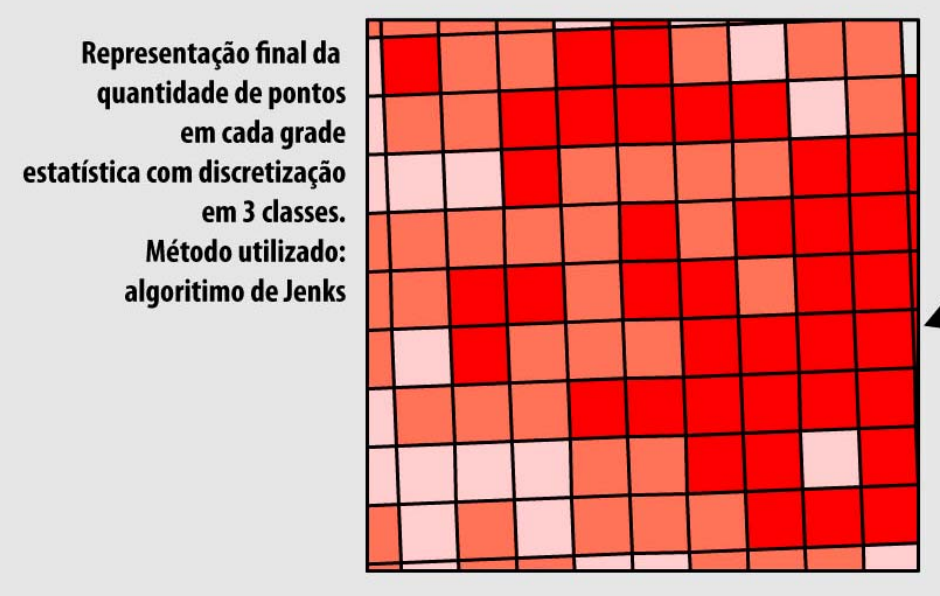

Agregando a camada 1

[Polígonos]

com a camada 2 [pontos]
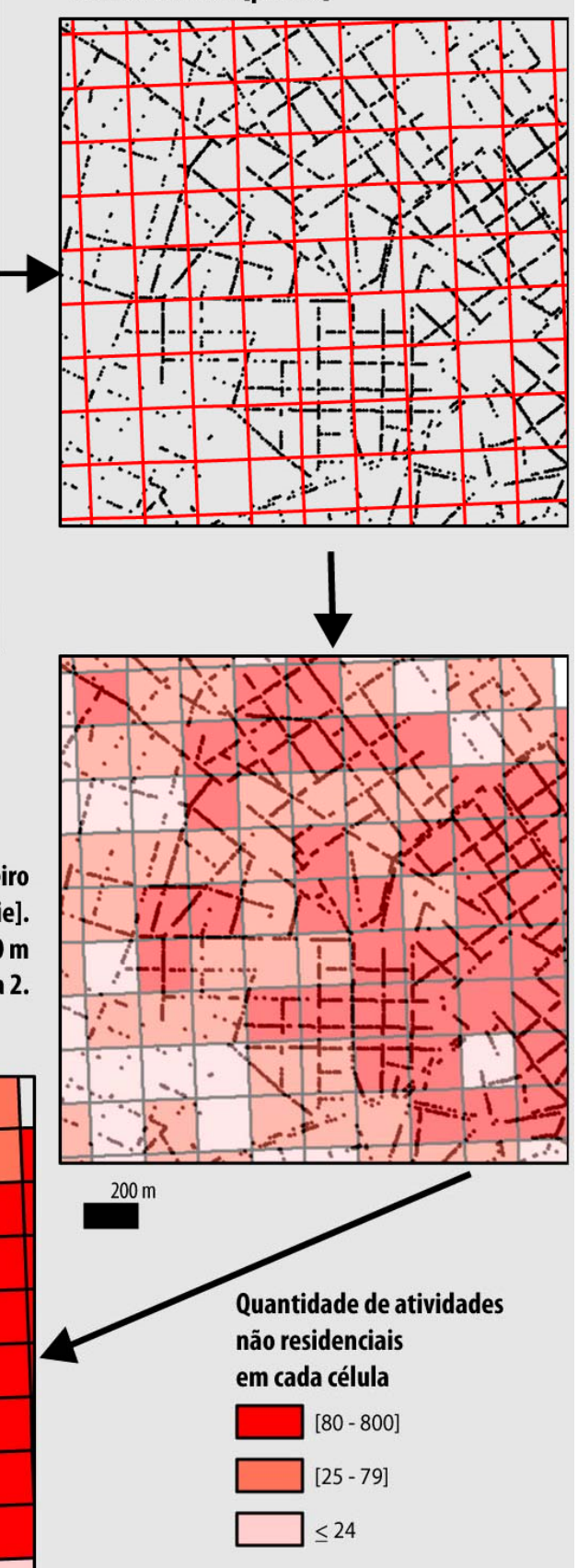

Elaborado em Adobe lllustrator. DUTENKEFER, Eduardo jun. 2017|

Agregamos a grade estatística do IBGE - que já conta com o número de habitantes e o número de domicílios ocupados - com a quantidade de atividades não residenciais. É uma oportunidade de relacionar domicílios e atividades, ou seja, número de atividades residenciais 
e não residenciais. Relacionar densidades de habitações humanas, densidades e diversidades de atividades humanas ligadas a dimensões comerciais, de serviços e industriais. Trabalhar com duas variáveis em uma única representação, em um mesmo mapa. Na literatura cartográfica encontraremos o método, por exemplo, na forma de representação cartográfica coroplética com duas variáveis ou - bivariate choropleth map - "mapa coroplético bivariado". Elmer (2012, p. 3) salienta: “Um mapa bivariado é, pela sua natureza, visualmente mais complexo do que um mapa univariado". A "complexidade" visual com a qual deparamos é com a composição visual que as duas variáveis formam no mapa. Na figura 29 sintetizamos o método por nós utilizado ${ }^{55}$. Elaboramos isoladamente cada variável em três classes de discretização com o algoritmo de Jenks. Estabelecemos o limite de 9 classes $^{56}$ de discretização com a composição das duas variáveis, para obtermos 3 classes expressivas que revelassem densidades de domicílios e atividades. Na figura 30 temos a representação cartográfica do método utilizado. Denominamos de "blocos ativos de urbanidade". É o mapa como uma imagem que revela visualmente "blocos", "células", "grades" que potencialmente podem demonstrar níveis, gradientes, graus mais ativos, menos ativos e com média atividade de habitações humanas e funções econômicas exercidas pela sociedade urbana em uma cidade [figura 30, imagem 30.1]; níveis de densidades e diversidades com dados quantitativos compostos pelos números de domicílios ocupados [figura 30 - imagem 30.2] e números de estabelecimentos com funções não habitacionais [figura 30 - imagem 30.3].

$\mathrm{Na}$ figura 31 representamos o mapa síntese destes níveis. Estabelecemos três hierarquias: baixa, média e alta influência residencial e não residencial na urbanidade de uma cidade. O mapa revelando as localizações, os "blocos" que influenciam, predomina neste recorte escalar de São Paulo. Na imagem 31.1 da figura 31 representamos o resultado mais expressivo de nosso mapa bivariado da figura 30 - a diagonal da composição das duas classes de variáveis utilizadas.

\footnotetext{
${ }^{55}$ Outras referências sobre o método bivariado podemos encontrar em:

<http://www.joshuastevens.net/cartography/make-a-bivariate-choropleth-map/> Acesso: 10/03/2017; <http://www.personal.psu.edu/cab38/ColorSch/SchHTMLs/CBColorSeqSeq.html> Acesso: 12/03/2017; <https://www.slideshare.net/aileenbuckley/arc-gis-bivariate-mapping-tools-28903069> Acesso: 12/03/2017

${ }^{56}$ Já apontada na página 44 e adotada aqui segundo “Cauvin et al (1987 e 2008a) -“..e até 10 se o mapa for utilizado particularmente pelo pesquisador".
} 
|Figura 29| Esquema sintético da elaboração de um mapa coroplético com duas variáveis ["bivariado"]

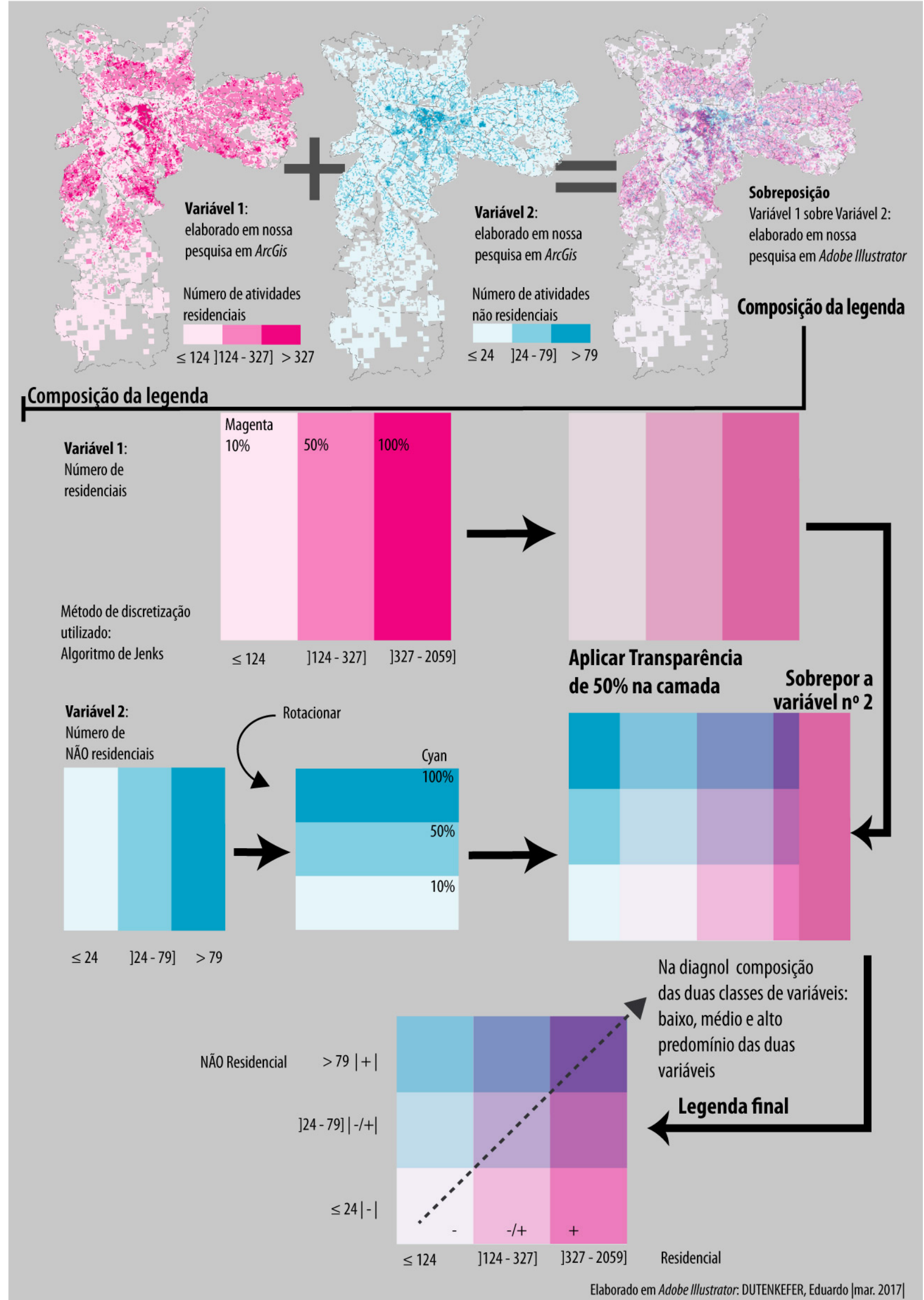




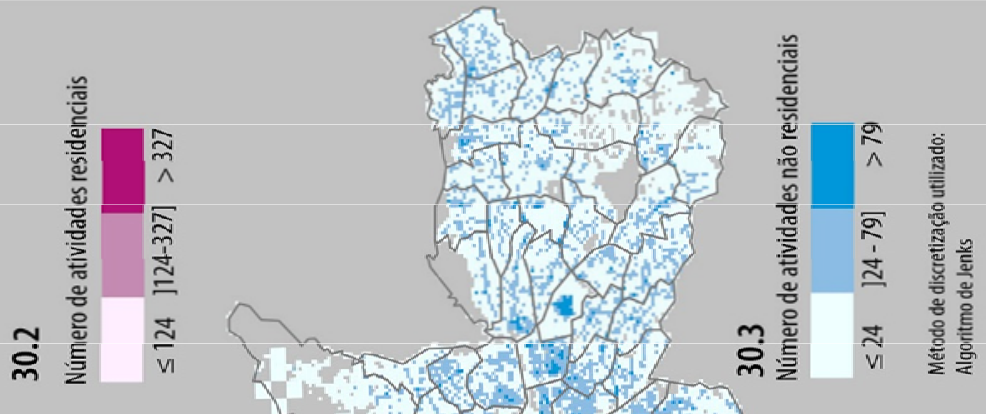

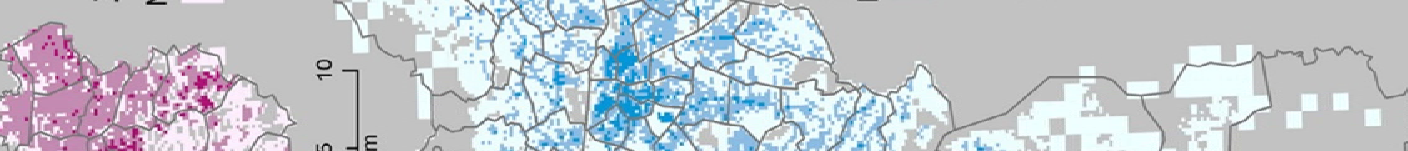

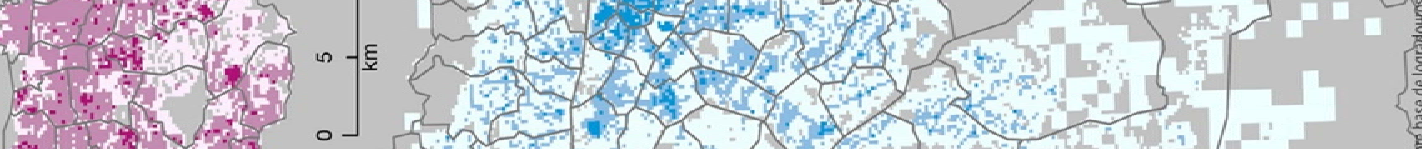
3.140 3503

Hom $3 \%$

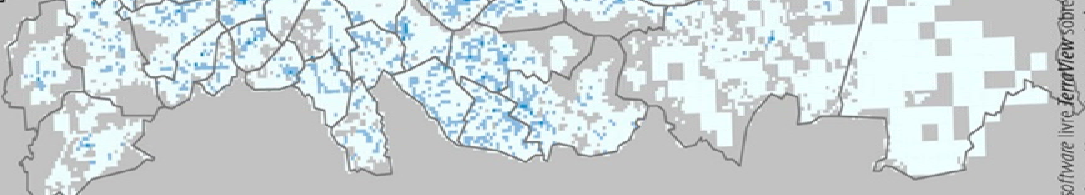

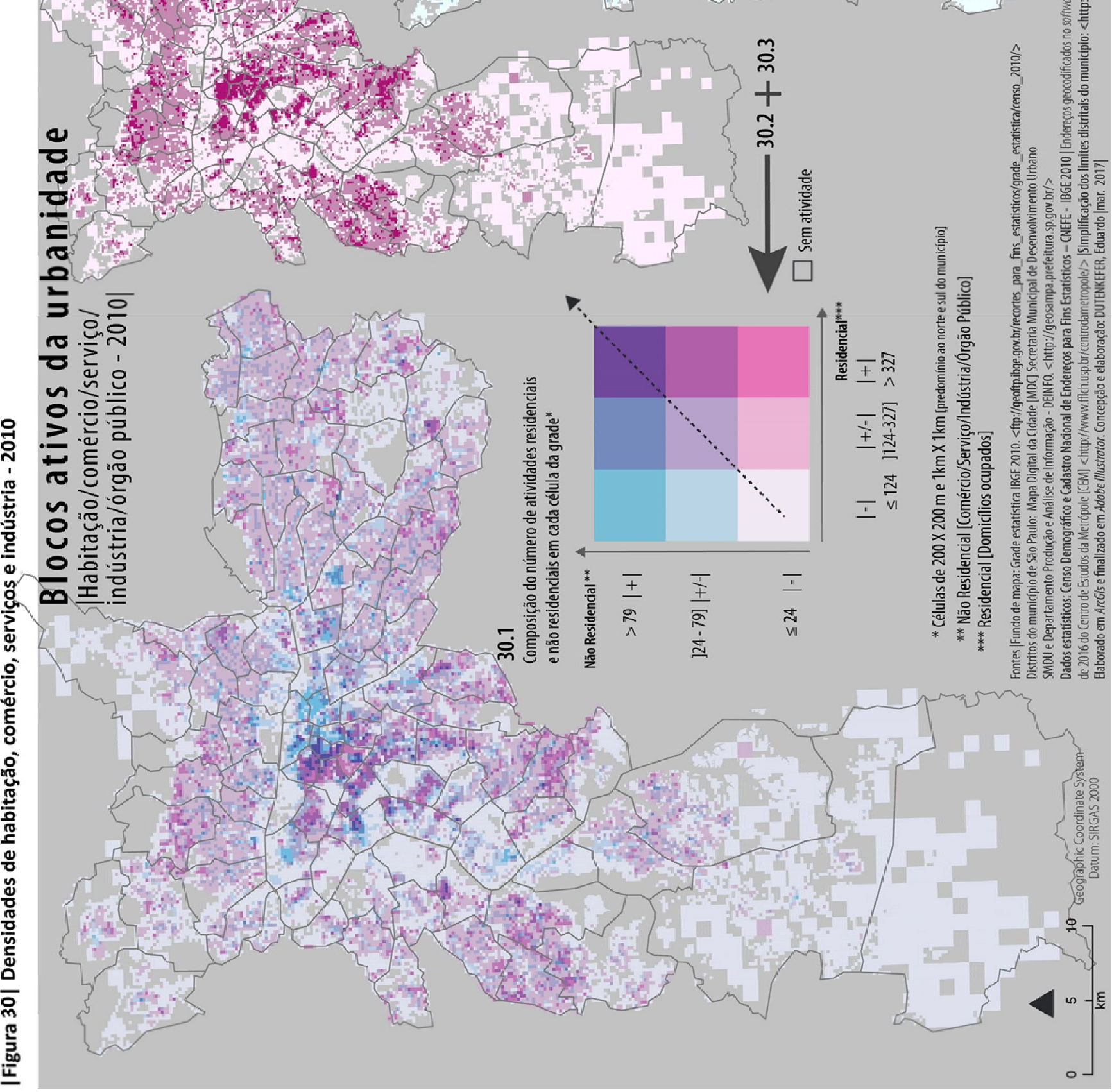




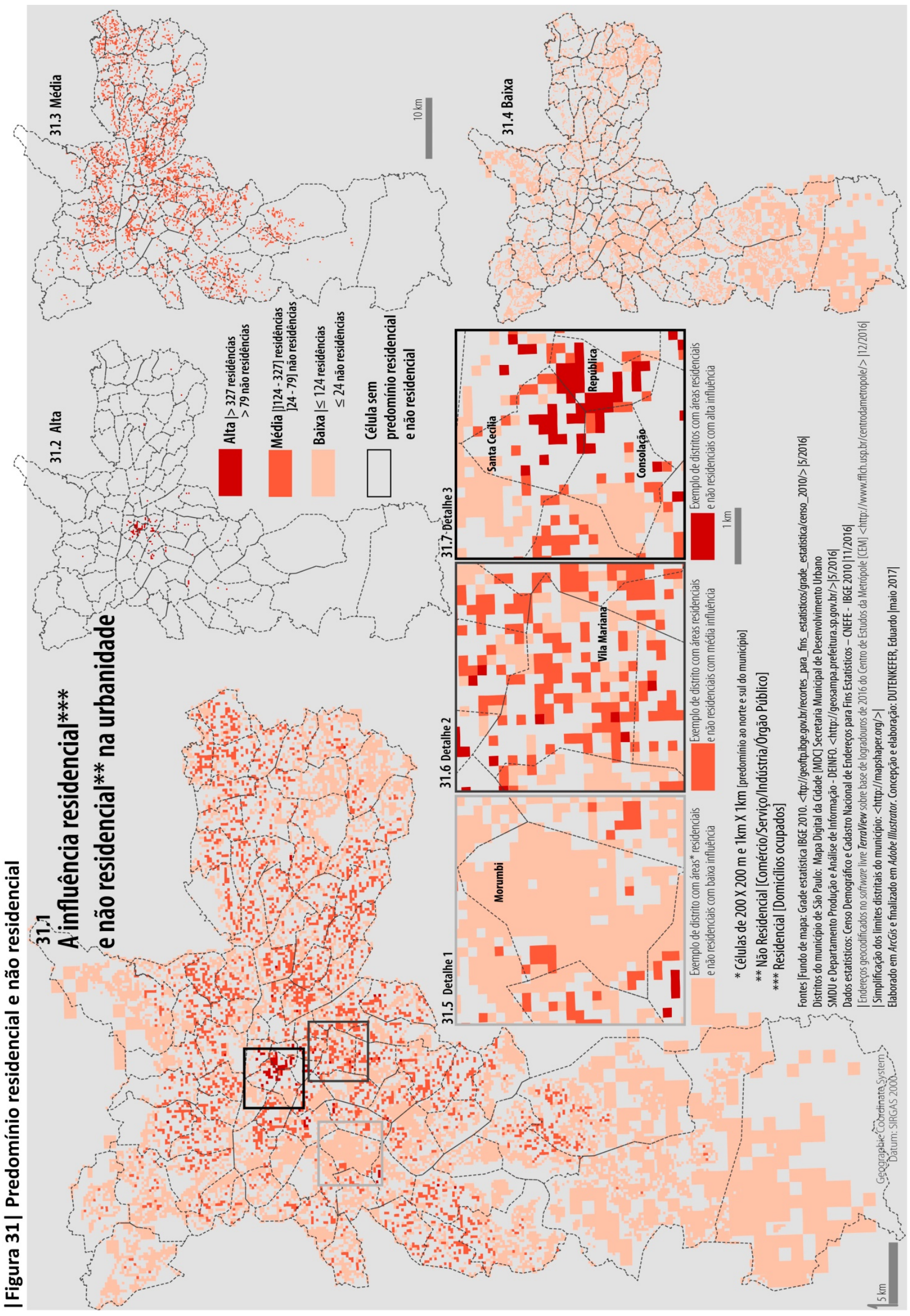


Nas imagens 31.2, 31.3 e 31.4 da figura 31representamos isoladamente estas três potencialidades que São Paulo oferece de urbanidade aos seus habitantes. Em 31.2 - Alta - é evidente a concentração desta qualidade - a urbanidade - gritante visualmente nesta imagem da área central do município. "Blocos" expressivos localizados ao redor do limite administrativo dos distritos de Santa Cecília e Consolação, com o limite do distrito República. É importante lembrar que o mapa com o método do anticartograma da figura 17 [A urbanidade fragmentada de São Paulo] já apontava indícios potenciais destas concentrações apenas pelo indicador de densidade de população. Em 31.3 temos áreas mais dispersas com níveis médios de concentrações residenciais e não residenciais. Um eixo mais ao norte em relação ao núcleo esboçado em 31.2, separado por uma faixa sem predomínio residencial e não residencial marcado pelo curso que o Rio Tiete percorre no município de São Paulo.

Tomando emprestado do saudoso professor Aziz Nacib Ab'Saber os conceitos de "área nuclear" ou "área Core", outro eixo, em relação a nossa área que podemos denominar de "Core" [área Core] "caminha" de sudeste a leste. Ao oeste e sudoeste fragmentos mais espaçados e separados pelo eixo do curso das águas do rio Pinheiros. Ao sul visualizamos fragmentos nos distritos de Socorro e Grajau. Em 31.4, com baixo nível, o restante do município com blocos menos intensos de urbanidade espalhados, na periferia da área Core.

Ainda na figura 31 isolamos, nas imagens 31.5, 31.6 e 31.7, detalhes de três áreas representativas como exemplo de distritos com baixa: Morumbi; média: Vila Mariana e alta: Consolação, República e Santa Cecília [área Core], densas e diversas de atividades comerciais, industriais e de serviços. Estas três áreas representativas serão mapeadas em seus detalhes na escala intraurbana, na sequência.

\section{3 - O recorte intraurbano como exemplo de densidades e diversidades expressivas}

0 recorte que a sequência metodológica dos mapas das figuras 30 e 31 revelaram, proporcionou a elaboração de outra sequência de mapas na escala intraurbana, que evidenciam detalhes de quadras e ruas que podemos flanar e experimentar em nossa escala humana diariamente em uma cidade.

Elaboramos 96 representações cartográficas espalhadas em 8 pranchas - figuras 32 a 38 - em formato para impressão em A3. A intenção foi de proporcionar ao leitor um olhar que possibilitasse a comparação visual entre os vários mapas presentes em cada prancha. São detalhes das densidades populacionais, residenciais e não residências presentes nesta amostra que os dados proporcionaram. 
Outra forma de apresentação e caracterização geral dos distritos escolhidos nesta pesquisa está representada na figura 31-A. A representação em formato gráfico é um aliado importante que contribui para o poder de síntese que os mapas propiciam e as diversas imagens que elaborações em formas gráficas proporcionam. Os gráficos são instrumentos gráficos e aqui oferecemos um instrumento onde podemos visualizar 4 informações: no eixo $\boldsymbol{Y}$ temos o número de atividades não residenciais, no $\boldsymbol{X}$ o nome dos distritos, os círculos são proporcionais ao número de domicílios totais recenseados em 2010 e, mais abaixo, incluímos as áreas de cada distrito. Nesta representação temos áreas territoriais bem próximas, com uma média em torno de $10 \mathrm{~km}^{2}$. Não era nossa intenção mostrar exemplos de espaços territoriais próximos em métricas euclidianas. Os mapas e esta sequência metodológica até aqui desenvolvida, permitiram revelar estes exemplos de relações entre a cidade e sua qualificação maior, que é a sua urbanidade. Distâncias territoriais próximas, mas com distâncias não euclidianas bem diferentes entre si.

|Figura 31 A| Número de atividades não residenciais e número de domicílios por distrito

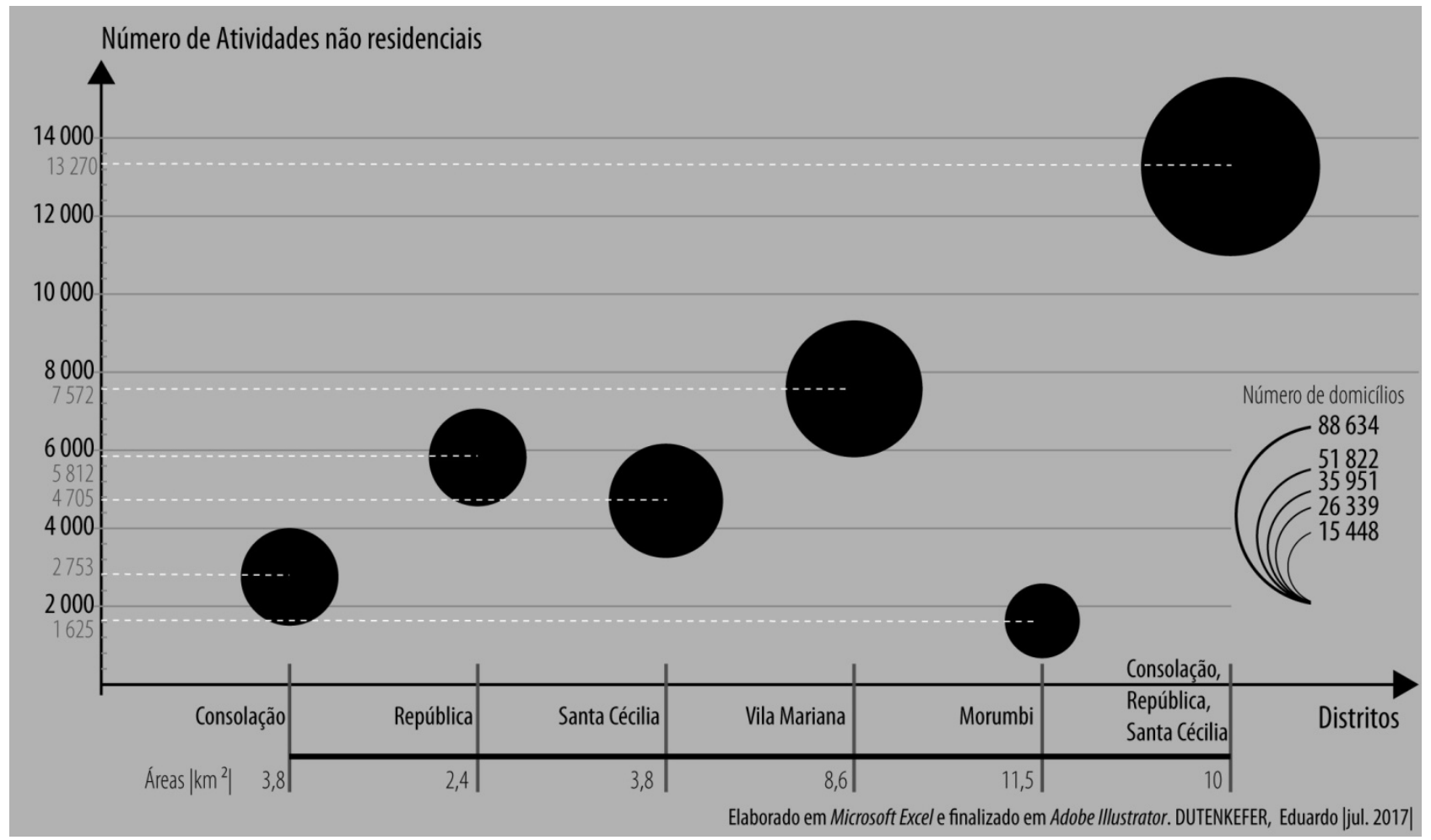

O gráfico reforça e evidencia o número de domicílios e os números de atividades nos distritos escolhidos como exemplo. Alto predomínio de residências e não residências na Consolação, República e Santa Cecília, média na Vila Mariana e baixa no Morumbi.

Na figura 32 e 32-A, estão representadas algumas características das áreas por nós elencadas como exemplo de uma hierarquia de baixas, médias e altas densidades e diversidades. Nas imagens 32.1, 32.2 e 32.3 oferecemos o recorte dos distritos que 
representam graus destes níveis de urbanidade. A sequência das imagens em mapas em células - de 32.4 a 32.9 compõe a origem dos mapas de 32.1 a 32.3. Em 32.10 a 32.12 evidenciamos as densidades dos humanos que habitam estas "células". Admitindo que a maioria das atividades humanas seja realizada durante o dia e não à noite, este habitar nestas células, "blocos", são expressões quantitativas bem próximas, retratando quando estes habitantes estão a dormir em suas noites de sono.

$\mathrm{Na}$ figura 32-A esboçamos outras características importantes que compõem a urbanidade destas áreas na escala de quadras destes espaços. De 32A.1 a 32A.3 utilizamos a tipologia que os dados do cadastro Territorial e Predial, de Conservação e Limpeza ${ }^{57}$ (TPCL), originado da Secretaria Municipal de Finanças e Desenvolvimento Econômico da Prefeitura do Município de São Paulo, oferece. Eles retratam o predomínio em uso em cada quadra do município.

$\mathrm{Na}$ imagem de 32 A.1 temos evidências das atividades principais do distrito do Morumbi, um território essencialmente ocupado por residências horizontais de alto padrão. 0 distrito de Vila Mariana (32A.2), por outro lado, é marcado por residências verticais de médio a alto padrão. Em nossa área central - Consolação, Santa Cecília e República (32 A.3), a ocupação já é mais heterogênea. Áreas comerciais/serviços próximas de áreas residenciais verticais com predomínio de médio a alto padrão e poucas ocupações em residências horizontais.

De 32 A.4 a 32 A.6 as principais feições das quadras e os principais eixos viários são confrontados com as localizações de cada atividade não residencial. Na área compreendida pelos distritos de Consolação, República e Santa Cecília temos um total de 13.270 atividades não residenciais. Em Vila Mariana já cai para 7.572 e Morumbi com apenas 1.625. [quantidade de atividades disponível na figura 31 A e tabela3].

57 TPCL é um cadastro de base fiscal, com a finalidade de permitir o lançamento e a cobrança do Imposto Predial e Territorial Urbano (IPTU) sobre a propriedade imobiliária. Mais detalhes consultar: <http://infocidade.prefeitura.sp.gov.br/index.php?sub=notas\&cat=17\&titulo=Uso\%20do\%20Solo\%20Urbano\& subtit $=\% 20-\% 20$ Notas $\% 20 \mathrm{~T} \%$ E9cnicas $>$ 
|Figura 32| Algumas característcas de áreas como exemplos de baixas, médias e altas densidades e diversidades $n^{\circ} 1$

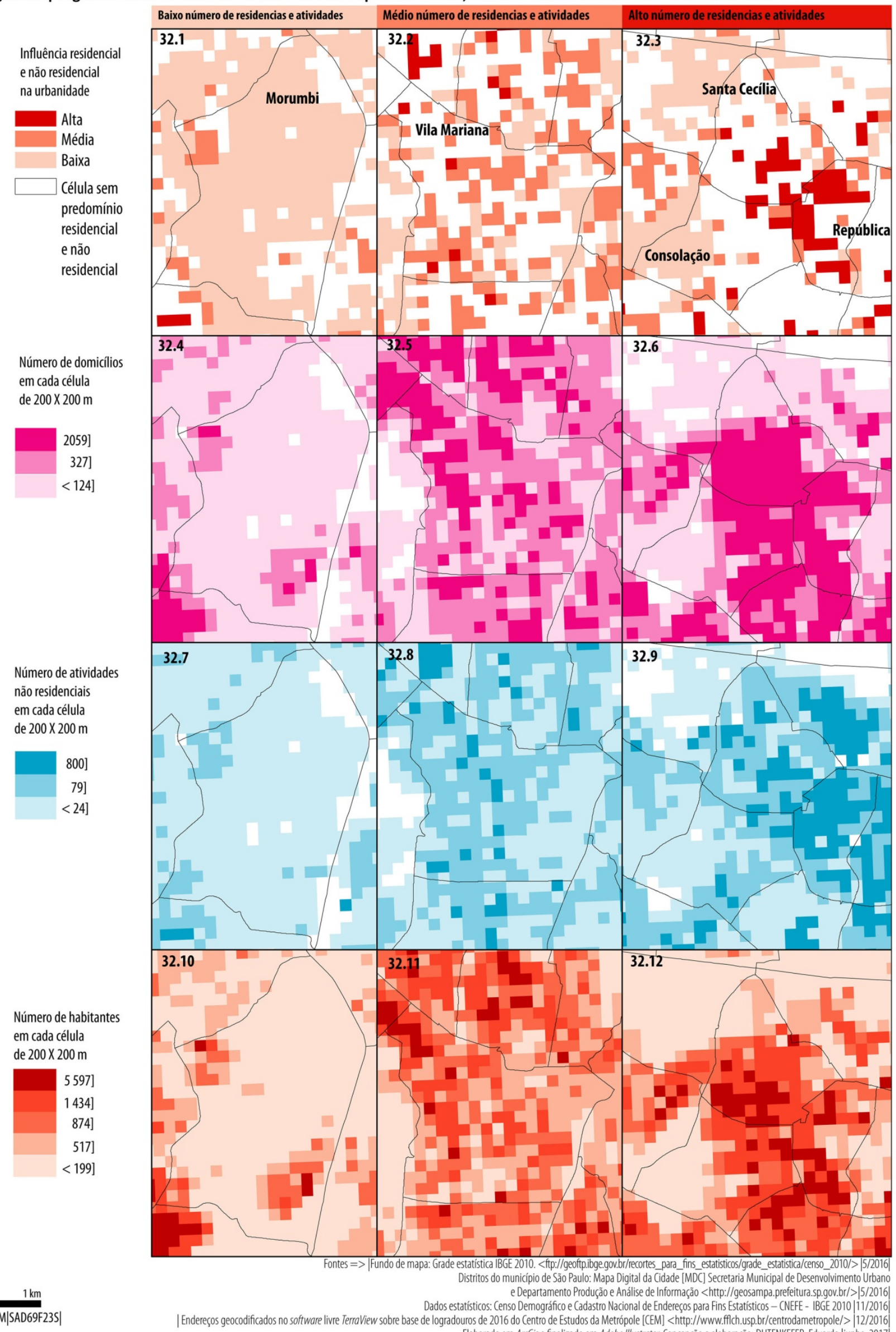


| Figura 32 - A | Algumas característcas de áreas como exemplos de baixas, médias e altas densidades e diversidades - $\mathrm{n}^{\circ} 2$

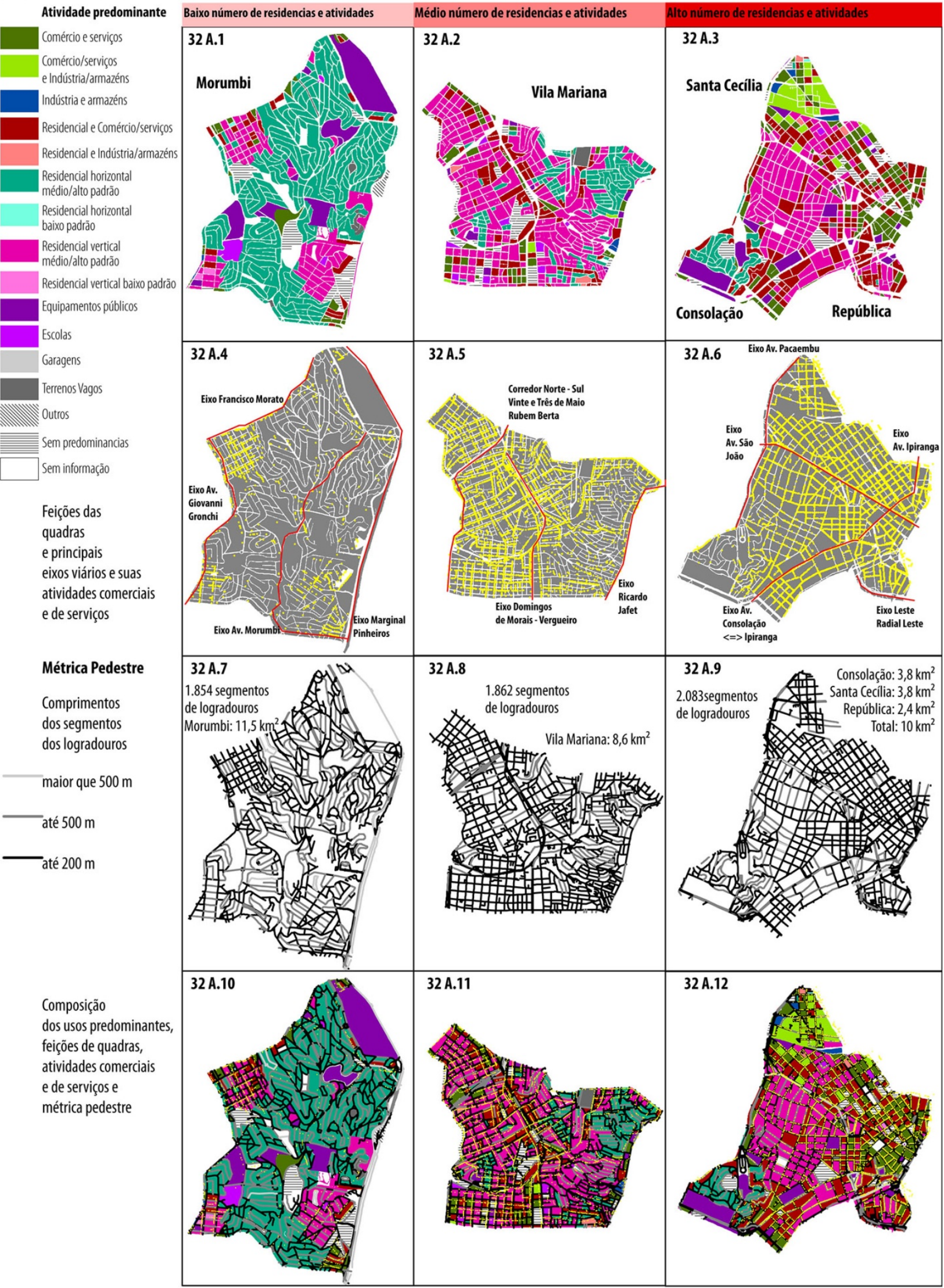

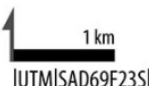

Fontes $\Rightarrow>$ Fundo de mapa: Distritos do município de São Paulo: Mapa Digital da Cidade [MDC] Secretaria Municipal de Desenvolvimento Urban e Departamento Produçăo e Análise de Informaçăo, Quadras, logradouros, uso predominante disponivel em: <http://geosampa.prefeitura.sp.gov.br/>|5/2016 Dados estatísticos: Cadastro Nacional de Endereços para Fins Estatísticos - CNEFE - IBGE 2010|11/2016

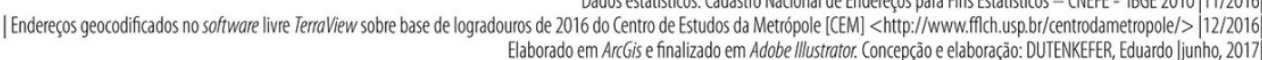


Em 32 A.7, 32 A.8 e 32 A.9, representamos os segmentos de logradouros presentes nas áreas exemplos. O urbanista Jan Gehl em seu livro "Cidades para Pessoas" escreve que a "distância aceitável de caminhada é um conceito relativamente fluido" (GEHL, 2015, p. 121). Uma caminhada em uma cidade depende da idade dos seus habitantes, dos obstáculos que encontra. A paisagem que irá percorrer é agradável? Em síntese; depende da qualidade que o percurso que enfrentaremos oferece aos nossos pés, cadeiras de rodas, bengalas... Jan Gehl ainda indica como aceitável uma distância de até 500 metros para nossas experiências caminháveis. Nesta sequência de mapas encontramos, de um modo geral, boa quantidade de ofertas de atividades não residenciais em logradouros que permitem uma caminhada de até $500 \mathrm{~m}$. Nas figuras 32 B alteramos a semiologia gráfica para uma melhor visualização da relação que afirmamos acima - atividades não residenciais e comprimento de logradouro. 0 comprimento do logradouro seria um indicador que permite avaliar o quanto estes espaços urbanos são receptivos em métrica pedestre, ou seja, que permitem aos moradores destas áreas ou cidadãos oriundos fora destes perímetros realizarem caminhadas não muito longas e demoradas, com a vantagem de ter várias opções de

|Figura 32 B| Logradouros e atividades não residenciais

\section{B.1}

Consolação: $3,8 \mathrm{~km}^{2}$ Santa Cecília: $3,8 \mathrm{~km}^{2}$ República: $2,4 \mathrm{~km}^{2}$ Total: $10 \mathrm{~km}^{2}$

2.083 segmentos de logradouros
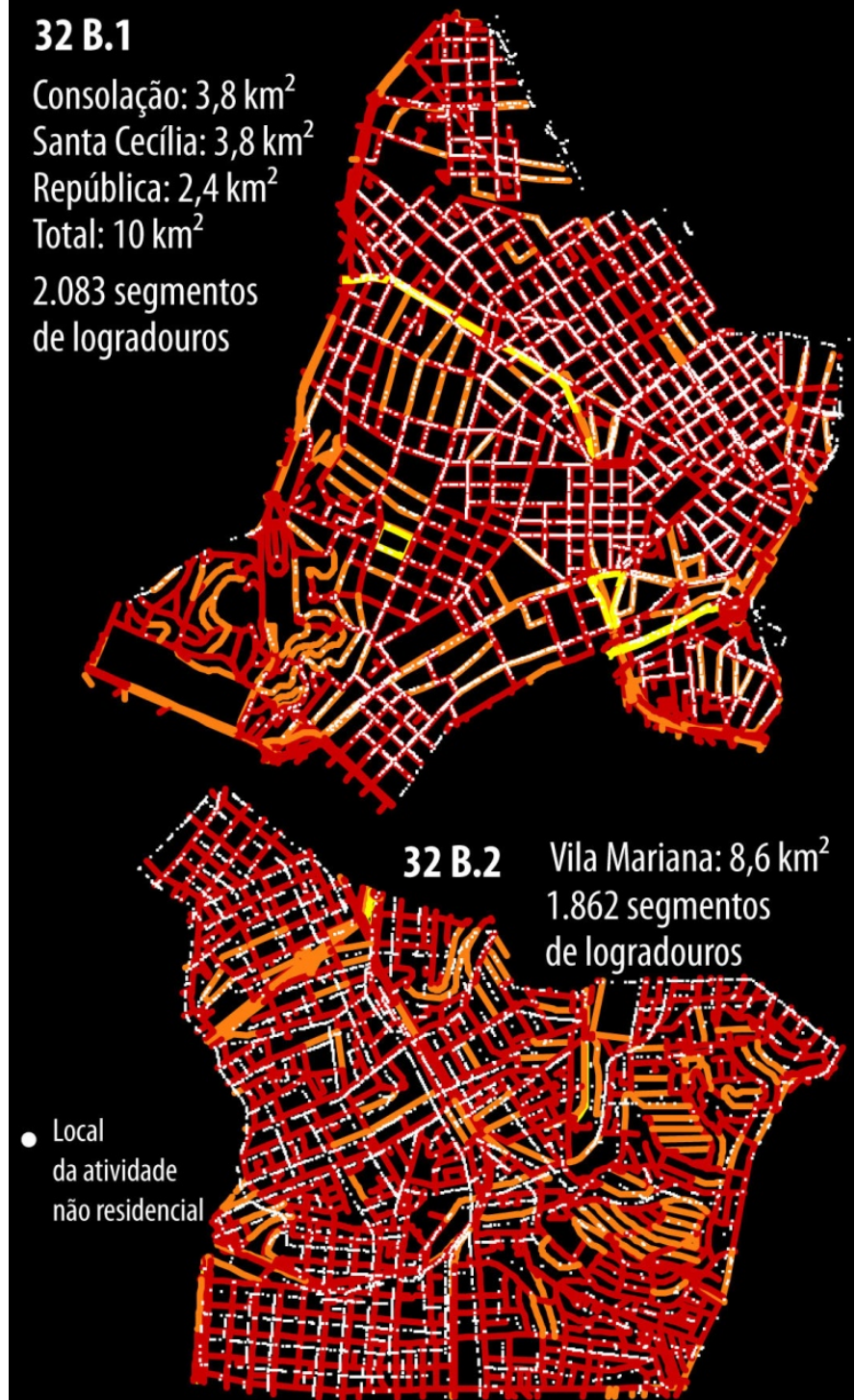

\section{B.3}

Morumbi: $11,5 \mathrm{~km}^{2}$ 1.854 segmentos de logradouros

Métrica Pedestre Comprimentos dos segmentos dos logradouros

_ maior que $500 \mathrm{~m}$

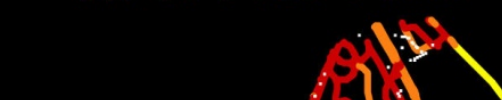

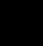

. (1) $1 / 1$ (N)

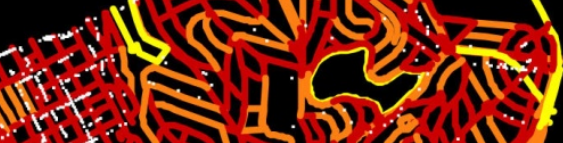
.

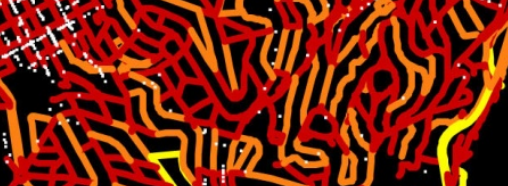

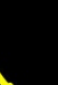


atividades comerciais e/ou de serviços. Estes comprimentos de logradouros refletem também o tamanho que cada quadra possui em um espaço urbano. Speck (2016) e Jacobs (2007) salientam a necessidade de que as quadras sejam os menores possíveis para permitir uma melhor caminhabilidade de seus usuários.

De modo geral, as cidades com menores quadras são as melhores no quesito caminhabilidade, enquanto aquelas com as maiores quadras são conhecidas como lugares sem vida nas ruas. (SPECK, 2016, p. 150)

A maioria das quadras deve ser curta; ou seja, as ruas e as oportunidades de virar esquinas devem ser frequentes. (JACOBS, 2007, p. 197)

Porque necessitamos de quadras menores? Uma das respostas é ter a possibilidade que o trajeto percorrido nestes espaços públicos seja o mais propenso a permitir maior sociabilidade entre os seres humanos!

Nas figuras 33 a 38 estão representadas as localizações espaciais de algumas atividades não residenciais que classificamos. Elaboramos pranchas com as diversas imagens das três áreas exemplos para comparação. Na figura 33 privilegiamos classificações mais genéricas, que não foram claramente identificadas e classificadas. 
|Figura 33| Comparando baixas, médias e altas densidades e diversidades - $\mathrm{n}^{\circ} 1$

\section{Comércio e/ou Serviços \\ [Atividade não \\ definida claramente] \\ - Comércio OU Serviços \\ - Comércio E/OU Serviços \\ - Comércio Variado \\ [loja, comércio, bazar] \\ Comércio e/ou Serviços \\ - Serviços E Comércio diversos \\ - Serviços E/OU Comércio Descrição genérica de: Centro Comercial \\ Edifício Comercial Prédio Comercial \\ - Descritas como "Galerias Comerciais" \\ A Shoping, Mini-Shoping}

\section{Serviços}

Indústria

- Serviço

[Genérico, não detalhado: ex.: Oficina,

serviço,

studio, etc.]

- Indústria em geral

UTM|SAD69F23S
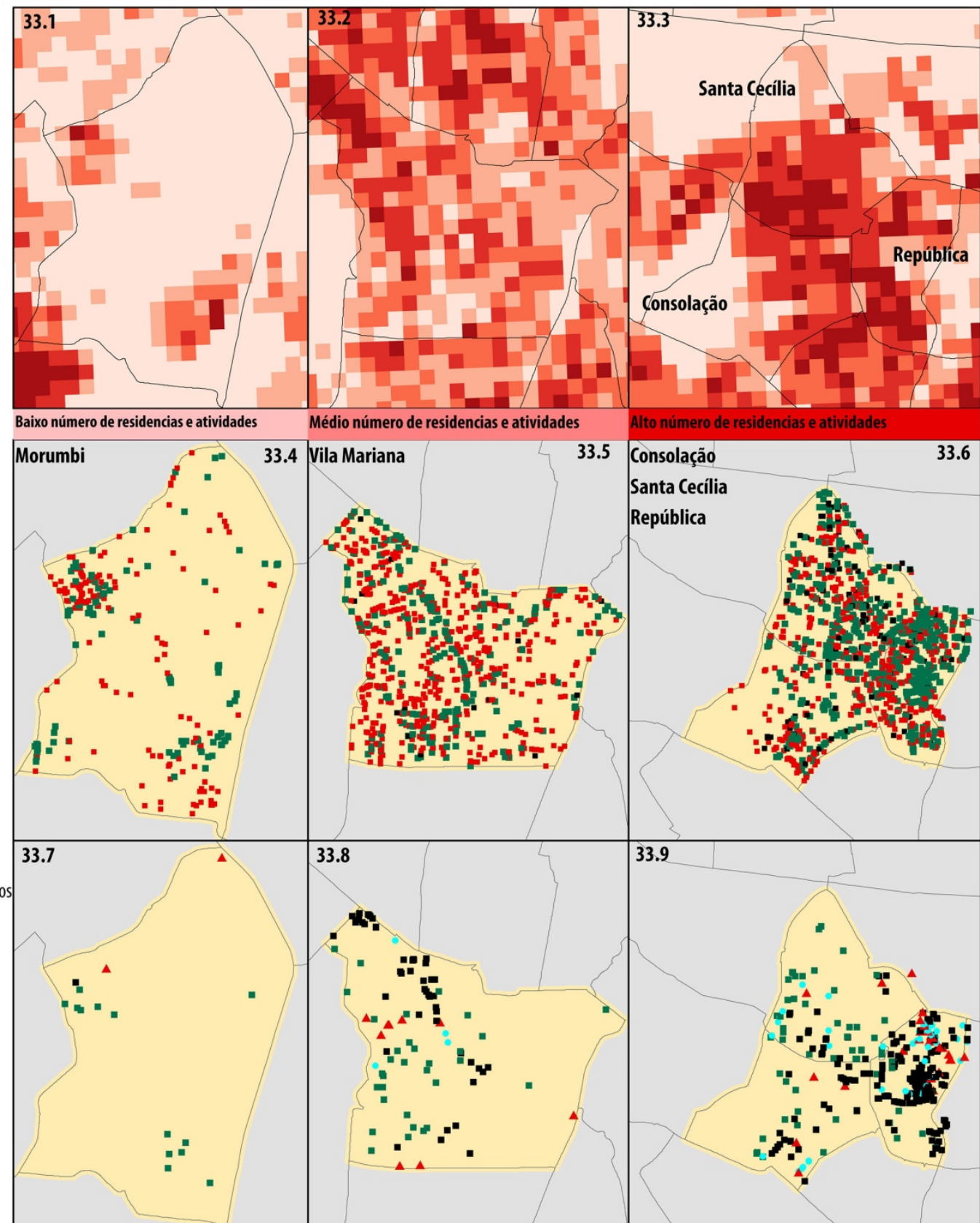

\begin{tabular}{l|l|l|l}
33.8 & 33.9 \\
\hline
\end{tabular}

33.9

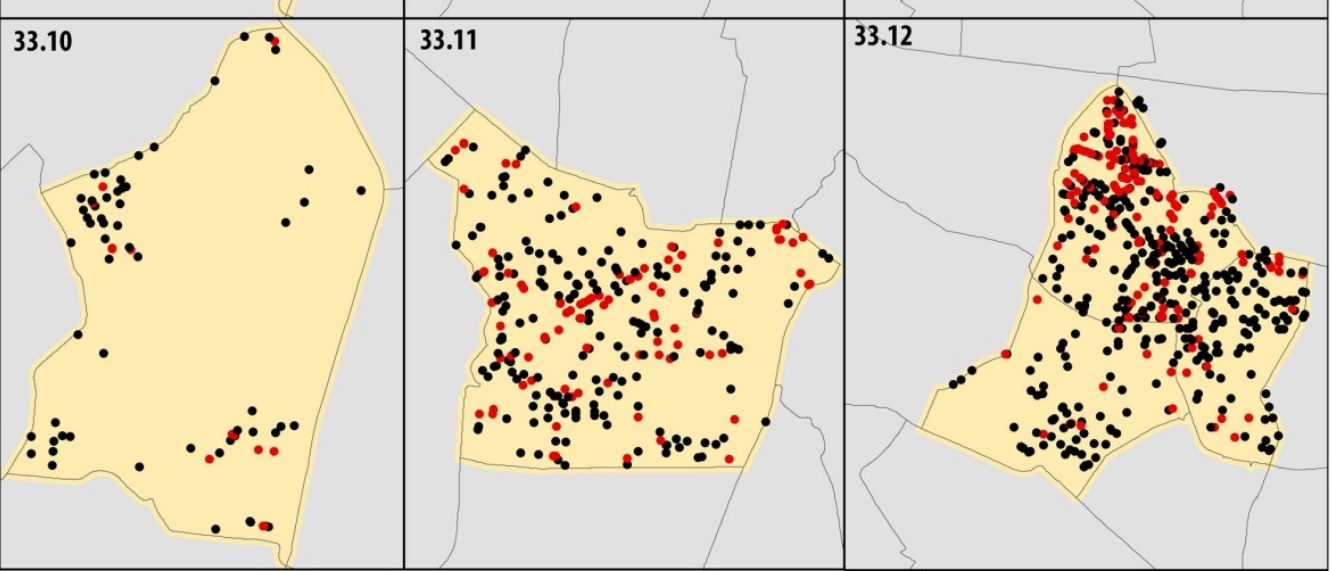

Fontes $=>$ Fundo de mapa: Grade estatística IBGE 2010 <ffp//geofftibgegovbr/recortes para fins estatisticos/grade estatistica/censo 2010/> /5/2016 Distritos do município de São Paulo: Mapa Digital da Gidade IMDCI Secretaria Municipal de Desenvolvimento Urbano e Departamento Produção e Análise de Informaçāo < htttp://geosampa.prefeitura.sp.gov.br/>|5/2016| Dados estatísticos: Censo Demográfico Cadastro Nacional de Endereços para Fins Estatísticos - CNEFE - IBGE 2010|11/2016 | Endereços geocodificados no software livre TerraView sobre base de logradouros de 2016 do Centro de Estudos da Metrópole [CEM] <http://www.fflch.usp.br/centrodametropole/> |12/2016| Elaborado em ArcGis e finalizado em Adobe lllustrator. Concepşão e elaboração: DUTENKEFER, Eduardo jjunho, 2017 
|Figura 33A| - Gráficos dos mapas da figura 33

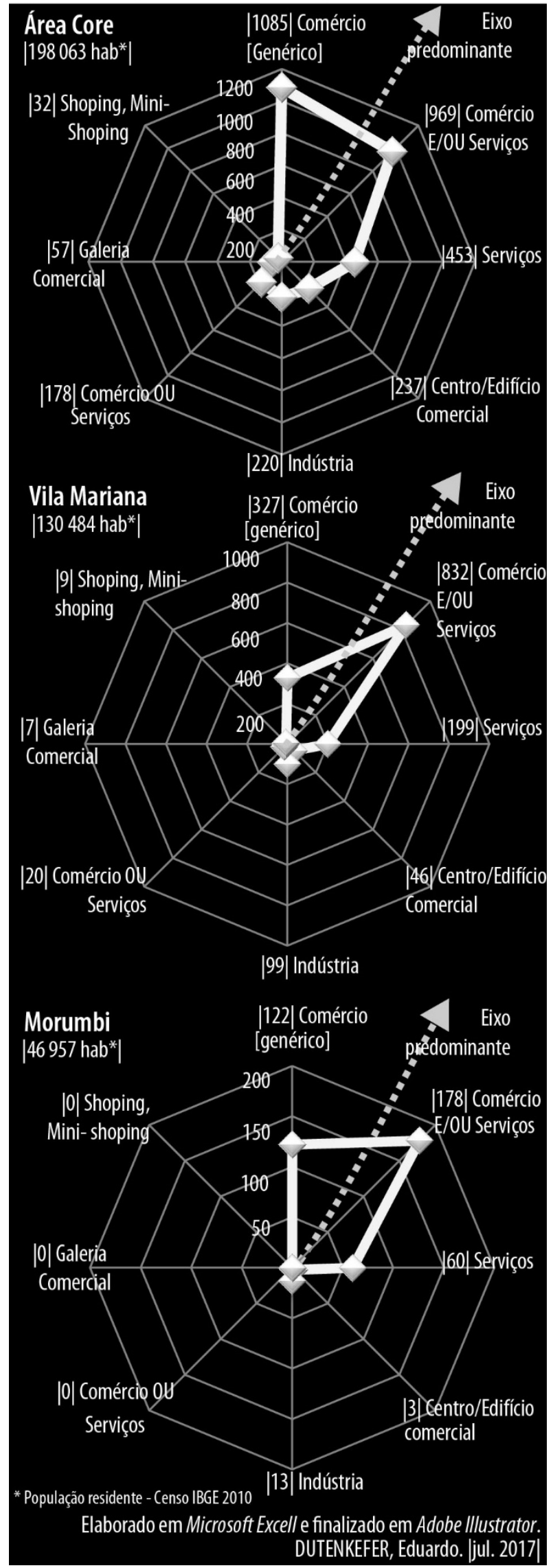

De 33.4 a 33.12 atividades que podem ser classificadas como Comércio de uma forma genérica; Comercial E/OU de serviços; Serviços de uma forma genérica; Centro/Edifício Comercial, Indústria em geral; Comércio OU Serviços - quando a atividade não está clara e bem definida na descrição; Galeria Comercial e finalmente como Shopping e/ou mini-shopping. O predomínio da atividade comercial e de serviços é evidente, como evidenciamos no gráfico polar da Área Core, Vila Mariana e Morumbi na figura 33A. A figura 33A oferece outra forma de explorarmos visualmente os números de atividades não residenciais em quantidades numéricas em gráficos denominados polares ou também

chamados de gráficos de radar ...que são constituídos por diversos eixos integrados numa única figura radial, tendo cada segmento uma determinada escala de medida na qual são projetados os dados, tanto mais elevados quanto mais longe do centro se posicionarem (SILVA, 2006, p. 147). 
|Figura 34| Comparando baixas, médias e altas densidades e diversidades - $\mathrm{n}^{\circ} 2$ em cada célula de $200 \times 200 \mathrm{~m}$
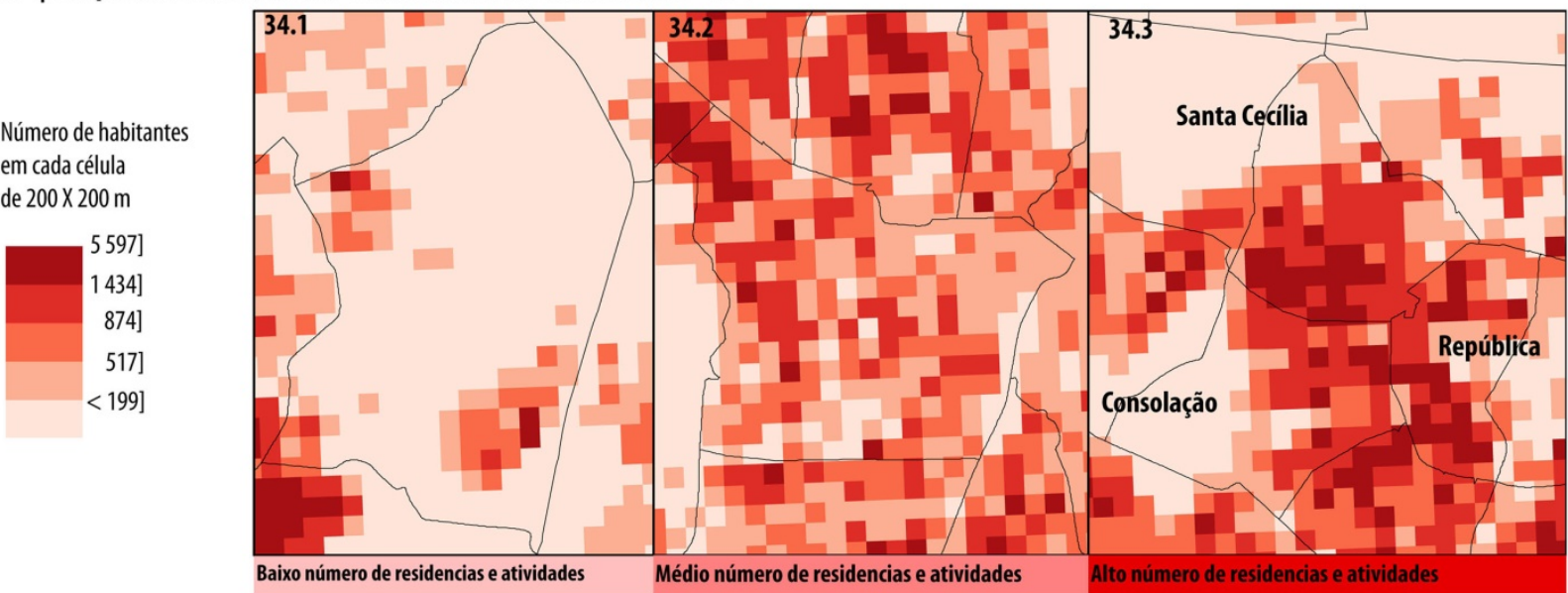

Alimentos e Bebidas

Comércio

- Alimentos em geral

- Mercado/Supermercado

- Açougue

- Padaria

- Pizzaria

- Água mineral

$\Delta$ Bebidas

\section{Alimentos e Bebidas}

Servicos

- Bar

Lanchonente

Restaurante

Vestuário/Calçados/Bolsas

- Comércio

Calçados

- Comércio

Malas/Bolsas e acessórios

- Comércio

Roupas/Tecidos

- Serviços Pessoais Alfaiataria/Costureira

|UTM|SAD69F23S| 
A partir da figura 34 procuramos detalhar os tipos mais importantes de atividades que oferecem alimentos, bebidas, roupas e calçados. Requisitos mínimos que uma cidade deve oferecer para a sobrevivência humana, no meio urbano. Com os gráficos da figura 34A podemos relacionar algumas reflexões. 0 distrito do Morumbi, com uma população residente em torno de 47.000 habitantes, em 2010, tem uma relação maior de seus habitantes com a oferta de estabelecimentos comerciais e de serviços que oferecem alimentos, bebidas, roupas e calçados - [133 hab/ativ] em relação à área de Vila Mariana [108 hab/ativ] e a Área Core [71 hab/ativ]. Na área de serviços alimentícios, por exemplo, temos apenas 201 estabelecimentos, enquanto a Vila Mariana oferece, mais que o dobro, 620. Em Consolação, Santa Cecília e República; 1.382 estabelecimentos. Uma relação, neste segmento, de 234 hab/serviços alimentícios; 210 hab/serviços alimentícios e 143 hab/serviços alimentícios, respectivamente. Peguemos outra relação interessante. Relacionar o número de atividades disponíveis nestas áreas exemplos de gradientes de urbanidade com a área disponível destes territórios. Os moradores residentes nestas áreas terão que percorrer, ou seja, ir até o estabelecimento mais próximo para obter o seu kit básico de sobrevivência alimentar e dignamente vestido e calçado. Os habitantes do Morumbi
|Figura 34A | - Gráficos dos mapas da figura 34

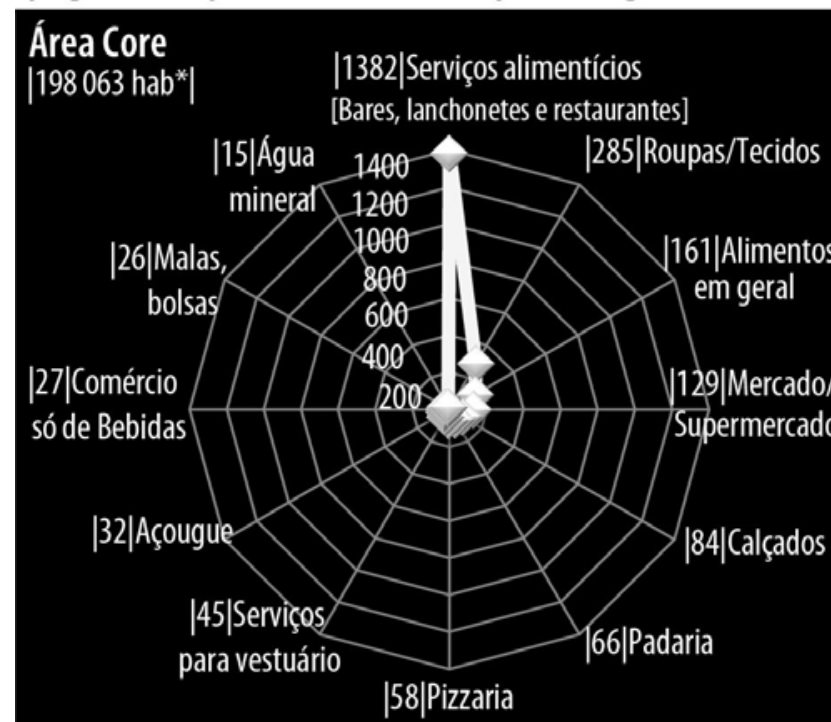

\section{Vila Mariana} |130 484 hab* $^{*}$

\section{|620|Serviços alimentícios}

[Bares, lanchonetes e restaurantes]

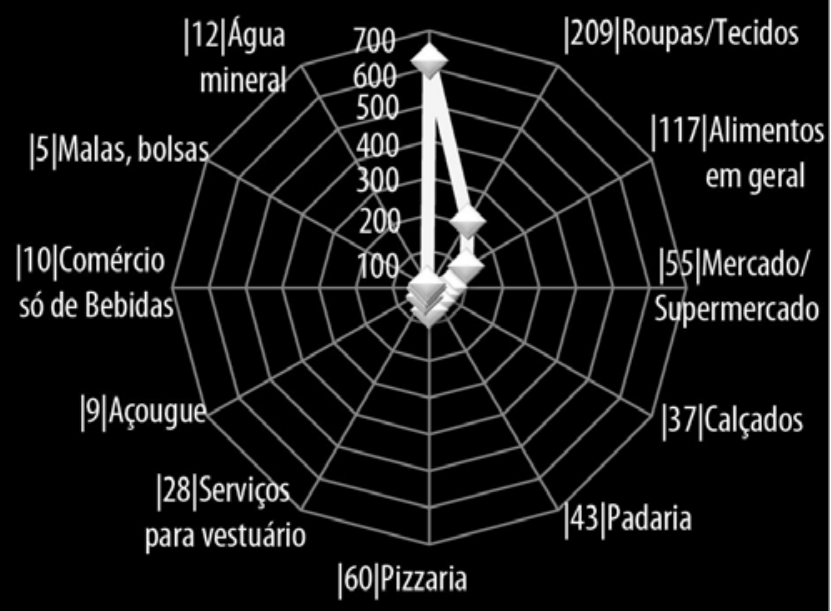

Morumbi

| 46957 hab*|

|201|Serviços alimentícios

[Bares, lanchonetes e restaurantes]

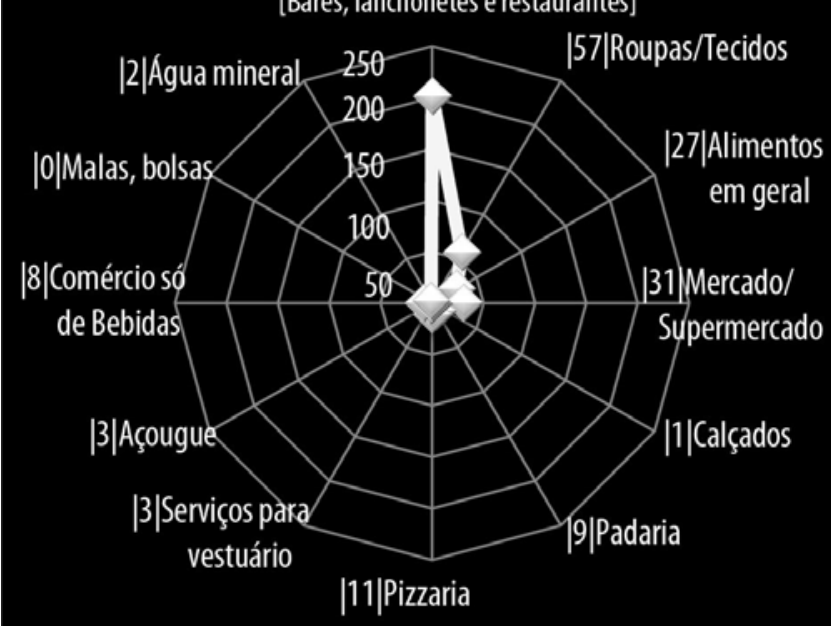

* População residente - Censo IBGE 2010

Elaborado em Microsoft Excell e finalizado em Adobe Illustrator. DUTENKEFER, Eduardo. |jul. 2017| 
terão 31 ofertas de atividades em cada quilômetro quadrado de seu território. Vila Mariana 140 e nossa área Core 279 atividades $/ \mathrm{km}^{2}$. Isto significa que o morador de nossa área Core tem a "felicidade" de encontrar, idealmente, pelo menos até 279 estabelecimentos no entorno de uma área de $1 \mathrm{~km}^{2}$. Se pensarmos na escala de nossas células de $200 \mathrm{X} 200 \mathrm{~m}$, este morador poderia encontrar, provavelmente, até 11 estabelecimentos que satisfariam suas necessidades básicas humanas. Nesta sequência de áreas de 200X200 m, encontraríamos em Vila Mariana até 6 estabelecimentos e no Morumbi, no máximo, 2 estabelecimentos. E, se observamos a distribuição espacial dos mapas da figura 34, se este morador fosse do centro do Morumbi, teria que percorrer a pé uns bons metros, ou pegar um ônibus, ou bem provável, ir de carro até o local. Um exemplo - figura 34B - hipotético: Morador próximo ao Hospital Alberto Einstein, altura da rua Av. Jules Rimet, 273. Necessita ir até uma padaria. A padaria mais próxima, segundo as geodocificações que obtivemos no distrito, é localizada próximo à Rua José Jannarelli, 496. Se simularmos no aplicativo Google Maps, teremos uma distância média de 1,6 km. A pé, levaríamos em média 22 minutos. Em transporte público - ônibus; 50 minutos. Em transporte privado - de automóvel - até 6 minutos e, ainda, se tivéssemos uma bicicleta, 8 minutos. Qual opção escolhemos?

| Figura 34 B | Exemplo de percurso a pé de uma residência até uma padaria no distrito do Morumbi em aplicativo Google Maps

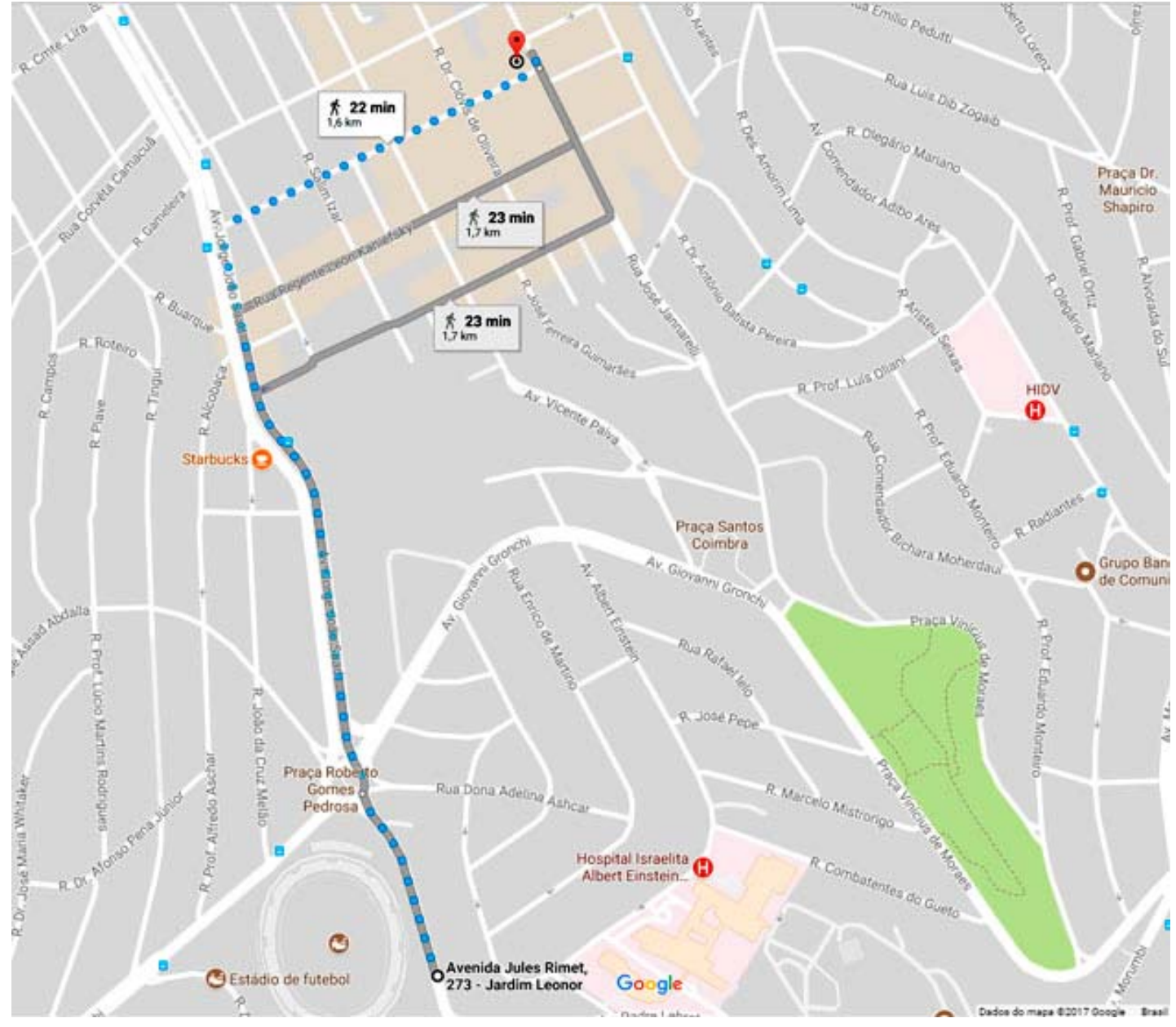


|Figura 35A| - Gráficos dos mapas da figura 35
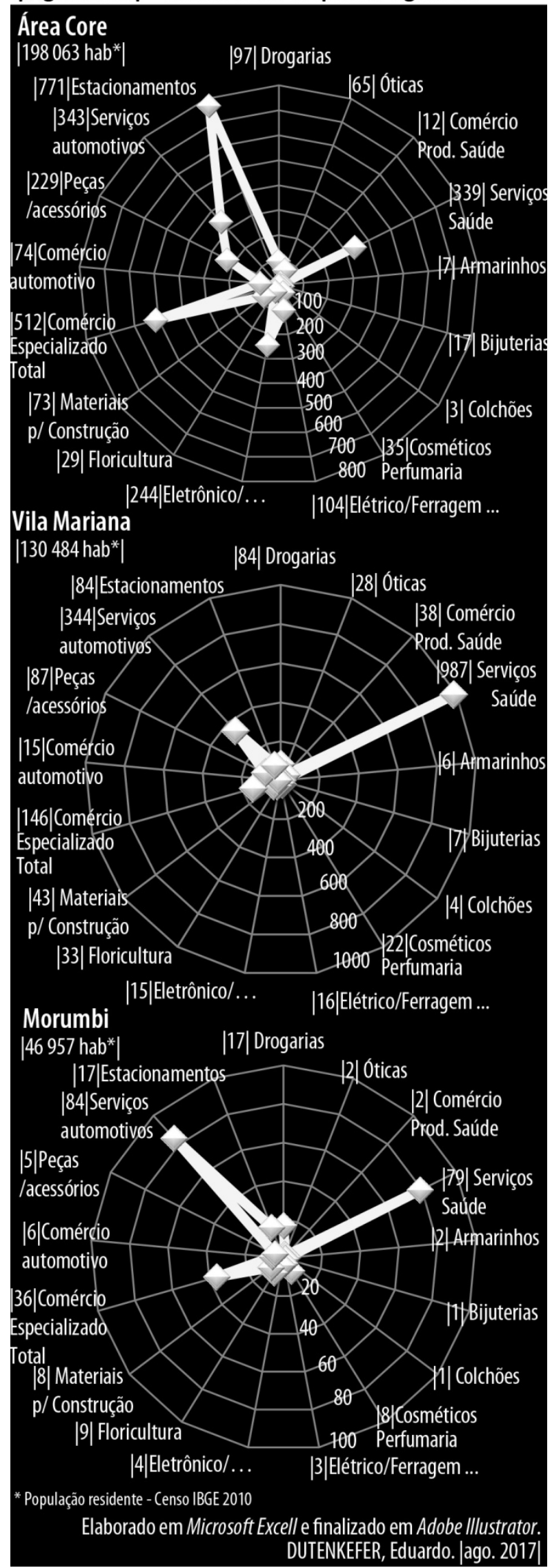

Será que teríamos dúvidas em escolher o local mais potencialmente diverso em oportunidades de experimentarmos comidas diversas, se fossem oferecidas apenas estas três opções de áreas em São Paulo?

Na figura 35, três temas em foco; Saúde, comércio especializado e automotivo. De 35.1 a 35.3 o predomínio de serviços ligados ao tema saúde prevalece sobre as drogarias, óticas e produtos em geral de saúde, nas três áreas. Vila Mariana sobressai com 987 atividades ligadas a serviços de saúde, mais que o dobro de nossa área Core [339]. De 35.4 a 35.6, o comércio mais especializado é relativamente bem distribuído em Vila Mariana e quantitativamente [512 estabelecimentos] maior em nossa área Core, com destaque para a concentração de comércio ligado à eletrônica e informática [244 estabelecimentos].

$\mathrm{Na}$ atividade automotiva [35.7 a 35.12] a influência maior dos serviços em relação ao de comércio. No comércio, em Vila Mariana, com um eixo mais central e, em nossa área Core, uma concentração mais nítida na divisa entre Santa Cecília e República. Em serviços, o predomínio de serviços automotivos em geral está no Morumbi e Vila Mariana. Por outro lado, em nossa área Core, a incrível quantidade de estacionamentos é flagrante com 771 estabelecimentos. 
|Figura 35| Comparando baixas, médias e altas densidades e diversidades - $\mathrm{n}^{\circ} 3$

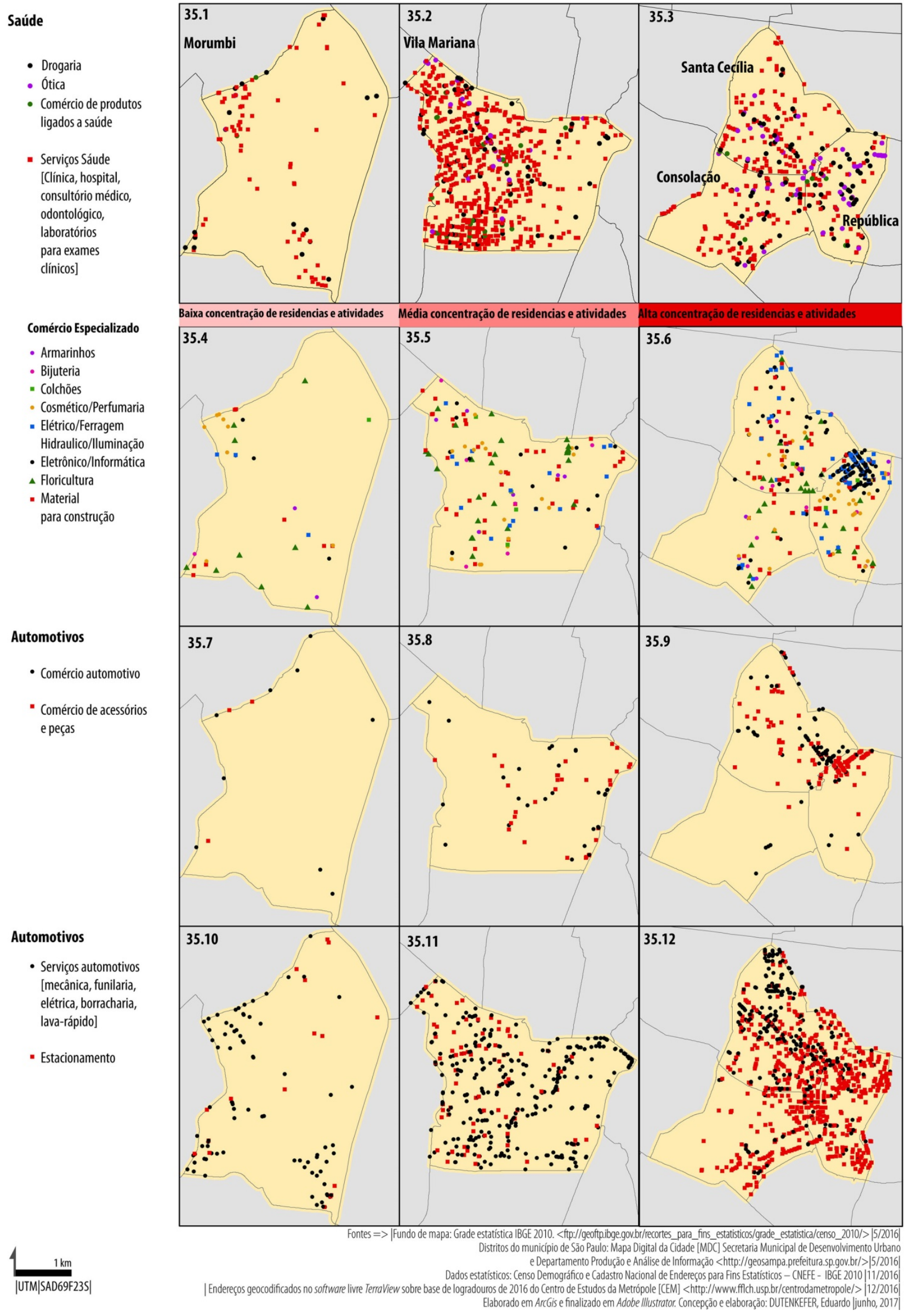


|Figura 36| Comparando baixas, médias e altas densidades e diversidades - $\mathrm{n}^{\circ} 4$

Serviços
- Contábeis
- Jinanceiros
- Lurídicos
Loterica

Serviços Pessoais

- Academia, Alfaitaria, Lavanderia, Barbearia,

Cabeleireiro, Chaveiro,

Clínica de Estética,

Salão de Beleza,

Depilação, Massagem

Serviços Sociais

- Sociais/

Assistenciais

Serviços Religiosos

$\Delta$ Templos/ Igrejas

- Outros

[Centro Espirita/Umbanda não detalhado]
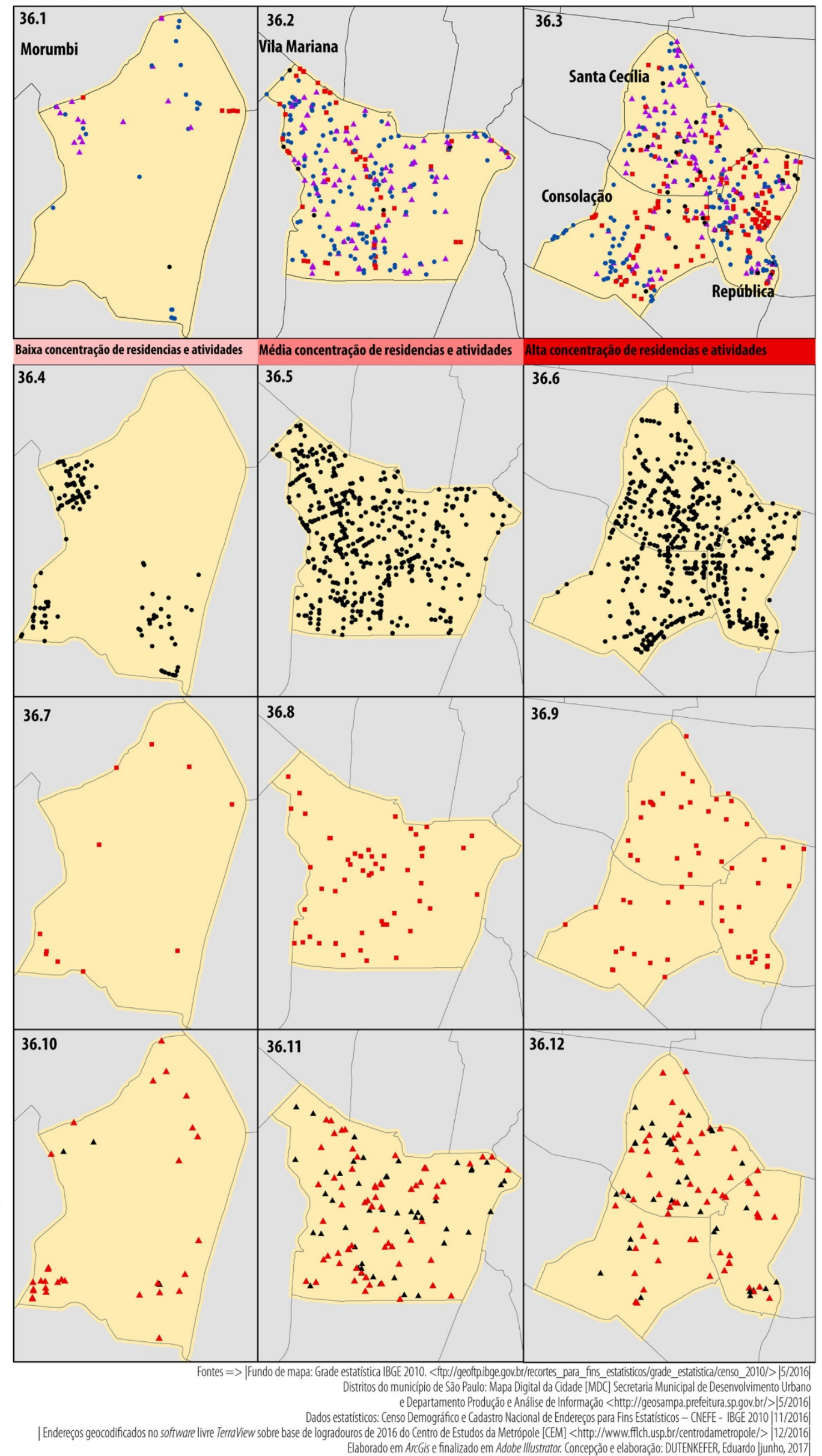
|Figura 36A| - Gráficos dos mapas da figura 36
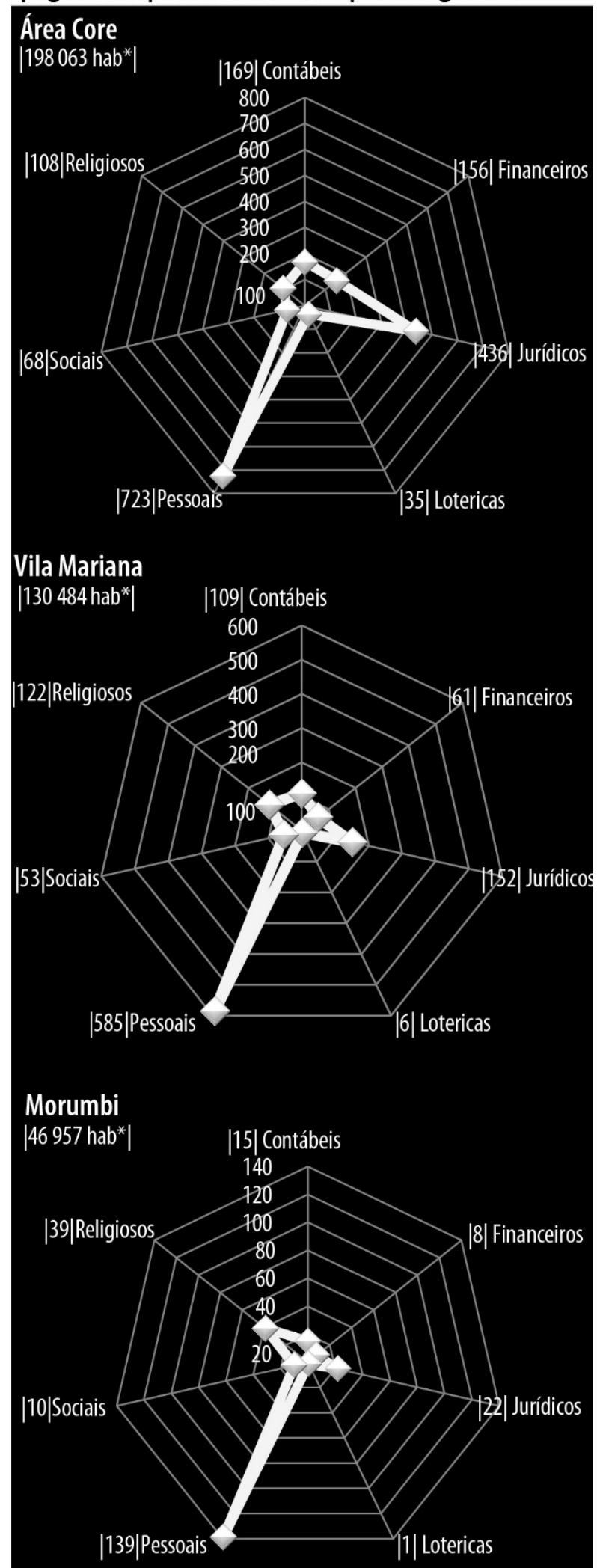

* População residente - Censo IBGE 2010

Elaborado em Microsoft Excell e finalizado em Adobe Illustrator. DUTENKEFER, Eduardo. |ago. 2017
$\mathrm{Na}$ figura 36 priorizamos atividades de serviços contábeis, financeiros [agências bancárias e instituições do mercado financeiro em geral], jurídico [principalmente advogados e escritórios de advocacia] de loteria, pessoais [academia, cabeleireiro, estética], sociais e religiosos.

Em 36.1 a 36.3 a atividade jurídica se destaca nas três áreas exemplos, com 436 atividades associadas ao jurídico em nossa área Core. Ela é mais que o dobro de Vila Mariana [152] e os parcos 22 estabelecimentos no Morumbi. Em todos os temas mapeados na figura 36 e nas demais sequências, o distrito do Morumbi vai ficando mais opaco em números de atividades não residenciais. Sua distribuição espacial em geral coincide com a maior quantidade de domicílios, ou seja, uma área mais a noroeste, outra a sudoeste e, por fim, a sudeste do distrito. São áreas mais densas em número de habitantes, como podemos observar em um relance de olhar no mapa 34.1 da figura 34. A distribuição de serviços pessoais em 36.4; sociais na 36.7 e religiosos na 36.10 , coincide com estas áreas mais densas. Em Vila Mariana e na área Core estão mais bem distribuídas e também coincidem, de uma forma geral, com áreas mais densamente habitadas [um olhar em 34.2 e 34.3 da figura 34 e um voltar "rapidamente" em 36.5 a 36.12 da figura 36]. Os gráficos da figura 36A mostram quantitativamente os serviços classificados 
como pessoais como expoentes principais desta oferta de serviços. Serviços estes orientados em maior quantidade à satisfação pessoal com seu corpo; academias de ginástica, cabeleireiro, estética, beleza, depilação e massagem.

Nos mapas da figura 37 representamos serviços na área de manutenção, cultura, associativo e público. Na atividade comercial em livros, móveis, papelaria e tintas. De 37.1 a 37.3, duas atividades orientadas a oferecer o "concertar" e o "copiar" de algo e, simultaneamente, locais que oferecem serviços que refletem o movimento frenético de uma cidade; a entrega de produtos materiais, de serviços, de "sonhos" de consumo, rapidamente executada nas "vias abertas" que os "moto-boys" constroem cotidianamente nas redes viárias de São Paulo. E, por outro lado, temos o Correio a encaminhar "desejos" pelas mesmas vias físicas que os moto-boys percorrem, mas com ares de vias mais institucionalizadas, "oficiais" que a cidade também oferece e compartilha. Como um quase padrão, no Morumbi é bem rarefeito. Na Vila Mariana é bem distribuída, excetuando a sudeste do distrito. Na área Core, já tem sua distribuição espacial "consolidada" nas áreas mais habitadas. De 37.4 a 37.6, as áreas ligadas a ofertas de serviços culturais como bibliotecas, cinemas, teatros, espaços culturais em geral, a nossa área Core é bem servida em relação à Vila Mariana e Morumbi. No gráfico da figura 37A a quantidade de sonhos, desejos, encantamentos, utopias, fantasia, ódios, amores que o cinema, teatro e o show oferecem, em nossa área Core é de encantar, com seus 179 locais disponíveis. Vila Mariana oferece, por outro lado, 28 e Morumbi apenas 4 espaços para "sonhar". Neste gráfico da figura 37A optamos em mostrar outra possibilidade de representar graficamente as três áreas exemplos simultaneamente em todas as opções das classificações por nós empreendidas.

De 37.7 a 37.9 mostramos mapas que apontam locais potencialmente favoráveis a discussões e participação política. São atividades ligadas a Associações, Sindicatos e Partidos políticos. Não são locais de manifestação em espaço público e sim restritos a debates, articulações, votações, convencimentos diversos que espelham a sociedade nestas áreas em particular, ou de dimensões mais amplas para o conjunto da cidade. Nas mesmas representações estão também localizados clubes recreativos, esportivos e órgãos do serviço público nas esferas municipal, estadual e federal, exceto aquelas já representadas nos temas de saúde, educação e cultura. Serviços específicos ligados à segurança pública também são localizados. De 37.10 a 37.12 temos atividades ligadas ao comércio de livros, móveis, papelaria e tintas. 0 destaque fica para 66 livrarias, 66 papelarias e 83 lojas de móveis para a nossa área Core. 
|Figura 37A | - Gráfico dos mapas da figura 37

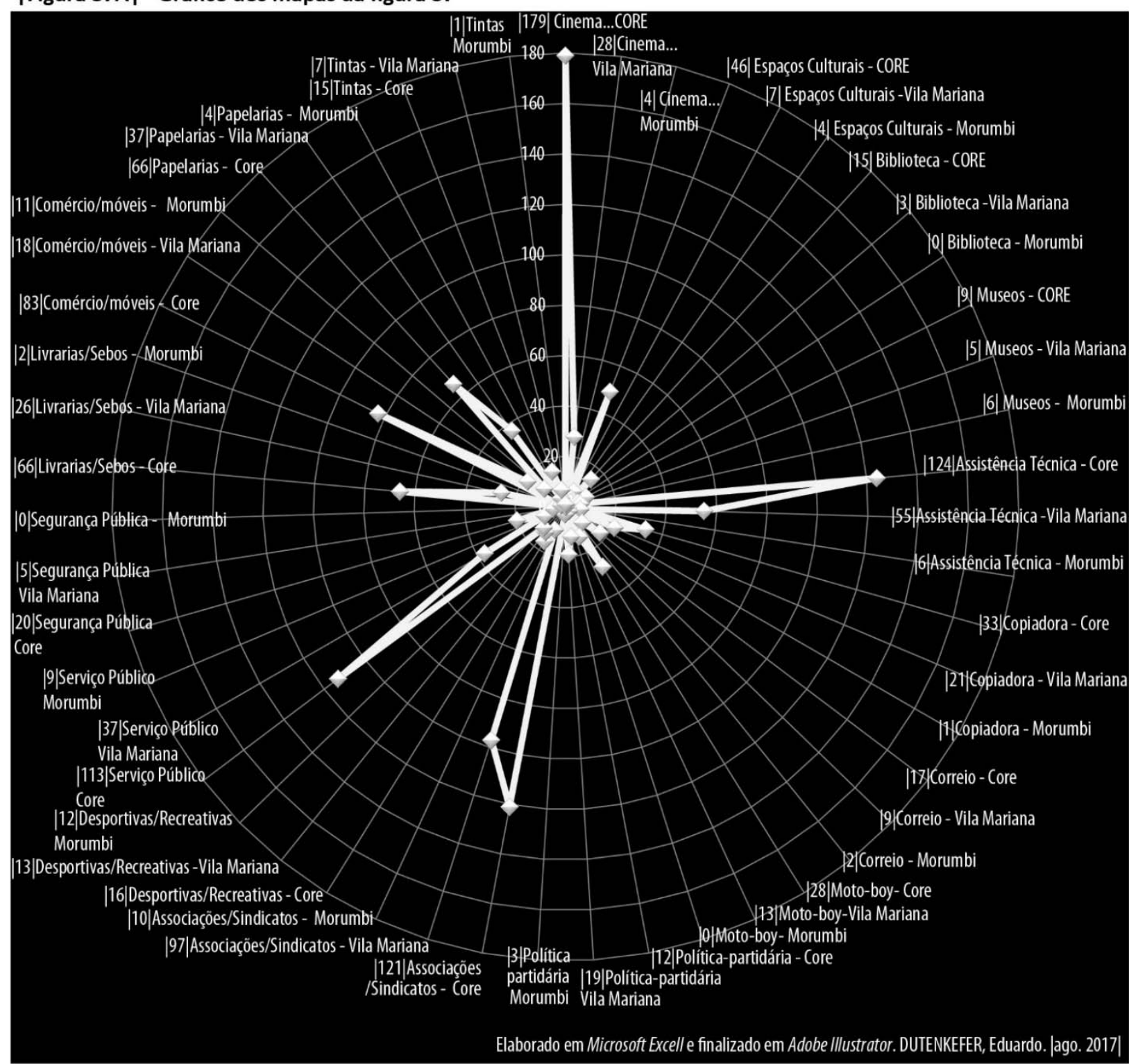

Para finalisar este capítulo e esta sequência de pranchas comparando baixas, médias e altas densidades e diversidades estão representadas na figura 38.

De 38.1 a 38.3 as localizações dos estabelecimentos educacionais em geral [Escolas Do ENSINO BÁSICO, CRECHES, ENSINO FUNDAMENTAL, MÉDIO - PÚBLICAS E PRIVADAS; CENTRO DE ESTUDOS, CURSINHOS, ESCOLAS DE IDIOMAS EM GERAL] e só de nível superior. De 38.4 a 38.6 desmembramos a classificação de serviços educacionais em geral para de ensino técnico público, infantil público, fundamental e médio público e privado e, por fim, escolas ligada ao sistema S; SENAI, SESI e SENAC. No Morumbi as distribuições espaciais mais distribuidas na áreas mais densas em domicilio; na Vila Mariana e em nossa área Core, estão melhor distribuídas em geral pelo território. Destaque para uma concentração ao sul de Vila Mariana de entidades ligadas ao ensino superior. 
|Figura 37| Comparando baixas, médias e altas densidades e diversidades - $n^{\circ} 5$

Serviços

- Assistência técnica/ Manutençao/

Concertos em geral

- Copiadora

- Correio

- Entrega rápida ["Moto boy"]

Serviços Culturais*

- Biblioteca

- Cinema, Teatro, Show

- Espaços Culturais [Centro, Galerias de Arte]

- Museos

\section{Serviços}

- Atividades Associativas [Sindicatos, Associaçôes]

- Atividade Partidárias

- Desportivas/Recreativas

- Serviço Público diversos**

- Serviço Público na área de segurança

[Delegacia/Batalhão Policial]

\section{Comércio}

- Livraria/Sebos

- Móveis

- Papelaria

- Tintas

*Dados da Prefeitura do Município de São Paulo <http://geosampa.prefeitura.sp.gov.br> ** Exceto servicos culturais, desportivo, correio, educação e saúde nas esferas federal, estadual e municipal.

$\frac{1 \mathrm{~km}}{|\mathrm{UTM}| S A D 69 F 23 \mathrm{~S} \mid}$
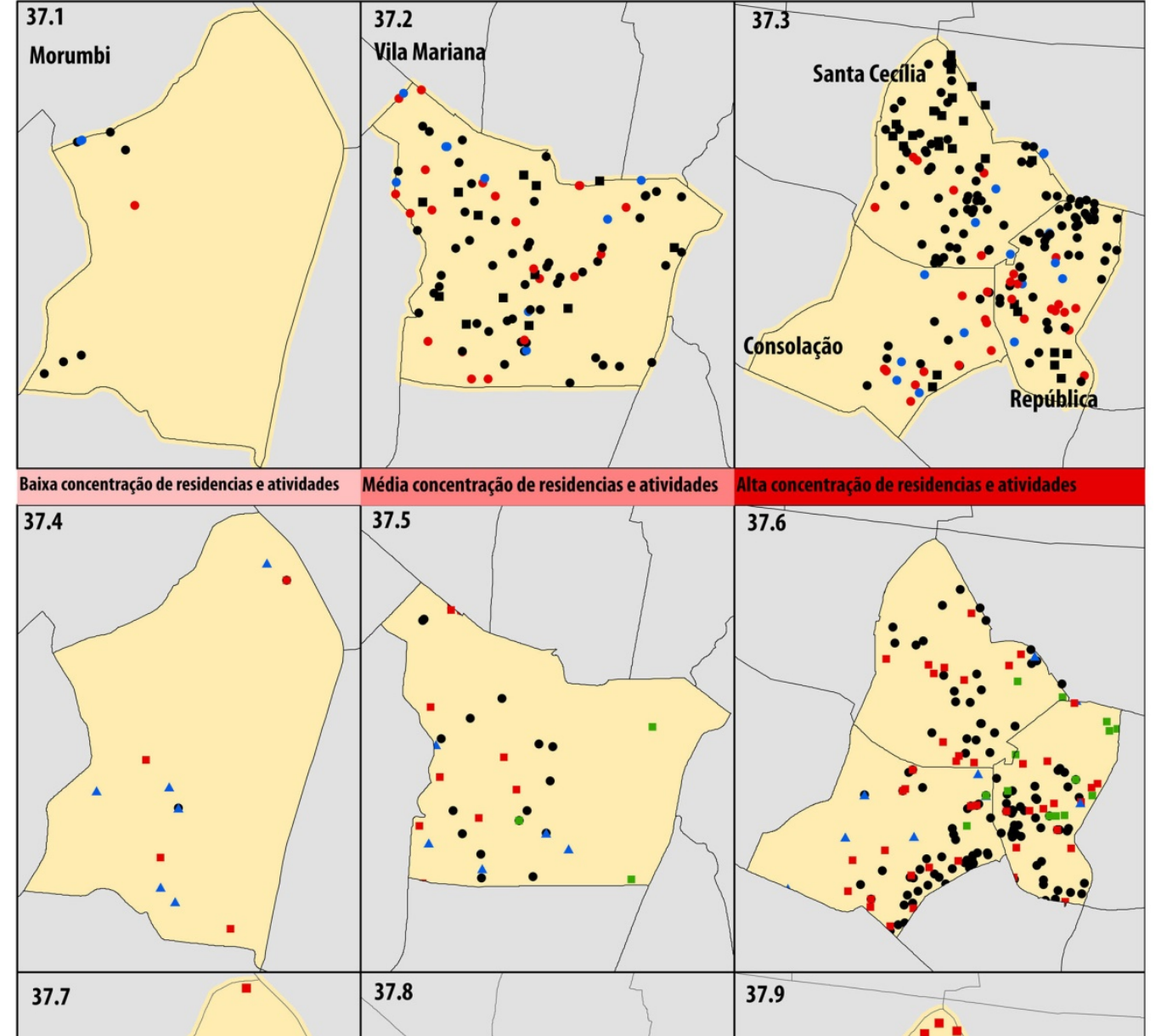

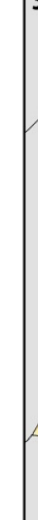
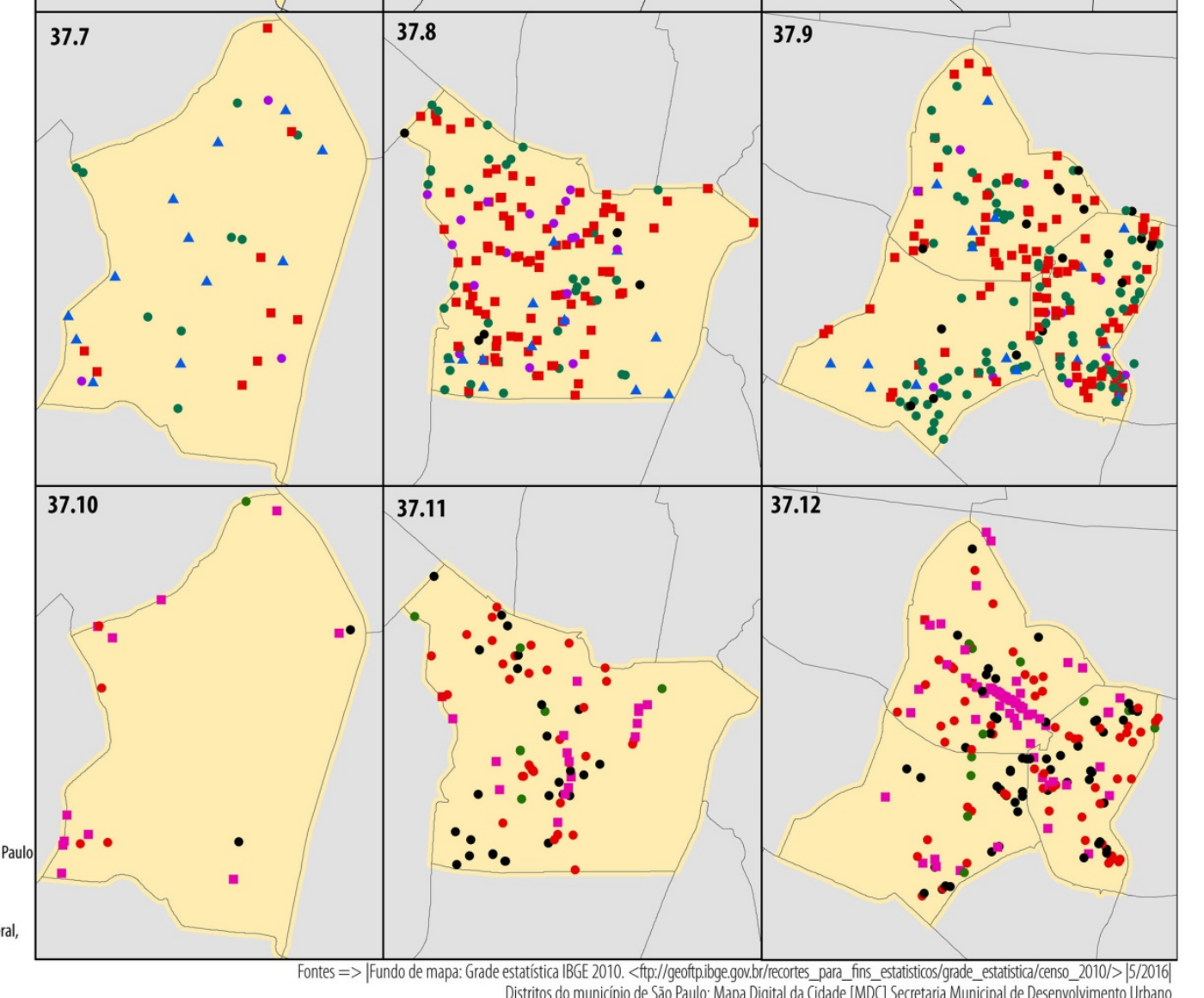

Distritos do municíio de São Paulo: Mapa Digital da Cidade [MDC] Secretaria Municipal de Desenvolvimento Urbano e Departamento Produção e Análise de Informação <http://geosampa.prefeitura.sp.gov.br/> |5/2016 Dados estatísticos: Censo Demográfico e Cadastro Nacional de Endereços para Fins Estatísticos - CNEFE - IBGE 2010 |11/2016 douros de 2016 do Centro de Estudos da Metrópole [CEM] < <http://www.fflch.usp.br/centrodametropole/> 12/2016
Elaborado em ArGGis e finalizado em Adobe Illustratoror. Concepcão e elaboraçāo: DUTENKEFER, Eduardo junho, 2017 
|Figura 38| Comparando baixas, médias e altas densidades e diversidades - $\mathrm{n}^{\circ} 6$

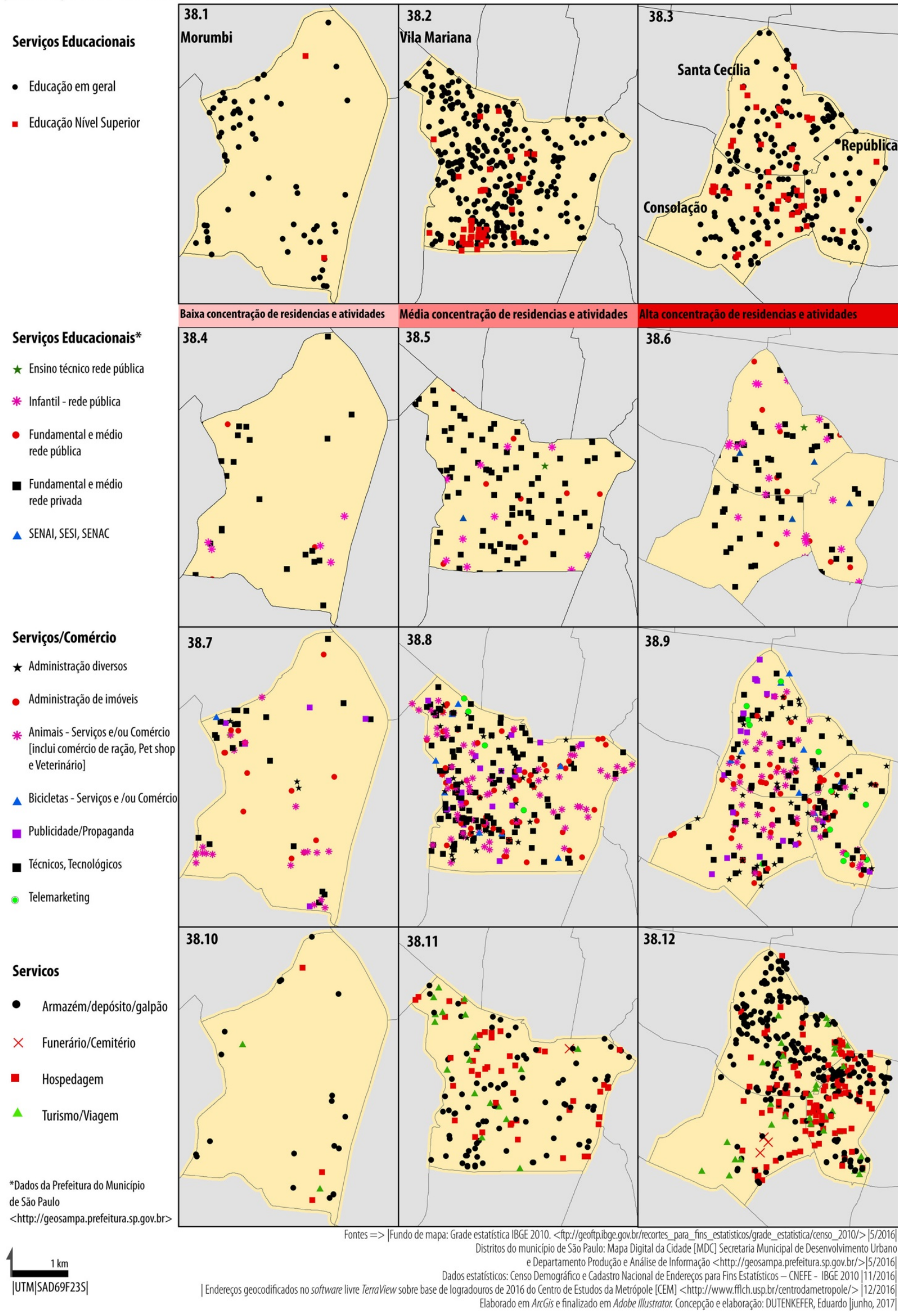


$\mathrm{Na}$ figura 38A representamos, em formato gráfico polar, o tema educacional. Em destaque a quantidade de estabelecimentos do ensino fundamental e médio privado em Vila Mariana, 67 em contraste com apenas 7 estabelecimentos da área pública. No ensino Superior, Vila Mariana também se sobressai, com 64 estabelecimentos.

De 38.7 a 38.12 uma miriade de serviços e comércios diversos para completar nossas representações cartográficas pontilhadas, que nos oferecem visualmente opções de baixas, médias e altas densidades e diversidades que formalmente classificamos como atividades econômicas. Temas dispares que englobam atividades administrativas, publicidade, técnicos, telemarketing, armazéns, funerárias, hospedagem, turismo, até serviços e comércios para animais de estimação e as carinhosas "magrelas" - bicicletas.

|Figura 38A | - Gráfico dos mapas da figura 38 [38.1 A 38.6]
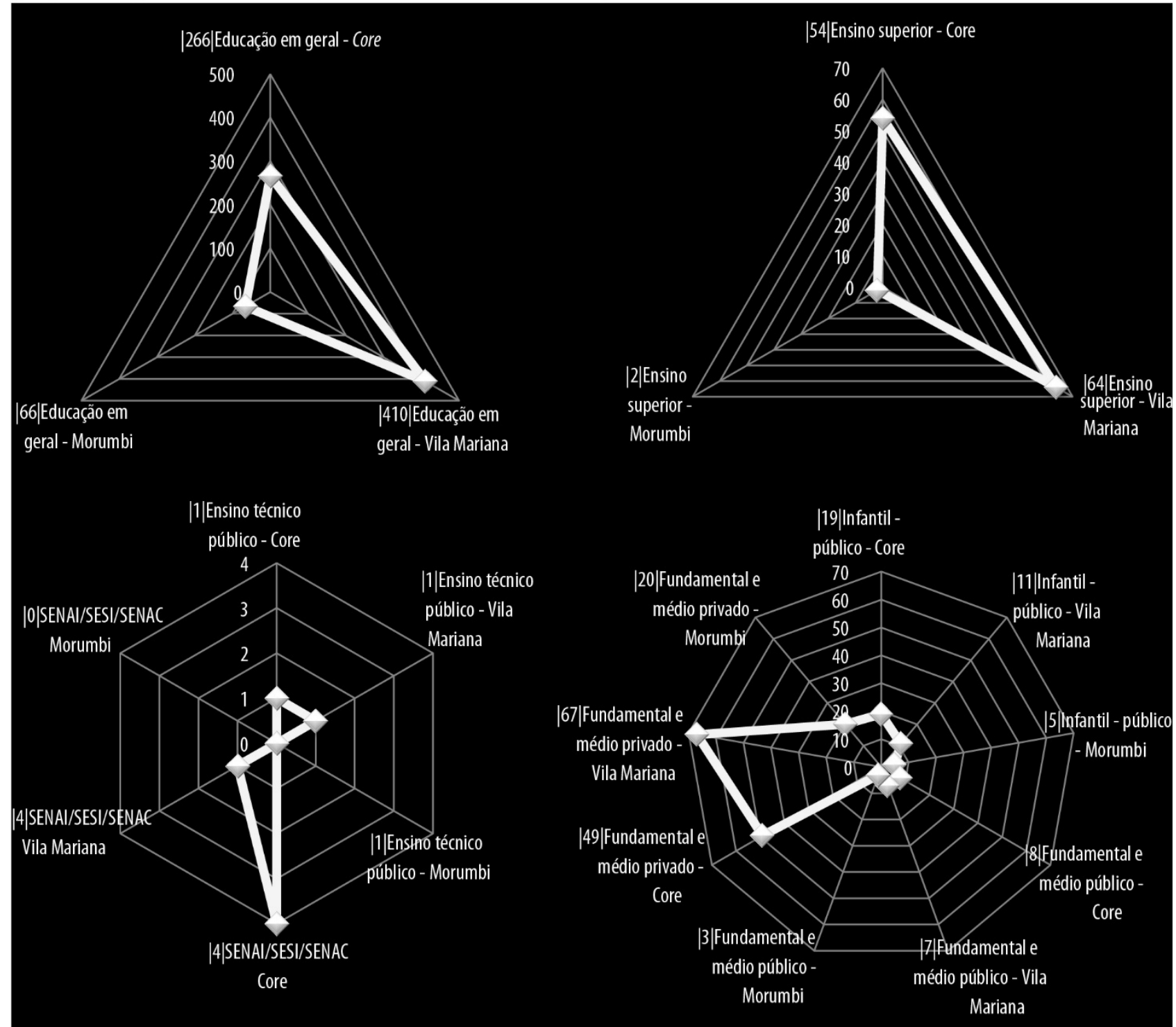
|Figura 38B| - Gráfico dos mapas da figura 38 [38.7 A 38.12]

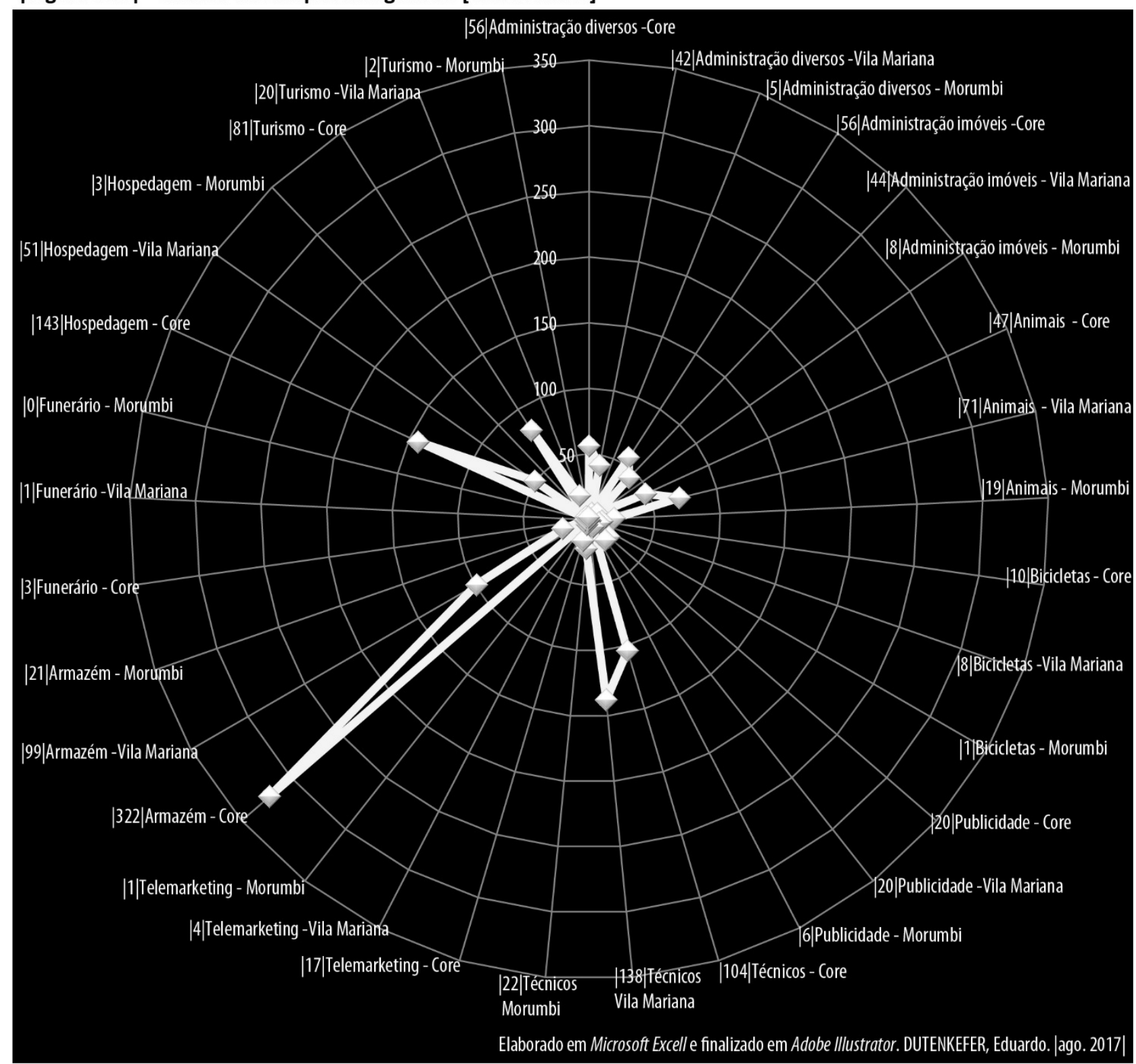

Em 38.8 observamos uma leve concentração, a sudoeste do distrito de Vila Mariana, de serviços orientados aos afazeres técnicos, tecnológicos. Serviços estes ligados aos ramos de engenharia, de um modo geral, arquitetura, tecnologias da informação, consultorias de informáticas, etc. Vila Mariana tem 138 locais ligados à tecnologia. Nossa área Core também chega perto, com 104 estabelecimentos. Interessante comparar, por exemplo, os serviços oferecidos ao cuidado de animais de estimação que, de uma forma geral, são bem distribuídos espacialmente em nossas áreas exemplos - com serviços de alimentação aos seres humanos no caso ao número de padarias. Na área Core temos 66 padarias e 47 estabelecimentos dedicados aos animais [ver figura 34, mapas 34.4 a 34.6 e gráfico na figura 34A]. Em Vila Mariana, saltou para 71 ligados aos serviços para animais contra 43 padarias; quase que o dobro! Será que estamos a estabelecer novas prioridades alimentícias, ou realmente o número 
de animais domésticos demanda mais estabelecimentos que oferecem estes serviços/comércios?

No gráfico da figura 38B temos um expressivo número de armazéns em nossa área Core [322]; um indicador da expressiva atividade comercial e de serviços que demandam espaços para armazenagem, depósito, estoque de mercadorias. Além dos números expressivos de atividade tecnológicos já comentados, o número de serviços de hospedagem é significativo em nossa área Core; 143 estabelecimentos. 0 número de serviços oferecidos às nossas carinhosas "magrelas" ainda é singelo: 10 em nossa área Core, espacialmente em maior número na Santa Cecília; 8 na Vila Mariana e apenas um no Morumbi.

A figura 38 finaliza a nossa série de detalhes aqui esboçados que os dados do CNEF proporcionaram. Evidenciar atividades classificadas como comerciais, industriais e de serviços em relação ao de habitar nestes espaços. Mapas em nuvens de pontos que revelam uma amostra das concentrações e das diversidades de objetos geográficos que oferecem interessantes espaços para relações sociais diversas. Concentrações e diversidades que contribuem para medir a "qualidade", a "alma" de uma cidade até aqui burilada como sua urbanidade.

Estes exemplos de concentrações e diversidades serão sintetizados e sofrerão uma transformação de agregação de dados para os 96 distritos do município de São Paulo por meio de três tipos de mapas-modelo, nos próximos capítulos. Antes de atingirmos esse propósito, no próximo capítulo - 6 [seis], a intenção é contribuir em métodos e metodologias que podem ser utilizados para revelar como acessar as concentrações e diversidades que uma cidade oferece em métricas do tipo distância-tempo. É um exemplo de como os habitantes de São Paulo podem acessar a maior concentração de atividades diversas que a nossa área Core revelou oferecer. Partiremos de uma lógica a partir da Praça da Sé - perto de nossa área Core em direção aos 95 outros distritos de São Paulo. Esta lógica também pode ser pensada em como acessar, dos distritos distantes da Sé, a nossa área Core. 


\section{0 - Acessibilidade no município de São Paulo ${ }^{58}$}

Este capítulo destoa um pouco dos anteriores. Foi elaborado antes de nossas pesquisas e reflexões culminaram no capítulo 5 - Diversidades de atividades. Até o capítulo anterior estávamos trabalhando com densidades e diversidades - os dois elementos centrais que focamos nesta pesquisa para "medir" a urbanidade. Este "medir" passa também pelo objetivo de mostrar e pensar métodos e metodologias que auxiliem a compor um quadro desta urbanidade da cidade de São Paulo. No capítulo anterior mostramos alguns exemplos das ofertas de diversidade de atividades que uma cidade pode oferecer. Esta diversidade de ofertas, fundamentalmente em atividades comercias e de serviços que São Paulo apresenta, só tem sentido se elas podem ser usufruídas pela maioria de seus moradores. Surge então o questionamento: como expressar graficamente o acesso a estas ofertas?

Este capítulo contribui para pensar a interacessibilidade entre os lugares que uma cidade oferece. Desenvolveremos, na verdade, a acessibilidade de um lugar para outros lugares. Uma acessibilidade unipolar será estabelecida em métricas topográficas, euclidianas em metros e quilômetros e também em métrica distância-tempo que as redes viárias de São Paulo possibilitam. Esta acessibilidade pode revelar proximidades - visíveis e/ou invisíveis espaciais da estrutura de São Paulo. Seria uma relação entre o seu território e a sua rede viária.

Continuaremos a utilizar o que Cauvin, Escobar e Serradj (2007a) denominam de “Cartografia analítica e transformacional” - métodos e metodologias utilizando aplicativos computacionais que permitem construir mapas que visualizem um conceito importante em particular para mapear a urbanidade de uma cidade, a sua acessibilidade.

0 nosso recorte espacial será a acessibilidade unipolar no município de São Paulo. Partindo de seu centro histórico, a Praça da Sé, no distrito da Sé, em direção aos demais 95 distritos administrativos que compõem o município, buscamos o que os mapas nos revelam da acessibilidade possível por meio do automóvel e da rede de transporte coletivo em particular, por meio de ônibus. É uma aproximação e uma lógica de pensarmos em como é o acesso à nossa área Core que os dados e mapas revelaram no capítulo anterior.

\footnotetext{
${ }^{58}$ Este capítulo foi publicado, com alterações, na Revista eletrônica Confins: Eduardo Dutenkefer, «Métodos e metodologias para desvendar a acessibilidade da cidade de São Paulo», Confins [Online], 28 | 2016, posto online no dia 20 Outubro 2016, consultado em 07 Maio 2017. URL: http://confins.revues.org/11116; DOI : 10.4000/confins. 11116
} 


\section{1 - Conceitos estruturadores: distância e métrica}

Anteriormente já tínhamos salientando que em Dutenkefer (2010) exercitamos um fazer cartográfico do urbano, em particular da metrópole de São Paulo, evidenciando uma característica fundamental de seu caráter, a sua densidade populacional. Trabalhamos com um olhar geográfico orientado por um espaço geográfico como uma dimensão da sociedade. Dimensão no sentido de fazer um recorte da realidade complexa da sociedade e apreende-la optando pelo conjunto de relações sociais que se dão simultaneamente e são mediadas pela(s) distância(s) que aproximam ou afastam realidade(s) diferentes ou "iguais". A cidade é este recorte privilegiado, esta dimensão mediada por vários tipos de distâncias que aproximam ou afastam possibilidades de interações sociais.

Para Pumain (2009) o conceito de distância é raramente questionado, sua existência nos parece óbvia, sendo uma medida que separa algo. Na Geografia ela é um conceito fundamental, ou deveria ser. Para passarmos nesta concepção, nas palavras de Pumain “"'trivial" (embora já muito enraizada em nossa cultura) como reduzida a qualquer número de separação de metros ou quilômetros para ir!" (PUMAIN, 2009, p. 34, tradução nossa) teremos que avançar, expandir o seu conceito.

Brunet abre seu artigo "Les sens de la distance" (2009), discorre sobre a "trivialidade" da "distância", de como medir uma distância. Medir a distância em geografia? Ora, nada mais trivial...diríamos nós; pegue um mapa em papel ou utilize um "Google Earth" e localize um lugar "X' e aponte uma "régua" para outro lugar, o "Y", por exemplo, o que obtemos? Algumas polegadas, milhas, alguns metros, quilômetros!? Este "trivial" necessita de uma reflexão; "medir as distâncias como dimensões sociais" (BRUNET, 2009, p. 14, tradução nossa).

Além de refletirmos a distância como "dimensão social" somos conduzidos a voltar ao seu sentido mais "trivial": pensar a distância como uma separação de algo, de algum lugar. Ela pode constituir-se também como um obstáculo a ser superado para propiciar interações sociais, para interagir com objetos das mais diversas naturezas. Usamos também o termo "distância" como metáfora para expressar distâncias sociais, culturais, econômicas, etc.

Para Lévy:

A distância é um conceito central nas ciências sociais do espaço. Esta é a importância, decisiva para a existência da sociedade, interações no contato entre os operadores. Há uma variedade de distâncias e, consequentemente, um número infinito de métricas que o definem e permitem a sua medição. (LÉVY, 2009, p.175, tradução nossa)

A ênfase sutil que Lévy (2003d) propõe é que a distância deve ser caracterizada pelo grau de separação, afastamento, da diferença do estado de contato entre duas ou mais realidades. Não é separável das condições de vida em sociedade, onde ocorrem interações 
sociais, implicando que temos operadores humanos ou objetos humanizados atuantes com intenções de realizar contatos ao invés de simplesmente de provocarem o afastamento. Em síntese "a não distância é a possibilidade de interação. Distância é o impedimento, forçado ou voluntário de interação" (LÉVY, 2009, p.176, tradução nossa).

Para operarmos e tratar a(s) distância(s) do espaço geográfico necessitamos de um componente particular que constitui o espaço. Este componente é a métrica, isto é, o modo de como medimos e tratamos a distância. Lévy chama-a de um dos "elementos determinantes elementares do espaço" (LÉVY, 2003e, p.608, tradução nossa). Junto com a substância, que "define o tipo de distância que corresponde a tal fenômeno, e a escala, que define os limites de descontinuidade na medida das distâncias" (LÉVY, 2003e, p.609, tradução nossa).

A métrica expressa aqui é um modo social de medir as distâncias. Na concepção de que o espaço é absoluto, a métrica é euclidiana, isto é, iremos tratá-lo tradicionalmente utilizando os instrumentos que a matemática à época que Euclides, por volta de 300 a.C., desenvolveu. Mas, se tratarmos o espaço geográfico como não sendo geométrico euclidiano, e sim como "uma das dimensões da sociedade", ou como "elemento transversal das relações sociais, cria distâncias cujas métricas não correspondem às métricas euclidianas" (FONSECA, 2004, p.40).

\section{2 - Acessibilidade}

Em um sentido amplo e sintético a acessibilidade para Lévy é a "oferta de mobilidade", isto é, "um conjunto de possibilidades eficazes para ligar dois lugares por meio de um deslocamento" (LÉVY, 2003a p.35, tradução e grifos nossos). Compreende assim, um conjunto de deslocamentos possíveis de serem realizados, dado um contexto especifico, não somente da infraestrutura de transportes existentes, mas também de outras condições de realização deste deslocamento, por exemplo, no seu custo, na qualidade, na oferta, nos horários disponíveis, nos lugares atrativos para estes deslocamentos, etc.

Para Chapelon:

Em geografia, a acessibilidade de um lugar, em geral, é definida como a maior ou menor facilidade com que este lugar pode ser alcançado a partir de um ou vários outros lugares, por um ou mais indivíduos para deslocarem-se utilizando a totalidade ou parte dos meios de transporte existentes. (CHAPELON, 2004, p.2, tradução e grifos nossos)

Para Cauvin:

A acessibilidade em uma cidade pode ser definida, num primeiro momento, como o grau de facilidade que um ponto [nó] de uma rede pode ser atingido [acessado] a partir de outro ponto. (CAUVIN, 1998, p.77, tradução e grifos nossos) 
Notemos que os três autores empregam as expressões "eficazes", "facilidade", "deslocamento", “acessado". Remete-nos a dialogar com o conceito anteriormente explanado de distância. Acessar um ou mais lugares por meio de um deslocamento efetuado em uma cidade, por exemplo, nos leva à necessidade de efetuar uma "marcha", a pé ou por outro meio qualquer de transporte, a atingir um determinado local que estará certamente a uma determinada distância. Teremos a necessidade de realizar um contato particular com outro lugar que oferece atrativos vários para suprir as nossas necessidades como seres sociais.

Esta distância, obviamente, pode ser expressa em métricas do tipo metros ou quilômetros, mas também pode ser expressa em tempo de deslocamento.

Cauvin (1998) usa em sua definição de acessibilidade como "grau de facilidade". Este grau de separação espacial poder ser quantitativamente mensurável, e devemos apenas exprimi-la em qual métrica trabalharemos. A métrica que Cauvin (1998) propõe e que adotaremos neste ensaio é a métrica-tempo.

A acessibilidade intraurbana é a distância-tempo mínima necessária para ligar dois lugares em um modo de locomoção, empreendendo um itinerário dado, levando em conta, se possível, a noção de conforto59. (ENAUX, apud CAUVIN, 1998, p.78, tradução nossa)

\section{3 - A cartografia do revelar o invisível:}

\section{a cartografia analítica e transformacional}

Para Cauvin, Escobar e Serradj (2007a) o mapa, para ser utilizado como um instrumento de pesquisa, deve restabelecer a sua função original, ou seja, de localizar. Mas este posicionar e localizar não devem ser apenas com relação a fenômenos espaciais observáveis, mas fundamentalmente às características invisíveis que não se manifestam claramente nestes fenômenos, em sua estrutura e em seus processos. "A cartografia deve ser, assim, uma disciplina do rastrear, do detectar o invisível" (CAUVIN, ESCOBAR E SERRADJ, 2007a, p.23, tradução nossa).

Já assinalamos anteriormente que o mapa passa por uma sucessão de transformações, de famílias de transformações. Cauvin, Escobar e Serradj (2007a) a denomina de "Cartografia Analítica Transformacional”, ou simplesmente "Cartografia Transformacional”. Tobler (2000) relata em um pequeno artigo disponível em seu site ${ }^{60}$ que, oriundo da Universidade de Washington, já usava computadores e aplicações com métodos quantitativos para o campo da Geografia. Na sua chegada à Universidade de Michigan, em 1961, deparou-se com uma

${ }^{59}$ Cauvin, neste texto, não discute a noção que Enaux propõe de "conforto". Detalhes desta noção em: ENAUX, C. La notion d'accessibilité: essai de mise au point d'une approche théorique. Mémoire de DEA, UFR de Géograhie, Strasbourg, 80 p, 1991.

60 <http://www.geog.ucsb.edu/ tobler/publications/pdf_docs/cartography/Analytic_2.pdf> 
cartografia realizada manualmente e mais preocupada com aspectos gráficos visuais do projeto cartográfico do que com os aspectos analíticos. Formulou então um curso de Cartografia voltado aos aspectos analíticos. Em suas palavras:

...o meu curso foi uma tentativa de formalizar a noção que métodos cartográficos eram usados com frequência por geógrafos em suas análises e investigações. Daí o nome "Cartografia Analítica", muito embora o curso começasse como "Cartografia Computacional". .... o acesso fácil aos computadores digitais permitiu que muitos dos métodos gráficos utilizados em mapas pudessem ser reformulados como operações matemáticas. Teoria da informação e codificação de Huffman também levou-nos a uma opinião de que as informações geográficas podem ser medidas, transmitidas, armazenadas e analisadas pelos computadores. (TOBLER, 2000, p.1, tradução nossa)

Notemos aqui que os instrumentos matemáticos, estatísticos, mapas em anamorfose, etc., não são, ou não deveriam ser, novidades para os geógrafos-cartógrafos que utilizam de seus afazeres, como já salientamos anteriormente. 0 que mudou à época de Tobler, década de 1960, aos nossos dias, é que com a proliferação de computadores pessoais e a ampliação da oferta de aplicativos voltados ao fazer cartográfico [nem todos alinhados a esta perspectiva carto-geográfica], os mesmos tornaram-se mais acessíveis e mais "palatáveis" no seu uso. A dificuldade maior, que ainda persiste no seio da Geografia, é formular teorias e conceitos consistentes com esses fazeres cartográficos.

\section{4 - Cartografando a distância-tempo: os instrumentos computacionais}

No universo das transformações cartográficas apresentadas por Cauvin, Escobar e Serradj (2007b, 2008b) temos duas grandes famílias: a primeira designada como transformações cartográficas de posição temáticas e a segunda como transformações cartográficas de posição diferenciais ou de comparação.

A primeira família subdivide-se em dois grupos. As transformações de "peso", que seriam as anamorfoses e os cartogramas em anamorfose (ver Dutenkefer 2010). Acrescentase a estas, o "piezoplético"61. No segundo grupo temos as transformações ligadas às direções, particularmente as transformações cartográficas de ligação e direção unipolar e as multipolares.

As transformações de ligação e direções unipolares estão associadas às distâncias ou direções entre um local de origem e a vários locais de destino. Distâncias como uma

\footnotetext{
61 Termo similar a coroplético e isoplético. Piezo [piezo] em grego significa "força, pressão" e plético [pléthos] grande quantidade" (CAUVIN, Colette. Anaplaste 2.0 - Mode d'emploi. Paris, Besançon, Strasbourg, 2011. Disponível em: <http://thema.univ-fcomte.fr/images/Productions/ME_Anaplaste.pdf>. Acesso: 6/2/2015). Método originalmente utilizado para calcular a resistência da estrutura de um material. Para detalhes ver: SCHNEIDER, Charles. Les cartes em champs de forces (piézoplèthes). MappeMonde, n 3, 1987 e CAUVIN, ESCOBAR E SERRADJ (2008b).
} 
quantidade de separação espacial, ou temporal, ou econômica, entre dois objetos comparáveis. São, portanto, métricas não euclidianas, do tipo distância-tempo, distânciacusto, distância cognitiva, de proximidades, etc.

Utilizamos para esta pesquisa as transformações cartográficas unipolares que foram realizadas com o aplicativo IsoDistAngle ${ }^{62}$, desenvolvido por Gilles Vuidel e concebido por Colette Cauvin. Este software contempla três métodos: o IsoDist, para distâncias, o IsoAngle, para ângulos e DistAngle, para distâncias e ângulos (Cauvin, 2013).

Conhecendo a posição dos localizantes espaciais $[\mathrm{X}, \mathrm{Y}]$ de $\boldsymbol{n}$ lugares, no método IsoDist, ele foi projetado para encontrar, usando cálculos vetoriais, as coordenadas desses $\boldsymbol{n}$ pontos em relação a um ponto de origem, utilizando por exemplo a métrica tempo, isto é, entre o ponto origem e os pontos considerados como pontos destino em função do tempo. Com este aplicativo, portanto, são estabelecidos novos pontos homólogos em função da métrica estabelecida. Estes "novos" pontos, com suas coordenadas, podem ser tratados no aplicativo Darcy $^{63}$. 0 resultado que o software Darcy oferece são as transformações cartográficas de posição diferenciais ou de comparação, e o resultado cartográfico será evidenciado em anamorfoses que oferecem possibilidades de análise do espaço estudado.

Segundo Cauvin (2009) o software Darcy permite aplicar um método de comparação espacial, denominado de "regressão bidimensional", desenvolvido por Waldo Tobler entre 1965 e 197764. Este método permite a comparação de duas superfícies distintas, determinadas pelos pontos homólogos respectivamente definidos pelas coordenadas [X,Y] (coordenadas geográficas originais ou fonte) e $[\mathrm{U}, \mathrm{V}]$ (coordenadas da imagem que será comparada). A imagem, para comparar com os pontos originais que correspondem ao fenômeno a ser estudado: posição em métricas tipo tempos de acesso, posição de cognição espacial estimada e também com a possibilidade de analisar posições em mapas antigos, etc.

\section{5 - Procedimentos metodológicos}

O nosso recorte espacial territorial utilizado configura um fundo de mapa dividido em 96 zonas que correspondem aos distritos administrativos usados pelo poder estatal municipal

62 Aplicativo escrito em Java e disponível em: <http://vuidel.org/isodist/>. Acesso: 6/12/2010. Atualmente para download ver: < http://thema.univ-fcomte.fr/le-laboratoire-thema/16-categories-en-francais/catproductions-fr/cat-logiciels-fr/295-art-isodistangle> Acesso: 2/5/20015.

63 Aplicativo escrito em Java e disponível em : <http://spatial-modelling.info/-Spatial-analysis-tools->. Acesso: 6/12/2010. Atualmente para download ver: < http://thema.univ-fcomte.fr/le-laboratoire-thema/16-categoriesen-francais/cat-productions-fr/cat-logiciels-fr/294-art-darcy> Acesso: 2/5/20015.

64 Para detalhes do método ver: CAUVIN, Colette. Une Methode generale de comparaison cartographique: la regression bidimensionnelle. Travaux et recherches, Fascicule 4. Strasbourg : U.E.R. DE GEOGRAPHIE, Universite Louis Pasteur/ E.R.A. 214 C.N.R.S., 1984.

Para o artigo de Tobler ver < http://www.geog.ucsb.edu/ tobler/publications/pdf_docs/BiDimensionalRegression.pdf> 
- a prefeitura de São Paulo - como base em seus planejamentos de governo. Fundo de mapa este, ou, como é mais conhecido, na literatura brasileira - base cartográfica oficial - em formato vetorial do tipo shapefile ${ }^{65}$.

Este formato foi transformado em aplicativo MapShaper ${ }^{66}$, que generalizou as suas feições, ou seja, generalizou seu contorno geométrico, com o objetivo de não agregar informações visuais desnecessárias na visualização final dos mapas elaborados (ver figura 39).

Na sequência foi transformado, em aplicativo SIG - ArcGis, em formato $k m z$ - compatível com o aplicativo on line [acesso pela internet] Google Earth ${ }^{67}$. Neste aplicativo estabelecemos os pontos nos 96 distritos de São Paulo. Coletamos assim, coordenadas geográficas em projeção Universal Transversa de Mercator [UTM] com Datum SAD 69 necessárias para estabelecer as coordenadas da rede dos pontos fonte. Neste mesmo aplicativo, definimos os itinerários da Sé para o restante dos outros 95 distritos. Ao definirmos o tipo de modalidade de transporte utilizado, o aplicativo pode se reportar ao Google $\mathrm{Maps}^{68}$. Neste aplicativo podemos refinar as nossas opções de modalidade, automóvel, ônibus, ônibus-metrô e coletar os tempos médios de acesso, [procuramos um horário de pico entre as 16 e 19h50, ou seja, a volta do centro de São Paulo aos distritos] o custo do transporte em questão, a distância do percurso em quilômetros, etc. Ver o exemplo do itinerário Sé-Grajaú em modalidade ônibus [figura 40]. Na figura 39 temos o fundo de mapa euclidiano generalizado com as representações dos 96 distritos do município de São Paulo e os respectivos locais de destino. O levantamento dos dados foi realizado em 10,11 e 12 de dezembro de 2013 no período entre $16 \mathrm{~h}$ e $19 \mathrm{~h} 50$.

65 Formato vetorial originalmente desenvolvido pela ESRI [Environmental Systems Research Institute]. 66 Aplicativo on line [acesso pela internet] que por meio de 3 diferentes métodos, generaliza fundos de mapa digitais que estejam em formato shape file. Disponível em: <http://mapshaper.org/>. Acesso: 20/02/2010. [MapShaper is a free online editor for Polygon and Polyline Shape files. It has a Flash interface that runs in an ordinary web browser - The MapShaper project was conceived in 2005 by Matthew Bloch

|<http://maps.grammata.com> - New York Times graphics editor| and Mark A. Harrower |Associate Professor of Geography, UW-Madison| |<http://www.geography.wisc.edu/ harrower/>| at the University of Wisconsin, Madison Geography Department - USA]. Detalhes do aplicativo no "paper" disponível em: <http://maps.grammata.com/autocarto2006_paper.pdf>.

67 Aplicativo on line [acesso pela internet] desenvolvido e distribuído pela empresa estadunidense Google e cuja função é apresentar um modelo bi ou tridimensional da superfície terrestre, construído a partir de um mosaico de imagens de satélite obtidas de fontes diversas.

${ }^{68}$ Aplicativo on line [acesso pela internet] desenvolvido e distribuído pela empresa estadunidense Google e cuja função é a visualização de mapas e imagens de satélite agregando serviços com ferramentas de busca por endereço, trajetos oferecidos em modo multimodal em redes viárias, etc. 
|Figura 39| Fundo de mapa dos distritos do município de São Paulo com o local de origem e destino

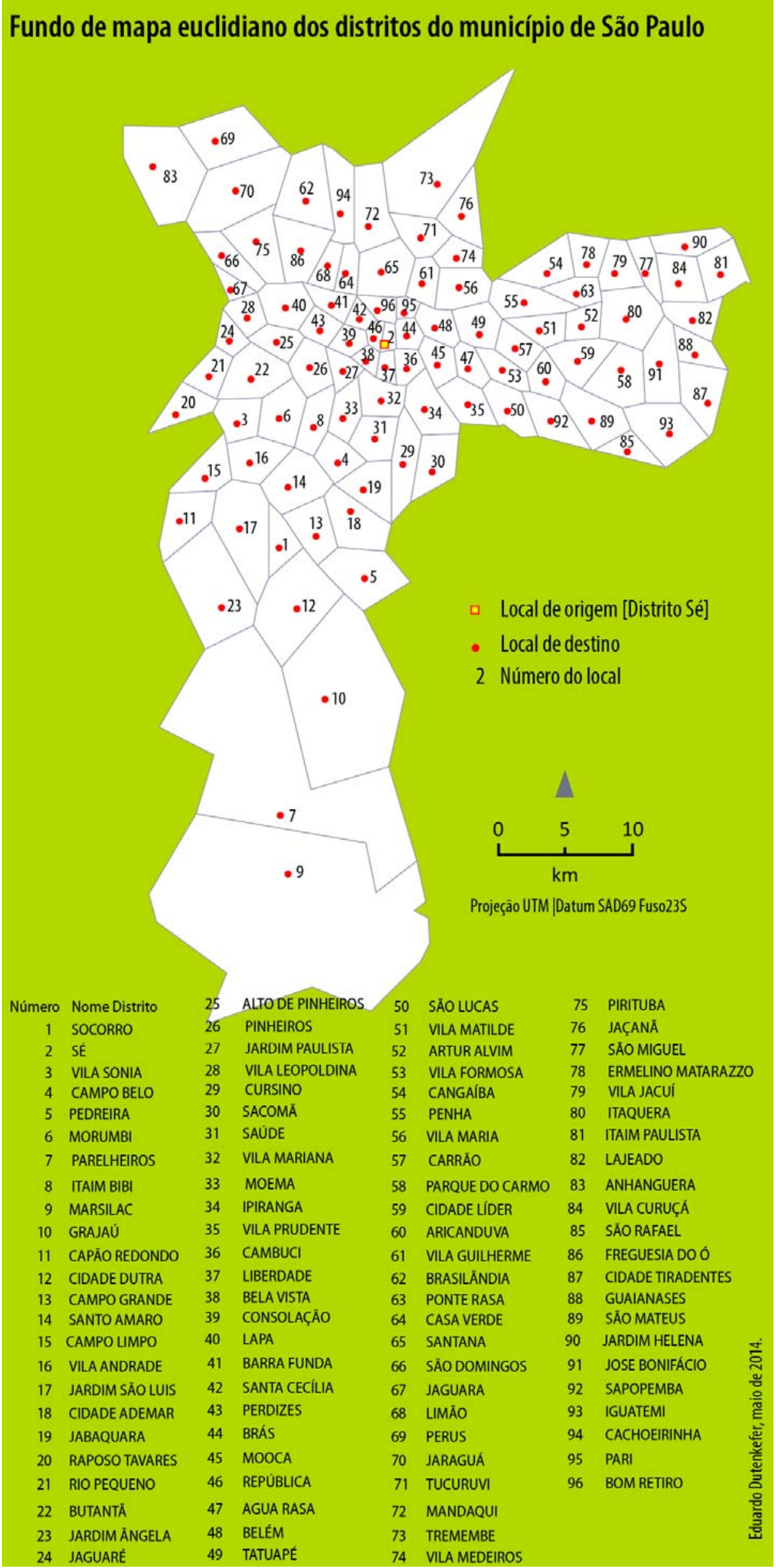


|Figura 40| Trajeto Sé-Grajaú em modalidade ônibus. [Informações de agências locais:SPTRANS. Dados cartográficos @2013 Google, MapLink].

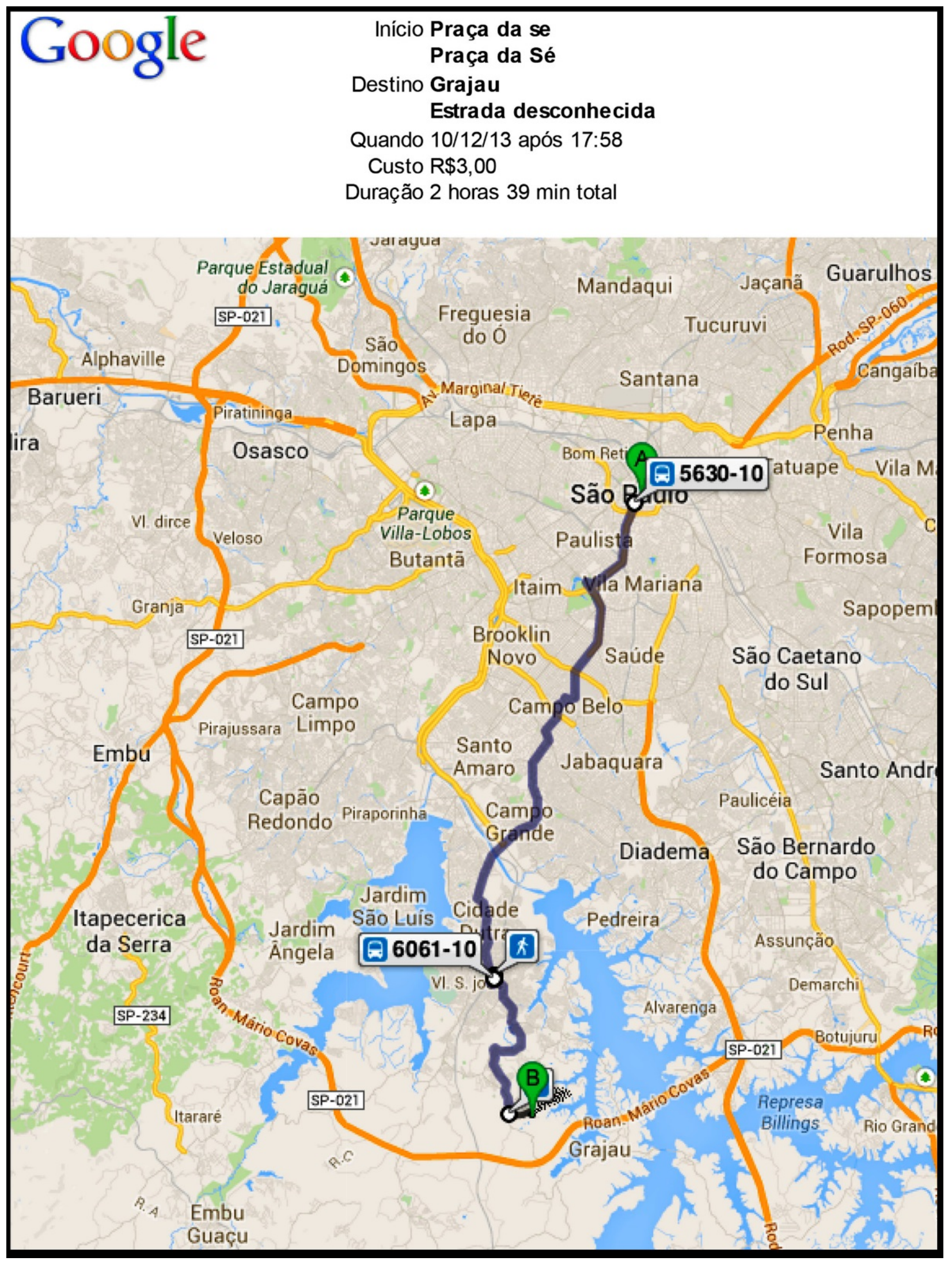


|Figura 41| Planilha eletrônica dos dados coletados

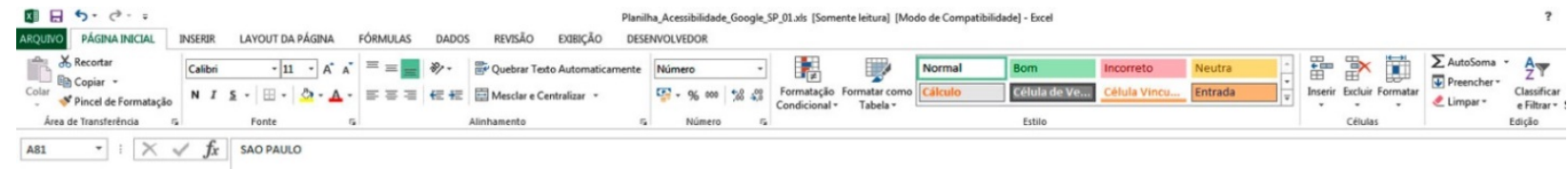

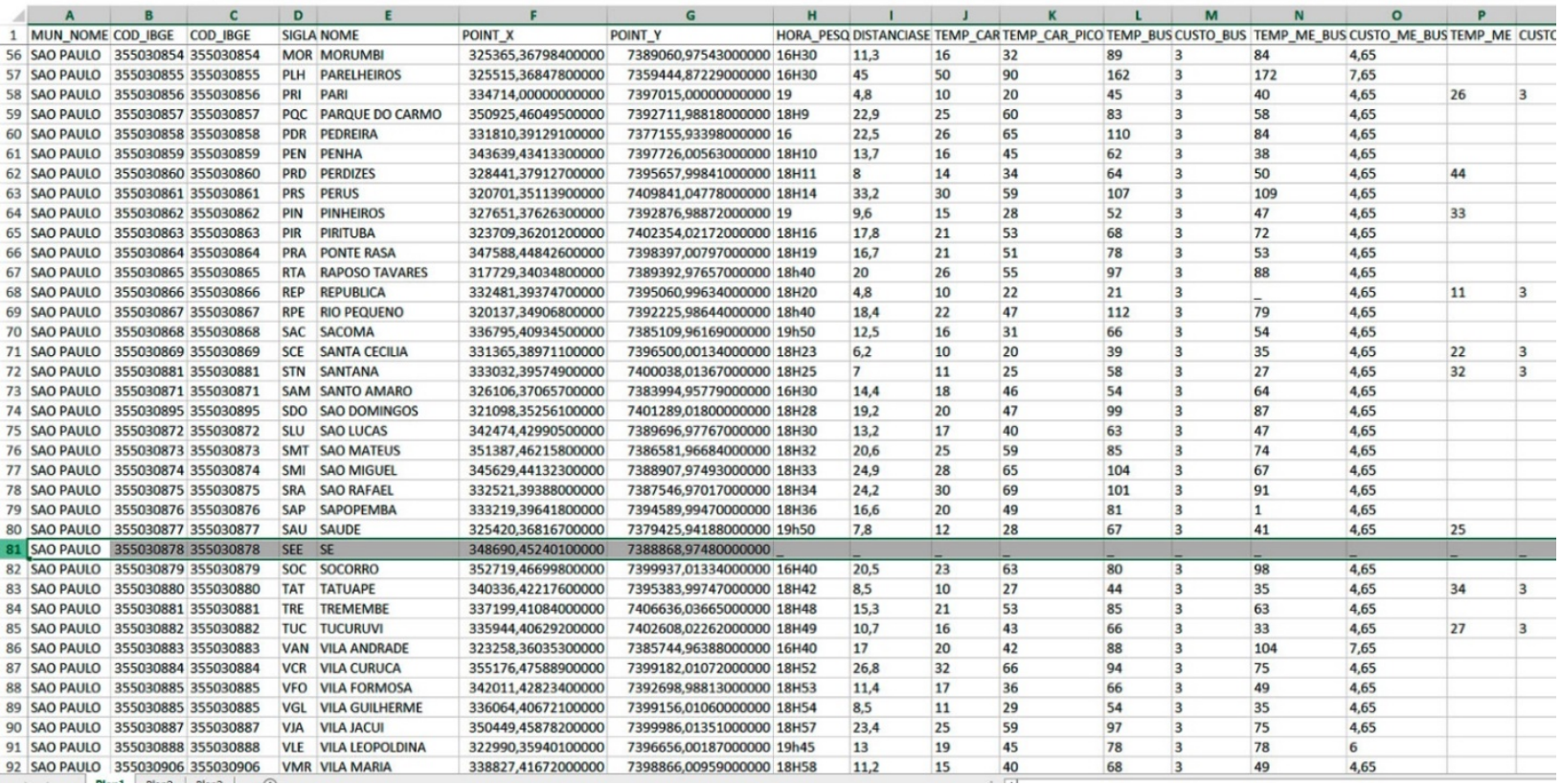

Construímos uma planilha no software Excel 3- figura 41 - com os diversos dados coletados por meio do Google Earth e Maps.

Criamos então um arquivo em formato txt com as coordenadas em UTM e com o tempo de percurso para dar entrada no aplicativo IsoDistAngle - figura 42.

No IsoDistAngle também é possível inserir um fundo de mapa em formato shape. Executamos os procedimentos necessários do aplicativo e exportamos o resultado em formato svg e txt. No arquivo em txt de saída coletamos então as novas coordenadas já transformadas em distância-tempo para usarmos no aplicativo Darcy.

|Figura 42| Coordenadas dos pontos e tempo de percurso em formato $t x t$.

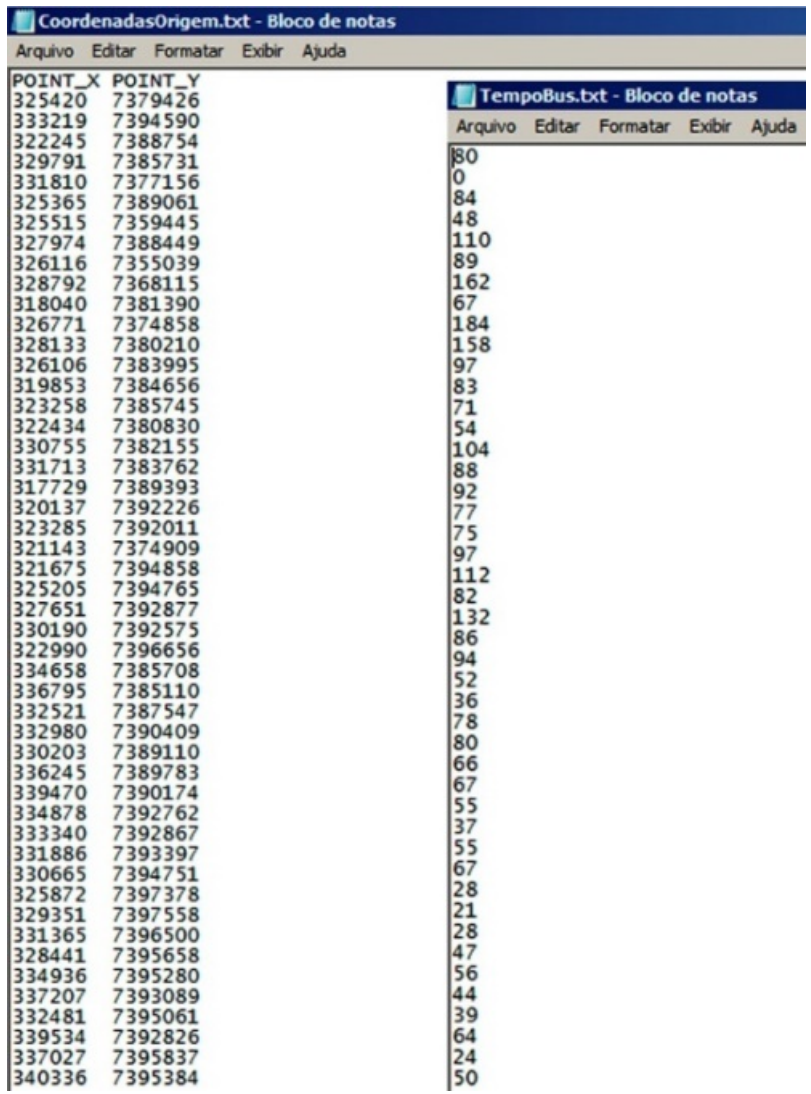




\section{6 - Explorando os dados}

Antes de mostrar os resultados desta metodologia exploramos um pouco o que é possível fazer em termos de representações cartográficas e gráficas com os dados coletados.

Na figura 43 temos quatro (4) representações cartográficas que exprimem o deslocarse dentro do município de São Paulo por meio de automóvel e ônibus avaliando quatro variáveis individualmente:

- $\quad$ em 5.1 o tempo médio de acesso utilizando o automóvel;

- em 5.2 o tempo médio de acesso utilizando o ônibus;

- em 5.3 a velocidade média realizada pelo automóvel;

- em pôr fim, em 5.4, a velocidade média desenvolvida por ônibus.

Em 5.1 e 5.2 não temos grandes surpresas dentro do que o nosso "senso comum" permite avaliar em relação ao tempo médio de deslocamento. Lugares mais afastados da origem possuem um maior valor em tempo em relação aos lugares mais próximos ao local no distrito da Sé. Com automóvel temos uma média de 20,11 minutos, enquanto que o realizado por ônibus mais que duplica: 77,28 minutos. 


\section{|Figura 43| Acessibilidade em função do tempo médio e velocidade média}

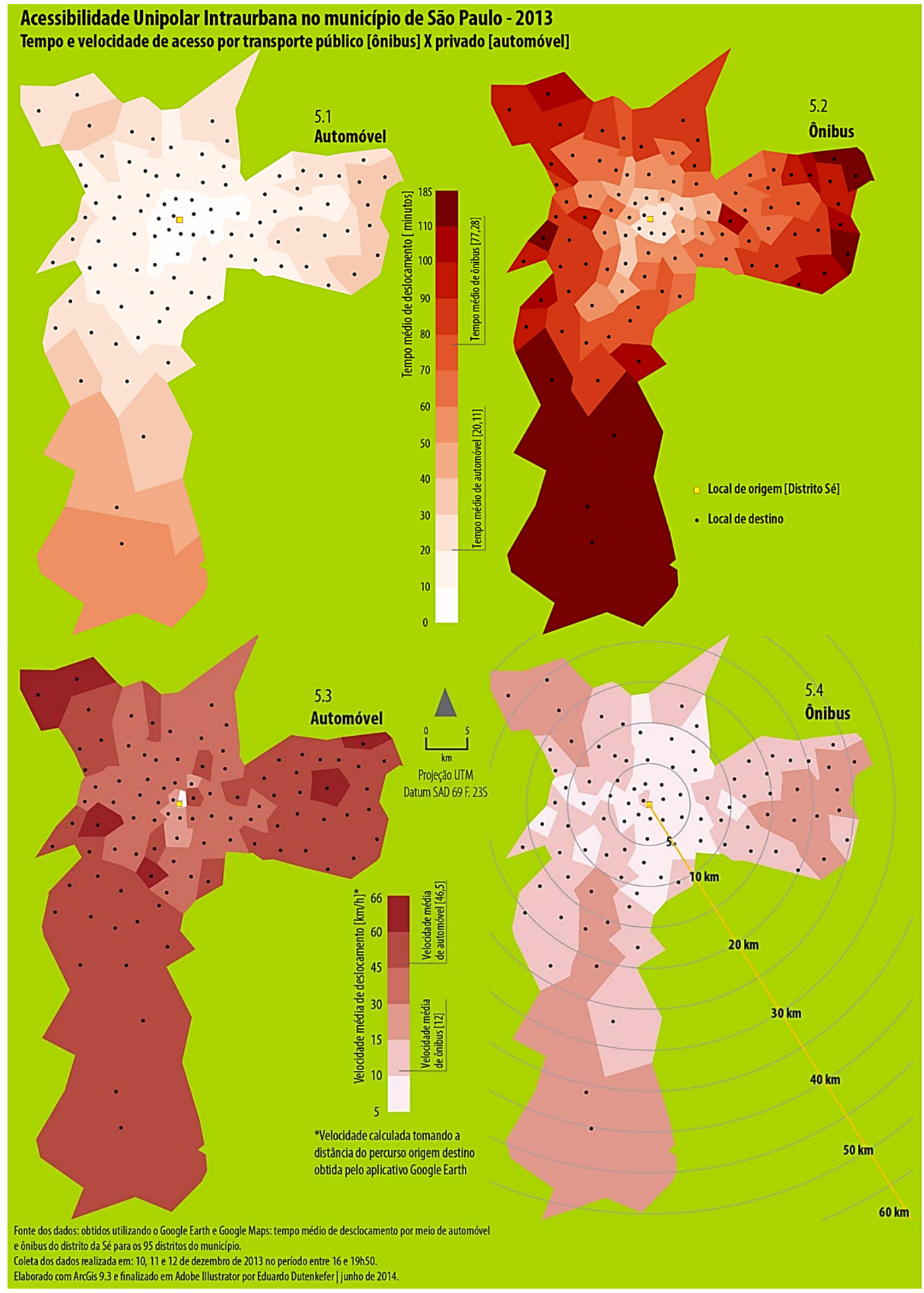


Em 5.3 e 5.4 vemos expressa a velocidade média de deslocamento na rede viária do município em $\mathrm{km} / \mathrm{h}$. Para o automóvel temos uma média de $46,5 \mathrm{~km} / \mathrm{h}$ enquanto que para o ônibus esta média cai para $12 \mathrm{~km} / \mathrm{h}$. Notamos visualmente que a velocidade média mais próxima ao local de origem diminui em ambos os meios de deslocamento. Notamos, ainda, alguns distritos com boas velocidades a noroeste do município para automóvel e ônibus. Notamos também uma faixa do extremo sul ao centro com "boa" velocidade para ônibus.

Na figura 44 cruzamos as duas variáveis, tempo de deslocamento com ônibus e tempo de deslocamento com automóvel. Para este cruzamento optamos em utilizar o método de quadrantes (Cauvin, Escobar e Serradj, 2008a). É uma generalização dos atributos temáticos. Por meio de um gráfico foram plotados os locais com os tempos de ônibus no eixo $\mathbf{Y}$ e, no eixo X, o tempo do automóvel. Obtivemos assim quatro (4) quadrantes separados pelas médias de tempo por ônibus e por automóvel que mostram:

- no quadrante 1 temos 44 distritos com locais com bom acesso em tempo por transporte privado (automóvel) e público (ônibus);

- no quadrante 2 somente 4 distritos com locais com bom acesso em tempo por transporte público e acesso ruim por transporte privado;

- no quadrante 3 com 14 distritos com locais com acesso ruim em tempo por transporte público e bom acesso por transporte privado;

- no quadrante 4 com 34 distritos com locais com acesso ruim em tempo por transporte público e privado.

O mapa da figura 44 é uma tentativa de expressar cartograficamente o resultado do método apresentado. 


\section{| Figura 44| Método de quadrantes}

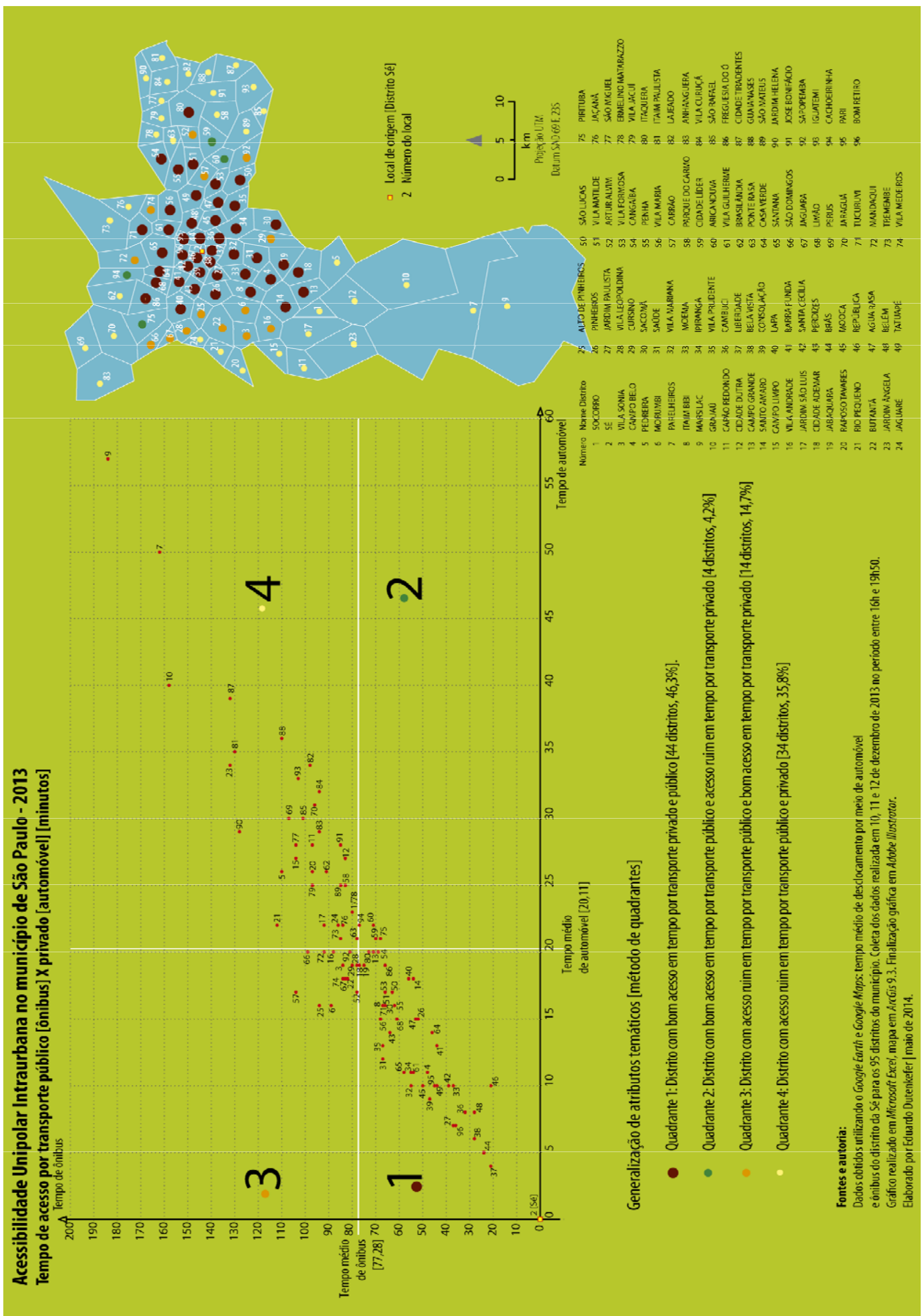




\section{7 - Resultados}

\subsection{1 - Etapa 1 - Aplicativo IsoDistAngle}

Na figura 45 temos a saída do aplicativo IsoDistAngle, com o método IsoDist, com o deslocamento efetuado por meio do automóvel e de ônibus.

Uma interpretação para os dois mapas é que quando os vetores se afastam e, portanto, os pontos distância-tempo estão afastados do centro de origem [Distrito Sé] teríamos uma acessibilidade média relativa mais prejudicada levando em conta toda a estrutura da rede viária que foi percorrida. Ao contrário, isto é, quando os vetores são "atraídos" para o centro, teríamos uma melhor acessibilidade relativa destas localizações. No detalhe, dois gráficos que expressam a velocidade com carro e ônibus. Temos uma velocidade média da rede para ambos os modos de locomoção. Se a velocidade for maior que a média da rede, temos uma aproximação dos pontos em distância-tempo. Com velocidade menor que a média da rede, temos um afastamento dos pontos.

0 resultado visual cartográfico não é tão comunicativo para chegar a estas interpretações. Estamos ainda em um referencial de fundo de mapa euclidiano. Na próxima etapa, utilizando o aplicativo Darcy, teremos uma melhor visualização dos resultados. 
|Figura 45| Deslocamento por meio de automóvel e ônibus e localizações em distância tempo -Aplicativo IsoDistAngle

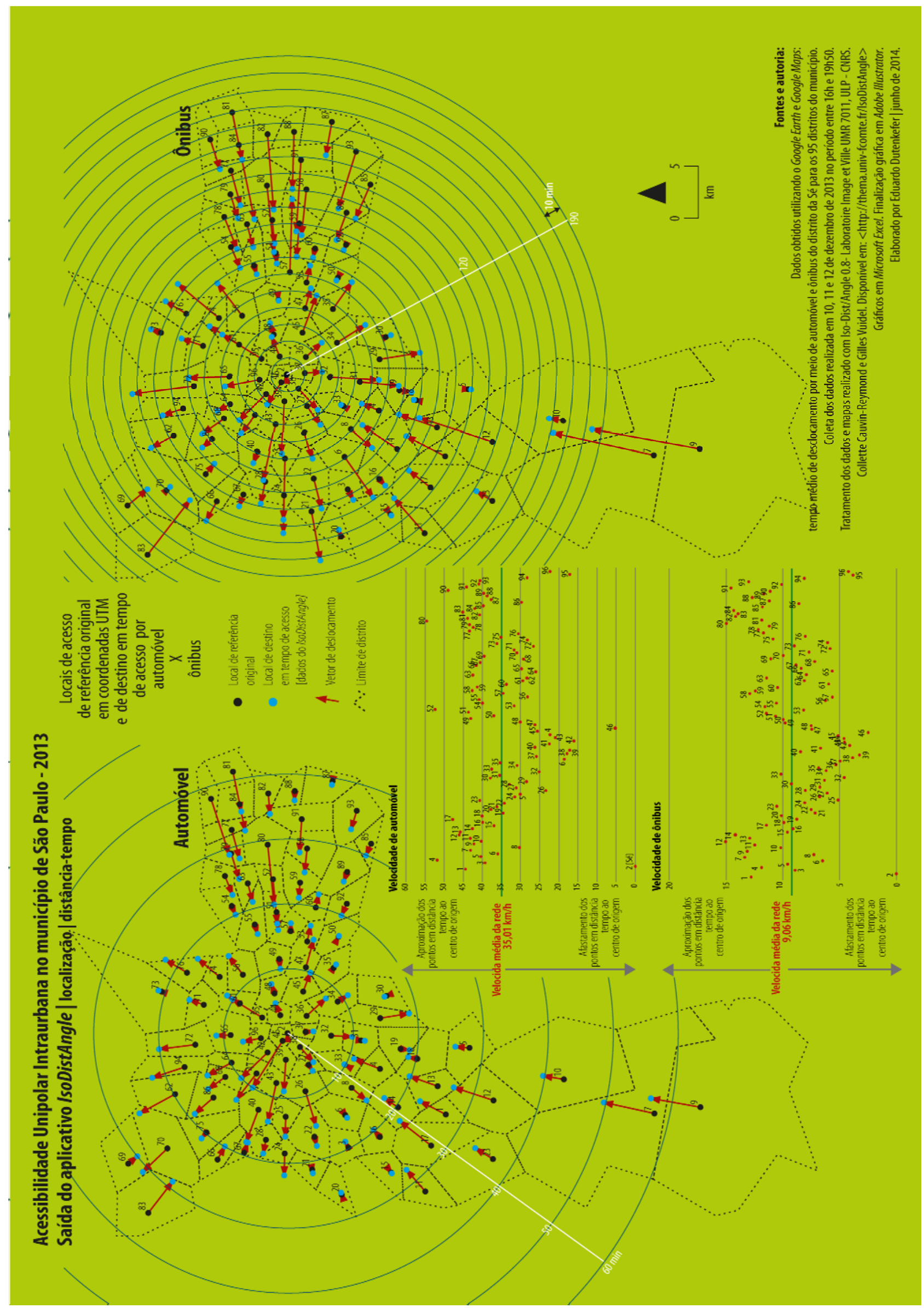




\subsection{2 - Etapa 2 - Aplicativo Darcy}

Entramos com os dados de referência iniciais - locais nos distritos em coordenadas UTM e com as coordenadas de distância-tempo realizados pelo aplicativo IsoDistAngle. Como os dados já foram ajustados pelo IsoDistAngle não precisamos ajustá-los novamente no Darcy. Passamos diretamente à segunda etapa que Cauvin (2009) denomina de método de interpolação, ou seja, será construído um novo conjunto de dados a partir do conjunto referência ou imagem inicial. Como resultado teremos anamorfoses evidenciando áreas de maior e menores acessibilidade média por meio de deslocamento efetuado com o automóvel e ônibus no município de São Paulo. Na figura 46 as duas transformações cartográficas de posição diferenciais ou de comparação são apresentadas. Marcamos também algumas áreas para as reflexões a seguir.

\section{8 - Reflexões parciais}

O método apresentado possibilita o "revelar do invisível", ou seja, por meio de instrumentos e métodos quantitativos utilizados pela cartografia analítica transformacional revelou-se a acessibilidade unipolar intraurbana no município de São Paulo. Um fenômeno geográfico importante para as cidades e que é difícil de revelar com mapas de fundo euclidiano.

Podemos visualizar claramente nos mapas na figura 46 as áreas com maiores e menores "graus de facilidade" que os usuários de transporte individual e coletivo - partindo da Praça da Sé - podem acessar os demais distritos de São Paulo. Quando há uma contração do grid indica uma maior acessibilidade dessa região comparada à média da rede. Inversamente, uma expansão do grid, indica uma menor acessibilidade.

No caso do automóvel percebemos 3 eixos com maiores destaques visuais. Um eixo a noroeste nos distritos de Anhanguera, Perus e Jaraguá, outra faixa de oeste a sudeste nos distritos de Jaguará, Jaguaré, Vila Leopoldina, Butantã, Pinheiros, Alto de Pinheiros, Morumbi, Itaim bibi, Campo Belo, Moema e Saúde. O terceiro na área "central” da zona leste do

município no eixo entre os distritos da Penha, Vila Formosa, Água Rasa, Cangaíba, Ponte Rasa e Aricanduva.

Por meio do transporte coletivo exclusivamente de ônibus percebemos 5 eixos: noroeste, nos distritos de Brasilândia, Pirituba e São Domingos. Uma faixa [a maior] de oeste em direção ao sudeste nos distritos da Lapa, Barra Funda, Vila Leopoldina, Butantã, Vila Sonia, Jaguaré, Vila Andrade, Itaim Bibi, Santo Amaro, Campo Grande, Socorro, Cidade Dutra, Campo Belo, Cidade Ademar, Saúde, Vila Mariana, Cursino e Sacomã. No setor leste são revelados dois setores; Carrão, Aricanduva e Sapopemba e em outro nos distritos de Vila Curuçá, Artur 
Alvim, Lajeado, Carrão, Cidade Líder e José Bonifácio. No sul dois setores “tentam se destacar": Grajaú e Parelheiros.

0 potencial oferecido pelos métodos e metodologias apresentados abre várias possibilidades na análise da acessibilidade utilizando o sistema viário intraurbano do município de São Paulo. Em seu potencial de revelar o "invisível" [o mapa sempre revela mais que o visível...] levanta questões que devem ser aprofundadas em outras pesquisas. Por que estes eixos revelaram melhor acessibilidade? Aqui neste ensaio apenas utilizamos a métrica tempo para medi-la. Que outros componentes deverão ser analisados? 0 que tem de particular nos trajetos viários de origem-destino que moldaram os mapas finais?

0 método da acessibilidade unipolar aqui apresentado não representa a "interacessibilidade entre os lugares", isto é, como é a acessibilidade entre todos os lugares possíveis em uma cidade como proposta por Lévy para ser considerada como um dos indicadores de urbanidade. Ele dá pistas da acessibilidade de um lugar para os demais lugares que teoricamente um habitante de São Paulo necessita em se locomover. Teríamos que utilizar a mesma metodologia para os demais 95 lugares dos distritos, um por um, para ter um quadro mais completo. Mas é um indicador prévio que permite "localizar", na escala distrital do município de São Paulo, os melhores distritos com uma melhor acessibilidade que outros em relação aos caminhos percorridos até atingir o centro histórico de São Paulo. É um "proxy" do estado que se encontra o uso da métrica pedestre na cidade revelada na modalidade ônibus. 
|Figura 46| Mapas elaborados no aplicativo Darcy com indicações dos setores com maior acessibilidade média relativa da rede viária com a métrica tempo de percurso com automóvel e ônibus.

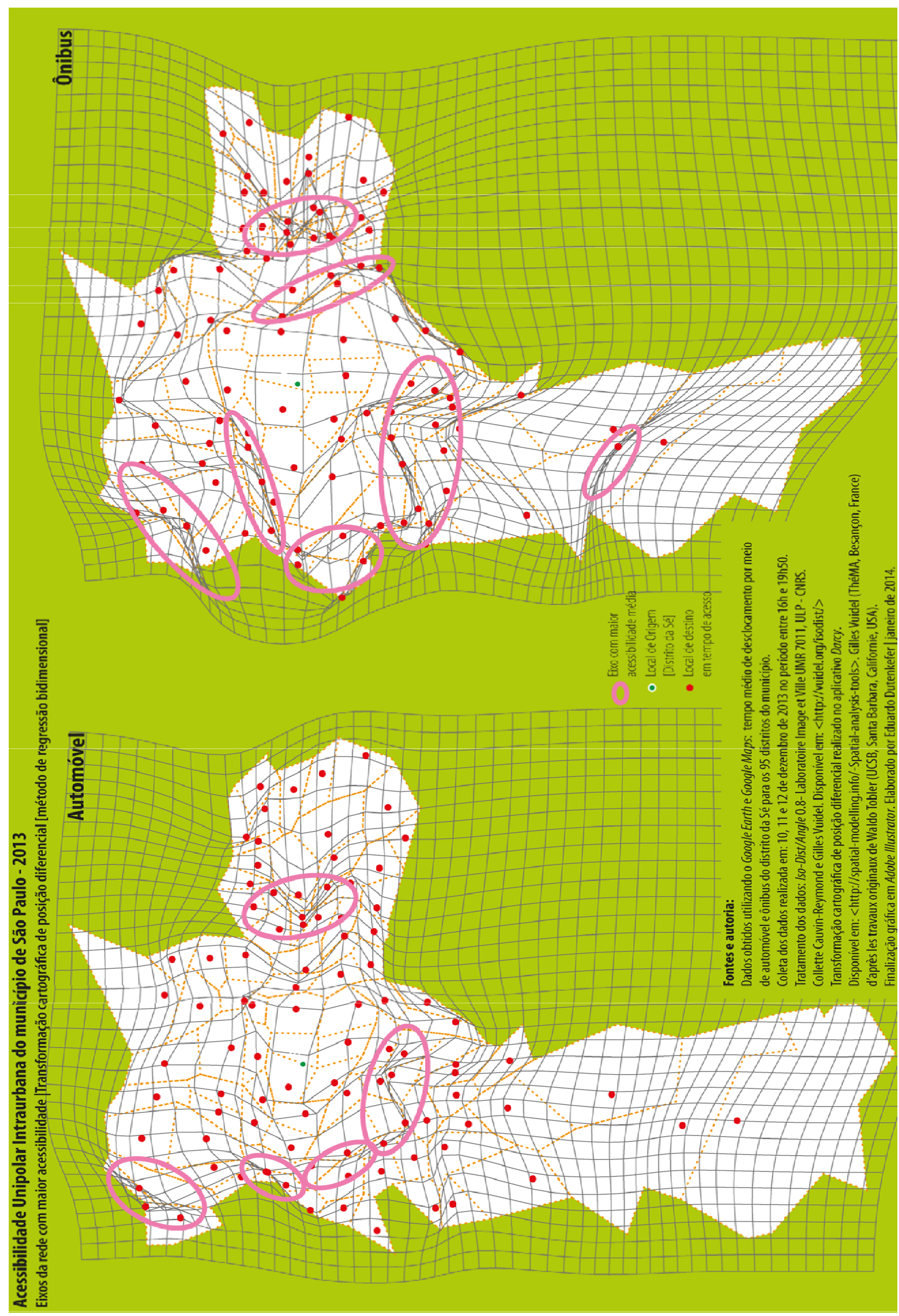




\section{0 - Um mapa-modelo para representar a urbanidade de São Paulo}

Um fenômeno, um conceito ou uma ideia, de modo geral, podem ser expressos por meio de uma representação visual seja ela um desenho, uma fotografia, uma pintura, um grafismo, um mapa... Essencialmente, esta representação visual é utilizada para facilitar a comunicação em nossa sociedade. Buscamos interagir socialmente por meio de mensagens. Esta mensagem pode ser polissêmica, isto é, pode expressar certa ambiguidade do que queremos expressar, representar. Ela pode criar ou ser uma imagem que pode ter vários significados individuais, coletivos, culturais. Dependente das múltiplas diversidades culturais que a sociedade humana permite expressar historicamente. Dentre estas representações visuais a representação gráfica tenta atenuar esta ambiguidade. Ela é uma linguagem visual que se insere no domínio que denominamos de sistema semiológico monossêmico. Ela é associada aos significados que os signos estabelecem em suas relações, isto é, o que podemos perceber quase que instantaneamente nas relações que os objetos, fatos e fenômenos apresentam em um relance ao nosso olhar. Uma representação gráfica tenta reduzir a complexidade de informações que um fenômeno pode apresentar. Informações que podem ter uma multiplicidade de dados e que isolamos, recortamos parcialmente para análise e estudo de uma realidade mais complexa. Transformamos, assim, em representações, em um conjunto de relações mais simples e globais com a finalidade de transmitir uma mensagem o menos polissêmica possível. Quando realizamos um gráfico de duas variáveis estabelecemos relações únicas entre elas. Uma representação de rede são as relações entre os elementos de um mesmo conjunto de variáveis que são estabelecidos. E, por fim, em um mapa, deveríamos estabelecer um único conjunto de relacionamentos espaciais entre os objetos representados. (FONSECA, 2004, MARTINELLI, 2014, DANTIER, 2008).

O objetivo principal deste capítulo é apresentar uma proposta de representação gráfica, em particular uma representação que podemos denominar de pós-cartográfica. Uma representação gráfica que altera a representação de seu fundo de mapa. Fundo este elaborado com as técnicas clássicas da cartografia de uma representação do território do município de São Paulo com as suas divisões administrativas usuais em distritos, usadas normalmente em planejamento pelo poder estatal municipal e pelos meios de comunicações jornalísticas em geral.

Iremos transformar os limites das unidades espaciais denominadas de distritos do município de São Paulo em representações gráficas geométricas mais "simples". O propósito principal é oferecer e estabelecer um fundo de mapa que não interfira em demasia nas 
propriedades visuais essenciais quando o principal desta representação é transmitir uma mensagem mais "clara” possível de um fenômeno que podemos representar graficamente.

Os mapas, para a Geografia, são representações espaciais particulares que deveriam revelar objetos e processos espaciais onde, de um modo geral, as localizações, diferenciações, limites ou continuidades espaciais, distâncias, sejam euclidianas ou não, conexões, interações localizadas, qualificações e quantificações possíveis de um fenômeno em estudo são fundamentais. Não estamos imbuídos aqui de localizar, de estabelecer limites e distâncias territoriais "precisas". Como geógrafos-cartógrafos nosso intuito aqui é tentar "preservar" uma imagem que lembre o território do município de São Paulo como um "todo". Compor uma representação gráfica que seja capaz de privilegiar temas qualitativos e/ou quantitativos para comunicar, transmitir uma mensagem menos equivocada, com menor grau de múltiplos sentidos e significados possíveis.

\section{1 - Motivações e inspirações}

A obra seminal de Jacques Bertin, publicada em 1967 - "La Sémiologie graphique"69, apresenta uma linguagem gráfica, uma "gramática visual" que deveria ser ensinada a todos que estejam em uma fase cognitiva mais favorável para a apreensão do significado que as imagens podem representar em sua forma de apreender o mundo. Ela oferece um conjunto de regras, caminhos possíveis para produzir representações gráficas que sejam eficazes em seu poder de comunicar, de transmitir uma mensagem mais clara possível. Em particular, para um “artesão geógrafo-cartógrafo”, a elaboração de mapas, que são objetos gráficos por excelência, deveria permitir mapas que façam sentido ao nosso olhar, "mapas para ver" e não "mapas para ler" como Bertin assinalava em seu artigo de 198070. (BERTIN, 1988).

0 mapa é uma imagem reduzida do mundo, é um recorte do espaço geográfico. Espaço que pode ser compreendido com o olhar cientifico e/ou filosófico que o privilegia como um espaço absoluto. Seria como um "palco" onde estamos mergulhados em nossos afazeres diários. Outro olhar é considerá-lo como espaço relacional, construído em nossa "labuta" diária impactada pelas intensidades de nossas relações sociais.

Expresso geralmente em duas dimensões do plano, esta "gramática visual" de Bertin, tem como objetivo transformar, "traduzir uma informação geográfica em sinais gráficos inscritos nas duas dimensões particulares do espaço" (ANDRIEU, 2014, p.123). Sinteticamente esta "gramática visual" deveria permitir transcrever relações que expressem informações

\footnotetext{
${ }^{69}$ Utilizamos aqui a edição reimpressa de 1998.

${ }^{70}$ Originalmente publicada em : «Voir ou lire », dans Cartes et figures de la Terre, Centre Georges Pompidou, Paris, Centre de création industrielle, p. 2-8. 1980.
} 
geográficas. Para Bertin (1998), seriam contempladas em algumas propriedades perceptivas que ele denominou de "variáveis visuais", ou seja, permitiriam que nosso olhar humano fosse sensível a variações do tipo:

1. Seletivo: informações que tem o caráter de ser diverso, diferente. Nosso aparelho visual deveria selecionar "naturalmente" expressões, sempre alertando que são representações em um plano de duas dimensões, que indiquem diferenças, diversidades visuais. Nosso olhar isola elementos distintos usados normalmente para objetos qualitativos em um mapa.

2. Associativo: nosso olhar associa objetos que são iguais, que tenham um mesmo valor visual;

3. Ordenado: os objetos representados criam uma ordem visual espontaneamente ao nosso olhar. Cria categorias que expressa uma ordem, uma hierarquia visual;

4. Quantitativo: exprime espontaneamente uma relação numérica, uma relação de proporção, tamanho.

Bertin (1998) elenca 8 variáveis visuais (figura 47). As duas dimensões do plano do mapa onde teremos o nosso fundo de mapa e a variação visual de tamanho, forma, valor, ordem, cor e granulação.

Nós apresentaremos aqui uma proposta onde a nossa intervenção visual se dá no fundo de mapa. A participação desta variável visual no plano muitas vezes "concorre", ou poderíamos dizer que ela também "disputa" a nossa percepção visual com outras variáveis visuais que podemos elaborar em nossas representações gráficas por meio de mapas.

Uma de nossas "inspirações" teve como origem um trabalho original de uma agência de design gráfica britânica ${ }^{71}$ onde propõe uma "London Squared", isto é, uma Londres desenhada como se fosse uma malha de quadrados [figura 49]. Lembrando as formas do mapa da cidade [figura 48] com seus bairros. Incluíram nesta proposta visual o rio Tamisa, um ícone da cidade de Londres. A proposta é oferecer um "fundo de mapa" sem variações do tamanho territorial para não ofuscar seriamente os possíveis dados, informações qualitativas ou quantitativas que devem ser privilegiadas em relação ao seu fundo de mapa original.

\footnotetext{
${ }^{71}$ Disponível em: <http://www.aftertheflood.co/projects/london-squared-map> Acesso: 10/04/2015, em parceria com a empresa Future Cities Catapult : <https://futurecities.catapult.org.uk/>
} 
|Figura 47| As variáveis visuais de Bertin: 2 DP = as duas dimensões do plano, $T$ = tamanho, $\mathbf{F}=$ forma, valor, $\mathrm{OR}=$ orientação, $\mathrm{C}=\mathrm{Cor}, \mathbf{G}=$ granulação

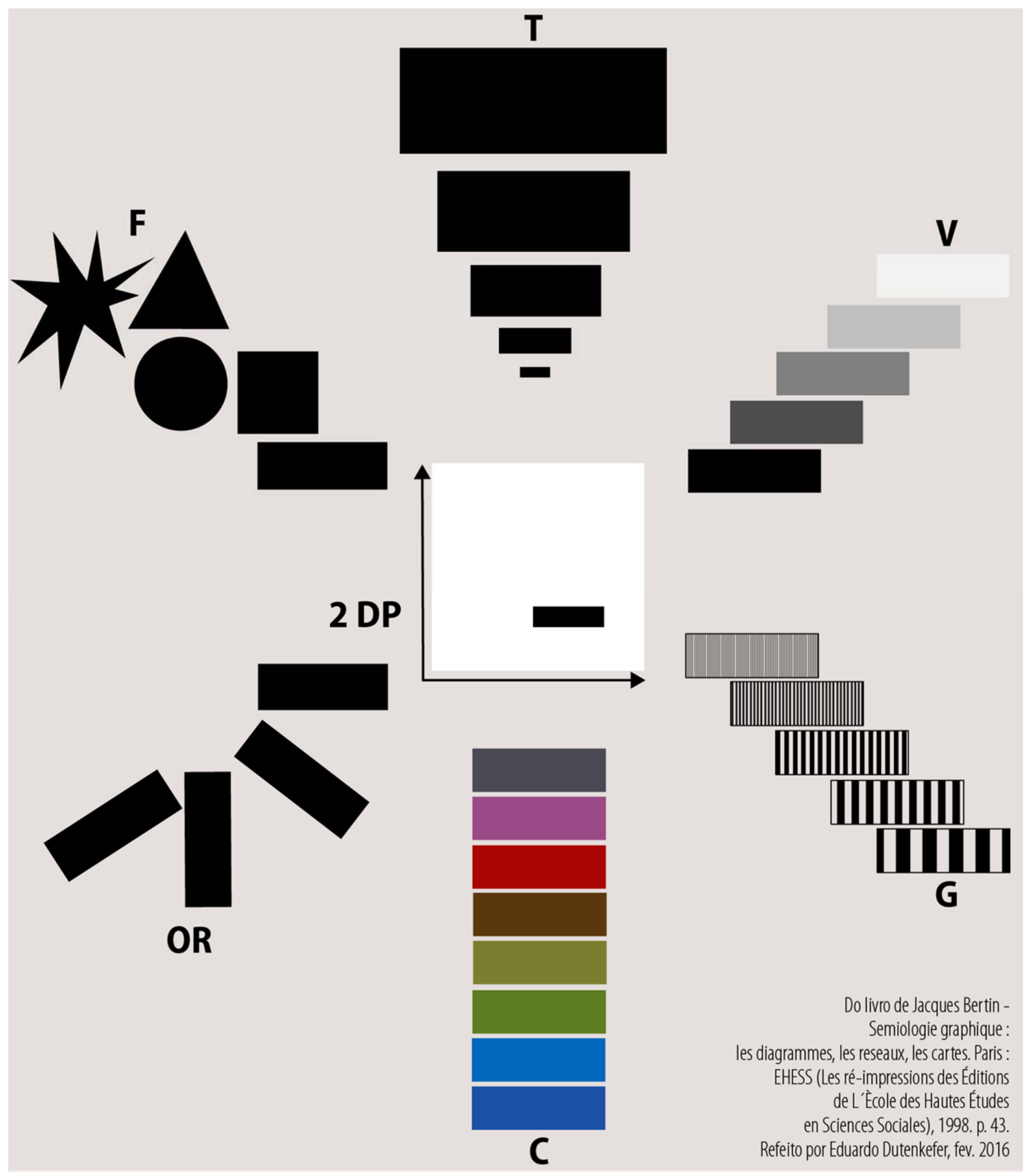


|Figura 48| Fundo de mapa territorial de Londres

com as suas subdivisões administrativas e mais o rio Tamisa

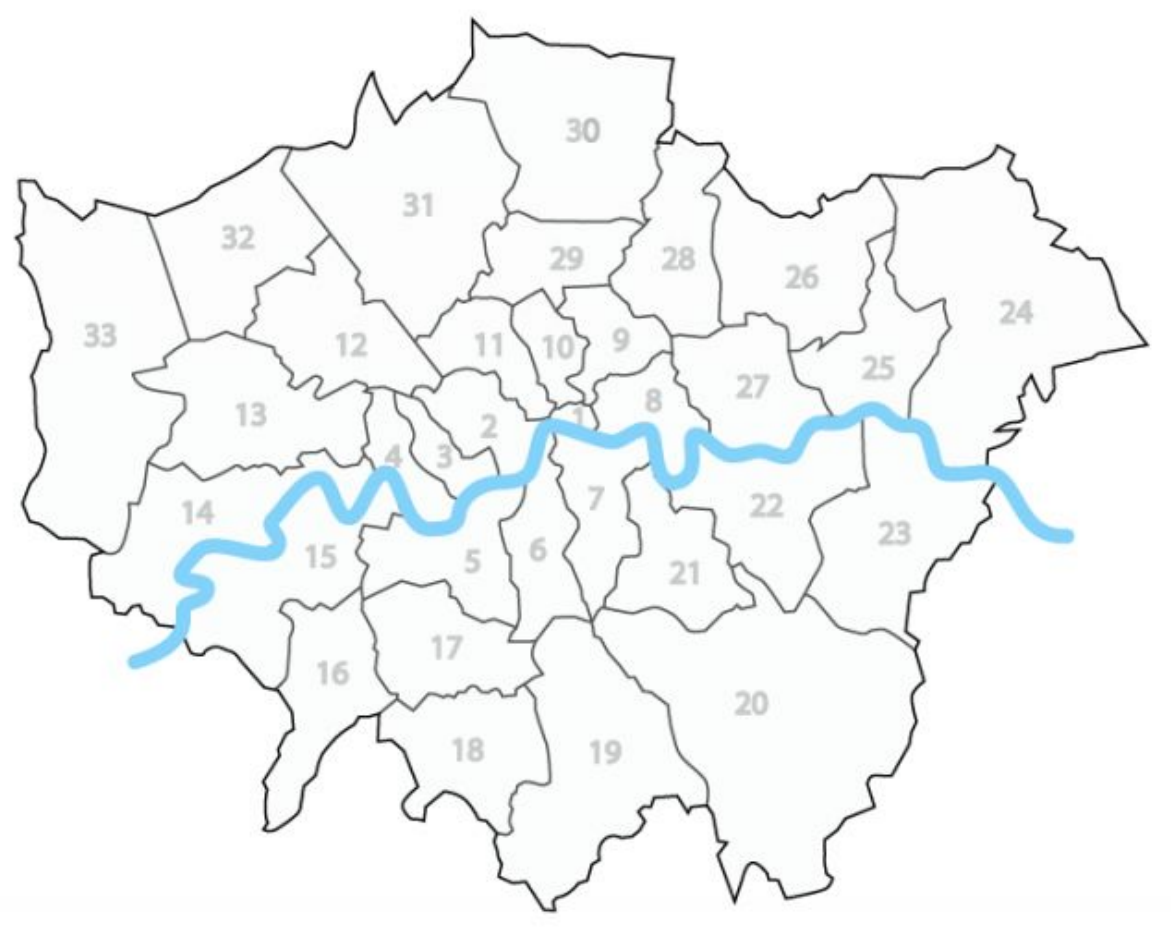

|Figura 49| A“London Squared”

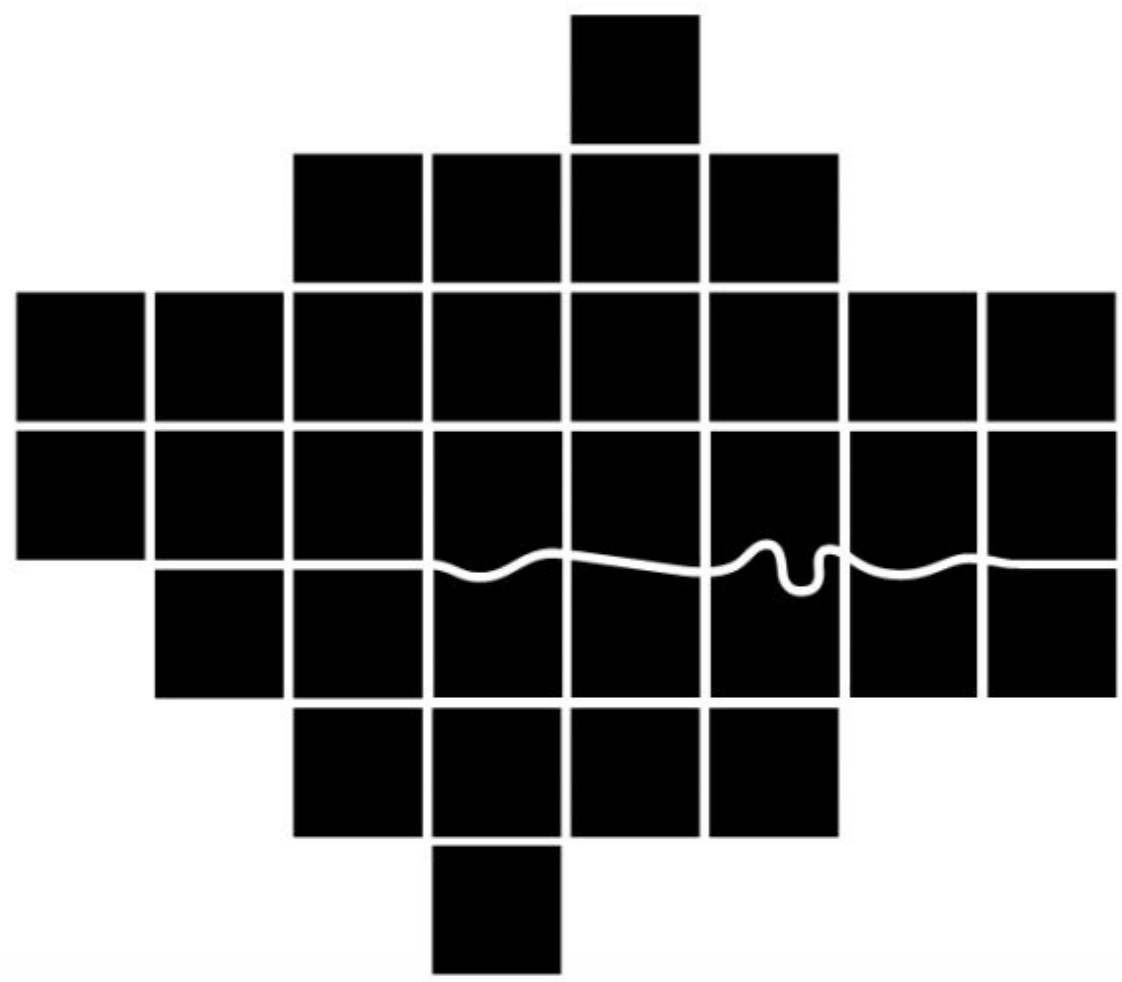


A outra "inspiração" para transformar radicalmente o fundo de mapa dos distritos do município de São Paulo vem da obra de Brunet, a Coremática72, ou a modelização gráfica. Em sua obra, "La carte, mode de emploi", de 1987, Brunet apresenta a ideia de modelizar um mapa. Diferentemente de um mapa tradicional, onde Brunet utiliza o termo "carte-reflet" - que seria em uma tradução livre um "mapa-reflexo", ou seja, um mapa que "conserva, em princípio, as coordenadas geográficas "fielmente", as formas das circunscrições dos Estados e seus lineamentos (rios, rotas), mesmo quando são fortemente generalizados" (BRUNET, 1987, p. 188, tradução nossa) em um "mapa-modelo" (carte-modèle).

Este "mapa-modelo" seria um novo instrumento de pesquisa, um modelo cartográfico, que não é simplesmente um esquema e que não visa somente "simplificar", uma "cartareflexo" por uma generalização extrema, mas que "exprima a estrutura e dinâmicas fundamentais do espaço geográfico em um mapa" (BRUNET, 1987, p. 189, tradução nossa). Este mapa-modelo é uma modelização gráfica, uma "escrita de modelos geográficos sob a forma de figuras” (GRATALOUP, 2003, p.629, tradução nossa).

Para Brunet, o espaço geográfico está estruturado e diferenciado em diferentes níveis de complexidade. Suas estruturas podem ser apreendidas conceitualmente e representadas graficamente seguindo certas regras de modelização. Assim, qualquer espaço é a combinação de estruturas elementares - os Coremas - representados por modelos gráficos. Expressam ações, projetos e resultados. Expressam, enfim, lógicas sociais elementares de controle ou dominação do espaço. Brunet distingue e classifica estas lógicas em 7 [sete]: "maillage" e "trilagge" [malha e ligação/disposição] - indicam meios diretos dessa dominação e os 5 [cinco] restantes: gravitação, contato, tropismo, dinâmica territorial e hierarquia refletem efeitos particulares derivados dos anteriores. (DUTENKEFER, 2010, p. 106)

A nossa proposta é apenas tomar de emprestado de Brunet o Corema "maillage" [malha] que se refere ao sistema de divisão e diferenciação de um território, em nosso caso objeto de cunho administrativo, os distritos do município de São Paulo.

A ideia de modelizar um território já vem de longa data. Robic (1989, 1991a, 1991b) mostra que, no caso da França, Emile Levasseur e Pierre Foncin propuseram "a forma hexagonal do território francês" (ROBIC, 1989, p. 18, tradução nossa) - figura 50 - para uma reforma de ensino dos anos 1860-1890.

\footnotetext{
72 Para maiores referências e detalhes consultar em francês:

BRUNET, Roger, Le déchiffrement du monde, théorie et pratique de la géographie. Paris: Belin, 2001, 402 p. Para um público em língua portuguesa: THÉRY, Hervé. Modelização gráfica para a análise regional: um método, Geousp - Espaço e Tempo n¹5, pp. 179-188, 2004.

THÉRY, Hervé. Chaves para a leitura do território paulista. In: Atlas Seade da economia paulista. Disponível em:

<http://www.seade.gov.br/produtos/atlasecon/index.php?texto=mapa\&cap_cod=11> Acesso: 30/09/2008 DUTENKEFER, Eduardo. Representações do espaço geográfico: mapas dasimétricos, anamorfoses e modelização gráfica. São Paulo, Dissertação (Mestrado em Geografia), FFLCH/USP, 2010. Disponível em: http://www.teses.usp.br/teses/disponiveis/8/8136/tde-25022011-115539/pt-br.php
} 
|Figura 50| A forma hexagonal da França. É um «mapa climático de LEVASSEUR, E., PERIGOT, Ch. s.d. Atlas de géographie physique politique et économique (France-Europe-Terre), Paris, Delagrave.» (ROBIC, 1989, p.21)

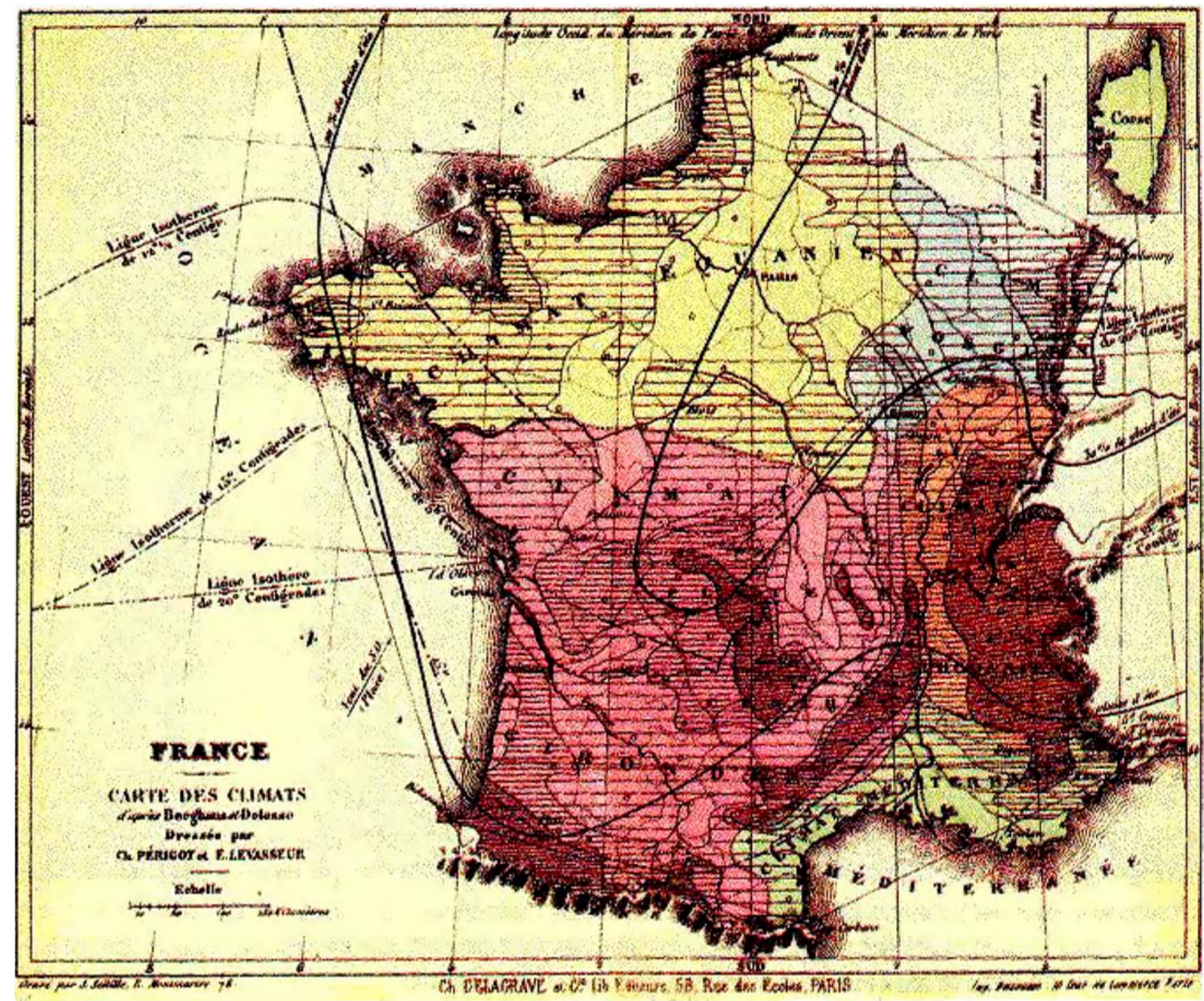

Já o geógrafo francês Elisée Reclus faz uma opção por uma geometria octogonal dos contornos da França em 1877 (ROBIC, 1989), figura 51.

Tudo indica, segundo Robic (1991a, 1991b), que a proposta de geometrizar, modelizar em figura mais "simples" a forma de um território, vem dos alemães, ou melhor, de um aluno suíço que teve como mestres "Ritter e Humbold em Berlin, nos anos de 1830" (ROBIC, 1991a, p. 43). 0 suíço Arnould Henrry Guyot ${ }^{73}$ foi um geólogo, geógrafo e educador que emigrou para os Estados Unidos da América em 1848 e elaborou vários materiais educacionais ${ }^{74}$ para o sistema educacional estadunidense com "métodos de construção gráfica (map-drawing)" (ROBIC, 1991, p. 43) para que os alunos desenhassem os mapas - figura 52.

${ }^{73}$ Para referência de sua vida e obra ver: J. D. Dana, “Memoir of Arnold Guyot (1807-1884)." in Biographical Memoirs. National Academy of Sciences, 2 (1886), 309-347. Disponível em:

http://www.nasonline.org/publications/biographical-memoirs/memoir-pdfs/guyot-arnold.pdf e. Acesso: 9/3/2016 e C. Faure, "Vie et travaux d'Arnold Guyot," in Globe, 23 (1884), 3-72. Disponível em :

http://www.persee.fr/doc/globe_0398-3412_1884_num_23_1_4628. Acesso : 9/3/2016.

${ }^{74}$ Algumas destas obras podem ser acessadas, entre outras, em:

<http://onlinebooks.library.upenn.edu/webbin/book/lookupname?key=Guyot\%2C\%20A.\%20(Arnold)\%2C\%2 01807-1884> . Acesso: 8/3/2016 
|Figura 51| A França octagonal de Elisée Reclus (RECLUS, E. Nouvelle géographie universelle. La terre et les hommes II. La France. Paris : Hachette. Disponível em:

http://gallica.bnf.fr/ark:/12148/bpt6k31511v/f1.item. Acesso: 9/3/2016

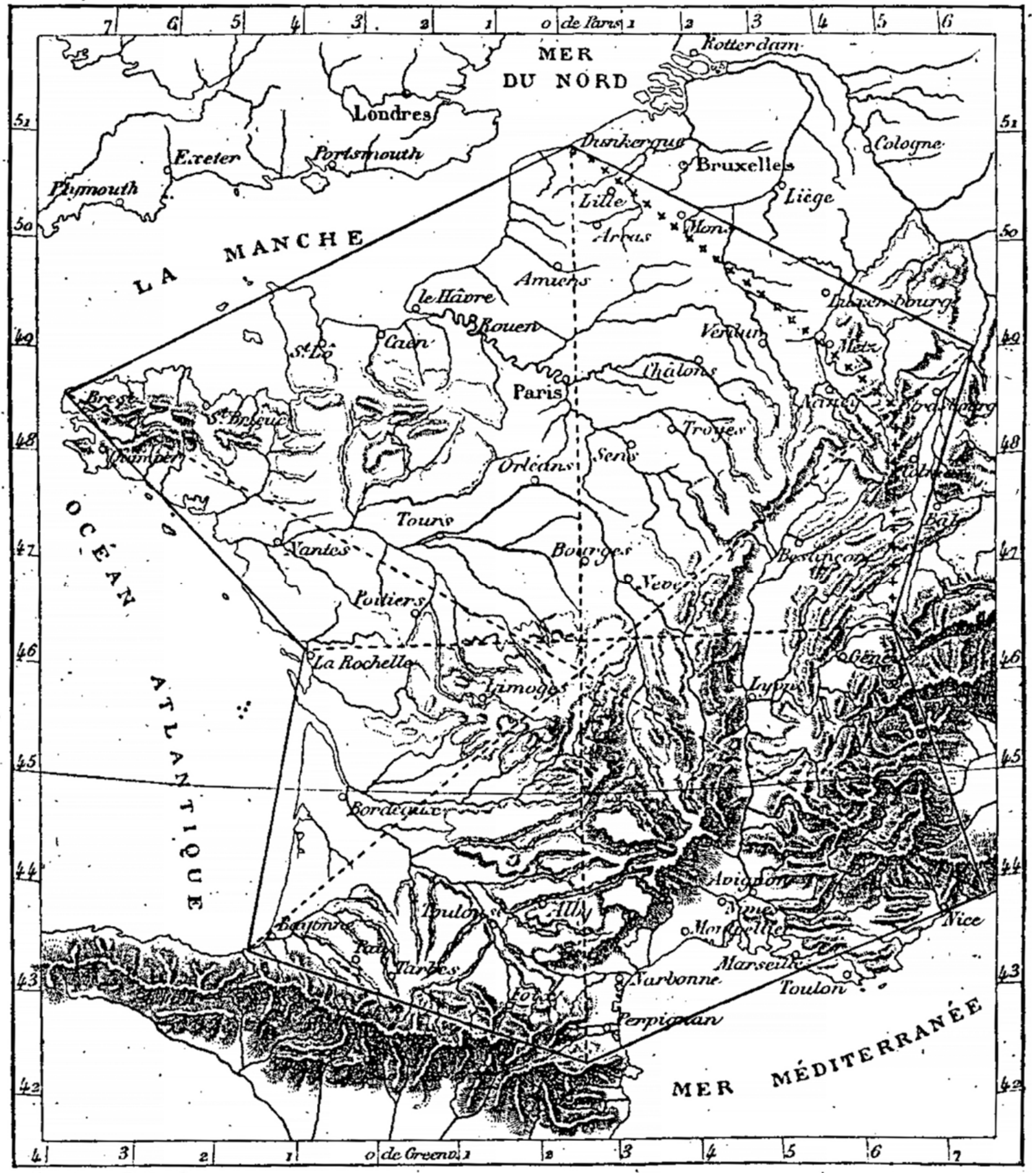


|Figura 52 | Capa da obra de Arnold Guyot de 1866 com o método construtivo "map drawing"da América do Sul e Europa.( Guyot, A. (Arnold), 1807-1884: Key to Guyot's wall maps : geographical teachings; being a complete guide to the use of Guyot's wall maps for schools. (New York : C. Scribner, 1866). Disponível em : http://babel.hathitrust.org/cgi/pt?id=uva.x001947316;view=2up;seq=6. Acesso: 8/3/2016)

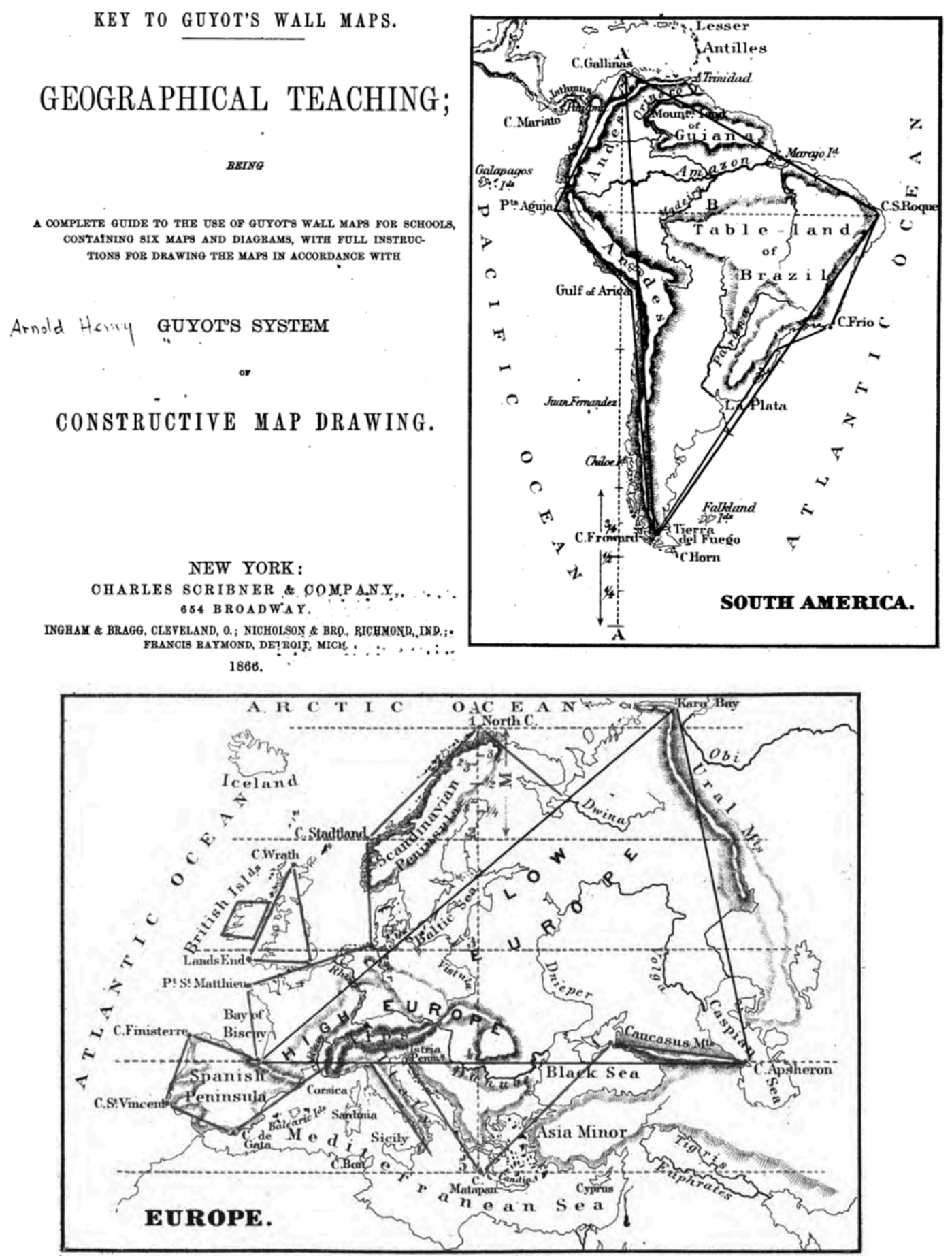


No Brasil, o trabalho de modelização é introduzido e incentivado pelo professor Hervé Théry (THÉRY, 2004, 2006), por exemplo, na figura 53. Nas décadas de 1970 e1980, a Empresa Paulista de Planejamento Metropolitano (EMPLASA) também utilizava em seus estudos um fundo de mapa mais generalizado da metrópole de São Paulo como podemos observar na figura 54, extraída de um estudo sobre o perfil industrial na Região Metropolitana de São Paulo publicado em 1978/1979.

|Figura 53| Modelização gráfica do território paulista do prof. Hervé Théry (THÉRY, 2006).
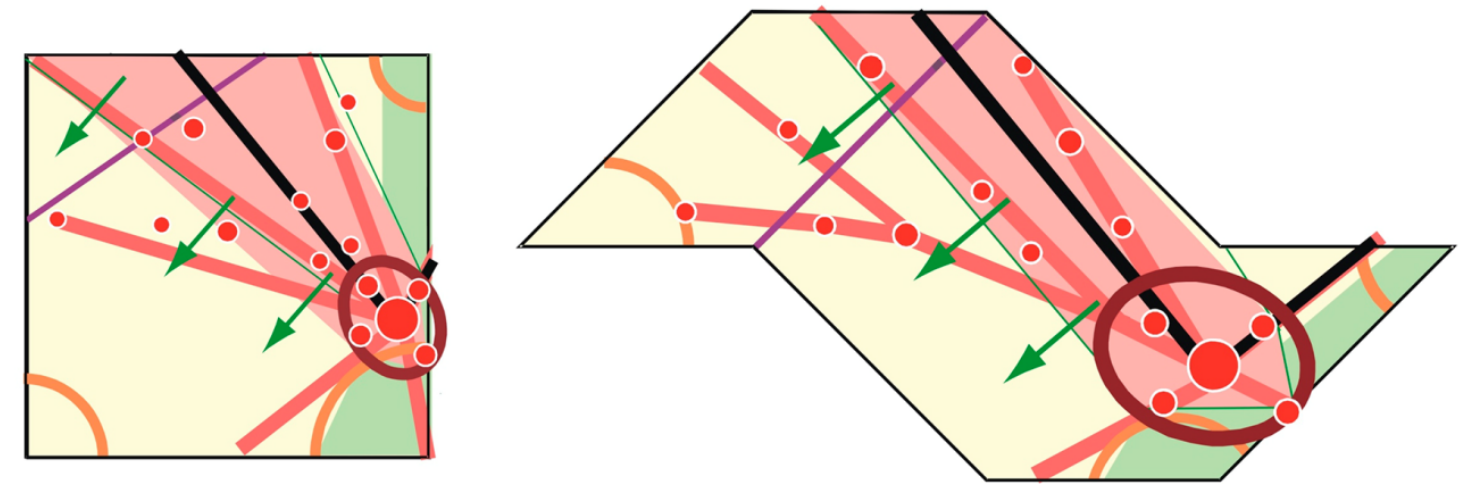

|Figura 54| Mapa da região metropolitana de São Paulo usado pela EMPLASA na década de 70/80 para estudos industriais.(EMPLASA, 1978, p. 24)

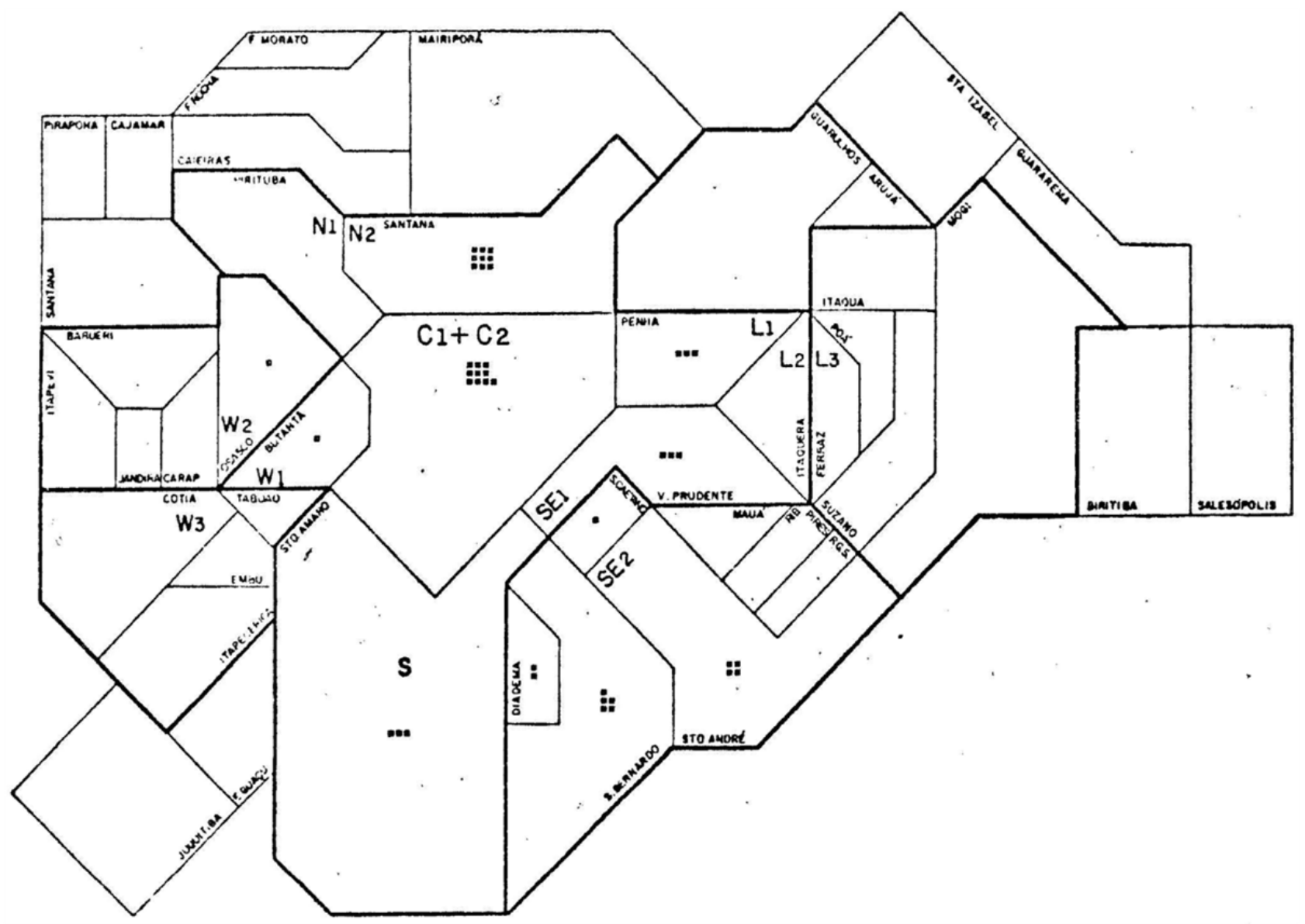




\section{2 - O mapa-modelo de São Paulo}

Elaboramos três (3) modelos dos distritos do município de São Paulo em formato shapefile. Nas três propostas acrescentamos os rios Tietê e Pinheiros para referência aos nossos leitores/visualizadores. A ideia é deixar todos os distritos com o mesmo peso visual, com um mesmo tamanho geométrico para não "desaparecer" visualmente quando for muito pequeno ou sobressair demais quando o peso territorial é muito grande. Propostas:

1. Mapa-modelo 1 - São Paulo em malha quadrada - figura 55;

2. Mapa-modelo 2 - São Paulo em malha retangular - figura 56;

3. Mapa-modelo 3 - São Paulo em hexágono - figura 57.

Estes três "quebra-cabeças" foram montados tentando manter o mais próximo possível da disposição dos distritos de um mapa de fundo euclidiano. Podemos notar que o mapamodelo 1 [malha quadrada] é o que mantem menos esta disposição. Os rios Tietê e Pinheiros são objetos geográficos que delimitam alguns distritos no mapa de fundo euclidiano. Também tivemos a preocupação de dispor estes traçados fazendo-o coincidir com os limites dos distritos modelizados.

A possibilidade de aplicação é diversa. A opção de colocar a sigla de cada distrito é um recurso que pode ser aplicado ou não, bem como os rios, como veremos em nossos exemplos. Mostraremos algumas opções onde utilizamos a variável visual tamanho e valor. Além disso, também podemos transformar o nosso fundo do mapa-modelo em uma anamorfose. 
|Figura 55| Mapa-modelo 1 - distritos de São Paulo em malha quadrada

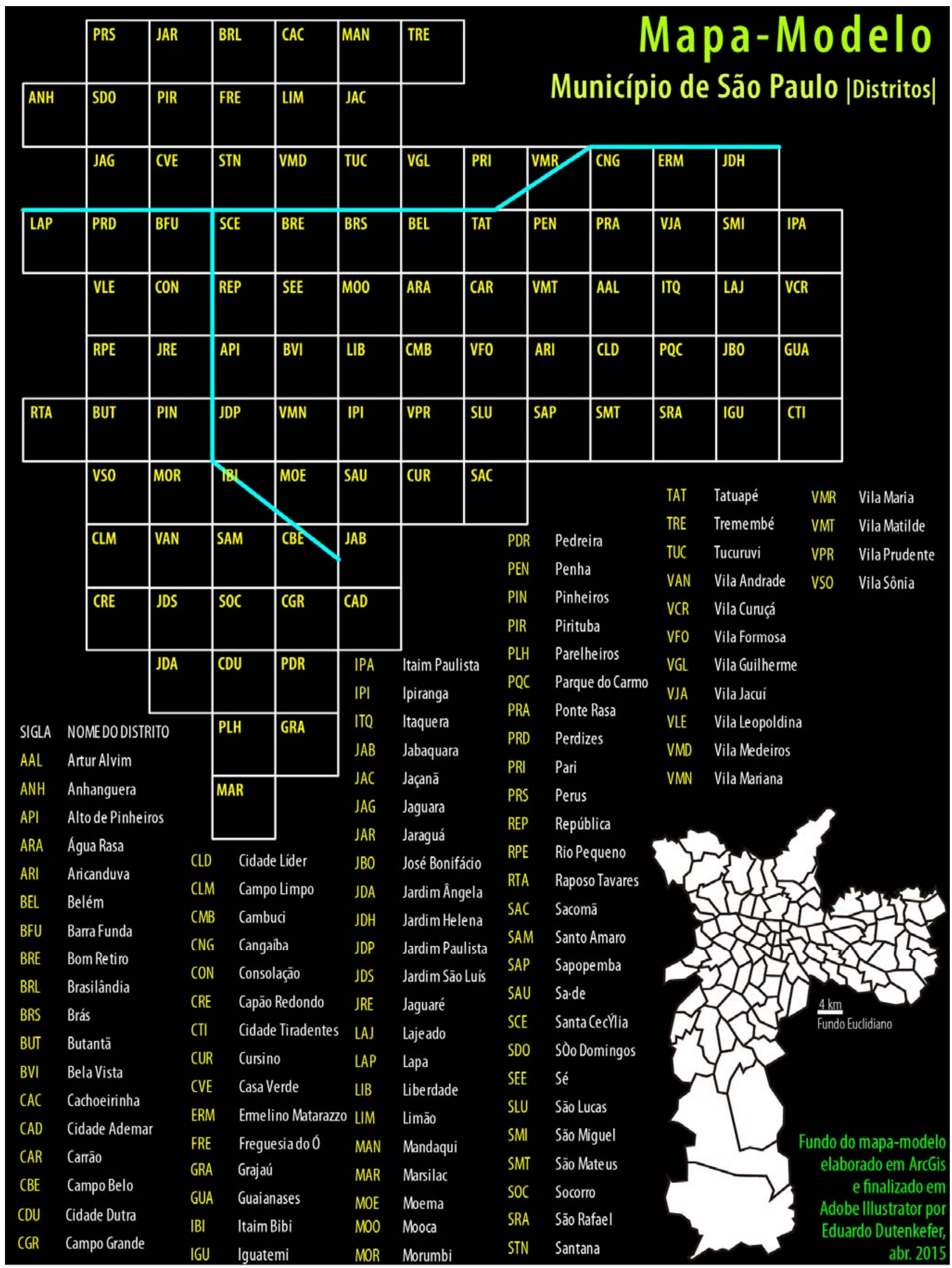




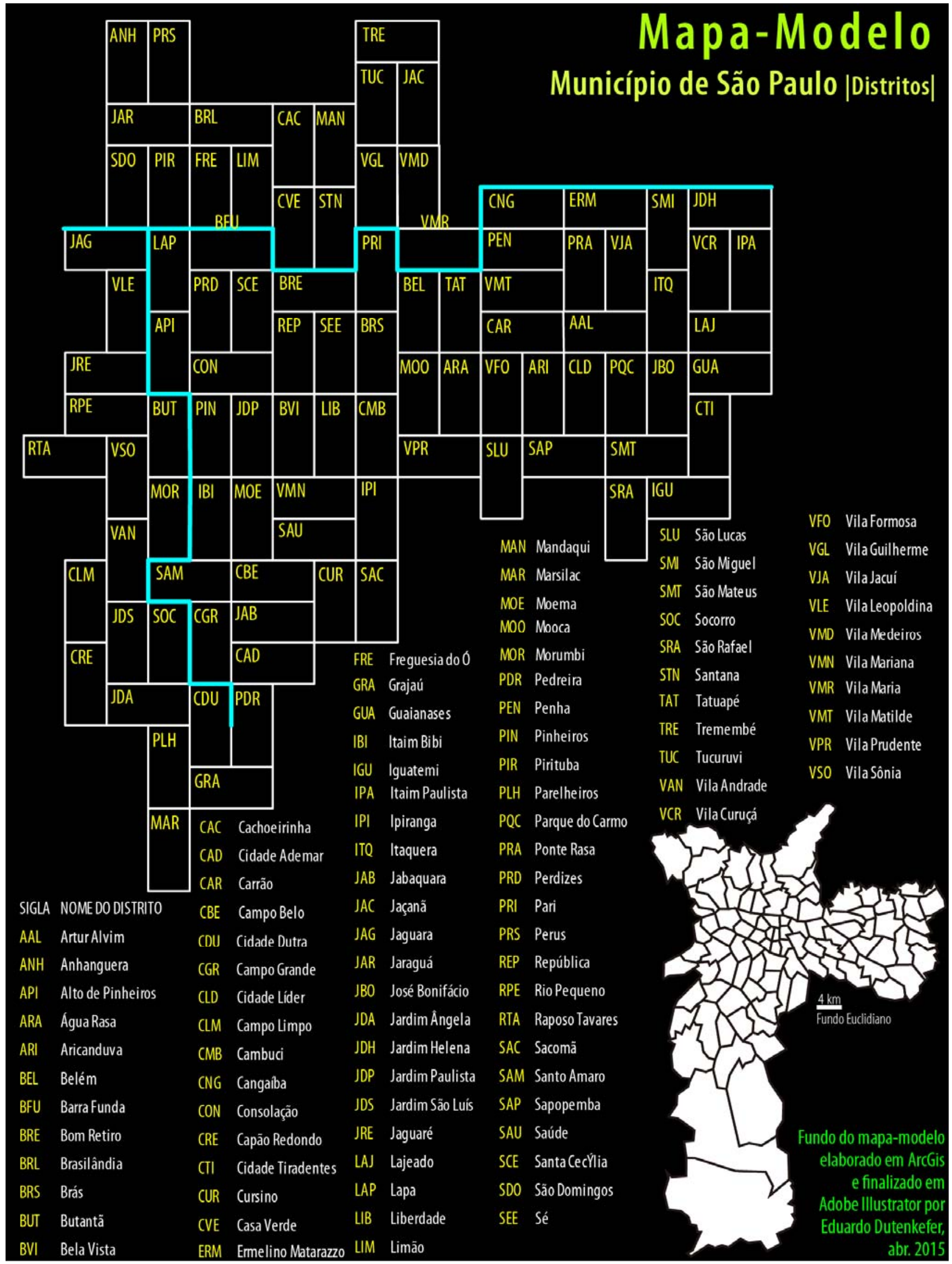




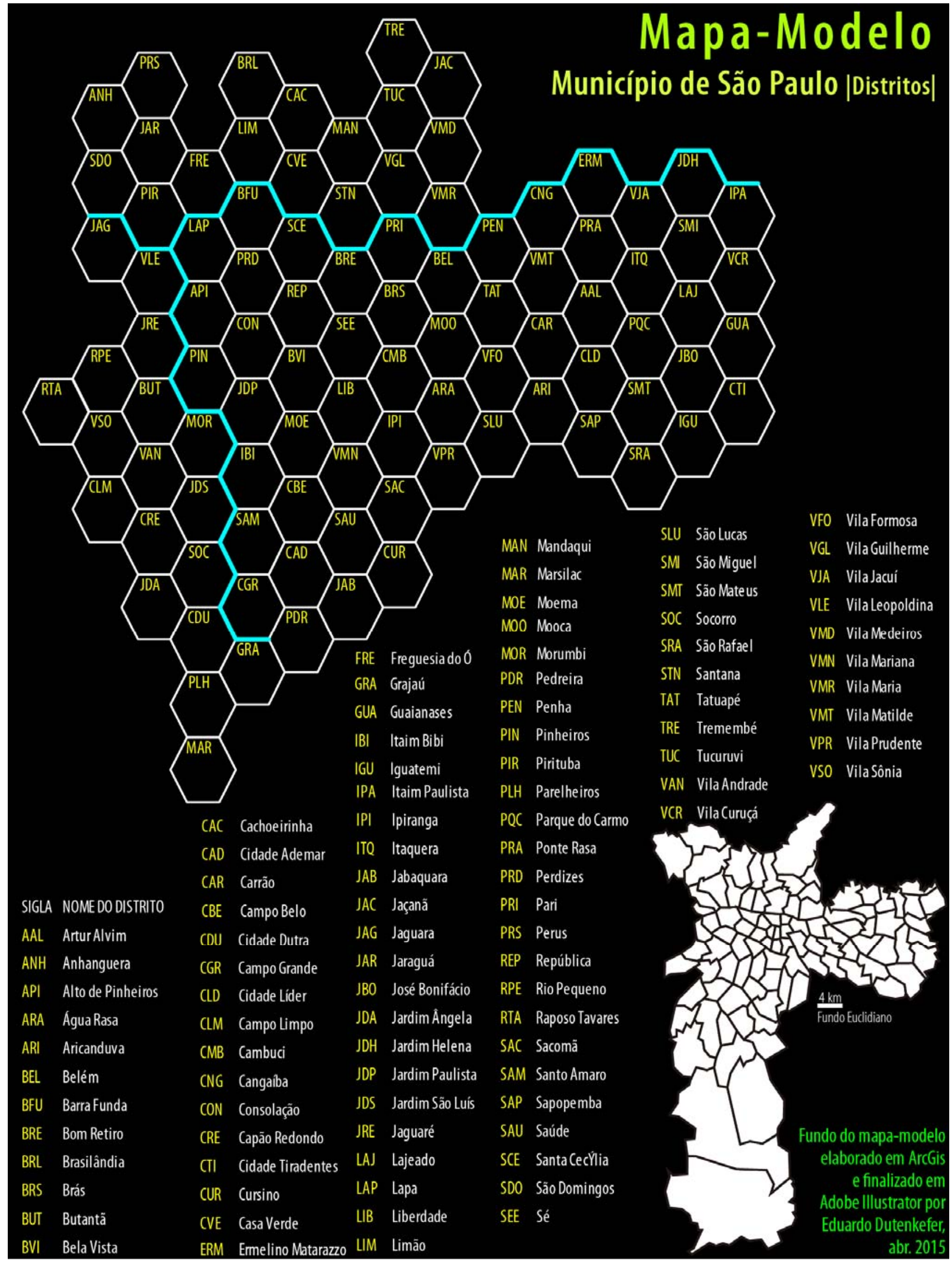




\section{0 - O mapa-modelo da urbanidade em São Paulo}

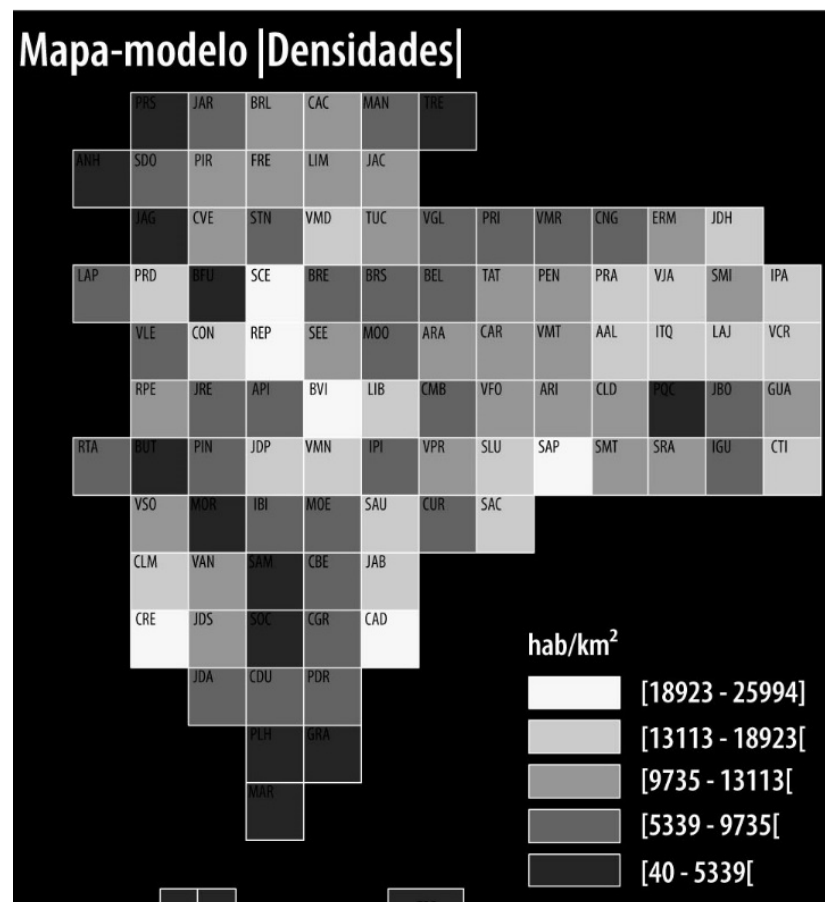

Método de discretização: algoritmo de Jenks
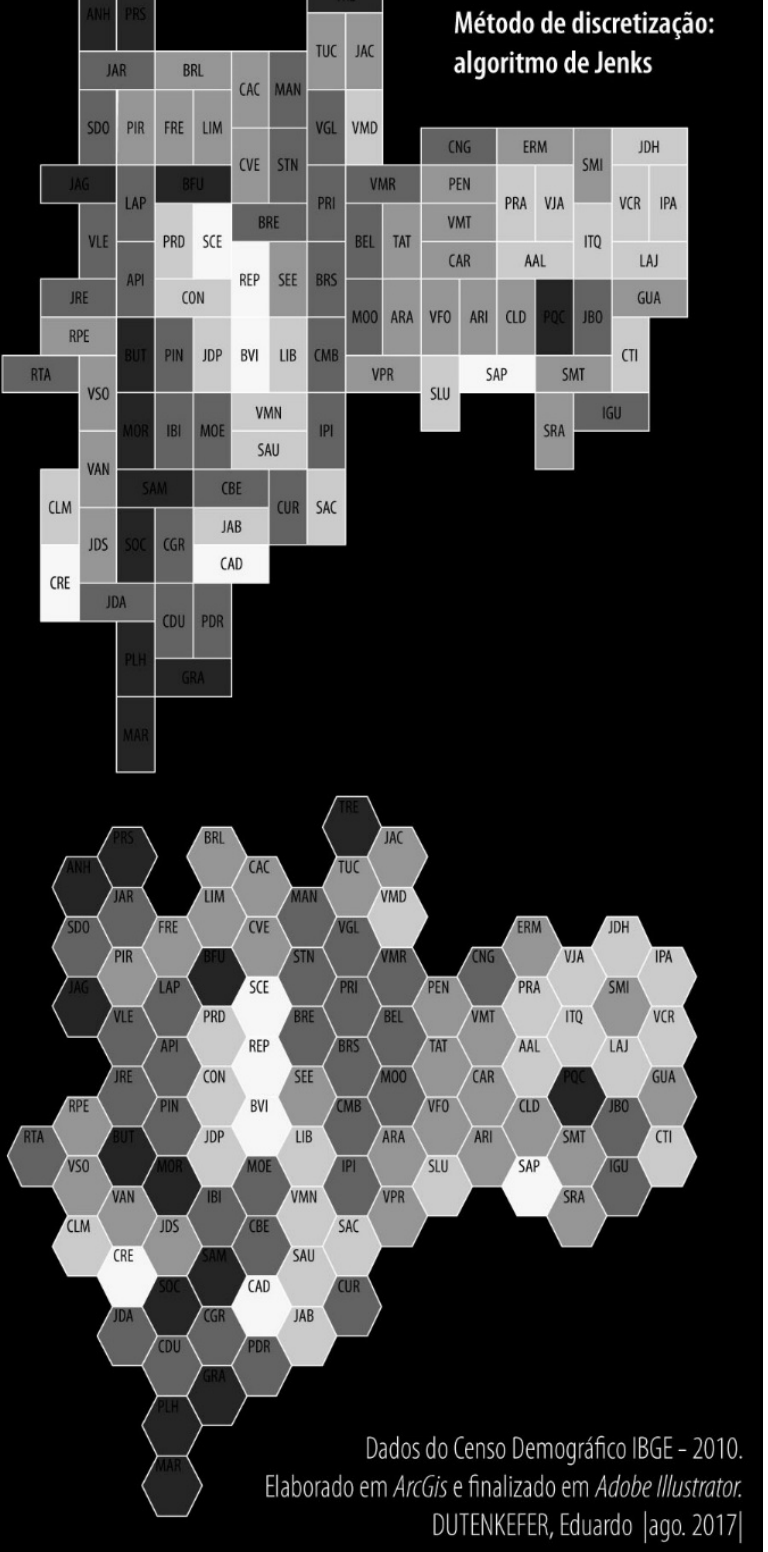

|Figura 58 | - Mapa-modelo em densidades

Apresentadas as três propostas de mapas-modelo no capítulo anterior, iremos agora utilizá-los como fundo de um mapa sintetizador de nossa dupla fundamental para caracterizar e "medir" a urbanidade de uma cidade; a sua densidade e diversidade. Um capítulo necessário para "enquadrar" e permitir "conclusões" parciais de nossas investigações da relação da urbanidade de uma cidade e seu possível interlocutor e representante; o mapa.

É sedutor para um pesquisador e/ou um planejador com foco no urbano obter sínteses gráficas de seu objeto de estudo. É quase ter uma sensação de poder sobre uma cidade. Mas não podemos esquecer que esta síntese almejada é apenas uma fração da realidade das lógicas múltiplas que uma cidade oferece aos olhares dos cientistas sociais e em particular aos geógrafos. Os mapas-modelo aqui apresentados são apenas contribuições para orientar nosso olhar aos temas que realmente são importantes aos estudos de uma cidade; a cidade é construída e movimentada por seres humanos.

$\mathrm{Na}$ figura 58 temos os mapas-modelo propostos ancorados no número de habitantes residentes distribuídos nas áreas dos distritos em 2010. 


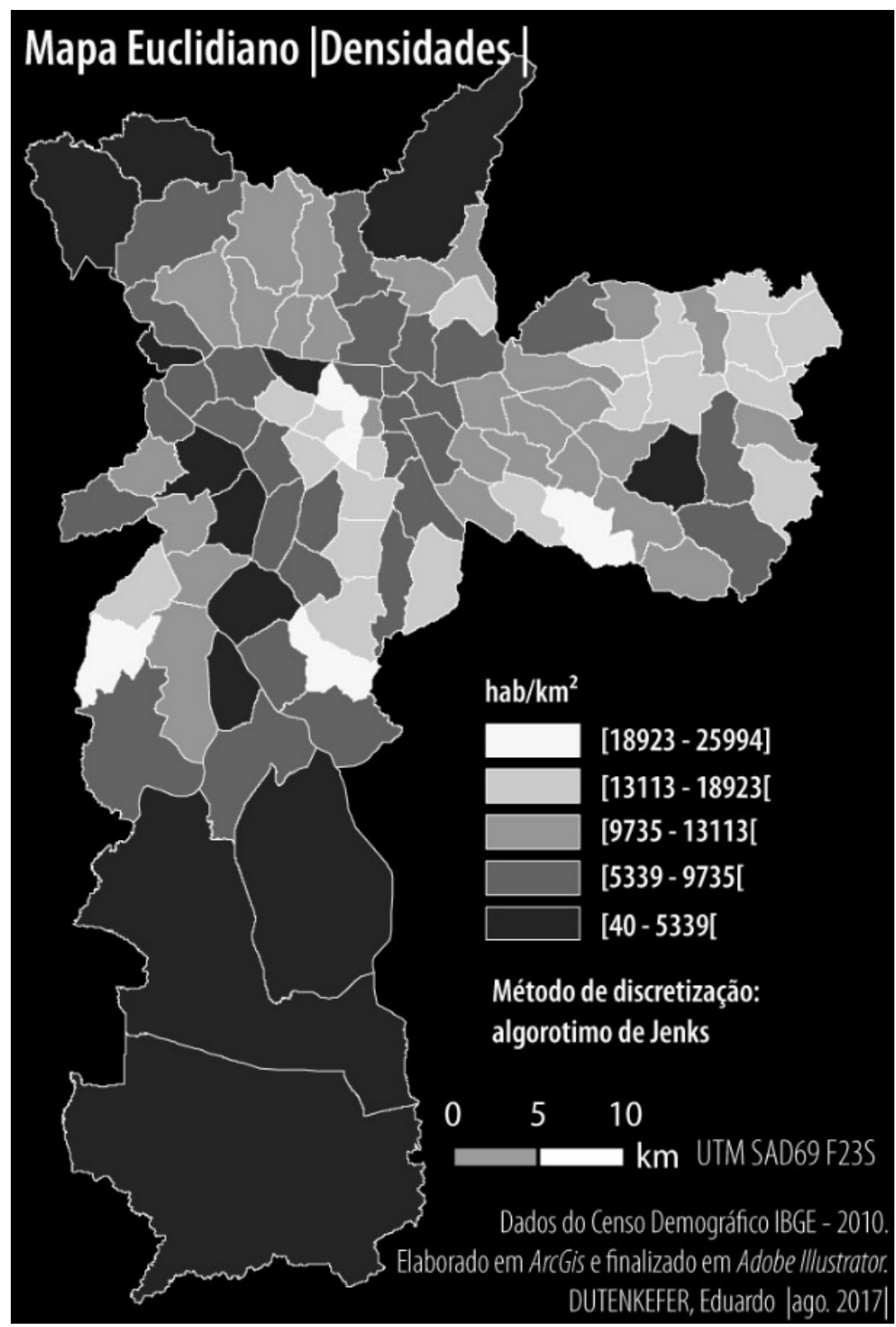

A opção semiológica adotada foi elaborar mapas coropléticos com fundos pretos e com as maiores densidades em valor de cinza próximo ao branco para impactar o nosso olhar.

$\mathrm{Na}$ figura 58A temos o mapa de São Paulo em seu fundo de mapa original com as densidades por distrito. 0 peso visual das áreas dos distritos maiores é evidente.

Nos três mapas-modelo da figura 58 sobressaem visualmente as maiores densidades nos distritos de Santa Cecília, República e Bela Vista na área central. Capão Redondo ao sudoeste, Sapopemba a leste e Cidade Ademar a sudeste. No mapamodelo haxagonal é evidente visualmente o eixo formado por Santa Cecília, República e Bela Vista.

Podemos alterar o nosso mapa modelo e transformá-lo em um cartograma em anamorfose - figura 59 e anticartograma - figura 60.0 objetivo foi experimentar nestes novos fundos de mapa o "peso" visual que a urbanidade absoluta e relativa poderia se comportar. As massas humanas em "quadriláteros" e "colmeias" expandidas e compactadas em nosso espaço-tempo em 2010.

Na figura 61 temos os cartogramas e anticartogramas em fundo euclidiano dos distritos de São Paulo. A proposta é comparar visualmente as vantagens e desvantagens dos mapasmodelo sem transformações cartográficas de posição, os com transformação - anamorfose e o mapa de fundo euclidiano em anamorfose. Para o nosso olhar, todas as propostas são impactantes e em anamorfose reforça visualmente os temas que estamos interessados em 
focar. O mapa-modelo oferece uma pequena vantagem em diminuir o que chamamos de "ruído" visual por se tratar de uma "padronização" em termos de tamanho dos "territórios". Com áreas iguais para cada distrito os modelos oferecem a proposta de um mesmo "peso" visual para cada distrito de São Paulo. Particularmente a proposta do mapa-modelo em "quadrados" e na forma hexagonal parece-nos mais elegante. Em forma retangular gera um pequeno "ruído" visual, pois a disposição dos retângulos não é a mesma para o conjunto da representação. 0 quadrado é uma forma geométrica de fácil construção. Não podemos esquecer as representações em "quadrados" do capítulo 4 - as quadrículas do IBGE - e o método carroyage que proporcionaram um olhar intraurbano de São Paulo revelador. Quando optamos por referenciar o nome dos distritos pelas suas siglas a malha quadrada e a hexagonal oferecem melhor posicionamento visual e uma elaboração mais rápida. A malha em retângulos necessita que posicionemos a sigla em cada distrito. Por outro lado, a malha em quadrados é a que menos "respeita" os posicionamentos dos distritos em relação ao fundo euclidiano. Já o retangular e o hexagonal apresentam melhores relações.

Acreditamos que os mapas-modelo permitem um uso mais sintético, elegante, versátil e, como principal vantagem, de manter o nosso foco no tema que iremos tratar e não com o peso que o fundo territorial sempre apresenta. 
|Figura 59| - A urbanidade absoluta em mapas-modelo

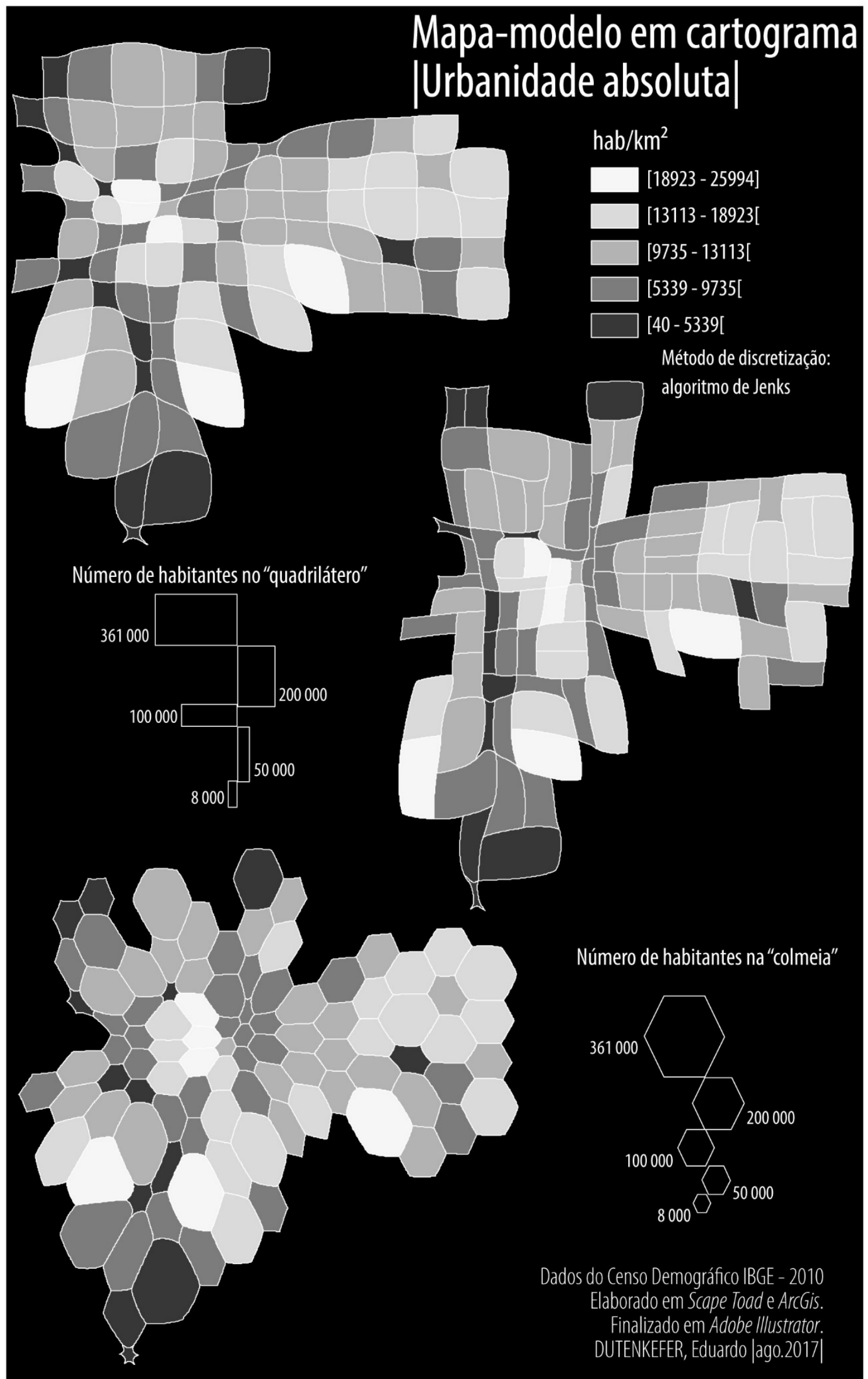


|Figura 60| - A urbanidade relativa em mapas-modelo

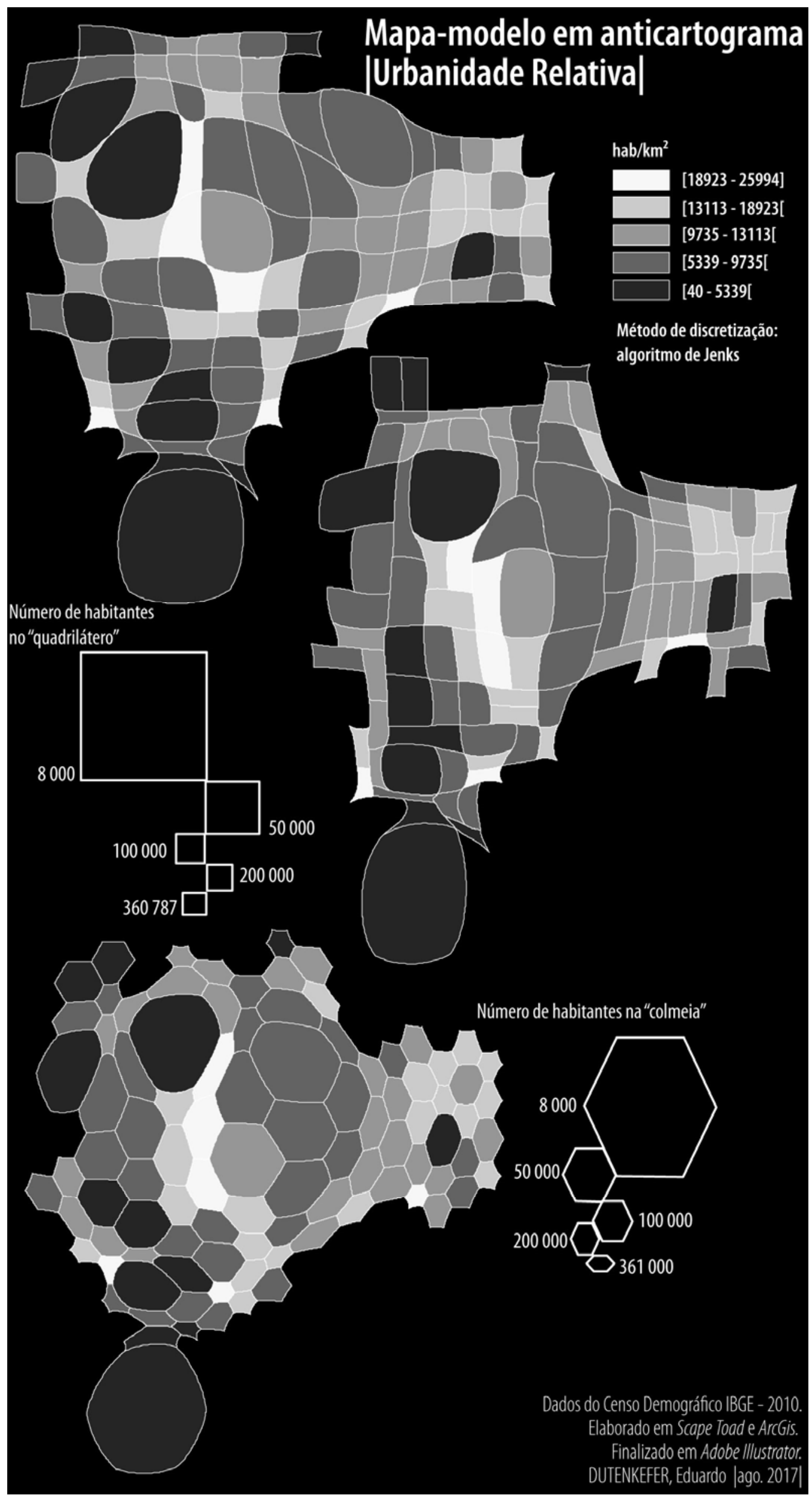


|Figura 61| - A urbanidade absoluta e relativa em cartogramas de fundo de mapa euclidiano

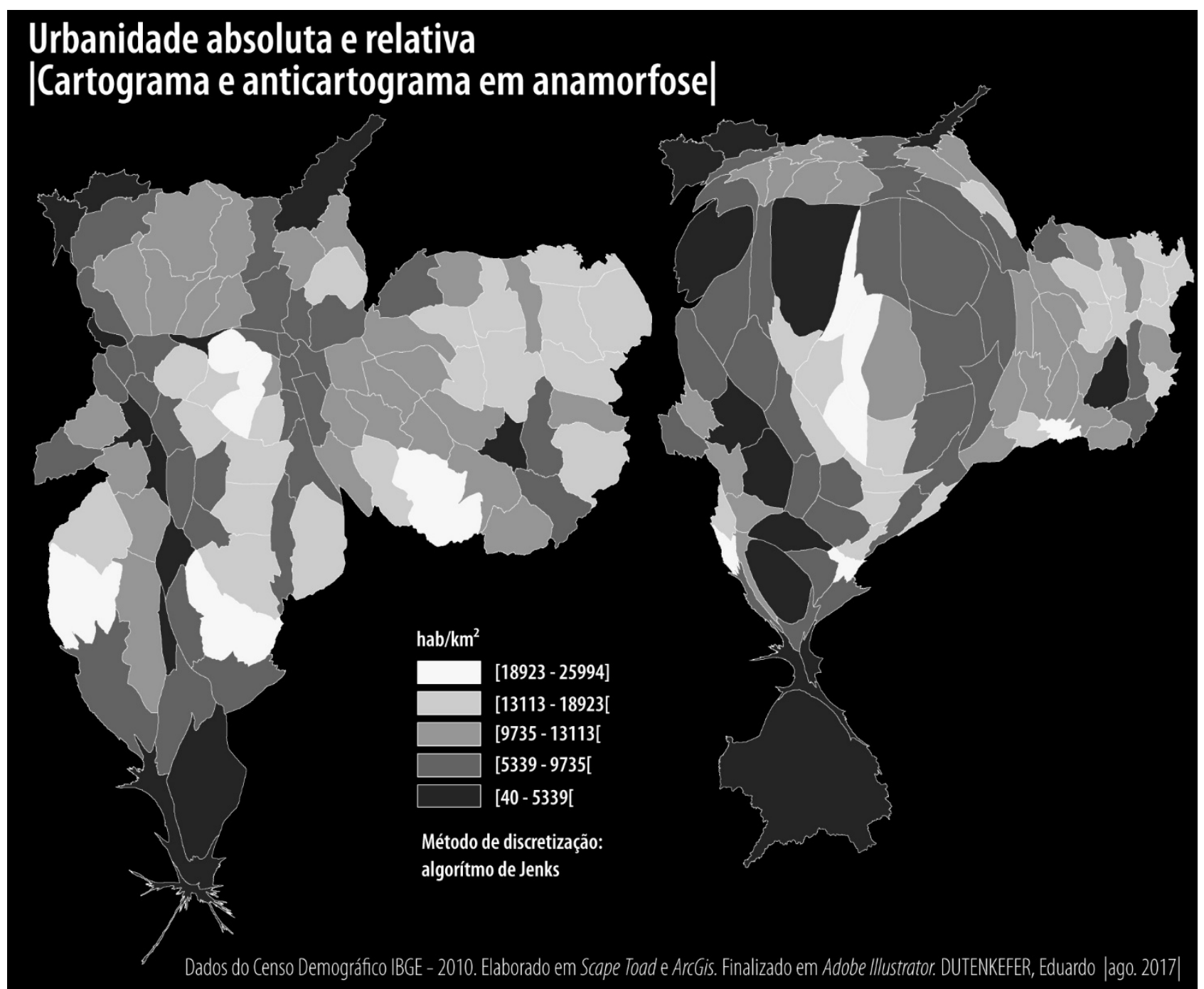

Nosso intuito neste capítulo é finalizar esta tese oferecendo uma síntese gráfica em mapas-modelo que permite visualizar a urbanidade de São Paulo com suas duas principais características: densidade e diversidade. A figura 65 [mapa-modelo em malha quadrada] oferece uma síntese de alguns índices de diversidade que exploramos originalmente no capítulo 3 em setores censitários, em particular em 3.6 - Diversidade e densidade.

Para chegarmos nesta elaboração [fig. 65] agregamos a heterogeneidade de gênero masculino e feminino - ao número de populações em faixas de idade em 4 grupos: criança, jovem, adulto e idoso. Estas quatro faixas partiram do critério de idade denominada de jovem e idoso. 0 jovem foi pelo critério adotado na Comissão Especial de Políticas Públicas para a Juventude ${ }^{75}$ - faixa dos 15 aos 29 anos. Para os idosos adotamos a população acima de 60 anos conforme o Estatuto do idoso ${ }^{76}$.

75 Ver PROJETO DE LEI N. 4.530, DE 2004 (Da Comissão Especial de Políticas Públicas para a Juventude) Aprova o Plano Nacional de Juventude e dá outras providências. 
Podemos estabelecer, portanto, 4 faixas de ambos os sexos; masculino e feminino:

1. menor que 15 anos como criança ;

2. 15 a 29 como jovem;

3. 30 a 59 como adulto;

4. igual ou maior que 60 como idoso.

Mantivemos as classificações de diversidade de etnia nos dados de cor/raça e na aproximação de classe social pelo número de habitantes recenseados que declararam a sua renda. Utilizamos os números de habitantes que recebem em número de salários mínimos em $2010[\mathrm{R} \$ 510,00)$ em 7 classes:

1. $<1 / 2$;

2. $] 1 / 2-1]$;

3. ]1-2];

4. $] 2-5]$

5. $] 5-10]$

6. $] 10-20]$

7. $>20$

Selecionamos uma amostra de 266.115 atividades do universo de 422.667 atividades geocodificadas para compor um índice de diversidade de atividades comerciais, industriais e de serviços nos 96 distritos. Na tabela 6 temos a amostra de atividades que conseguimos classificar e identificar com razoável confiabilidade com as descrições que cada recenseador anotou em seu trabalho [classificadas em ordem decrescente de número de atividades].

| Tabela 6|: Amostra das atividades selecionadas para os 96 distritos de São Paulo

\begin{tabular}{|l|l|l|}
\hline Sequência & ATIVIDADE & QUANTIDADE \\
\hline 1 & SERVICOS/ALIMENTOS/BEBIDAS & 51174 \\
\hline 2 & SERVICOS/PESSOAIS & 32990 \\
\hline 3 & SERVICOS/AUTOMOTIVOS & 26469 \\
\hline 4 & COMERCIO/ALIMENTOS/BEBIDAS & 24477 \\
\hline 5 & SERVICOS/RELIGIAO & 16028 \\
\hline 6 & INDUSTRIA & 15581 \\
\hline 7 & SERVICOS/SAUDE & 14722 \\
\hline 8 & COMERCIO/ROUPAS & 12659 \\
\hline 9 & SERVICOS/EDUCACAO & 11178 \\
\hline 10 & SERVICOS/TECNICOS & 6881 \\
\hline 11 & COMERCIO/AUTOMOTIVOS & 5139 \\
\hline 12 & SERVICOS/JURIDICOS & 4827 \\
\hline 13 & SERVICOS/CONTABEIS & 4098 \\
\hline
\end{tabular}




\begin{tabular}{|l|l|l|}
\hline 14 & SERVICOS/ASSISTENCIA TECNICA/MANUTENCAO & 3903 \\
\hline 15 & COMERCIO/MATERIAL PARA CONSTRUCAO & 3665 \\
\hline 16 & COMERCIO/FARMACEUTICO & 2758 \\
\hline 17 & COMERCIO/COMBUSTIVEL & 2200 \\
\hline 18 & SERVICOS/FINANCEIROS & 1999 \\
\hline 19 & SERVICOS/VESTUARIO & 1963 \\
\hline 20 & COMERCIO/PAPELARIA & 1867 \\
\hline 21 & COMERCIO/SERVICOS/ANIMAIS & 1843 \\
\hline 22 & COMERCIO/SERVICOS/MOVEIS & 1820 \\
\hline 23 & ATIVIDADES/CULTURAIS & 1607 \\
\hline 24 & ATIVIDADES/ASSOCIATIVAS & 1596 \\
\hline 25 & COMERCIO/ELETRONICA/INFORMATICA & 1485 \\
\hline 26 & COMERCIO/COSMETICOS/PERFUMARIA & 1475 \\
\hline 27 & COMERCIO/CALCADOS & 1401 \\
\hline 28 & COMERCIO/SERVICOS/INFORMATICA & 1342 \\
\hline 29 & COMERCIO/ELETRICO/FERRAGENS/HIDRAULICA/ILUMINACAO & 1260 \\
\hline 30 & COMERCIO/OTICA & 1119 \\
\hline 31 & SERVICOS/SOCIAIS & 1012 \\
\hline 32 & ATIVIDADES/DESPORTIVAS/RECREATIVAS & 925 \\
\hline 33 & COMERCIO/SERVICOS/EQUIPAMENTOS EM GERAL & 740 \\
\hline 34 & COMERCIO/TECIDOS & 502 \\
\hline 35 & COMERCIO/LIVRARIA/SEBOS & 499 \\
\hline 36 & COMERCIO/SERVICOS/EDIFICIO COMERCIAL NAO ESPECIFICADO & 478 \\
\hline 37 & ADMINISTRACAO/ORGAO/PUBLICO & 450 \\
\hline 38 & ATIVIDADE/POLITICA/PARTIDARIA & 429 \\
\hline 39 & SERVICOS/CORREIO & 359 \\
\hline 40 & COMERCIO/BOLSAS/ACESSORIOS & 343 \\
\hline 41 & SERVICOS/LOTERICA & 341 \\
\hline 42 & ADMINISTRACAO/ORGAO PUBLICO/SEGURANCA & 291 \\
\hline 43 & COMERCIO/SERVICOS/GALERIA COMERCIAL & 220 \\
\hline & TOTAL & 266115 \\
\hline & & \\
\hline & & 190 \\
\hline
\end{tabular}

Classificações que permeiam as necessidades básicas de qualquer ser humano e entrelaçadas ao modo de viver urbano. Atividades complexas, mas necessárias em nosso modo de viver e conviver em cidades. Necessitamos de alimentos [serviços alimentícios em primeiro lugar, com 51.174 e de comércio em $4^{\circ}$ lugar, com 24.477 locais], de vestimentas [12.659 locais] aos nossos corpos, de um carinho à nossa saúde [14.722], educação [11.178]. Um viver em cidades necessita de serviços jurídicos [4.827], financeiros [1.999], contábeis [4.098], técnicos [6.881] e um surpreendente segundo lugar da amostra de número de atividades [32.990] englobadas como pessoais como podemos verificar na tabela 6 e figura 62. Particularidades pessoais de assistência ao nosso corpo humano: cabelo, mão, pé, massagem, ginástica... Para o alimento de nossa "alma" é imprescindível os serviços culturais [em $23^{\circ}$ lugar com 1.607 locais] aliados a uma boa disponibilidade de um "seboso" livro [35 
lugar com 499 livrarias/sebos]. Parece que as atividades ligadas aos nossos melhores amigos animais [em $21^{\circ}$ lugar com 1.843 locais] já ultrapassam as nossas necessidades culturais... Os serviços religiosos também podem contribuir para a inquietude de nossas existências com 16.028 locais [5을. lugar]. Além disso, nossos lares de moradia, trabalho e lazer, necessitam de manutenção, reposições de peças... Não menos importante, os espaços que cultivem o associativo e o debate político; mesmo que este espaço político seja um sindicato, uma associação de moradores de bairro ou um comitê partidário ou espaço pessoal de um vereador, deputado... Somos hoje da "espécie urbanus" e sedenta das múltiplas atividades que uma cidade pode oferecer.

|Figura 62| Gráfico do quantidade de atividades selecionadas nos 96 distridos de São Paulo

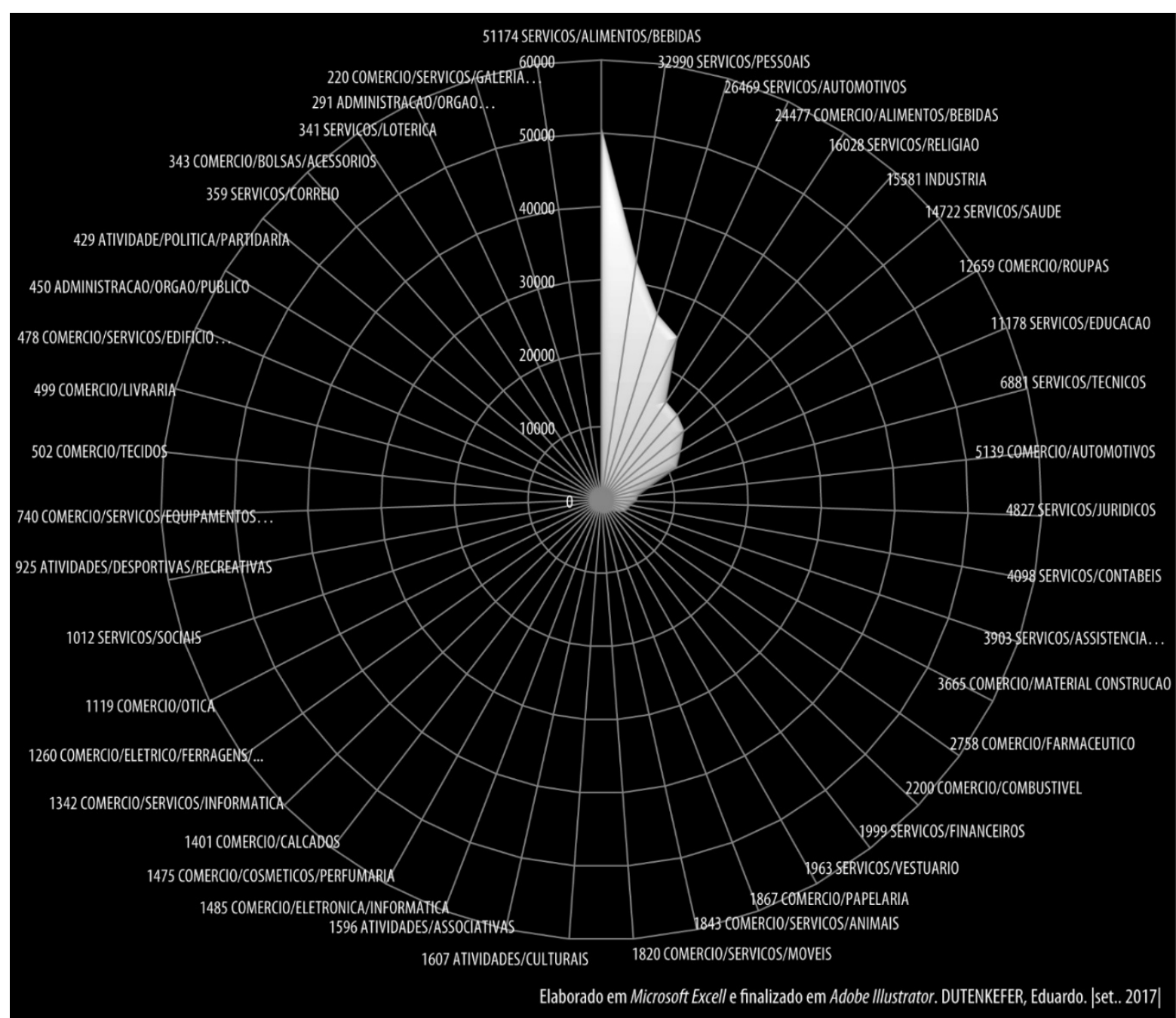


Na figura 64 temos o número de atividades escolhidas distribuída pelos 92 distritos com suas densidades populacionais em mapa-modelo hexagonal. Ampliando as nossas possibilidades em elaborarmos mapas temáticos utilizamos o aplicativo em linha Magrit ${ }^{77}$. Este software foi apresentado na Conferência Internacional de Cartografia em Washington em julho de 201778 e foi desenvolvido e é mantido pelo RIATE79. É importante ressaltar que este aplicativo possui uma boa tela para decidirmos o tipo de discretização que iremos utilizar baseados em nossas reflexões do capítulo 2. Ele mostra, com bom detalhe visual, o histograma de frequência e a distribuição das classes que escolhemos como método de discretização (Ver figura 63).

|Figura 63| Tela do aplicativo Magrit para escolha do método de discretização Options de discrétisation - MAPA_MODELO_3_FINAL - DENSI201_1

\begin{tabular}{|c|c|}
\hline Jenks & $\begin{array}{l}\text { Resume } \\
\text { Population : } 96\end{array}$ \\
\hline $\begin{array}{l}\text { Intervalles égaux } \\
\text { Quantiles } \\
\text { Ecart-type } \\
\text { Q6 } \\
\text { Progression arithmétique }\end{array}$ & $\begin{array}{l}\text { Min : } 39.628523 \mid \text { Max }: 25994.343932 \\
\text { Moyenne : } 10920.718756 \\
\text { Méciane : } 10643.950171 \\
\text { Variance : } 26018202.657236 \\
\text { Ecart-type : } 5100.8 \\
\text { Coefficient de variation : } 0.47\end{array}$ \\
\hline Jenks & \\
\hline Progression géométrique & \\
\hline
\end{tabular}
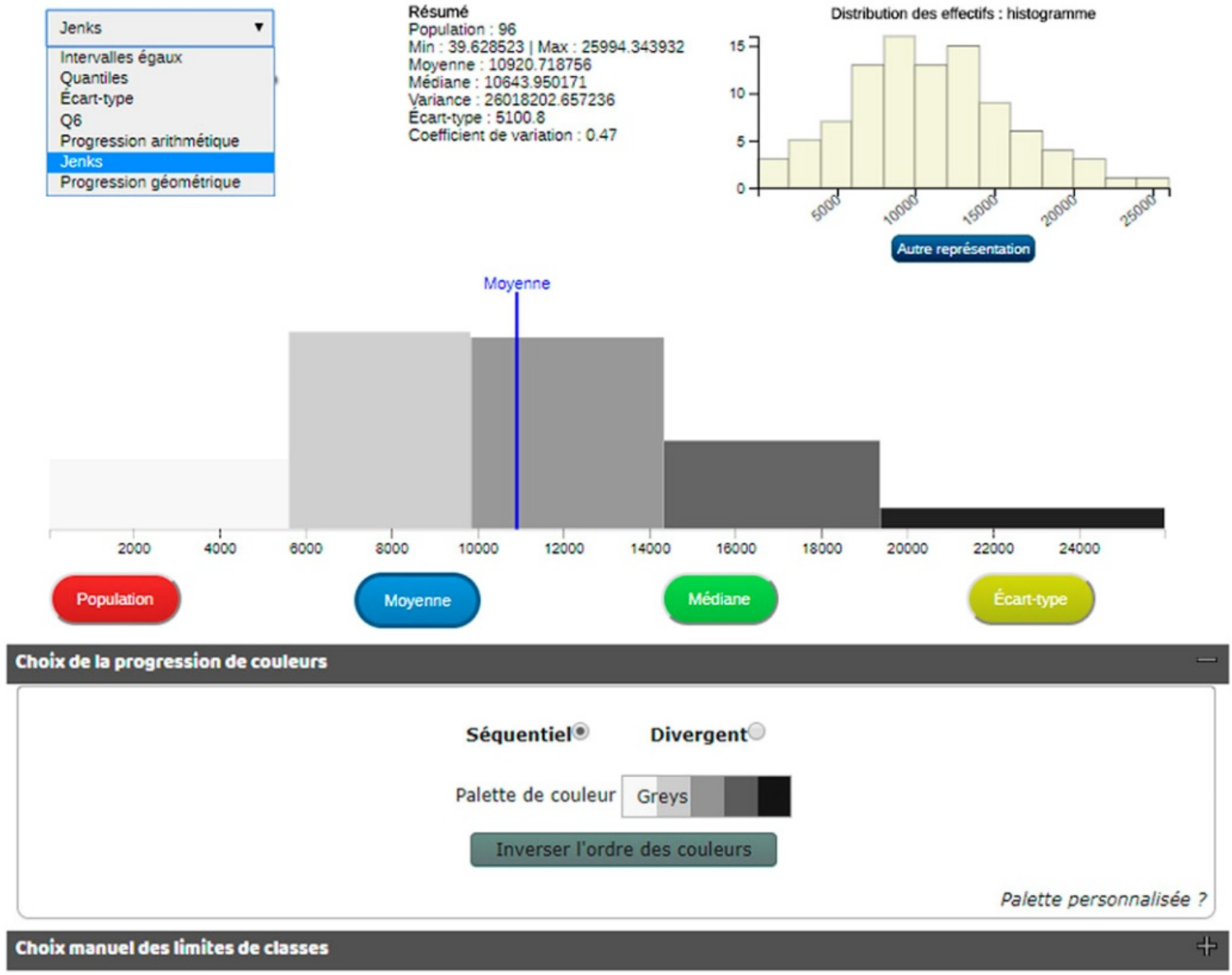

${ }^{77}$ Aplicativo com "as funcionalidades clássicas da cartografia temática acopladas a métodos inovadores (símbolos proporcionais, mapas coropléticos, mapas de descontinuidade, mapas de potenciais, quadrículas (carroyages), anamorfoses, etc" Disponível em: <http://magrit.cnrs.fr/ > Acesso: 12/9/2017 (tradução nossa).

78 https://magrit.hypotheses.org/571\#more-571. Acesso: 12/9/2017

79 "Rede Interdisciplinar para o Ordenamento e a Coesão dos Territórios da Europa e suas vizinhanças (RIATE). Apoia a investigação sobre o ordenamento do território europeu. Sob os auspícios do Centre national de la recherche scientifique (CNRS), da Universidade Diderot de Paris e do Commissariat Général à Égalité des Territoires (CGET)" < http://riate.cnrs.fr/ Acesso: 12/9/2017 (tradução nossa). 
Ele permite optar por todos os métodos de discretização presentes no software Philcarto, Cartes\&Donnés ou de SIG e mais duas discretizações importantes que não encontramos nos aplicativos que utilizamos: a progressão aritmética e geométrica. 0 método em progressão geométrica foi mostrado no capítulo 2, em como realiza-lo em Microsoft Excel.

No Magrit o seu cálculo é muito mais rápido. Outro ponto importante deste aplicativo é a escolha de cores para mapas coropléticos, por exemplo, já adequados às possibilidades que o software ColorBrewer oferece.

|Figura 64| Mapa-modelo de densidades e atividades

\section{Mapa-modelo Densidades e Atividades não residenciais}

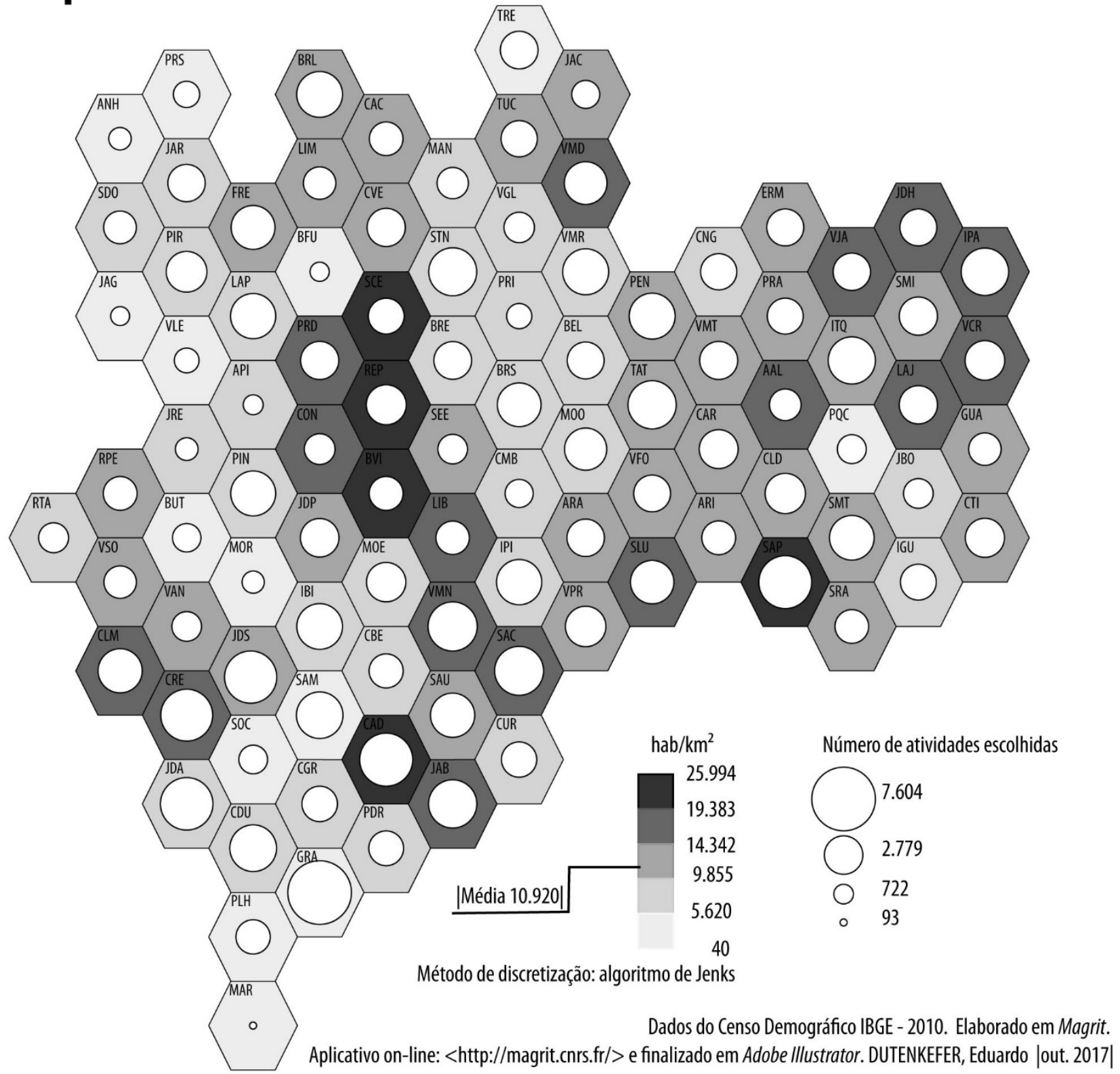

Na figura 64 elaboramos duas relações em um mesmo mapa. A densidade populacional por distrito e o número de atividades escolhidas em nossa amostra. Grajaú se destaca pelo 
número de atividades, mas com sua densidade na última faixa da discretização 40 a 5.620 hab $/ \mathrm{km}^{2}$, abaixo da média do município que é de $10.920 \mathrm{hab} / \mathrm{km}^{2}$. Já os distritos que se destacam em sua densidade, por exemplo, Santa Cecilia, República e Bela Vista possuem em torno de 2.000 a 3.000 atividades não residenciais. Ao sul, o destaque é Cidade Ademar, com maior densidade e número de atividades em torno de 5.000 .

Vamos agora tentar estabelecer a relação densidade de habitantes e diversidades de atividades não residenciais, cor/raça, renda e sexo/idade em um mesmo mapa modelo.

Diferentemente do método do índice de diversidade utilizado no capítulo 3, o Índice de Gibbs, optamos aqui em utilizar o índice de entropia. Entropia como um grau de "desordem" que pode exprimir uma maior diversidade ou menor diversidade, baseado em pesquisas mais recentes para estudos em áreas urbanas, realizadas por Philippe Apparicio ${ }^{80}$ do INRS [Institut National de la Recherche Scientifique] do Québec, Canada. Para o cálculo dos índices utilizamos o software Geo-Segregation Analyzer ${ }^{81}$ desenvolvido por Philippe Apparicio e equipe do Laboratoire d'équité environnementale (LAEQ) do Institut de la recherche scientifique - Centre Urbanisation Culture Société (INRS-UCS) que é

...capaz de calcular 43 índices de segregação residencial, independentemente dos grupos da população ou da região metropolitana sob estudo. Em termos práticos, o usuário só precisa ter um arquivo em Shape file contendo as contagens dos grupos populacionais que diferem em origem étnica, país de nascimento, idade ou renda através de uma área metropolitana em um pequeno nível de área (por exemplo, em setores censitários). Desenvolvido em Java usando a biblioteca GeoTools, este aplicativo é gratuito e de código aberto, multiplataforma e multilíngue. Funciona em sistemas operacionais do Windows, Mac OS X e Linux. Atualmente suporta 10 idiomas (Inglês, Francês, Espanhol, Catalão, Alemão, Italiano, Português, Crioulo, Vietnamita e Chinês). A aplicação permite aos usuários exibir e manipular vários arquivos geográficos e calcula 19 índices de um grupo, 13 índices de dois grupos, 8 índices multigrupo e 3 medidas locais que podem ser mapeadas (quociente de localização, medida de entropia, tipologia das áreas étnicas, entre outros. (APPARICIO et al, 2014, p. 117, tradução nossa).

Em particular utilizamos o Índice de entropia [H], ou índice de diversidade, utilizado para detectar unidades espaciais completamente homogenias $(\mathrm{H}=0)$, ou unidades espaciais com diversidade máxima ( $\mathrm{H}=1$ ) (APPARICIO et al, 2008).

${ }^{80}$ Ver por exemplo: Apparicio, Philippe; Leloup, Xavier y Rivet, Philippe (2007). "La diversité montréalaise à l'épreuve de la ségrégation : pluralisme et insertion résidentielle des immigrants". Revue de l'intégration et de la migration internationale / Journal of International Migration and Integration, 8 (1), 63-87.

Apparicio, Philippe; Petketich, Valera y Charron, Mathieu (2008). «Segregation Analyzer: a C\#.Net application for calculating residential segregation indices». Cybergeo: European Journal of Geography, no 414, 13 p.

Apparicio, Philippe; Fournier, Éric y Apparicio, Denis (2012). Geo-Segregation Analyzer. a multi-platform application (version 1.0), Spatial Analysis and Regional Economics Laboratory (SAREL), INRS Urbanisation Culture Société, Montreal.

${ }^{81}$ Disponível em <http://geoseganalyzer.ucs.inrs.ca/FR/Accueil.html> Acesso: 27/02/2017 
A sua formula matemática original utilizada pelo aplicativo é baseado nos trabalhos de Henri Theil e Anthony J. Finezza da década de 1970.82:

Em linguagem matemática - Eq. $12^{83}$ (APPARICIO et al, 2008), temos:

$$
\begin{aligned}
& H=\sum_{i=1}^{n}\left[t_{i}\left(E-E_{i}\right) / E T\right] \\
& \text { com } \\
& E=(P) \ln [1 / P]+(1-P) \ln [1 /(1-P)] \\
& \mathrm{e} \\
& E_{i}=\left(p_{i}\right) \ln \left[1 / p_{i}\right]+\left(1-p_{i}\right) \ln \left[1 /\left(1-p_{i}\right)\right] \\
& \mathrm{P}=\text { Proporção de um grupo em uma área espacial, isto é, } \mathbf{X} / \mathbf{T} \\
& \mathbf{X}=\text { Total de população de um grupo "X" em uma área espacial } \\
& \mathbf{T}=\text { Total da população da área espacial }
\end{aligned}
$$

Na figura 65 temos o resultado destes índices em nosso fundo de mapa-modelo, em malha quadrada.

No mapa-modelo 65.1 temos o índice aplicado ao que denominamos de etnia [o número de populações das cores autodeclaras de branca, parda, preta, amarela e indígena]. 0 índice médio foi de 0,521. O maior "equilíbrio" alcançado foi no distrito de Bom Retiro com 0,70 e o menor valor em Moema com 0,25. Este valor indica também uma concentração. Olhando os dados de Moema temos que 99\% da população autodeclarada é branca com 75.550 habitantes de um total de 76.401 habitantes em todo o distrito. Excetuando Moema, os demais distritos estão nas faixas de baixa à média diversidade.

Em 65.2 temos o índice de renda. 0 índice médio é 0,753. Com o máximo no distrito do Morumbi com 0,912 e o menor com 0,607 no distrito de Jardim Ângela, com um predomínio na faixa de 1 a 2 salários mínimos. 0 índice do Morumbi é explicado pelo equilíbrio entre as faixas. Com 41.574 habitantes que declararam sua renda temos um predomínio em torno de 5.000 habitantes nas faixas de 1 a 2, 2 a 5, 5 a 10 e maior que 20 salários mínimos.

No mapa-modelo em 65.3, com a dimensão gênero [homem e mulher] e idade, é evidente uma homogeneização do índice. Com média de 0,938 alcançou um máximo no Pari com 0,971 e um mínimo em Anhanguera com 0,887. Isto significa que temos uma

82 Ver: THEIL, H. Statistical Decomposition Analysis. North-Holland: Amsterdam, 1972. E

THEIL, H., \& FINEZZA, A. J.. A note on the measurement of racial integration of schools by means of informational concepts. Journal of Mathematical Sociology, 1 (2), 187-194, 1971. doi:10.1080/0022250X.1971.9989795.

83 Equações disponíveis em: Apparicio, Philippe; Petketich, Valera y Charron, Mathieu (2008). «Segregation Analyzer: a C\#.Net application for calculating residential segregation indices». Cybergeo: European Journal of Geography, no 414, 13 p. Acesso: 28/02/2017 
probabilidade média de $93 \%$ de encontrar até dois membros diferentes do sexo masculino ou feminino em duas faixas de idade diferentes.

0 índice de atividades não residenciais encontrou em 65.4 uma média de 0,730 enquadrada como diversidade média em nossa faixa de classificação. Explorando o mapamodelo podemos observar o predomínio de distritos nas faixas de média à alta diversidade. 0 máximo ficou para o distrito da República com 0,81 .

0 resultado do distrito da República é um resultado interessante. Ele faz parte do distrito de nossa área Core revelada no mapa das figuras 30 e 31, no subcapítulo 5.2 - os denominados "blocos ativos de urbanidade". Os distritos que escolhemos neste subcapítulo como representativos de baixa, média e alta densidade de domicílios e atividades não residenciais tiveram os seguintes índices de diversidade:

1. República $=0,811$;

2. Santa Cecília $=0,778$;

3. Consolação = 0,776; $\rightarrow$ Área Core

4. Vila Mariana $=0,764$;

- Morumbi $=0,744$

Em nossa faixa de classificação teríamos os 4 primeiros distritos acima classificados como de alta diversidade. Morumbi fica com a faixa de média diversidade.

Temos que assinalar que estamos trabalhando com dados agregados em distritos administrativos e a cidade "real" não tem limites rígidos. Os mapas em células de 200 X $200 \mathrm{~m}$ [figuras já assinaladas - 30 e 31] permitiram revelar uma cidade quase ao nível de métrica pedestre e, provavelmente, o distrito do Morumbi não se enquadraria em uma diversidade média. Voltaremos no capítulo das ponderações finais sobre esta questão.

Em 65.5 temos o mapa-modelo com o índice médio geral de diversidade, isto é, a soma dos índices anteriores dividida pelo número de índices utilizados [4]. A média do índice médio é de 0,735. O destaque ficou para os distritos de Belém e Casa Verde, com 0,78. 0 nosso destaque de atividades não residências - República - ficou com 0,754, considerado alta diversidade pela classificação adotada. 0 distrito com menor índice, 0,65, foi o distrito de Marsilac. 
|Figura 65 | Índices de diversidade em mapa-modelo em malha quadrada

Mapa-modelo |Diversidades - Índices|
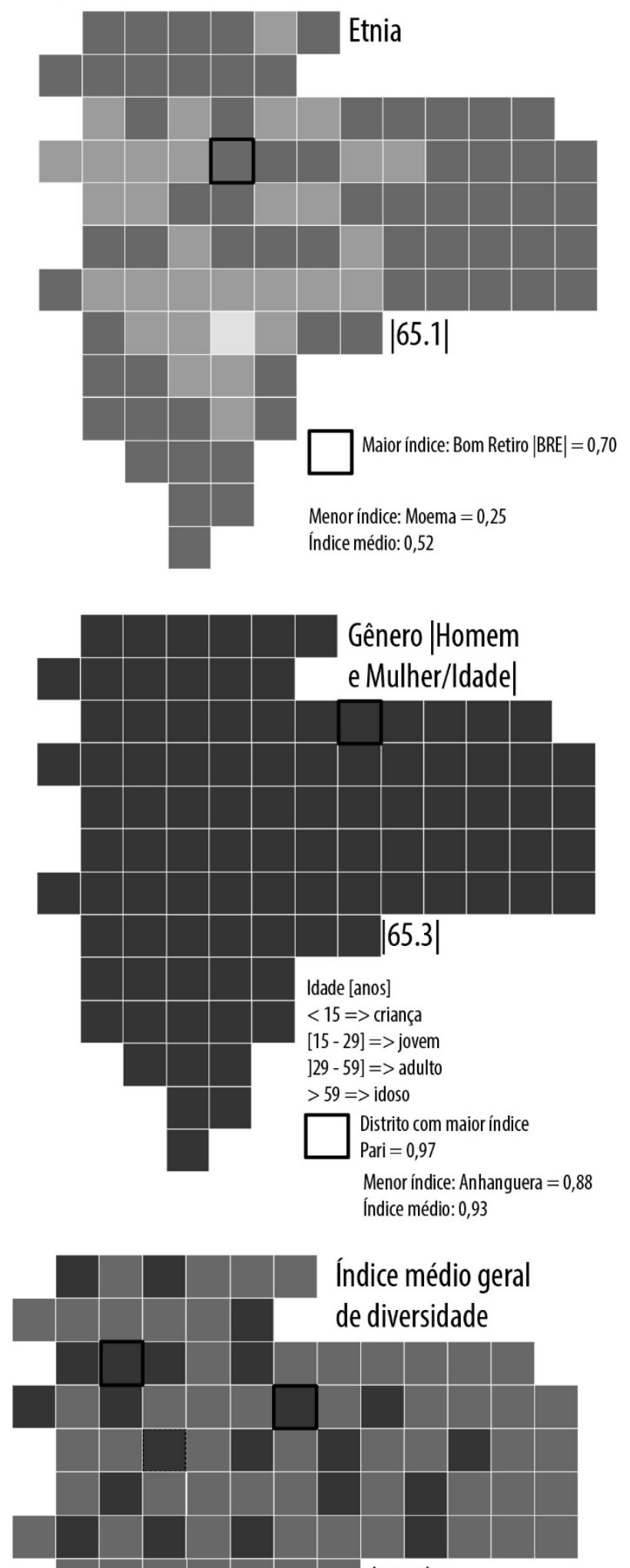

$|65.5|$

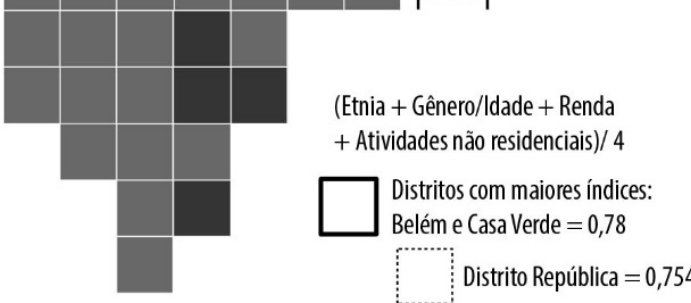

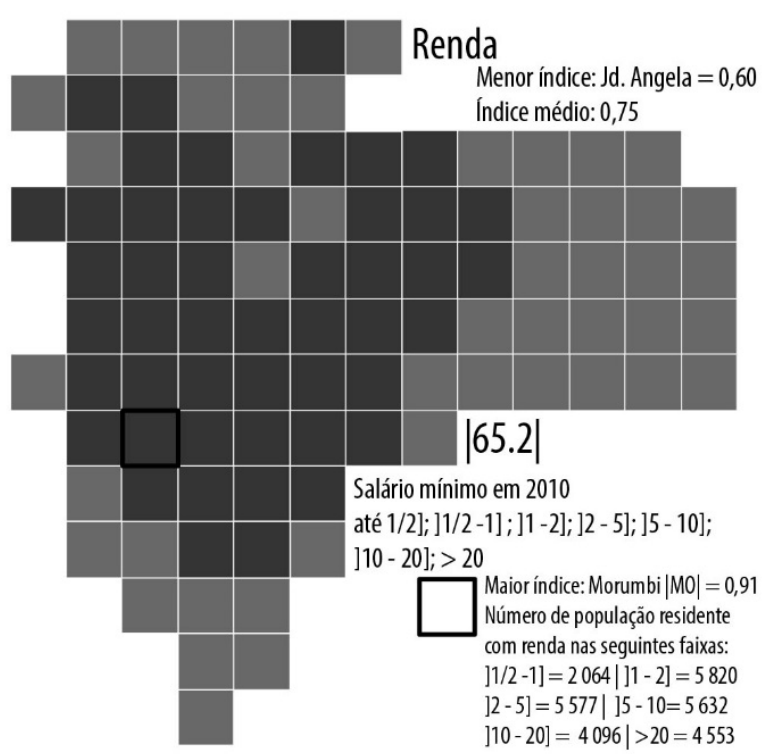
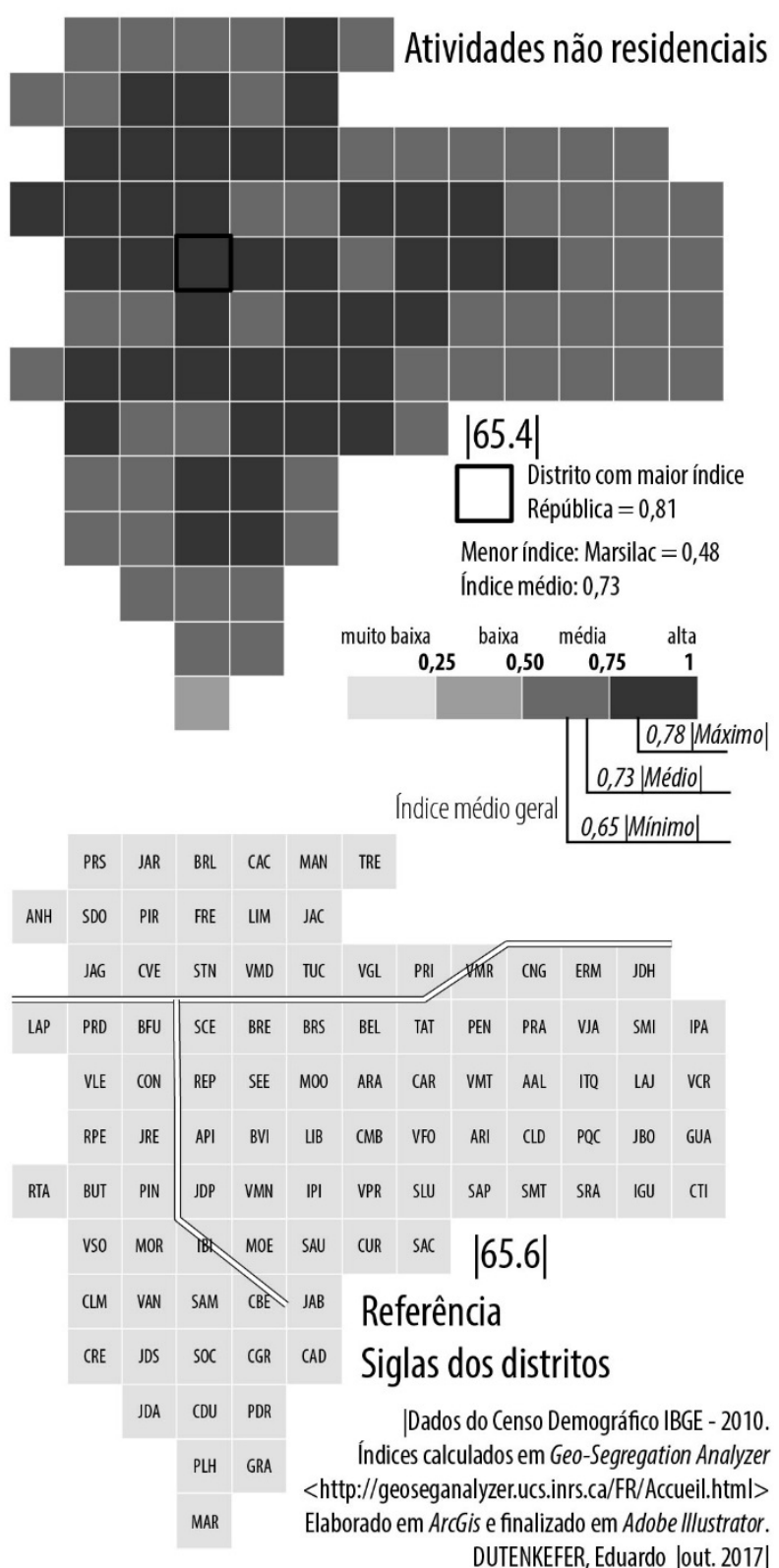
Vamos agora cruzar densidades e diversidades em um único mapa-modelo. Utilizamos o método de quadrantes, já utilizado no capítulo 6 - Acessibilidade, para expressar esta relação.

Na figura 66 temos o gráfico que orienta o método de quadrantes. As densidades populacionais no eixo $\mathbf{Y}$ e os índices médios da média dos índices no eixo $\boldsymbol{X}$. Temos assim quatro quadrantes:

1. Distritos com densidades acima da média e com índices de diversidade abaixo da média;

2. Distritos com densidades acima da média e com índices de diversidade acima da média;

3. Distritos com densidades abaixo da média e com índices de diversidade abaixo da média;

4. Distritos com densidades abaixo da média e com índices de diversidade acima da média;

|Figura 66| Gráfico do método de quadrantes para as variáveis densidade e diversidade

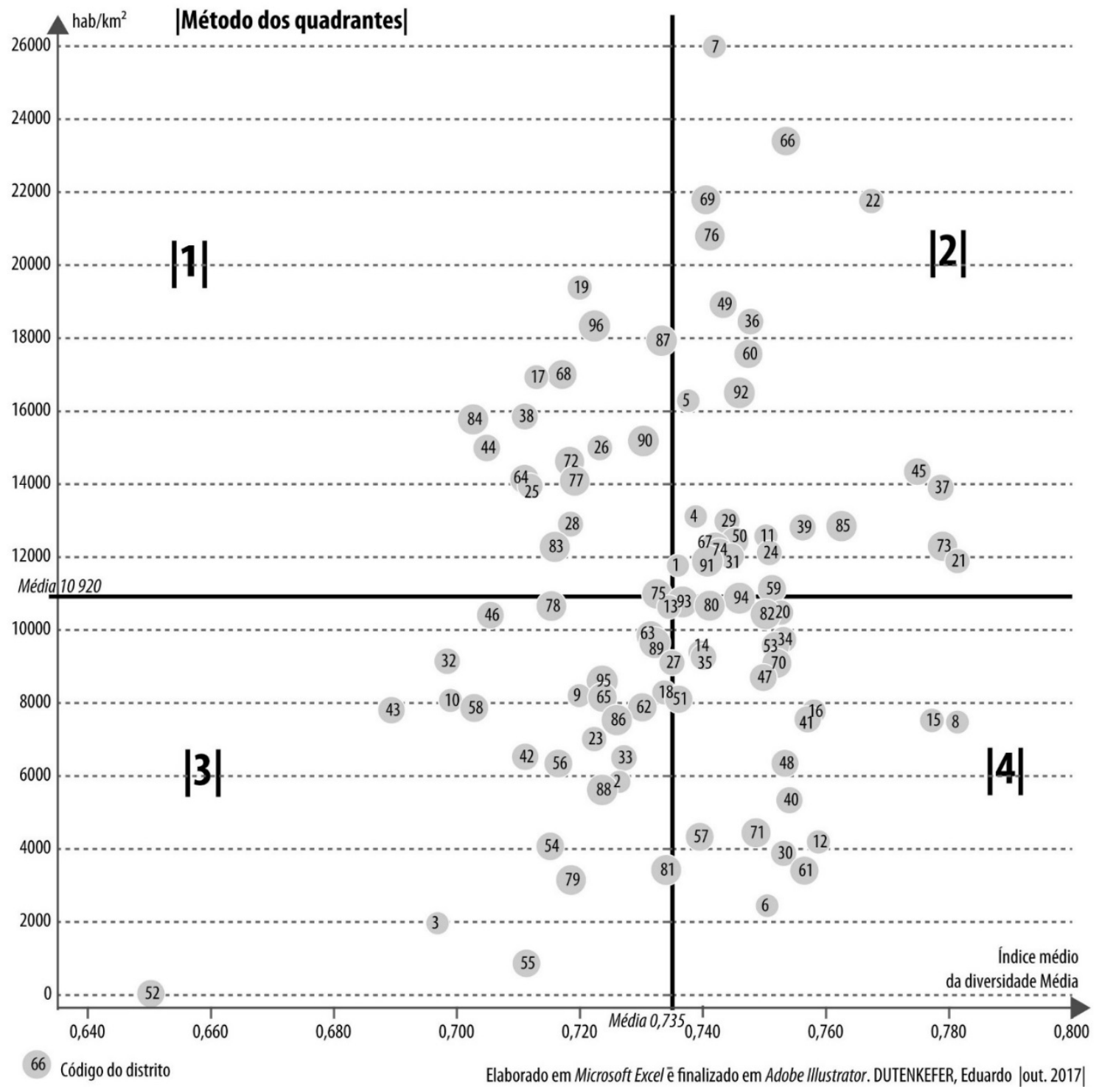


Antes de trabalharmos as duas variáveis é necessário explicitar o código do distrito da figura 66. Eles estão relacionados na tabela 7.

|Tabela 7| Relações do código da Prefeitura de São Paulo, IBGE, nome e sigla dos distritos de São Paulo

\begin{tabular}{|c|c|c|c|}
\hline CODIGO PMSP & CODIGO IBGE & NOME DISTRITO & SIGLA \\
\hline 1 & 35503080100 & AGUA RASA & ARA \\
\hline 2 & 35503080200 & ALTO DE PINHEIROS & API \\
\hline 3 & 35503080300 & ANHANGUERA & ANH \\
\hline 4 & 35503080400 & ARICANDUVA & ARI \\
\hline 5 & 35503080500 & ARTUR ALVIM & AAL \\
\hline 6 & 35503080600 & BARRA FUNDA & $\mathrm{BFU}$ \\
\hline 7 & 35503080700 & BELA VISTA & BVI \\
\hline 8 & 35503080800 & BELEM & BEL \\
\hline 9 & 35503080900 & BOM RETIRO & BRE \\
\hline 10 & 35503081000 & BRAS & BRS \\
\hline 11 & 35503081100 & BRASILANDIA & BRL \\
\hline 12 & 35503081200 & BUTANTA & BUT \\
\hline 13 & 35503081300 & CACHOEIRINHA & CAC \\
\hline 14 & 35503081400 & CAMBUCI & $\mathrm{CMB}$ \\
\hline 15 & 35503081500 & CAMPO BELO & CBE \\
\hline 16 & 35503081600 & CAMPO GRANDE & CGR \\
\hline 17 & 35503081700 & CAMPO LIMPO & CLM \\
\hline 18 & 35503081800 & CANGAIBA & CNG \\
\hline 19 & 35503081900 & CAPAO REDONDO & CRE \\
\hline 20 & 35503082000 & CARRAO & CAR \\
\hline 21 & 35503082100 & CASA VERDE & CVE \\
\hline 22 & 35503082200 & CIDADE ADEMAR & CAD \\
\hline 23 & 35503082300 & CIDADE DUTRA & CDU \\
\hline 24 & 35503082400 & CIDADE LIDER & CLD \\
\hline 25 & 35503082500 & CIDADE TIRADENTES & CTI \\
\hline 26 & 35503082600 & CONSOLACAO & CON \\
\hline 27 & 35503082700 & CURSINO & CUR \\
\hline 28 & 35503082800 & ERMELINO MATARAZZO & ERM \\
\hline 29 & 35503082900 & FREGUESIA DO O & FRE \\
\hline 30 & 35503083000 & GRAJAU & GRA \\
\hline 31 & 35503083100 & GUAIANASES & GUA \\
\hline 32 & 35503083200 & MOEMA & MOE \\
\hline 33 & 35503083300 & IGUATEMI & IGU \\
\hline 34 & 35503083400 & IPIRANGA & IPI \\
\hline 35 & 35503083500 & ITAIM BIBI & $|\mathrm{B}|$ \\
\hline 36 & 35503083600 & ITAIM PAULISTA & IPA \\
\hline 37 & 35503083700 & ITAQUERA & ITQ \\
\hline 38 & 35503083800 & JABAQUARA & $J A B$ \\
\hline 39 & 35503083900 & JACANA & JAC \\
\hline 40 & 35503084000 & JAGUARA & JAG \\
\hline 41 & 35503084100 & JAGUARE & JRE \\
\hline
\end{tabular}




\begin{tabular}{|c|c|c|c|}
\hline 42 & 35503084200 & JARAGUA & JAR \\
\hline 43 & 35503084300 & JARDIM ANGELA & JDA \\
\hline 44 & 35503084400 & JARDIM HELENA & $\mathrm{JDH}$ \\
\hline 45 & 35503084500 & JARDIM PAULISTA & JDP \\
\hline 46 & 35503084600 & JARDIM SAO LUIS & JDS \\
\hline 47 & 35503084700 & JOSE BONIFACIO & $\mathrm{JBO}$ \\
\hline 48 & 35503084800 & LAPA & LAP \\
\hline 49 & 35503084900 & LIBERDADE & LIB \\
\hline 50 & 35503085000 & LIMAO & LIM \\
\hline 51 & 35503085100 & MANDAQUI & MAN \\
\hline 52 & 35503085200 & MARSILAC & MAR \\
\hline 53 & 35503085300 & MOOCA & MOO \\
\hline 54 & 35503085400 & MORUMBI & MOR \\
\hline 55 & 35503085500 & PARELHEIROS & PLH \\
\hline 56 & 35503085600 & PARI & PRI \\
\hline 57 & 35503085700 & PARQUE DO CARMO & $P Q C$ \\
\hline 58 & 35503085800 & PEDREIRA & PDR \\
\hline 59 & 35503085900 & PENHA & PEN \\
\hline 60 & 35503086000 & PERDIZES & PRD \\
\hline 61 & 35503086100 & PERUS & PRS \\
\hline 62 & 35503086200 & PINHEIROS & PIN \\
\hline 63 & 35503086300 & PIRITUBA & PIR \\
\hline 64 & 35503086400 & PONTE RASA & PRA \\
\hline 65 & 35503086500 & RAPOSO TAVARES & RTA \\
\hline 66 & 35503086600 & REPUBLICA & REP \\
\hline 67 & 35503086700 & RIO PEQUENO & RPE \\
\hline 68 & 35503086800 & SACOMA & SAC \\
\hline 69 & 35503086900 & SANTA CECILIA & SCE \\
\hline 70 & 35503087000 & SANTANA & STN \\
\hline 71 & 35503087100 & SANTO AMARO & SAM \\
\hline 72 & 35503087200 & SAO LUCAS & SLU \\
\hline 73 & 35503087300 & SAO MATEUS & SMT \\
\hline 74 & 35503087400 & SAO MIGUEL & SMI \\
\hline 75 & 35503087500 & SAO RAFAEL & SRA \\
\hline 76 & 35503087600 & SAPOPEMBA & SAP \\
\hline 77 & 35503087700 & SAUDE & SAU \\
\hline 78 & 35503087800 & SE & SEE \\
\hline 79 & 35503087900 & SOCORRO & SOC \\
\hline 80 & 35503088000 & TATUAPE & TAT \\
\hline 81 & 35503088100 & TREMEMBE & TRE \\
\hline 82 & 35503088200 & TUCURUVI & TUC \\
\hline 83 & 35503088300 & VILA ANDRADE & VAN \\
\hline 84 & 35503088400 & VILA CURUCA & VCR \\
\hline 85 & 35503088500 & VILA FORMOSA & VFO \\
\hline 86 & 35503088600 & VILA GUILHERME & VGL \\
\hline 87 & 35503088700 & VILA JACUI & VJA \\
\hline
\end{tabular}




\begin{tabular}{|l|l|l|l|}
\hline 88 & 35503088800 & VILA LEOPOLDINA & VLE \\
\hline 89 & 35503088900 & VILA MARIA & VMR \\
\hline 90 & 35503089000 & VILA MARIANA & VMN \\
\hline 91 & 35503089100 & VILA MATILDE & VMT \\
\hline 92 & 35503089200 & VILA MEDEIROS & VMD \\
\hline 93 & 35503089300 & VILA PRUDENTE & VPR \\
\hline 94 & 35503089400 & VILA SONIA & VSO \\
\hline 95 & 35503089500 & SAO DOMINGOS & SDO \\
\hline 96 & 35503089600 & LAJEADO & LAJ \\
\hline
\end{tabular}

|Figura 67| Sequência da construção da legenda com o método de duas variáveis

A
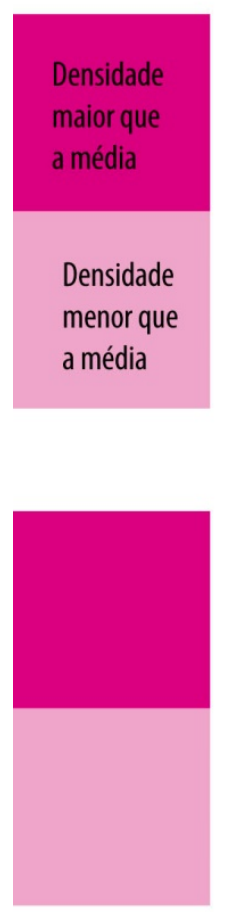

B

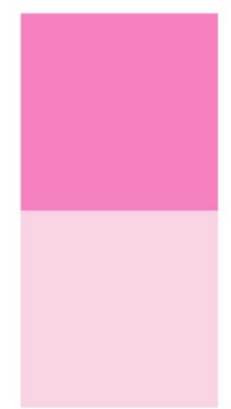

Transparência de $50 \%$

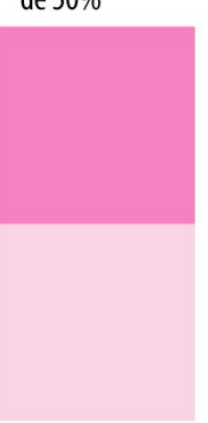

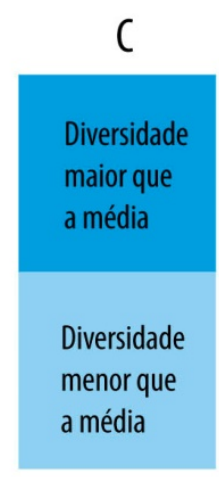

D

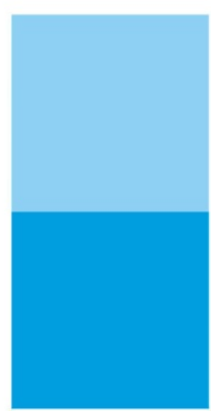

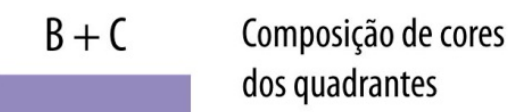

2 - Maior densidade e maior diversidade

3 -Menor densidade e menor diversidade

$$
B+D
$$

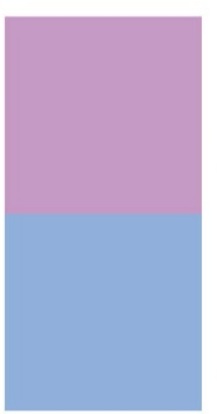

1 - Maior densidade e menor diversidade

4 - Menor densidade e maior diversidade

Como trabalhamos com duas variáveis, optamos na semiologia adotada na legenda, com o método de duas variáveis [bivariado], para mapas coropléticos utilizados, por exemplo, no subcapítulo 5.2. A composição da legenda de duas variáveis irá se transformar em 4 variáveis. Em quadrantes, conforme o gráfico da figura 66 e composição da legenda da figura 67.

Em aplicativo de SIG, em particular em ArcGis, elaboramos duas camadas com as respectivas classes e cores:

1. A primeira camada com a variável densidade populacional em duas classes e duas saturações da cor magenta: $50 \%$ de magenta para os distritos com densidades menores/iguais a média de $10.920 \mathrm{hab} / \mathrm{km}^{2}$ e $100 \%$ de magenta para os distritos com densidades maiores que a média. 
2. Uma segunda camada com o índice de diversidade média em duas classes e duas saturações da cor cyan: $50 \%$ de cyan para distritos com menor/igual à média e $100 \%$ de cyan para distritos com a média maior que 0,735.

Estas camadas foram finalizadas em software Adobe Ilustrator onde atribuímos 50\% de transparência à primeira camada - a variável densidade. 0 resultado desta composição está representado na figura 68.

0 mapa-modelo da figura 68 é uma possível síntese de nossas pesquisas. Um mapamodelo em "colmeias" que sintetizariam graficamente a urbanidade de São Paulo.

A figura 68 é produto de uma longa jornada de transformações cartográficas, gráficas e de dados. Conquistou o seu "brilho" em forma de "colmeia". Foi adquirindo "força" até chegar a este patamar. Antes ainda destas transformações, passou pelo crivo de um olhar teórico da qualidade do urbano que uma cidade pode trilhar e alcançar. Graus de urbanidade expressas em suas duas fundamentais dimensões de densidade e diversidade. Dimensões que foram ganhando "massa" e "peso" no decorrer desta pesquisa com olhares que tentamos manter como "artesãos geo-cartográficos".

Uma característica positiva que os nossos mapas-modelo podem permitir é uma "leitura" visual menos "ruidosa", mais direta. A "colmeia" de nosso mapa-modelo da figura 68 revela 27 distritos (é fácil estabelecer este valor ao contá-los como uma matriz de linhas e colunas) que sobressaem com a dupla densidade e diversidade expressiva (quadrante 2): Um eixo do norte ao centro e dois distritos a nordeste. Em sentido leste com dois eixos: um eixo em "V" e outro mais ao sul com um "V" ao contrário [^]. Ao sul do mapa-modelo encontramos apenas um “CAD” [Cidade Ademar] como um distrito solitário.

Outro olhar/contagem que o mapa-modelo proporciona visualmente é de 17 distritos com predomínio populacional (quadrante 1) em detrimento ao de diversidade. Distritos com predomínio residencial.

No quadrante 4 temos 24 distritos menos densos em relação à média, mas com diversidades mais expressivas.

No quadrante 3 temos o maior número de distritos [28] menos densos e menos diversos. Um eixo expressivo que começa ao norte com o distrito de Anhanguera até ao sul com o distrito de Marsilac. 


\section{Mapa-modelo Densidades e Diversidades |Método dos quadrantes|}

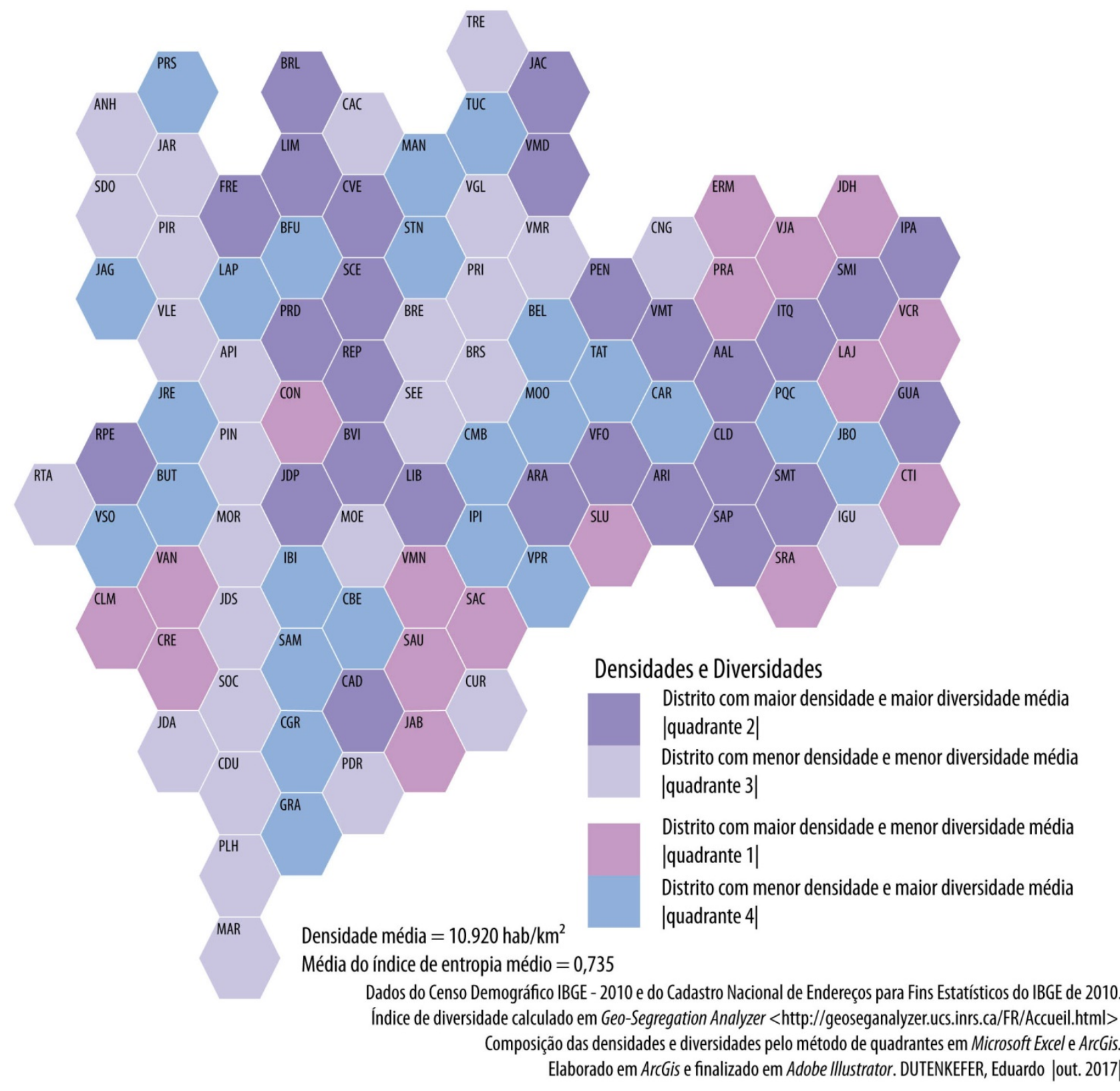

0 método e a metodologia adotados nesta síntese em mapa-modelo permite avaliar que o município de São Paulo tem como caráter urbano, a sua urbanidade, uma composição diversa, não homogênea de densidades e diversidades em seu universo dos 96 distritos "mensurados". É uma imagem como um mosaico de níveis, de gradientes de urbanidades. É um retrato sintético de uma urbanidade que pode permitir potencialmente maiores, médias ou menores interações humanas. 


\section{Conclusões |celebrando uma etapa|}

Atribuir à última etapa de uma pesquisa o título de "Conclusões", "Considerações Finais", etc., é muito ingrato. 0 "concluir" transparece que estamos resolutos e confiantes em resultados que "encerram", “fecham", “terminam”, “acabam”, “sepultam”, “finalizam” uma pesquisa. As palavras e o seu sentido também nos traem no que realmente queremos exprimir.

0 "celebrando uma etapa" que agregamos à palavra "Conclusões" parece-nos menos finalizador. É mais otimista no sentido que realizamos uma etapa de reflexões que oferece como resultado métodos e metodologias de como construir representações, imagens cartográficas com o "poder" de "medir", "construir" aproximações visuais da urbanidade de uma cidade. Mas não são conclusivas no poder de afirmar que os métodos e metodologias mobilizados nesta pesquisa são os únicos e exclusivos para elaborar mapas da urbanidade de uma cidade. São contribuições que esperamos continuar investigando.

0 conceito de urbanidade que trabalhamos foge ao senso comum que atribuímos normalmente e procuramos trazer reflexões de autores da Geografia que transformam o seu sentido trivial de "cortesia", "delicadeza" e "gentileza" em um conceito geográfico.

0 termo urbanidade se transforma nestas reflexões em conceito, em elaborações sofisticadas no seio da Geografia e que tentamos integrar ao diálogo geográfico $\Leftrightarrow$ cartográfico. Não somos detentores desta sofisticação. Tentamos apenas contribuir do que entendemos e refletimos sobre esta elaboração conceitual em uma linguagem gráfica.

Atribuir expressões como:

"Urbanidade: Fazer do urbano ser urbano";

"o mapa como imagem da urbanidade";

"blocas ativos de urbanidade".

São possíveis síntese desta pesquisa. A cidade com sua urbanidade, com seus gradientes de densidades e diversidades tem o potencial de transformar o urbano em uma categoria superior de urbano. Com mais urbanidade a cidade adquire uma qualidade que tem o potencial de propiciar interações humanas mais intensas e diversas. Uma cidade com urbanidade expressiva pode oferecer, em tese, uma "qualidade de vida" mais rica, intensa e diversa aos seus habitantes.

Tentamos nesta pesquisa fazer do mapa o revelador, o representante mais adequado em evidenciar e tentar traduzir o conceito de urbanidade em imagens gráficas. Transformamos um conceito - o de urbanidade - em dados quantitativos que aproximam nas qualificações de densidade e diversidades. Com esta transformação mobilizamos um arsenal 
geo-cartográfico para oferecer como resultado imagens gráficas de gradientes de uma "qualidade de vida" mais intensa e diversa, ou menos intensa e diversa e ou em suas nuances deste gradiente.

A primeira imagem desta urbanidade que elaboramos foi utilizar os cartogramas em anamorfose. Testamos a tese defendida por Poncet (2011), onde ele relaciona o cartograma em anamorfose ao conceito de urbanidade absoluta e o anticartograma à urbanidade relativa. Aqui começa a nossa tentativa de diálogo entre a geografia - com os conceitos de urbanidade absoluta e relativa - com a cartografia. Comparamos estes conceitos na escala territorial francesa, em comunas, e na brasileira, com seus 5.565 municípios. Na brasileira, uma escala nacional próxima a continental. Em seguida, na escala estadual, também com as unidades municipais, e a local na metrópole de São Paulo, usando a divisão em setores censitários.

Foi uma primeira aproximação da urbanidade utilizando densidades populacionais nestas escalas geográficas, que culminou na figura 17 da página 62. Uma urbanidade "fragmentada" de São Paulo. Nesta imagem já tínhamos indícios de áreas com maiores e menores potenciais de urbanidade na cidade.

Em nossa apresentação apontávamos que a tese desta pesquisa é que o mapa teria o poder de revelar uma urbanidade a priori em uma cidade. Em nossas primeiras elaborações com os cartogramas e anticartogramas, como da página 62, começa a confirmar esta tese. Esboços de características importantes da urbanidade começam a ser delineadas.

Apontávamos também que o mapa seria a "régua" deste "medir" a cidade. Percebemos, contudo, que o seu "comportamento" ora era de "régua" ora de condutor desta pesquisa. Como linguagem gráfica ele teve o poder de construir imagens e conduzir caminhos possíveis, reveladores das possibilidades que a urbanidade de uma cidade pode ser expressa visualmente.

Em seguida, avançamos em direção ao conceito de diversidade utilizando um índice originário de pesquisas de graus de urbanização e diversidades industriais da década de 1960, utilizando o índice de Gibbs e Martin (1962).

0 capítulo 4 abre novas possibilidades gráficas de detalhes de uma urbanidade absoluta e relativa que uma cidade possui. 0 uso da grade estatística do IBGE transforma uma unidade abstrata "matemática" em possibilidades de comunicar graficamente outros conceitos importantes da geografia: distância e métricas pedestres. E observem que estamos em um espaço cartográfico bem "preciso" com projeção cartográfica e datum muito bem estabelecidos pelo IBGE. Esta distância é estabelecida por células de 200 m X 200 m. Estas células transformam o conceito de urbanidade em "blocos ativos de urbanidade", como 
denominamos o mapa da figura 30 na página 94. Porque "blocos ativos"? Porque são as células do grid do IBGE mais propensas em transmitir visualmente densidades de domicílios, de habitantes. Estes blocos ativos serão realmente "ativados" se a diversidade de objetos geográficos nestes blocos também for expressiva.

Estes blocos foram "ativados" quando introduzimos em nossas representações gráficas os dados do CNEF. Atividades não residenciais com um método cartográfico de duas variáveis mostraram estes "blocos ativos" de densidade de domicílios e de atividades não residenciais. Em tese, o maior número de atividades também representaria uma maior diversidade.

O modo e a quantidade de dados que utilizamos do CNEF parecem-nos, até a conclusão desta etapa de pesquisa, singulares. Foi um esforço em geocodificação e de classificação de atividades. Estes dados classificados permitem futuras reflexões que aqui não trabalhamos. Detalhes em cada distrito e em cada quadra da cidade de São Paulo estão mapeados e podem ser relacionados aos mais diversos olhares dos geógrafos.

Com o método cartográfico de duas variáveis foi possível estabelecer 3 exemplos de baixa, média e alta concentração de residências e atividades. Exploramos estas atividades não residenciais em uma sequência de 96 mapas que evidenciam, além de suas funções econômicas, densidades e diversidades de objetos materiais no espaço urbano de São Paulo.

A grade estatística do IBGE e a nuvem de pontos dos locais de atividades não residenciais revelaram a escala onde o caminhar é literalmente em métrica pedestre. Imaginem um pedestre a "flanar" estes espaços "quadriculares". Uma malha de 200 m X 200 m. Ele teria, por exemplo, que percorrer a diagonal desta célula. Este percorrer seria em torno de 300 metros. Seria uma distância aceitável. Mas existem locais de interesse do habitante desta cidade que resolveu caminhar nesta diagonal? Se sim, ótimo, esta célula em particular possui uma atratividade. Mas se precisamos percorrer distâncias maiores que 300, 500 metros para encontrar uma atividade de nosso interesse, é um espaço atraente em percorrer ou habitar? Talvez o seja. Pode ser um percorrer agradável, ou não, com paisagens não muito monótonas... Particularmente, demos como exemplo um flanar no Morumbi, com suas atividades não residenciais menos concentradas, que a busca de uma padaria [figura 34b, página 107] pode se transformar em um caminhar de até 1,6 km.

0 grid do IBGE permitiu um dos mapas de maior impacto visual nesta tese [figura 24, página 77] para o nosso olhar. Ao transformá-lo em cartogramas em anamorfose e em anticartogramas eles foram como sintetizadores de nossos diálogos de cidade, urbanidade e mapa. 0 impacto visual do anticartograma em particular é impressionante. Evidenciou o acerto em utilizar o inverso da população para marcar visualmente espaços cartográficos 
expressivos de sua urbanidade. Uma imagem como um "raio X" da estrutura "óssea" - mais densa da cidade de São Paulo.

Na sequência, fizemos uma pequena parada e mostramos, com métodos e metodologias da cartografia analítica, um diálogo com a acessibilidade de São Paulo. Representações que acreditamos inusuais de uma acessibilidade unipolar ao centro de São Paulo.

Em seus últimos capítulos esta tese oferece 3 fundos de mapas que denominamos de mapas-modelo. Em quadriláteros e "colmeias". Três simbolismos do município de São Paulo. Nestes mapas-modelo agregamos os dados que utilizamos nesta jornada e transformamos em expressões gráficas de densidade e diversidade.

Esta síntese gráfica que construímos é uma aproximação a partir de uma composição das diversas dimensões de densidades e diversidades trabalhadas. Na escala representada, é uma primeira imagem que podemos ter como porta de entrada da "medida" da urbanidade de uma cidade. Teríamos então uma "régua" inicial para começar a medir a urbanidade.

Entendemos que a dupla densidade-diversidade idealmente deve caminhar parelha, isto é, a cidade e sua urbanidade podem ser "medidas" com uma "régua" indicativa de suas densidades e diversidades. Como "régua" indicativa ela pode proporcionar cortes bruscos, repentinos. 0 mapa tradicional e o nosso mapa-modelo é essa régua brusca. As fronteiras administrativas ainda imperam na imagem de nossos mapas-modelos. Eles propiciaram um melhor conforto visual como imagem de fundo. Mas continuam determinando que as dimensões por nós trabalhadas sejam reféns de suas fronteiras. Os mapas em grade estatística do IBGE, ou em "Carroyage", evitam estes cortes bruscos. Ficou nítido que não é um distrito com maior densidade e diversidade e sim células de 200 m X 200 m situadas nas fronteiras de três distritos, a nossa área Core do mapa da figura 30, página 94 e figura 31 na página 95. De certa forma esta área Core também foi revelada em nosso mapa-modelo, apesar da agregação de dados e do corte "brusco" mencionado anteriormente.

Uma pergunta que fazemos a um bom tempo é qual a densidade populacional ideal ou máximo possível em uma cidade?

Jane Jacobs apontou:

Quais são as densidades apropriadas a áreas residências em cidades? A resposta para isso é algo como a resposta que Abraham Lincoln deu à questão. 'Qual deve ser o comprimento das pernas de um homem? Longas o suficiente para alcançarem o chão, disse Lincoln'. Assim é, densidades apropriadas a áreas residências em cidades são uma questão de performance. Elas não podem estar baseadas em abstrações sobre as quantidades de solo urbano que idealisticamente devem ser alocadas para tal ou tal número de pessoas (vivendo em alguma sociedade dócil e imaginária). Densidades são muito 
baixas, ou muito altas, quando frustram a diversidade da cidade ao invés de estimulá-la. (JACOBS, 2000, p.230-231, grifos nossos).

Com esta pesquisa podemos arriscar e admitir que não temos limites muito bem definidos para a quantidade de hab $/ \mathrm{km}^{2}$ em um dado espaço urbano. 0 limite, Jacobs já tinha ensaiado uma resposta: “Densidades são muito baixas, ou muito altas, quando frustram a diversidade da cidade ao invés de estimulá-la" (JACOBS, 2000, p. 231). A cidade, com sua urbanidade, foi o objeto desta tese. Com os métodos e metodologias usados elaboramos uma aproximação em forma de mapas que ajudam em uma resposta à questão levantada nesta conclusão. Não existe resposta isolada, apenas para a questão da densidade. 0 balanço ideal é quando as densidades populacionais e/ou de habitar não superem em demasia as diversidades sociológicas, econômicas... Densidades e diversidades que não coloquem em risco a urbanidade de uma cidade. 0 mapa-modelo da figura 68 de certa forma tenta responder a esta indagação. Teríamos quatro respostas possíveis:

1. cidades com densidades e diversidades expressivas;

2. cidades com densidades expressivas e diversidades inexpressivas;

3. cidades com densidades inexpressivas e diversidades expressivas;

4. cidades com densidades inexpressivas e diversidades inexpressivas.

Não podemos esquecer que estas respostas são possíveis também em escalas geográficas outras, por exemplo, quando pensamos em espaços internos a esta cidade. Graus de densidades e diversidades heterogêneos.

Podemos arriscar, ainda, que a resposta do ideal ou máximo de densidade é um entendimento que o espaço geográfico, em particular o espaço urbano, não é "medido" absolutamente e sim "medido" como relativo-relacional. Sem associar com a sua diversidade, a densidade de uma cidade fica sem parte de sua "alma gêmea". Não temos apenas uma única resposta e sim várias respostas relacionadas de uma questão que tenta impor uma única resposta. Densidade e diversidade são essências que não devem ser separadas. Separadas, teremos o distanciamento, as fragmentações, os guetos, a homogeneidade, concentrações de múltiplas dimensões. Estes afastamentos espaciais dificultam à cidade em prover ambientes favoráveis à relacionamentos humanos mais ricos e diversos. Parece-nos que se tencionarmos em demasia um distanciamento entre estas duas "fibras" da cidade, provocará uma ruptura de um viver em cidades. 


\section{Referências bibliográficas}

ANDRIEU, Dominique. Les cartogrammes: une séquence d'enseignement de la sémiologie à la géographie. Cartes \& Géomatique. Paris: Revue du Comité français de cartographie. $\mathrm{N}^{\circ} 222$, décembre 2014.

APPARICIO, Philippe; PETKETICH, Valera ; CHARRON, Mathieu. Segregation Analyzer: a C\#.Net application for calculating residential segregation indices. Cybergeo: European Journal of Geography, no 414, 13 p. 2008.

Disponível em: < http://cybergeo.revues.org/16443?file=1>. Acesso: 28/02/2017

APPARICIO, Philippe ; MARTORI, Joan Carles; PERSON, Amber L.; FOURNIER, Éric; APPARICIO, Denis. An open-source software for calculating indices of urban residential segregation. Social Science and Computer Review, Vol. 32(I) 117-128 p., 2014. Disponível em:

<http://journals.sagepub.com/doi/pdf/10.1177/0894439313504539>. Acesso: 27/02/2017. ARCHELA, Rosely Sampaio; THÉRY, Hervé. Orientação metodológica para construção e leitura de mapas temáticos. Confins [En ligne], 3 | 2008, mis en ligne le 23 juin 2008, consulté le 11 octobre 2008. URL : http://confins.revues.org/3483 ; DOI : 10.4000/confins.3483 AULETE, iDicionário. Urbanidade in: Dicionário da Língua Portuguesa Aulete [em linha]. Rio de Janeiro: Lexikon Editora Digital, 2007-2015. Disponível em: <http://www.aulete.com.br/urbanidade>. Acesso: 7/1/2015.

Centre National de Ressources Textuelles et Lexicales (CNRTL). Urbanité. Disponível em: < http://www.cnrtl.fr/definition/urbanité>. Acesso: 7/1/2015.

BÉGUIN, Michèle; PUMAIN, Denise. La représentation des données géographiques statistique et cartographie. Paris: Armand Colin, 2007.

BERTIN, Jacques. Ver ou ler. Seleção de Textos (AGB), São Paulo, n.18, p. 45-62, maio 1988. BERTIN, Jacques. Semiologie graphique : les diagrammes, les reseaux, les cartes. Paris : EHESS (Les ré-impressions des Éditions de L’Ècole des Hautes Études en Sciences Sociales), 1998.

BESSE, Jean-Marc. Vues de ville et géographie au XVI e siècle : concepts, d'emarches cognitives, fonctions. F. Pousin. Figures de la ville et construction des savoirs. Architecture, urbanisme, géographie, CNRS Editions, pp.19-30, 2005. Disponível em: <http://books.openedition.org/editionscnrs/4280>, acesso: 20/7/2015. 
BEAUDE, Boris. Éléments pour une géographie du lieu réticulaire. Thèse de doctorat, Université Paris 1, p. 99-164, juin 2008. Disponível em:< http://sciencespo.macrocosme.net/lectures/BeaudeTheseAvoirlieu99-164.pdf >Acesso: 12/11/2009. BORD, Jean-Paul. L'univers des cartes. La carte et le cartographe. Paris: Belin, Mappemonde, 2012.

BORD, Jean-Paul. Cartes e Géomatique. Comité Français de Cartographie [CFC] BulletinNº218 -Décembre, 2013. Disponível em: <http://www.lecfc.fr/new/articles/218article-5.pdf> acesso: 11/2/2015.

BORRUSO, Giuseppe. Geographical Analysis of Foreign Immigration and Spatial Patterns in Urban Areas: Density Estimation, Spatial Segregation and Diversity Analysis. Transactions on Computational Science VI. Volume 5730 of the series Lecture Notes in Computer Science. Springer-Verlag Berlin Heidelberg, p. 301-323, 2009, .

BREWER, Cynthia A.; HARROWEN, Mark. ColorBrewer.org: An Online Tool for Selecting Colour Schemes for Maps. The Cartographic Journal Vol. 40 No. 1 pp. 27-37 June 2003.

BRUNET, Roger. La carte, mode d'emploi. Paris: Fayard/Reclus, 1987.

BRUNET, Roger. Des modèles en géographie? Sens d'une recherche. Bulletin de la Société de Géographie de Liège, 2000, $\mathrm{n}^{\circ} 2$, p. 21-30. Disponível em :

<http://www.mgm.fr/ARECLUS/page_auteurs/Brunet3.html> Acesso: 16/02/2010

BRUNET, Roger. Le déchiffrement du monde, théorie et pratique de la géographie. Paris: Belin, 402 p. 2001.

BRUNET, Roger. In: Sylvain Allemand (dir.), Comment je suis devenu géographe. Paris : Le Cavalier Bleu, 2007.

BRUNET, Roger. Les sens de la distance. In : La distance, objet géographique. Revue ATALA n ${ }^{\circ}$ 12, p.13-32. 2009. < http://www.lycee-chateaubriand.fr/cruatala/fiche.php?publication_id=23>. Acesso: 24/1/2014. BRUNET, Roger ; FERRAS, Robert ; THÉRY, Hervé. Carroyage. In: Les Mots de la géographie, dictionnaire critique. Montpellier-Paris: RECLUS - La Documentation Française, 3 édition, p. 88, 1993.

BUENO, Maria do Carmo. Grade estatística: uma abordagem para aumentar o potencial analítico de dados censitários. Campinas, - Tese (Doutorado em Demografia), Instituto de Filosofia e Ciências Humanas da Universidade Estadual de Campinas, 2014. Disponível em: $<$ http://www.bibliotecadigital.unicamp.br/document/?code=000937903> Acesso: 28/04/2016. 
CAUVIN, Colette. Transformações cartográficas espaciais e anamorfoses. In: DIAS, Maria Helena (coord). Os mapas em Portugal: da tradição aos novos rumos da Cartografia. Lisboa: Cosmos. p. 269-310, 1995.

CAUVIN, Colette. L'accessibilité intraurbaine : une approche méthodolohique. In: CAUVIN, Colette; REYMOND, Henri; KLEINSCHMAGER, Richard (Org). L'espace géographique des villes. Paris: Anthropos, p. 77-100, 1998.

CAUVIN, Colette. Logiciel de comparaison spatiale Darcy 2.0. Mode d'emploi. Paris, Besançon, Strasbourg: 2009. <http://spatial-modelling.info/-Spatial-analysis-tools->. Acesso: $6 / 12 / 2010$.

CAUVIN, Collete. Logiciel de transformation cartographique unipolaire IsoDistAngle. Mode d'emploi . Besançon, Strasbourg: 2013. < http://thema.univfcomte.fr/images/Productions/ME_IsoDistAngle.pdf>. Acesso: 05/12/2013. CAUVIN, Colette; REYMOND, Henri; SERRADJ, Abdelaziz [Aziz]. Discrétisation et représentation cartographique. Montpellier : GIP RECLUS, 1987.

CAUVIN, Colette; ESCOBAR, Francisco; SERRADJ, Aziz. Cartographie Thématique 1. Paris: Lavoisier, 2007a.

CAUVIN, Colette; ESCOBAR, Francisco; SERRADJ, Aziz. Cartographie Thématique 2. Paris: Lavoisier, 2007b.

CAUVIN, Colette; ESCOBAR, Francisco; SERRADJ, Aziz. Cartographie Thématique 3. Paris: Lavoisier, 2008a.

CAUVIN, Colette; ESCOBAR, Francisco; SERRADJ, Aziz. Cartographie Thématique 4. Paris : Lavoisier, 2008b.

CAUVIN, Colette. Anaplaste 2.0 - Mode d'emploi. Paris, Besançon, Strasbourg, 2011. Disponível em: <http://thema.univ-fcomte.fr/images/Productions/ME_Anaplaste.pdf>. Acesso: 6/2/2015.

CHAPELON, Laurent. Accessibilité. HYPERGE0. 2004. Disponível em: <http://www.hypergeo.eu/spip.php?article30> Acesso: 8/12/2013. COSTA NETO, Pedro Luiz de Oliveira. Estatística. São Paulo: Edgard Blücher, 1977. CLAVAL, Paul. A nova geografia. Coimbra: Livraria Almeida, 1982.

DANTIER, Bernard. La représentation et l'étude visuelles des informations: Jacques Bertin, Sémiologie graphique. Extrait de: Jacques Bertin, Sémiologie graphique. Les diagrammes - Les réseaux — Les cartes. Paris, Éditions de l'ÉHESS, 4e édition, 2005 [Première édition, Paris: Éditions Gonthier-Villar, 1967], pp. vii-xi, 5- 
14. Collection: Méthodologie des sciences sociales. Disponível em:

<http://classiques.uqac.ca/collection_methodologie/bertin_jacques/representations_visuelle S_info/semiologie_graphique_\%20Jacques\%20Bertin.pdf> Texte mis en ligne jeudi aprèsmidi, le 11 décembre 2008. Acesso: 13/11/2013.

DUCKHAM, M.; KEALY, A.; WALLACE, J. Geomatics. In: International Encyclopedia of Human Geography. KITCHIN, Rob; THRIFT, Nigel. (editors). Amsterdam: Elsevier, 1a ed., p.435, 2009. DUTENKEFER, Eduardo. Representações do espaço geográfico: mapas dasimétricos, anamorfoses e modelização gráfica. São Paulo, Dissertação (Mestrado em Geografia), FFLCH/USP, 2010. Disponível em: <http://www.teses.usp.br/teses/disponiveis/8/8136/tde25022011-115539/pt-br.php>.

DUTENKEFER, Eduardo. Anamorfose como mapa: história, aplicativos e aplicações. In:

3 Simpósio Iberoamericano de História da Cartografia. SÃO PAULO, 2010a.

ELMER, Martin E. Symbol considerations for bivariate thematic mapping. Thesis of master of Science. University of Wisconsin-Madison. 2012. Disponível em:

< http://resources.maphugger.com/melmer_webedition.pdf>. Acesso: 11/03/2017.

EMPRESA PAULISTA DE PLANEJAMENTO METROPOLITANO - EMPLASA. Alternativas para o desenvolvimento industrial. Localização industrial na grande São Paulo (2ª edição) considerações preliminares. 1978. Disponível em:

<http://www.enerweb.emplasa.sp.gov.br/ExibirDetalhes.aspx?funcao=kcDocumentos\&id=16 0\&retorno=sim\&Lingua $=\mathrm{PT}>$. Acesso: $2 / 8 / 2012$.

FITZ, Paulo Roberto. Geoprocessamento sem complicação. São Paulo: Oficina de Textos, 2008.

FONSECA, Fernanda Padovesi; OLIVA, Jaime Tadeu. A Geografia e suas linguagens: o caso da cartografia. In: CARLOS, A. F. A. A Geografia em sala de aula. São Paulo: Contexto, 2001. FONSECA, Fernanda Padovesi. A inflexibilidade do espaço cartográfico, uma questão para a Geografia: análise das discussões sobre o papel da Cartografia. São Paulo, - Tese (Doutorado em Geografia), FFLCH/USP, 2004.

GASTNER, Michael T.; NEWMAN, Mark. E. J. Diffusion-based method for producing density equalizing maps. Proceedings of the National Academy of Sciences. USA 101, 7499-7504. 2004. Disponível em:< http://www.pnas.org/content/101/20/7499.full.pdf >. Acesso:06/04/2008.

GEHL, Jan. Cidade para pessoas. São Paulo: Perspectiva, 2015. 
GIBBS, Jack P.; MARTIN, Walter T. Urbanization, Tecnology, and the the Division of Labor: International Patterns. American Sociological Review. Vol. 27, № 5, pp 667-677, Oct., 1962. Disponível em:< http://www.jstor.org/stable/2089624> Acesso: 25/8/2015.

GIRARDI, Gisele. Apontamentos para uma cartografia da Cartografia Geográfica brasileira. Revista da ANPEGE, v. 7, n. 1, número especial, p. 237-250, out. 2011.

GIRARDI, Gisele. Funções de mapas e espacialidade: elementos para modificação da cultura cartográfica na formação em geografia. Revista Brasileira de Cartografia no 66/4, p. 861876, julho/agosto 2014 .

GLAESER, Edward L. Os centros urbanos - a maior invenção da humanidade. Rio de Janeiro: Elsevier, 2011

GOODCHILD, M.F. GIS and Cartography. In: International Encyclopedia of Human

Geography. KITCHIN, Rob. THRIFT, Nigel. (editors). Amsterdam: Elsevier, $1^{\underline{a}}$ ed., p. 500, 2009.

GRATALOUP, Christian. Chorème. In: LÉVY, Jacques; LUSSAULT, Michel (Org.). Dictionnaire de la Géographie et de l'espace des sociétés. Paris: Belin,. p. 154-155, 2003a.

GRATALOUP, Christian. Modélisation graphique. In: LÉVY, Jacques; LUSSAULT, Michel (Org.). Dictionnaire de la Géographie et de l'espace des sociétés. Paris: Belin,. p. 629-631, 2003b. GROUPE CHADULE. CHAMUSSY, Henri; CHARRE, Joël; DUMOLARD, Pierre; DURAND, MarieGeneviève; LE BERRE, Maryvonne. Initiation aux pratiques statistiques en géographie. Paris: Masson, 1994.

GUERMOND, Yves. Géomatique. In: Lévy, Jacques;Lussault Michel (Org.). Dictionnaire de la Géographie et de l'espace des sociétés.Paris: Belin, p. 402, 2003.

HARLEY, John Brian. A nova história da cartografia. O Correio da UNESCO (Mapas e cartógrafos), Brasil, ano 19, n. 8, ago. p. 4-9, 1991.

HARLEY, John Brian. Textos y contextos en la interpretación de los primeros mapas. In: La nueva naturaleza de los mapas. Ensayos sobre La historia de La cartografia. México: FCE, 2005.

INSTITUTO BRASILEIRO DE GEOGRAFIA E ESTATÍSTICA (IBGE). Grade Estatística. Rio de Janeiro: IBGE, 2016. Disponível em:

<ftp://geoftp.ibge.gov.br/recortes_para_fins_estatisticos/grade_estatistica/censo_2010/grad e_estatistica.pdf>. Acesso: 28/04/2016.

JACOBS, Jane. Morte e vida de grandes cidades. São Paulo: Martins Fontes, 2007. 
KRAFTI, P.; HORTON, J. Urban - Representation/Imagination. In: KITCHIN, Rob. THRIFT, Nigel. (editors). International Encyclopedia of Human Geography. Amsterdam: Elsevier, 1aㅡ., vol. 12, p.94, 2009.

LAROUSSE, Urbanidade, in: Grande Enciclopédia Larousse Cultural. São Paulo: Nova Cultural, p. 5842, 1998.

LE GOFF, Jacques. Por amor às cidades: conversações com Jean Lebrun. São Paulo: Fundação Editora da UNESP, 1998.

LÉVY, Jacques. Le Tournant géographique. Penser l' espace pour lire le monde. Paris: Belin, 1999.

LÉVY, Jacques . Espace. In: Lévy, Jacques; Lussault Michel (Org.). Dictionnaire de la Géographie et de l'espace des sociétés. Paris: Belin, p. 325-332, 2003.

LÉVY, Jacques . Accessibilité. In: Lévy, Jacques; Lussault Michel (Org.). Dictionnaire de la Géographie et de l'espace des sociétés. Paris: Belin, p. 35, 2003a. Anamorphose. In: Lévy, Jacques; Lussault Michel (Org.). Dictionnaire de la

Géographie et de l'espace des sociétés.Paris: Belin,. p. 74, 2003b. Tradução de trabalho de Fernanda Padovesi Fonseca e Jaime Tadeu Oliva.

.Carte. In: LÉVY, Jacques; LUSSAULT, Michel (Org.). Dictionnaire de la

Géographie et de l'espace des sociétés. Paris: Belin, p. 128-132, 2003c. Tradução de trabalho de Fernanda Padovesi Fonseca e Jaime Tadeu Oliva. Distance. In: Lévy, Jacques; Lussault Michel (Org.). Dictionnaire De La Géographie et de l'espace des sociétés. Paris: Belin, p. 267, 2003d. Métrique. In: Lévy, Jacques; Lussault Michel (Org.)..). Dictionnaire de la Géographie et de l’espace des sociétés. Paris: Belin, p. 607, 2003e. .Substance. In: Lévy, Jacques; Lussault Michel (Org.).Dictionnaire de la Géographie et de l'espace des sociétés. Paris: Belin, p. 880, 2003f. . Ville. In: Lévy, Jacques; Lussault Michel (Org.). Dictionnaire de la Géographie et de l'espace des sociétés. Paris: Belin, p. 988-99, 2003g. LÉVY, Jacques. La carte, un espace à construire. In: LÉVY, Jacques; PONCET, Patrick; TRICOIRE, Emmanuelle. La carte, enjeu contemporain. Documentation photographique no 8036. Paris: La Documentation Française, p. 1-14, 2004.

LÉVY, Jacques. Uma virada cartográfica? In: ACSELRAD, Henri (org.). Cartografias sociais e território. Rio de Janeiro: UFRJ/IPPUR, p. 153-167, 2008. 
LÉVY, Jacques (Dir.) L'Invention du Monde : Une Géographie de la mondialisation. Paris : Sciences Po. Les Presses, 2008a.

LÉVY, Jacques. Entre contact et écart. La distance au coeur de la réflexion sur l'espace des sociétés. In : La distance, objet géographique. Revue ATALA nº 12, 2009. < http://www.lyceechateaubriand.fr/cru-atala/fiche.php?publication_id=23>. Acesso: 24/1/2014.

LÉVY, Jacques. Cartogramme. In: Lévy, Jacques; Lussault Michel (Org.). Dictionnaire de la Géographie et de l'espace des sociétés. Paris: Belin, p.295, 2013.. Dimension. In: Lévy, Jacques; Lussault Michel (Org.). Dictionnaire de la Géographie et de l'espace des sociétés. Paris: Belin, p.281, 2013a. .Diversité. In: Lévy, Jacques; Lussault Michel (Org.). Dictionnaire de la Géographie et de l'espace des sociétés. Paris: Belin, p.157, 2013b. . Urbanité (modèle d'). In: Lévy, Jacques; Lussault Michel (Org.). Dictionnaire de la Géographie et de l'espace des sociétés. Paris: Belin, p. 1055-1060, 2013c. LÉVY, Jacques. Entretien / Jacques Lévy à propos du film Urbanités. In: Revue Urbanités. 2014. Disponível em: < http://www.revue-urbanites.fr/entretien-jacques-LÉVY-a-propos-dufilm-urbanites-urbanityies/>. Acesso: 18/5/2015.

LIBAULT, André. Geocartografia. São Paulo: EDUSP, 1975.

LOCH, Ruth E. Nogueira. Cartografia - Representação, comunicação e visualização de dados espaciais. Florianópolis: UFSC, 2006.

LOUISET, Odette. Introduction à la ville. Paris: Armand Colin., 2011.

LUSSAULT, Michel. L'home spatial. La construction sociale de l'espace humain. Paris: Seuil, 2007.

LUSSAULT, Michel. Coprésence. In: Lévy, Jacques; Lussault Michel (Org.). Dicitionnaire de la Géographie et de l’espace des sociétés. Paris: Belin, p. 234-235, 2013.

LUSSAULT, Michel. Urbanité. In: Lévy, Jacques; Lussault Michel (Org.). Dicitionnaire de la Géographie et de l'espace des sociétés. Paris: Belin, p. 1053-1055, 2013a.

MARTINELLI, Marcello. Curso de Cartografia Temática. São Paulo: Contexto, 1991. MARTINELLI, Marcello. Mapas da Geografia e Cartografia Temática. São Paulo: Contexto, 2003.

MARTINELLI, Marcello. Mapas, Gráficos e Redes - elabore você mesmo. São Paulo: Oficina de Textos, 2014.

MONGIN, Olivier. A condição Urbana: A cidade na era da globalização. São Paulo: Estação Liberdade, 2009. 
MONMONIER, Mark. Comment faire mentir les cartes. Paris: Flammarion, 1993. [do original em inglês: How to Lie with Maps. University of Chicago Press, 1991]. MULLER, Jean-Claude. Ignorance Graphique ou cartographie de l'ignorance. Cartographica,vol. $20 \mathrm{~N}^{\circ} 3$, p. 17-30, 1983.

NASCENTES, Antenor. Dicionário etimológico da Língua Portuguêsa. Rio de Janeiro: Livraria Academica, São José, de Portugal, Francisco Alves, 1955. Disponível em: <https://ia801700.us.archive.org/25/items/AntenorNascentesDicionaroEtimologicoDaLingu aPortuguesaTomoI/DicionarioEtimolgicoDaLinguaPortuguesa.pdf>. Acesso: 10/1/2015. OLIVA, Jaime Tadeu. A cidade como ator social: a força da urbanidade. In: ALESSANDRI CARLOS, Ana Fani; LEMOS, Amália Inês Geraiges (Orgs.). Dilemas urbanos: novas abordagens sobre a cidade. São Paulo: Contexto, p. 73-80, 2003.

OLIVA, Jaime Tadeu. A Cidade sob Quatro Rodas. O automóvel particular como elemento constitutivo e constituidor da cidade de São Paulo: o espaço geográfico como componente social. (Tese de Doutorado). São Paulo: Universidade de São Paulo, Faculdade de Filosofia, Letras e Ciências Humanas, Programa de Pós-Graduação em Geografia Humana, 2004.

ORESME, Nicole. Les Ethiques en françois . Traduites par Nicolas Oresme. [AUTEUR : Aristote (0384-0322 av. J.-C.)]; ÉDITEUR : Antoine Caillaut et Guy Marchant. Paris : r Antoine Vérard, 1488. Disponível em: <http://gallica.bnf.fr/ark:/12148/bpt6k109464g/f1.image>. Acesso: $7 / 1 / 2015$.

PALSKY, Gilles. Origines et évolution de la cartographie Thématique (XVII_XIX siècles). Revista da Faculdade de Letras - Geografia I série, vol. XIV, Porto, p. 39-60, 1998. Disponível em: <http://ler.letras.up.pt/uploads/ficheiros/1607.pdf> Acesso: 1/06/2007. Carta. Hypergéo. Revista em linha disponível em:

<http://www.hypergeo.eu/spip.php?article362> Acesso: 07/09/2009.

PALSKY, Gilles. Carte choroplèthe. Hypergéo. Revista em linha disponível em: http://www.hypergeo.eu/spip.php?article274\#.>. Acesso: 1/4/2007.

PONCET, Patrick. Antigéographie : L’anticartogramme et ses interprétations. WhereSciences, 2011. Disponível em <http://www.wheresciences.com/articles.php?id=60\#> Acesso: 22/06/2011.

PORTO-SALES, Andréa Leandra; COUTO, Edna Maria Jucá; WHITACKER, Arthur Magon; SPOSITO, Maria Encarnação Beltrão; REDÓN, Sérgio Moreno; MIYAZAKI, Vitor Koiti. Pesquisas em Geografia Urbana: Desafios e possibilidades de análise espacial com o uso do 
Cadastro Nacional de Endereços para Fins Estatísticos (CNEF). Caderno Prudentino de Geografia. Presidente Prudente: Associação dos Geógrafos Brasileiros - Seção Local. №36, v.2, p.81-103, ago./dez., 2014.

Disponível em: < http://revista.fct.unesp.br/index.php/cpg/article/view/3194/2854> Acesso: 29/05/2017.

PUMAIN, Denise. Essai sur la distance et l'espace géographique. In: La distance, objet géographique.Revue ATALA nº 12, 2009. Disponível em : < http://www.lyceechateaubriand.fr/cru-atala/fiche.php?publication_id=23>. Acesso: 24/1/2014. RISERIO, Antonio. A cidade no Brasil. São Paulo: editora 34, 2012. ROBIC, Marie-Claire. Sur les formes de l'Hexagone . Mappemonde. Montpellier: Reclus, no, p. 18-23, 1989. Disponível em : http://www.mgm.fr/PUB/Mappemonde/M489/p18-23.pdf. Acesso: 27/1/2010.

ROBIC, Marie-Claire. Variations sur la forme : l'exercise cartographique à l'école (1868-1889). Mappemonde. Montpellier: Reclus, n², p. 38-44, 1991a. Disponível em: http://www.mgm.fr/PUB/Mappemonde/M291/EXOCARTO.pdf. Acesso: 30/5/2008. ROBIC, Marie-Claire. Variations sur la forme : l'exercise cartographique à l'école (1868-1889). Mappemonde. Montpellier: Reclus, n³, p. 34-40, 1991b. Disponível em: http://www.mgm.fr/PUB/Mappemonde/M391/EXOCARTO.pdf. Acesso: 30/5/2008. ROGERSON, Peter A. Métodos estatísticos para geografia: um guia para o estudante. Porto Alegre: Bookman, 2012.

SANTOS, Milton. Por uma Geografia Nova. São Paulo: EDUSP, 2002.

A Natureza do Espaço: Técnica e Tempo, Razão e Emoção. São Paulo: EDUSP, 2002a.

Espaço e método. São Paulo: EDUSP, 2008.

SCHNEIDER, Charles. Les cartes em champs de forces (piézoplèthes). MappeMonde, $\mathrm{n}^{\circ} 3$, 1987. Disponível em: <http://www.mgm.fr/PUB/Mappemonde/M387/p19-21.pdf>. Acesso: Acesso: 05/12/2013.

SILVA, Ana Alexandrino. Gráficos e Mapas - representação de informação estatística. Lisboa: Lidel - Edições Técnicas, 2006.

SPECK, Jeff. Cidade Caminhável. São Paulo: Perspectiva, 2016.

THÉRY, Hervé. Modelização gráfica para a análise regional: um método, Geousp - Espaço e Tempo ${ }^{\circ} 15$, p. 179-188, 2004. 
Chaves para a leitura do território paulista. In: Atlas Seade da economia

paulista. São Paulo: SEADE, 2006. Disponível em:

<http://www.seade.gov.br/produtos/atlasecon/index.php?texto=mapa\&cap_cod=11> Acesso: 30/09/2008.

TOBLER, Waldo. Map transformations of geographic space. Ph.D. Thesis, University of Washington, Seattle (University Microfilm \#61-4011).1961. Disponível em:

<http://www.geog.ucsb.edu/ tobler/index.html> Acesso: 24/09/2007.

. Choropleth maps without class intervals? Geographical Analysis, 5, p. 262-265, 1973.

. A Transformational View of Cartography. American Cartographer, vol. 6, n 2, p.101-106, 1979.

. Interactive construction of contiguous cartograms. Computer Graphics, 13-17.

Anaheim, CA: National Computer Graphics Association Conference.1984. Disponível em:

<http://www.geog.ucsb.edu/ tobler/index.html> Acesso: 24/09/2007.

. The Development of Analytical Cartography: A Personal Note.2000.

Disponível em:

<http://www.geog.ucsb.edu/ tobler/publications/pdf_docs/cartography/Analytic_2.pdf>Ac esso: $16 / 9 / 2013$.

. Thirty-Five Years of Computer Cartograms. Annals of the Association of

American Geographers, 94(1), p. 58-73. 2004.

WANIEZ, Philippe. Cartographie thématic et analyse des données avec Philcarto 5.xx pour

Windows, UMR 5185 ADES, Col. DOC de GRANIT n 1, p.251, 2008. Disponível em:

<http://philcarto.free.fr>. Acesso: 1/4/2010.

WIRTH, Louis. 0 urbanismo como modo de vida. In Velho, Otávio (org.). 0 Fenômeno

Urbano. Rio de Janeiro: Jorge Zahar, 1967. 